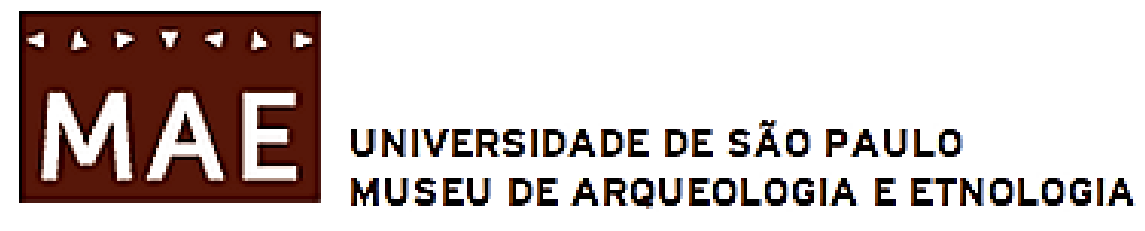

PROGRAMA DE PÓS-GRADUAÇÃO EM ARQUEOLOGIA

DANIELA DIAS ORTEGA

MICROVESTÍGIOS BOTÂNICOS EM ARTEFATOS LÍTICOS DO SÍTIO LAPA DO SANTO (LAGOA SANTA, MINAS GERAIS)

SÃO PAULO

2019 


\section{MICROVESTÍGIOS BOTÂNICOS EM ARTEFATOS LÍTICOS DO SÍTIO LAPA DO SANTO (LAGOA SANTA, MINAS GERAIS)}

Dissertação de mestrado apresentada ao Programa de Pós-graduação em Arqueologia do Museu de Arqueologia e Etnologia da Universidade de São Paulo, como requisito para obtenção do título de Mestre em Arqueologia.

Orientadora: Prof ${ }^{\mathrm{a}} \mathrm{Dr}^{\mathrm{a}}$ Ximena Suarez Villagran.

Co-orientadora: Dr ${ }^{\mathrm{a}}$ Célia Helena Cezar Boyadjian.

Apoio Financeiro:

Fundação de Amparo à Pesquisa do Estado de São Paulo (FAPESP) e Coordenação de Aperfeiçoamento de Pessoal de Nível Superior (CAPES) - Processos n n 2017/01769-7 e $n^{\circ}$ 2017/25020-5/BEPE.

e Conselho Nacional do Desenvolvimento Científico

e Tecnológico (CNPq) - Processo n 134224/20167.

\section{SÃO PAULO}




\section{Citar como:}

ORTEGA, Daniela Dias. Microvestígios botânicos em artefatos líticos do sítio

Lapa do Santo (Lagoa Santa, Minas Gerais). Dissertação (Mestrado - Prograrma de Pós-Graduação em Arqueologia), Museu de Arqueologia e Etnologia, Universidade de São Paulo, 2019. 244 p.

Ficha catalográfica elaborada pelo Serviço de Biblioteca e Documentação, MAE/USP, com os dados fornecidos pelo(a) autor(a)

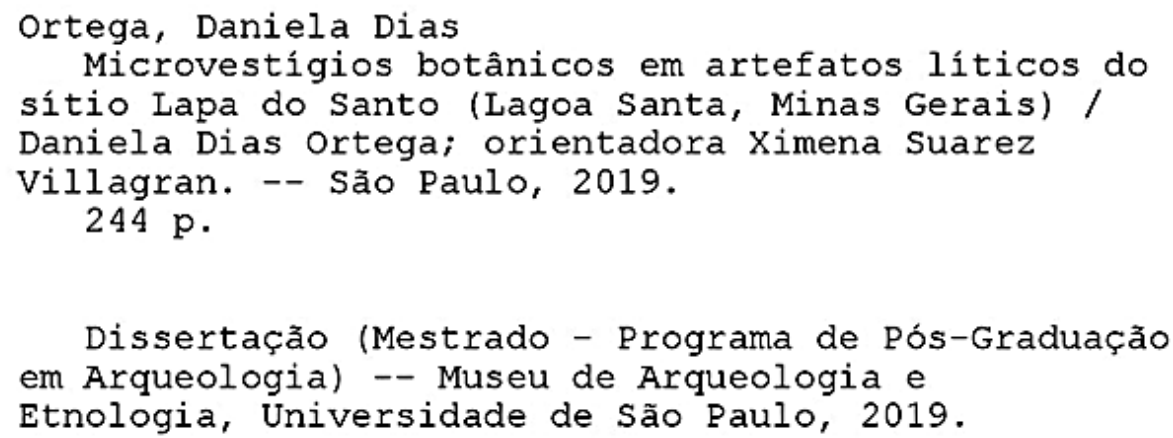

1. Microarqueologia. 2. Lagoa Santa. 3.

Fitólitos. 4. Amido. 5. Instrumentos líticos. I. Villagran, Ximena Suarez, orient. II. Título. 
Dissertação de Mestrado apresentada com requisito para obtenção do título de Mestre em Arqueologia

Defendida e Aprovada em 25/05/2019

Banca de Avaliação:

\section{Prof $^{\mathrm{a}}$ Dr $^{\mathrm{a}}$ Ximena Suarez Villagran}

(Orientadora)

Museu de Arqueologia e Etnologia da Universidade de São Paulo

\section{Prof. Dr. Walter Alves Neves}

Departamento de Genética e Biologia Evolutiva da Universidade de São Paulo

\section{Profa. Dra. Rita Scheel-Ybert}

Departamento de Antropologia do Museu Nacional, Universidade Federal do Rio de Janeiro 


\section{AGRADECIMENTOS}

Ao Conselho Nacional de Desenvolvimento Científico e Tecnológico (CNPq) pela concessão de bolsa de mestrado no período de vigência de 01/07/2016 a 30/06/2018 (Processo no 134224/2016-7).

À Fundação de Amparo à Pesquisa do Estado de São Paulo (FAPESP) e à Coordenação de Aperfeiçoamento de Pessoal de Nível Superior (CAPES), pela concessão de bolsa de mestrado em convênio/acordo, no período de vigência de 01/06/2017 a 27/09/2018 (Processo no 2017/01769-7). Também agradeço à FAPESP pela concessão de Bolsa de Estágio no Exterior (BEPE/FAPESP, Processo $\mathrm{n}^{\circ}$ 2017/25020-5) para a Universitat Pompeu Fabra (UPF), em Barcelona, no período de vigência de 01/03/2018 a 27/05/2018.

Á minha orientadora, Profa. Dra. Ximena Suarez Villagran, pelas correções, orientações e por me abrir e direcionar em vários caminhos, você é um exemplo para $\operatorname{mim} !$

À minha co-orientadora Dra. Célia Boyadjian, pela generosidade intelectual, orientações valiosas e apoio não só acadêmico, mas também a considero uma grande amiga.

Ao coordenador do projeto e co-orientador, Prof. Dr. André Strauss, tenho a maior gratidão por ter me acolhido no projeto, admiro muito sua postura como cientista, sempre aberto a compartilhar. Você é genial.

Ao Prof. Dr. Marco Madella e ao Ms. Javier Ruiz-Pérez por terem me orientado com tanta dedicação.

À Profa. Dra. Verônica Wesolowski e ao Dr. Leandro Cascon pelas contribuições na qualificação. Aos colegas que contribuíram mais diretamente com a minha pesquisa, Dr. João C. Moreno de Sousa, Ms. Rodrigo Angeles, Dra. Jennifer Watling, Ms. Marcos Paulo Ramos, Dr. Glauco Constantino e Dra. Caroline Caromano.

À minha família e aos meus pais, em especial, que me apoiam e são meus melhores amigos. À meus avós Ilda Félix e Florindo Ortega e minha tia Patrícia Ortega.

Aos amigos Óliver Papanikolopoulos, Alexandre Guimarães, Ícaro Bevilaqua e Max Denvir. 
Aos amigos e colegas Jordana Barbosa, Renata Estevam, Isabela Muller, Kelly Brandão, Aline Oliveira, Eliane Chim, Renato Panunzio, Letícia Corrêa, Gabriela Mingatos, Marcony Alves, Jéssica Cardoso, Juliana Freitas, Henrique Valadares, Letícia Ribeiro, Laura Furquim, Emerson Nobre, Mariana Inglez, Nina Hochreiter, Anya Iris, Caroline Rutz, Esther Venezia, Melina Pissolato, Fabiana Merencio, Henrique Kozlowski, Marcelo da Costa, Marcelo Manfrini, Paulo Spengler, Thiago Kater, Nicolás Batalla, Odair Vassoler, Rodrigo Araújo de Lima, Caroline Oliveira, Daniel Fidalgo, Elver Mayer, Alex Martire, Marjori Pacheco, Marina Gratao, Suelen Bueno, Haruan Straioto, Fabrício Bernardes, Cláudio Duarte, Nádia Nuni, Lisi Muller, Tomás Partiti, Bruno Barreto, Meliam Gaspar, Renata Araujo, Guilherme Mongeló, Renan Pezzi e todos os demais colegas.

Aos professores coordenadores e técnicos por me receberem em seus laboratórios: Dra. Rita Scheel-Ybert, Dra. Sabine Eggers, Dr. Walter Neves, Dr. Rui Murrieta, Dr. Rodrigo Elias Oliveira, Dr. Gregório Ceccantini, Dra. Mercedes Okumura, Max Ernani Cezario, Dr. Luís Pezo-Lanfranco, Job Carvalho e Dr. Andersen Lyrio.

Aos professores do MAE, especialmente ao Prof. Dr. Astolfo Araujo, a Prof ${ }^{a} \operatorname{Dr}^{a}$ Fabíola Silva, Prof. Dr. Levy Figuti, Dr ${ }^{\mathrm{a}}$ Márcia Angelina, Dr ${ }^{\mathrm{a}}$ Maria Cristina Kormikiari, Profa. Dra. Águeda Vialou, Prof. Dr. Denis Vialou.

Aos servidores do MAE, especialmente Hélio Miranda, Alberto, Gilberto, Cleberson Moura, Mau Silva, Regina, Karen, Cláudia, Jeanne, Matheus, Rodrigo, Renato e Rubens.

Aos professores da minha graduação em Arqueologia, que contribuíram com o início dos planos de mestrado e em minha formação, especialmente Dr $^{\mathrm{a}}$ Rosiclér Silva, Dr. Júlio Rubin, Ms. Loriza Dantas, Ms. Ludmilia Vaz, Dr ${ }^{a}$ Sibeli Viana, Ms. Simone Rosa, Dr ${ }^{\mathrm{a}}$ Camila Wichers e todos os demais.

Aos meus amigos e colegas de graduação.

Aos professores Dr. Marcos Antonio de Menezes, Dr ${ }^{a}$ Sandra Nara e Dr ${ }^{\mathrm{a}}$ Cláudia Graziela.

À equipe de escavação na Lapa do Santo (Etapa 2016), e as equipes do LAAAEIB/USP, LABMICRO-MAE /USP e CaSEs (UPF-Barcelona). 
A todos os colegas e amigos! 


\section{ÍNDICE DE FIGURAS}

Figura 1. Localização geográfica da região de Lagoa Santa na América do Sul (à esquerda) (fonte: Strauss et al; 2015:6) e fotografia aérea do maciço calcário e da Lapa do Santo (à direita,

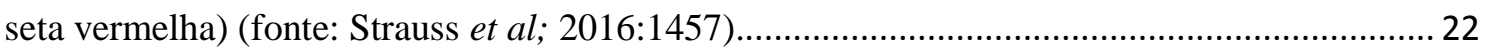

Figura 2. Sítio Lapa do Santo. Etapa de Escavação de 2016. ................................................... 23

Figura 3. Sítios Arqueológicos do carste de Lagoa Santa. Adaptado de IBAMA-CPRM, Prous et

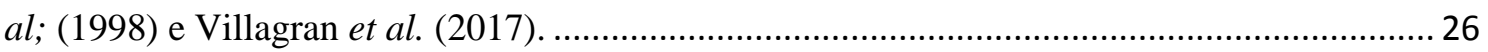

Figura 4. Modelo dos Dois Componentes Biológicos. As rotas pretas representam o componente não-mongoloide e as brancas o componente mongoloide. Fonte: Neves et al. (2003). .............. 41 Figura 5. Escavação de um sepultamento na Lapa do Santo durante etapa de campo em 2016. Pesquisadores: Dr. Rodrigo Elias de Oliveira, Dr. André Strauss e arqueóloga Lycia Macley. 57 Figura 6. Crânio do sepultamento 26 da Lapa do Santo. Fonte: Strauss et al. (2015:13). .......... 58 Figura 7. Fotografia do petroglifo (A) e ilustração do contorno (B). Fonte: Neves et al. (2012:2).

Figura 8. Características básicas de um grão de amido. Adaptado de Fiona Roberts (Gott et al;

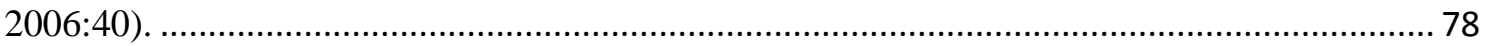

Figura 9. Unidades de Escavação. A) N23, B) P11 e C) A.E.1. Lapa do Santo, 2016. ................ 86 Figura 10. Sepultamento 39. Autoria da foto: Projeto "As Práticas Mortuárias dos Primeiros

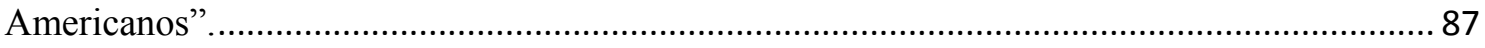

Figura 11. Localização em planta das quadras escavadas na Lapa do Santo. ............................. 88 Figura 12. Localização e proporções de escala aproximadas das quadras N23 e P11. Os pontos coloridos indicam o material arqueológico em todas as camadas escavadas até o ano de 2016. Os pontos são, preto=carvão, azul=lítico, rosa=fauna. 89 Figura 13. A) Lítico detectado durante a escavação. B) Lítico coletado com colher plástica. Sondagem N23, Lapa do Santo, 2016. 90 Figura 14. Líticos analisados. Líticos da quadra N23: A) 13014, B) 14029, C) 14017, D) 13120 , E) 13067, F) 13962, G) 13885. Líticos da quadra P11: H) 14292, I) 14410, J) 14469, K) 14385, L) 14369, M) 14391. Líticos da quadra A1: N) 14267, O) 14236, P) 14335, Q) 14297, R)

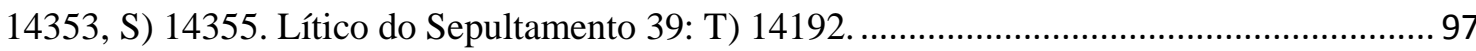
Figura 15. A) Lítico e sedimento coletado abaixo do mesmo. B) Sedimento coletado a $5 \mathrm{~cm}$ do lítico. C) Sedimento coletado a $10 \mathrm{~cm}$ do lítico. 99 Figura 16. Coleta de sedimento na parte superior do abrigo (C2), pela Dra. Ximena Villagran. 101

Figura 17. Coleta de sedimento em paleolago ao sul do abrigo (C3) .................................... 101

Figura 18. Coleta de sedimento em perfil ao norte da área de escavação do sítio (C1)............ 101

Figura 19. Croquis em planta e perfis da quadra N23.......................................................... 103

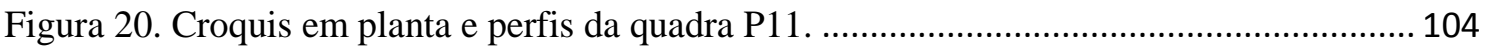

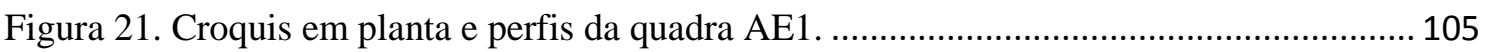

Figura 76. Períodos cronológicos da Lapa do Santo para as escavações de 2001 a 2009. Fonte:

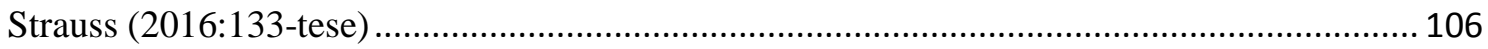

Figura 22. Método de extração de microvestígios com pipeta. 1) Materiais utilizados na higinenização do laboratório. 2) Extração. 3-4) Aplicação da gota de água. 5) Montagem das lâminas. 109 
Figura 23. Locais onde as amostras foram extraídas nos oito líticos da quadra N23. 1) Lítico PN: 13014, 2) PN: 13067, 3) PN: 13120 , 4) PN: 13431, 5) PN: 13885, 6) PN: 13962, 7) PN:

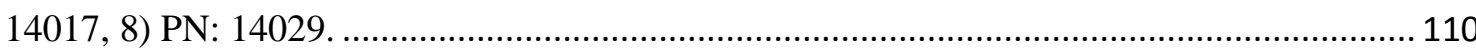

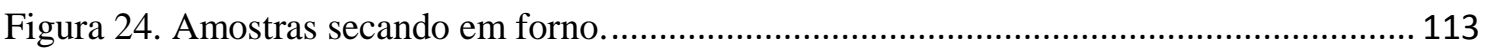

Figura 25. Preparação de Calgon. Calgon em pó (A) e Calgon 5\% (B)..................................... 114

Figura 26. Centrifugação de amostras e pipetagem do sobrenadante. ..................................... 115

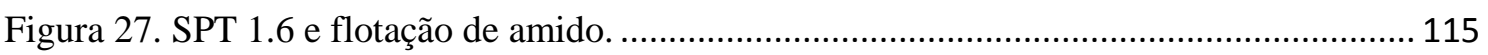

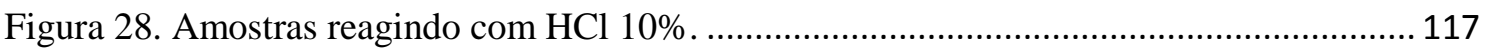

Figura 29. Amostras com o peróxido de hidrogênio em banho de ultrassom........................... 117

Figura 30. Microvestígios do lítico 13014. Não foram detectados microvestígios nas amostras coletadas com pipeta. Estes são provenientes de amostra sonicada. Fitólitos: 1) cross de

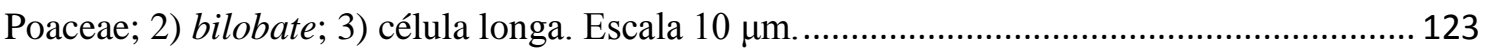
Figura 31. Microvestígios do lítico 13067. Fitólitos coletados com pipeta: 1) bilobate de Panicoideae; 2) não identificado; 3 ) globular granulate; 4) bulliform de Poaceae; 5) célula longa. Fitólitos provenientes de sonicação: 6, 7, ,8 e 9) bilobate de Poaceae; 10) stippled polygonal cone de Cyperaceae; 11) não identificado; 15) célula longa. 14) espícula de esponja. 16, 17 e 18) não identificados. 12-13) não identificado. Escala $10 \mu \mathrm{m}$. 124 Figura 32. Microvestígios do lítico 13431. Fitólito proveniente de sonicação: 1) bilobate. 2) célula longa. 3-4) possível amido proveniente de sonicação. Escala $10 \mu \mathrm{m} . \ldots \ldots \ldots \ldots \ldots \ldots \ldots \ldots \ldots \ldots . . . . . . . . . . . .125$ Figura 33. Microvestígios do lítico 13885. Provenientes de coleta com pipeta: 1-2) pontoações areoladas. Fitólitos de sonicação: 3) bilobate de Panicoideae; 4) bilobate. 8, 9 e 10) células longas. 7) não identificado. Amido de sonicação: 5 e 6 . Escala $10 \mu \mathrm{m}$. 125 Figura 34. Microvestígios do lítico 14017. Escala $10 \mu \mathrm{m}$. Fitólito proveniente de sonicação: 1) globular granulate; 2) célula longa. Escala $10 \mu \mathrm{m}$. 126 Figura 35. Microvestígios do lítico 14029. Escala $10 \mu \mathrm{m}$. Provenientes de coleta com pipeta: 1) se assemelha a rondel wavy-top mas é achatado e quase plano; 2) não identificado. Fitólitos provenientes de sonicação: 3 e 4) bilobates de Panicoideae. Escala $10 \mu \mathrm{m}$. 126 Figura 36. Microvestígios do lítico 13962. Proveniente de pipeta: 1) não identificado. Provenientes de sonicação: 2-3) amido não identificado; 4-5) amido não identificado; 6-7) amido não identificado. 8) estrutura não identificada. Escala $10 \mu \mathrm{m}$. 127 Figura 37. Microvestígios do lítico 13120. Possível célula longa proveniente de amostra sonicada. Escala $10 \mu \mathrm{m}$. 127 Figura 38. Exemplos para ilustrar cada morfotipo de fitólito e outros elementos identificados nas análises provenientes de líticos e sedimento arqueológicos da Lapa do Santo. 1) bilobate de Aristidoideae, 2) bilobate de Bambusoideae, 3) bilobate de Panicoideae, 4) cross de Poaceae "variante 1", 5) cross de Poaceae "outras variantes", 6) rondel de Poaceae, 7) 3-spiked rondel de Bambusoideae, 8) collapsed saddle de Bambudoideae, 9) saddle de Chloridoideae, 10) bulliform de Poaceae, 11) globular echinate de Arecaceae (palmeira), 12) globular echinate elongate de Arecaceae, 13) globular echinate de Arecaceae with short acute projections, 14) stippled polygonal cone de Cyperus/Kyllinga sp; 15) polygonal stippled de Cyperaceae, 16) globular nodular de Zingiberales, 17) globular granulate de Eudicotiledônea (arbóreas), 18) jigsaw de Eudicotiledônea, 19) globular psilate de Eudicotiledônea, 20) diatomácea, 21) espícula de esponja. Escala $10 \mu \mathrm{m}$. 132

Figura 39. 1-2) Estes dois fitólitos do conjunto são o mofotipo rondel, com aparente, mas não confirmada, ondulação característica do rondel tipo wavy-top (Zea mays). Escala $10 \mu \mathrm{m}$........ 133 Figura 40. Medição da largura das cruzes. Escala $10 \mu \mathrm{m}$....................................................... 138 Figura 41. Grãos de amido classificados como Morfotipo A.................................................... 141 


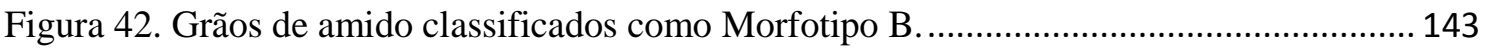

Figura 43. Grãos de amido classificados como Morfotipo C..................................................... 144

Figura 44. Grãos de amido classificados como Morfotipo D.................................................. 145

Figura 45. Grãos de amido classificados como Morfotipo E.................................................... 145

Figura 46. Grão de amido classificados como Morfotipo F...................................................... 147

Figura 47. Grãos de amido classificados como Morfotipo G................................................ 147

Figura 48. Grãos de amido classificados como Morfotipo H..................................................... 148

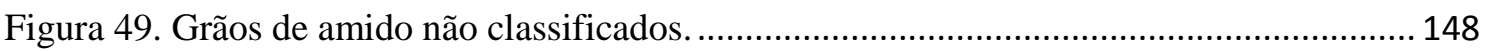

Figura 50. Microvestígios do Lítico 13014. Fitólitos: 1) bilobate de Aristidoideae, 2) bilobate de Bambusoideae, 3) bilobate de Panicoideae, 4) cross de Poaceae "variante 1", 5) cross de Poaceae "outras variantes", 6) rondel de Poaceae, 7) rondel de Poaceae, 8) 3-spiked rondel de Bambusoideae, 9) collapsed Saddle de Bambudoideae, 10) saddle de Chloridoideae, 11) bulliform de Poaceae, 12) globular echinate de Arecaceae (palmeira), 13) globular granulate de Eudicotiledônea (arbóreas), 14) diatomácea (organismo aquático), 15) espícula de esponja. Amido:16-17)Não identificado;18-19, 20-21, 22-23 e 24-25) Morfotipo A. Escala 10 m..... 153 Figura 51. Microvestígios do Lítico 13014. Fitólitos e outros: 1) bilobate de Bambusoideae, 2) bilobate de Panicoideae; 3, 4 e 5) cross de Poaceae "variante 1"; 6) cross de Poaceae "outras variantes", 7) rondel de Poaceae, 8) 3-spiked rondel de Bambusoideae, 9) collapsed Saddle de Bambudoideae, 10) saddle de Chloridoideae, 11) bulliform de Poaceae, 12) globular echinate de Arecaceae (palmeira), 13) globular echinate elongate de Arecaceae, 14) globular echinate de Arecaceae with short acute projections, 15) stippled polygonal cone de Cyperus/Kyllinga sp; 16) globular nodular de Zingiberales, 17) globular granulate de Eudicotiledônea (arbóreas), 18) jigsaw de Eudicotiledônea, 19) globular psilate de Eudicotiledônea, 20) fragmento de diatomácea (organismo aquático), 21) espícula de esponja. Amido: 22-23) Morfotipo B. ...... 155 Figura 52. Microvestígios do Lítico 14017. Fitólitos e outros: 1) e 2) cross de Poaceae "outras variantes", 3) rondel de Poaceae, 4) bulliform de Poaceae, 5) globular granulate de Eudicotiledônea (arbóreas), 6) globular psilate de Eudicotiledônea, 7) espícula de esponja, 13) saddle de Chloridoideae, 14) bulliform de Poaceae, 15) rondel de Poaceae, 16) 3-spiked rondel de Bambusoideae, 17) globular granulate de Eudicotiledônea (arbóreas), 18) globular psilate de Eudicotiledônea, 19) espícula de esponja. Amido: 9-10 e 11-12 Morfotipo A. Escala 10 m. 157 Figura 53. Microvestígios do Lítico 13067. Fitólitos e outros: 1) bulliform de Poaceae, 2) bilobate de Panicoideae; 3, 4, 5 e 6) cross de Poaceae "variante 1"; 7) cross de Poaceae "outras variantes", 8) rondel de Poaceae, 9) 3-spiked rondel de Bambusoideae, 10) collapsed Saddle de Bambusoideae, 11) saddle de Chloridoideae, 12) bulliform de Poaceae, 13) globular echinate de Arecaceae (palmeira), 14) globular echinate de Arecaceae with short acute projections, 15) globular nodular de Zingiberales, 16) globular granulate de Eudicotiledônea (arbóreas), 17)

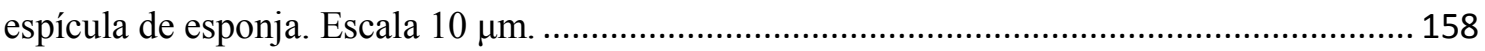

Figura 54. Microvestígios do Lítico 13885. Fitólitos: 1) cross de Poaceae "variante 1" e 2)

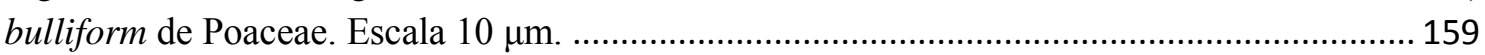

Figura 55. Microvestígios do Lítico 14029. Fitólitos: 1) bulliform de Poaceae, 2) globular granulate de Eudicotiledônea (arbóreas), 5) bilobate de Panicoideae; 6, 7 e 8) cross de Poaceae "variante 1"; 9) cross de Poaceae "outras variantes", 10) rondel de Poaceae, 11) bulliform de Poaceae, 12) globular echinate de Arecaceae (palmeira), 13) globular echinate elongate de Arecaceae, 14) globular echinate de Arecaceae with short acute projections, 15) stippled polygonal cone de Cyperus/Kyllinga sp; 16) polygonal stippled de Cyperaceae, 17) globular nodular de Zingiberales, 18) globular granulate de Eudicotiledônea (arbóreas), 19) espícula de esponja. Amido: 3-4 e 20-21) Não identificados. Escala $10 \mu \mathrm{m}$. 160 
Figura 56. Microvestígios do Lítico 13120. Fitólitos: 1) bilobate de Panicoideae, 2) cross de Poaceae "variante 1", 3) bulliform de Poaceae, 4) globular granulate de Eudicotiledônea (arbóreas), 5) rondel de Poaceae. Escala $10 \mu \mathrm{m}$. 161

Figura 57. Microvestígios do Lítico 13962. Fitólitos: 1) bilobate de Panicoideae, 2) cross de Poaceae "outras variantes", 3) 3-spiked rondel de Bambusoideae, 4) bulliform de Poaceae, 5) stippled polygonal cone de Cyperus/Kyllinga sp; 6) globular granulate de Eudicotiledônea (arbóreas), 7) espícula de esponja. Amido: 8-9) Não identificado. Escala $10 \mu \mathrm{m}$. 161 Figura 58. Microvestígios do Lítico 14292. Fitólitos: 1) bulliform de Poaceae, 4) rondel de Poaceae, 5) bulliform de Poaceae, 6) globular nodular de Zingiberales, 7) globular granulate de Eudicotiledônea (arbóreas), 8) globular psilate de Eudicotiledônea, 9) espícula de esponja. Amido: 2-3 e 10-11) Morfotipo A. Escala $10 \mu \mathrm{m}$. 162

Figura 59. Microvestígio do Lítico 14385. Amido: Não identificado. Escala $10 \mu \mathrm{m}$. 163 Figura 60. Microvestígio do Lítico 14391. Fitólitos e outros: 1) bilobate de Panicoideae, 2) cross de Poaceae "variante 1", 3) cross de Poaceae "outras variantes", 4) bulliform de Poaceae, 5) globular echinate de Arecaceae (palmeira), 8) bilobate de Panicoideae, 9) cross de Poaceae "variante 1", 10) rondel de Poaceae, 11) collapsed Saddle de Bambusoideae, 12) bulliform de Poaceae, 13) stippled polygonal cone de Cyperus/Kyllinga sp; 14) globular granulate de Eudicotiledônea (arbóreas), 15) espícula de esponja. Amido: 6-7) Morfotipo G; 16-17, 18-19 e 22-23 Morfotipo A; 20-21) Não identificado; 24-25) Morfotipo D. Escala $10 \mu \mathrm{m}$. 164 Figura 61. Microvestígio do Lítico 14410. Fitólitos: 1) rondel de Poaceae, 2) bulliform de

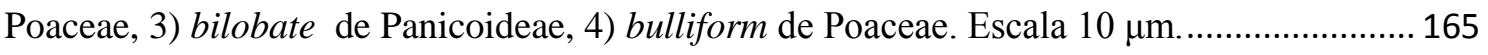
Figura 62. Microvestígio do Lítico 14469. Fitólitos: 1) globular echinate de Arecaceae (palmeira), 4) bilobate de Aristidoideae, 5) bilobate de Panicoideae; 6, 7 e 8) cross de Poaceae "variante 1"; 9) rondel de Poaceae, 10) 3-spiked rondel de Bambusoideae, 11) bulliform de Poaceae, 12) globular echinate de Arecaceae (palmeira), 13) globular echinate de Arecaceae with short acute projections, 14) globular granulate de Eudicotiledônea (arbóreas), 15) espícula de esponja. Amido: 2-3) Morfotipo I. Escala $10 \mu \mathrm{m}$. 166 Figura 63. Microvestígio do Lítico 14369. Fitólitos: 3) bulliform de Poaceae, 4) globular echinate de Arecaceae with short acute projections, 5) globular granulate de Eudicotiledônea (arbóreas). Amido: 1-2) Morfotipo A. Escala $10 \mu \mathrm{m}$. 167 Figura 64. Microvestígio do Lítico 14267. Fitólitos: 1) rondel de Poaceae, 2) bulliform de Poaceae, 3) globular echinate de Arecaceae (palmeira), 4) globular granulate de Eudicotiledônea (arbóreas), 5) espícula de esponja. Amido: 6-7 e 12-13) Morfotipo H; 8-9) Morfotipo F; 10-11 e 16-17) Morfotipo A; 14-15) Morfotipo I; 18-19) Não identificado. Escala $10 \mu \mathrm{m}$. 168

Figura 65. Microvestígio do Lítico 14236. Fitólitos: 1) bulliform de Poaceae, 2) collapsed Saddle de Bambudoideae, 3) bulliform de Poaceae, 4) globular granulate de Eudicotiledônea (arbóreas), 5) globular nodular de Zingiberales, 8) espícula de esponja. Amido: 6-7) Morfotipo B. Escala $10 \mu \mathrm{m}$. 169

Figura 66. Microvestígios do Lítico 14355. 14355. Fitólitos: 1) saddle de Chloridoideae, 6) bulliform de Poaceae, 7) globular granulate de Eudicotiledônea (arbóreas). Amido:2-3) Não identificado; 4-5) Morfotipo B, 8-9 e 10-11) Não identificados. Escala $10 \mu \mathrm{m}$. 170 Figura 67. Microvestígio do Lítico 14335. Fitólito: 1) cross de Poaceae "variante 1". Escala 10 $\mu \mathrm{m}$. 171

Figura 68. Microvestígio do Lítico 14353. Fitólitos e outros: 9) espícula de esponja, 10) rondel de Bambusoideae, 11) bulliform de Poaceae, 12) stippled polygonal cone de Cyperus/Kyllinga sp; 13) globular granulate de Eudicotiledônea (arbóreas), 14) jigsaw de Eudicotiledônea, 15) 
espícula de esponja. Amido:1-2) Morfotipo C; 3-4) Morfotipo H, 5-6) Morfotipo I; 7-8) Morfotipo E, 16-17) Morfotipo A; 18-19 e 22-23 Não identificados; 20-21) Morfotipo A. Escala $10 \mu \mathrm{m}$.

Figura 69.. Microvestígio do Lítico 14297. Fitólitos: 1) bulliform de Poaceae, 2) espícula de esponja, 3) bulliform de Poaceae, 4) globular granulate de Eudicotiledônea (arbóreas), 5) espícula de esponja. Amido:6-7) Morfotipo D; 8-9) Não identificado. Escala $10 \mu \mathrm{m}$ 173

Figura 70. Microvestígios do Lítico 14192. Fitólitos:1) bulliform de Poaceae. Amido: 2-3 e 6-7) Morfotipo A; 4-5) Morfotipo B. Escala $10 \mu \mathrm{m}$. 174 Figura 71. Microvestígios de sedimento da quadra N23. Fitólitos e outros: 1) bilobate de Aristidoideae, 2) bilobate de Bambusoideae, 3) bilobate de Panicoideae; 4, 5, 6, 7, 8, 9 e 10) cross de Poaceae "variante 1"; 11, 12, 13, 14 e 15) cross de Poaceae "outras variantes", 16 e 17) rondel de Poaceae, 18) 3-spiked rondel de Bambusoideae, 19) collapsed Saddle de Bambudoideae, 20) saddle de Chloridoideae, 21) bulliform de Poaceae, 22) globular echinate de Arecaceae (palmeira), 23) globular echinate elongate de Arecaceae, 24) stippled polygonal cone de Cyperus/Kyllinga sp; 25) globular nodular de Zingiberales, 26) globular granulate de Eudicotiledônea (arbóreas), 27) espícula de esponja. Escala $10 \mu \mathrm{m}$. 176 Figura 72. Microvestígios de sedimento da quadra P11. Fitólitos: 1) bilobate de Panicoideae; 2) cross de Poaceae "variante 1", 3) cross de Poaceae "outras variantes", 4) rondel de Poaceae, 5) 3-spiked rondel de Bambusoideae, 6) saddle de Chloridoideae, 7) bulliform de Poaceae, 8) globular echinate de Arecaceae with short acute projections, 9) stippled polygonal cone de Cyperus/Kyllinga sp; 10) globular granulate de Eudicotiledônea (arbóreas), 11) espícula de esponja. Amido: 12-13) Morfotipo I, 14-15) Morfotipo A. Escala $10 \mu \mathrm{m}$. 177 Figura 73. Microvestígios de sedimento da quadra AE1. Fitólitos: 1) bilobate de Panicoideae, 2 e 3) cross de Poaceae "variante 1", 4) rondel de Poaceae, 5) collapsed Saddle de Bambudoideae, 6) saddle de Chloridoideae, 7) bulliform de Poaceae, 8) globular echinate de Arecaceae (palmeira), 9) globular echinate de Arecaceae with short acute projections, 10) globular granulate de Eudicotiledônea (arbóreas), 11) jigsaw de Eudicotiledônea, 12) espícula de esponja. Escala $10 \mu \mathrm{m}$. 178 Figura 74. Microvestígios de sedimento da amostra C2. Fitólitos: 1) bilobate de Aristidoideae, 2) bilobate de Panicoideae, 3) cross de Poaceae "variante 1", 4) rondel de Poaceae, 5) saddle de Chloridoideae, 6) stippled polygonal cone de Cyperus/Kyllinga sp; 7) globular granulate de Eudicotiledônea (arbóreas), 8) polygonal stippled de Cyperaceae, 9) bulliform de Poaceae, 10) globular psilate de Eudicotiledônea, 11) diatomácea (organismo aquático), 12) espícula de esponja, 13) pelo radicial de planta. Autoria da foto do abrigo: Maurício de Paiva. Escala 10 $\mu \mathrm{m}$. 179

Figura 75. Itens identificados em amostra de água destilada: amido nas duas primeiras imagens e, itens de origem vegetal. Em papel toalha: fibras vegetais. Em esmalte: itens de origem vegetal. Escala $10 \mu \mathrm{m}$ 180 


\section{ÍNDICE DE TABELAS}

Tabela 1.Táxons Botânicos em Lagoa Santa no passado ........................................................... 71

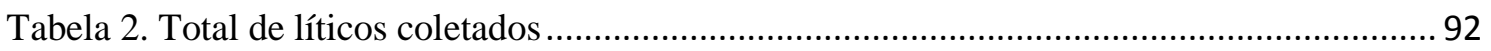

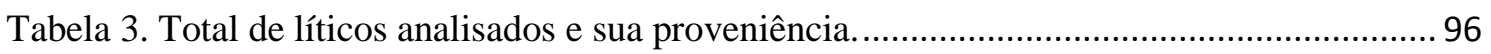

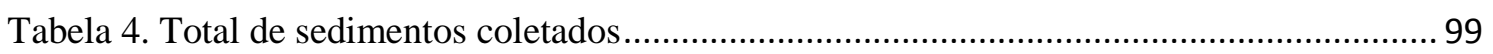

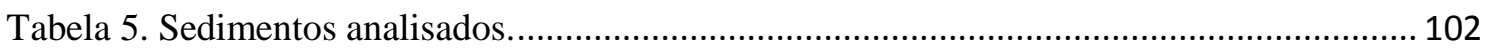

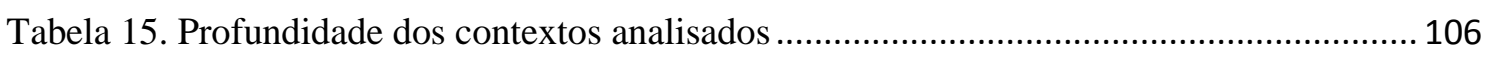

Tabela 6. Quantidade absoluta de fitólitos e amido presente nas amostras de líticos ............... 122

Tabela 7. Quantidade Absoluta de Fitólitos e Amido Presente nas Amostras de Líticos .......... 128

Tabela 8. Quantidade Absoluta de Fitólitos e Amido Presentes em Sedimento ........................ 129

Tabela 9. Fitólitos e Associação Taxonômica....................................................................... 130

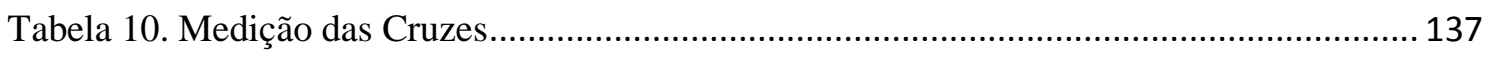

Tabela 11. Descrição dos morfotipos de grãos de amido encontrados nas amostras da Lapa do

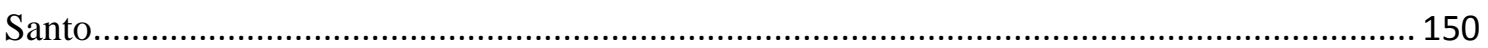

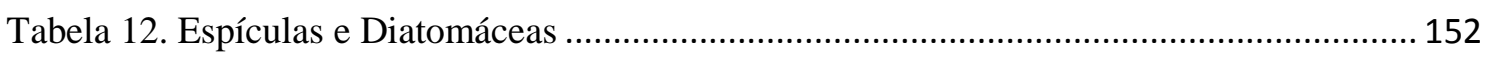

Tabela 13. Descrição tecnológica preliminar dos líticos ......................................................... 181

Tabela 14.Espécies de Arecaceae e os fitólitos que produzem. Estas não produzem fitólitos que

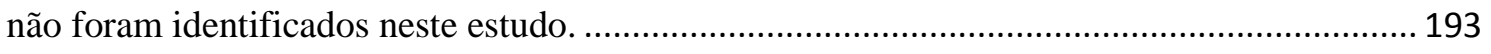

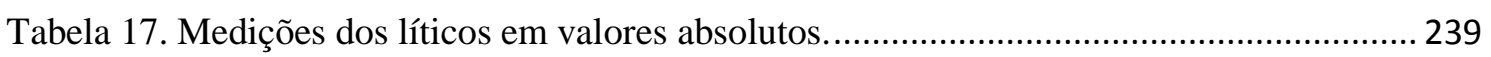




\section{ÍNDICE DE GRÁFICOS}

Gráfico 1. Diagrama da proporção relativa (\%) dos grupos taxonômicos botânicos identificados a partir da análise fitolítica das amostras provenientes de sonicação (Etapa 2) de líticos das quadras N23, P11, AE1 e do Sepultamento 39. O total de elementos contados na lâmina estão em valor absoluto. 134

Gráfico 2. Diagrama da proporção relativa (\%) dos grupos taxonômicos botânicos identificados a partir da análise fitolítica das amostras provenientes de escovação (Etapa 2) de líticos das quadras N23, P11, AE1 e do Sepultamento 39. O total de elementos contados na lâmina estão em valor absoluto. 135

Gráfico 3. Diagrama da proporção relativa (\%) dos grupos taxonômicos botânicos identificados a partir da análise fitolítica das amostras de sedimento arqueológico coletado das quadras N23, P11, AE1 e de fora do sítio (C2) (Etapa 2). O total de elementos contados na lâmina estão em valor absoluto. 136

Gráfico 4. Dimensões dos líticos em espessura, largura e comprimento. 183

Gráfico 5. Dimensão média (comprimento, espessura e largura) dos líticos 184 


\section{SUMÁRIO}

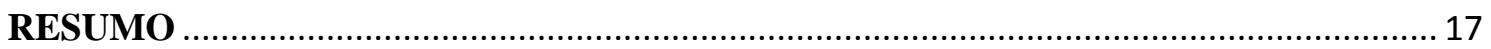

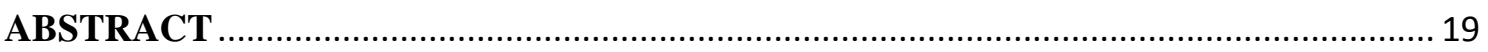

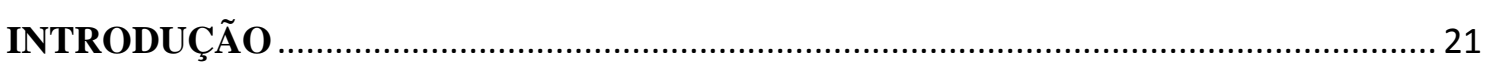

1. CONTEXTO ARQUEOLÓGICO: LAGOA SANTA E LAPA DO SANTO ............... 32

1.1. As Pesquisas Arqueológicas em Lagoa Santa ............................................................ 32

1.2. Processos de Formação dos Sítios de Lagoa Santa .................................................... 42

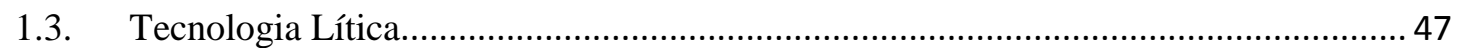

1.4. Cronologia e Sepultamentos da Lapa do Santo ............................................................ 55

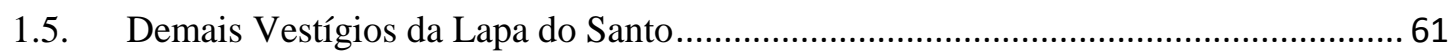

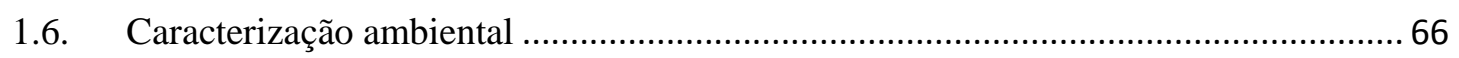

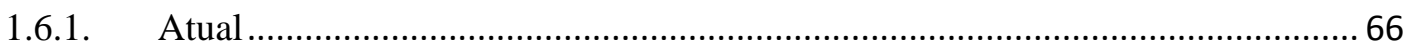

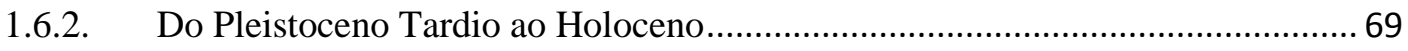

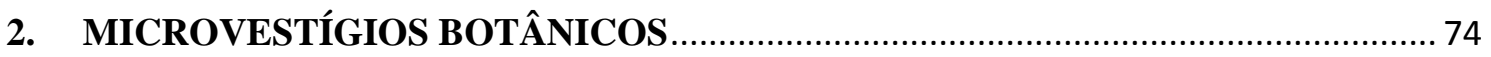

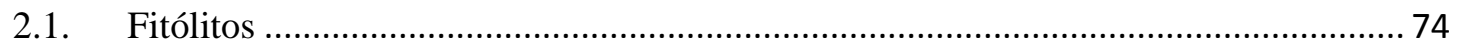

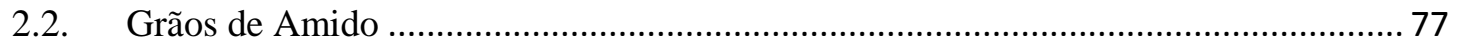

2.3. Breve Histórico e Potencial dos Estudos de Amido e Fitólitos.................................... 79

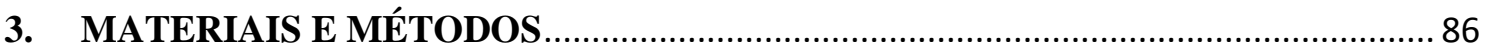

3.1. Escavação e coleta do material arqueológico............................................................ 90

3.1.1. Protocolo De Escavação e Coleta de Artefatos e Sedimento para Análise de

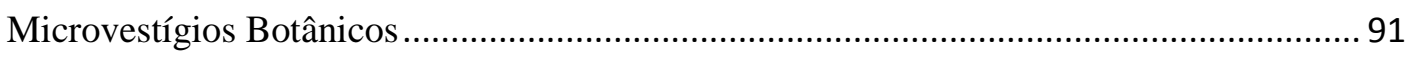

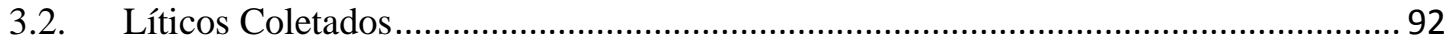

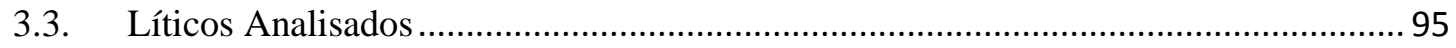

3.4. Amostras de Sedimentos para controle de contaminação ............................................ 98

3.4.1. Amostras de Sedimento Coletadas ........................................................................ 99

3.4.2. Amostras de Sedimento Analisadas ................................................................ 102

3.5. Localização das amostras na planta e perfis das quadras analisadas.......................... 102

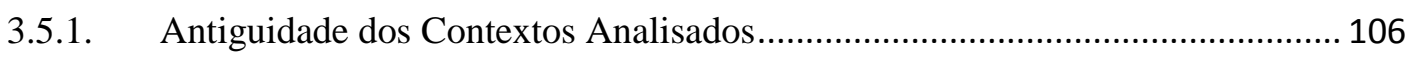

3.6. Extração de Microvestígios Botânicos ...................................................................... 108

3.6.1. Etapa 1a: Pipeta ou Método Step-Wise ............................................................ 108

3.6.2. Etapa 1b: Técnica de Escovação e Sonicação ........................................................... 110

3.7. Etapa 2: Método com Sonicação e Aplicação de Reagentes ....................................... 112 
3.7.1. Protocolo Usado para Processamento das Amostras e Recuperação de Fitólitos e Amido 113

3.7.2. Amostras de materiais utilizados em laboratório para controle de contaminação 119

3.8. Análise dos Microvestígios Botânicos 120

4. RESULTADOS

4.1. Etapa 1: Microvestígios Extraídos Pelo Método da Pipeta (Etapa 1a, Método StepWise) e Sonicação (Etapa 1b).

4.2. Etapa 2: Microvestígios extraídos de líticos e sedimento pelo método da sonicação/escovação e aplicação de reagentes 128

4.2.1. Relação da presença de microvestígios nos líticos e no sedimento de referência 128

4.2.2. Identificação dos Fitólitos 129

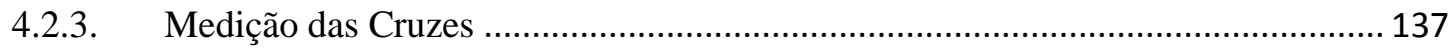

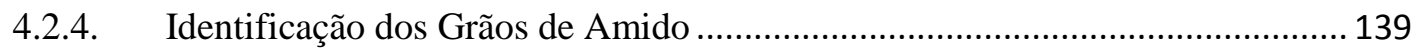

4.2.6. Síntese dos microvestígios identificados em de cada lítico analisado................... 152

4.2.7. Microvestígios identificados no sedimento arqueológico e natural ................... 175

4.2.8. Amostras de materiais utilizados em laboratório para controle de contaminação 180

4.3. Descrição tecnológica preliminar dos artefatos líticos. 181

5. DISCUSSÃO

5.1. Comparação dos métodos aplicados para recuperação de microvestígios botânicos (Etapa 1 vs. Etapa 2) 186

5.1.1. Recuperação de Microvestígios em Quantidade ................................................ 186

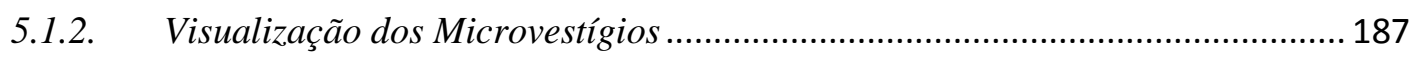

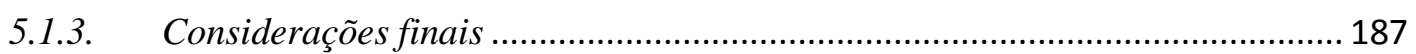

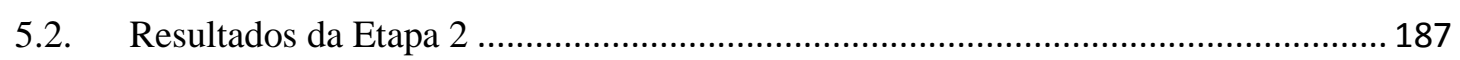

5.2.1. Comparação dos microvestígios nos líticos com o sedimento de cada quadra. 189

5.2.2. Comparação do sedimento arqueológico (quadras N23, P11 e AE1) com o

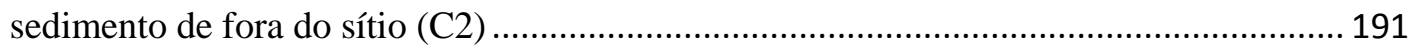

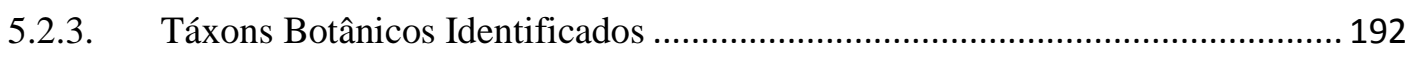

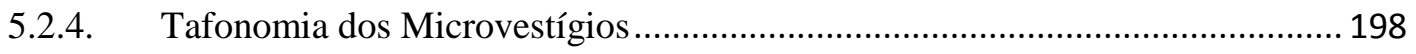

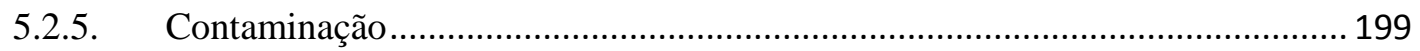

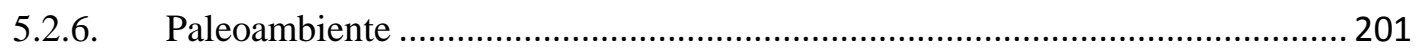

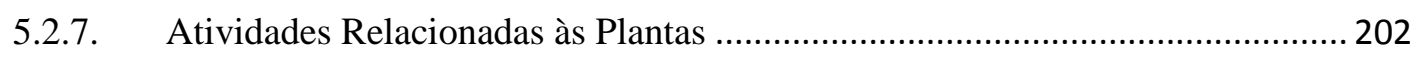

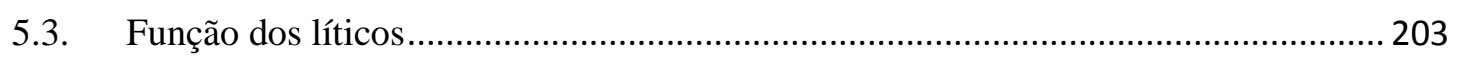




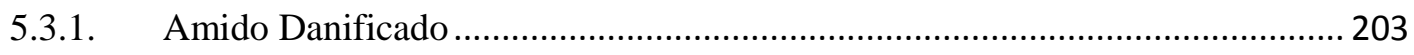

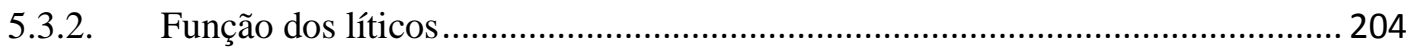

5.4. Contexto regional: função dos líticos da Lapa do Santo e de Lapa Grande de

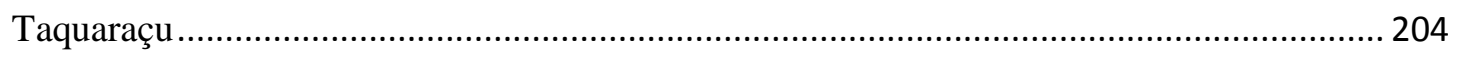

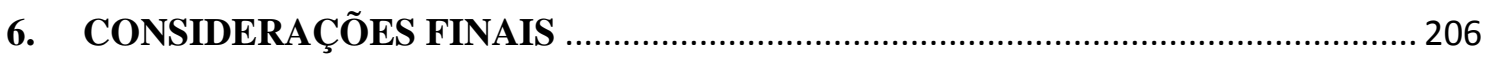

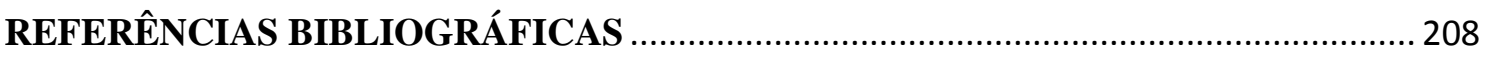

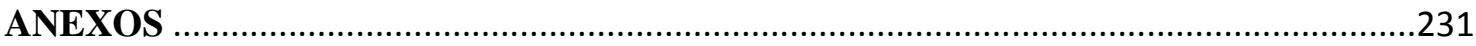




\section{RESUMO}

A região cárstica de Lagoa Santa (Minas Gerais) contém dezenas de sítios arqueológicos, cujos mais antigos datam do Holoceno Inicial (período entre 10.000 e 7000 anos A.P.), com coleções numerosas de remanescentes esqueletais humanos bem preservados. O sítio em abrigo Lapa do Santo, localizado ao norte do carste, contém mais de 30 sepultamentos humanos escavados, tendo sido identificadas práticas funerárias complexas que incluem o descarnamento, a decapitação e a remoção intencional de dentes. A matriz sedimentar que contém os vestígios é constituída de cinzas de antigas estruturas de combustão, acesas em um período de 3000 anos. Muitos artefatos líticos foram escavados no sítio, a maioria com pequenas dimensões (comprimento com cerca de $22 \mathrm{~mm}$ ). Os líticos do sítio são lascas (raramente retocadas), núcleos e resíduos de lascamento, grande parte produzidos com cristais de quartzo hialino. Estudos tecnológicos e experimentais prévios sugerem que os líticos seriam usados para cortar e raspar materiais pequenos e macios, como plantas. Nesta pesquisa, para verificar o uso dos líticos da Lapa do Santo para o processamento de plantas, foram realizadas análises de microvestígios botânicos (fitólitos e amido) recuperados em 20 líticos do sítio. Esses artefatos foram recuperados de três unidades de escavação diferentes e do contexto de um sepultamento, seguindo um protocolo específico para evitar a contaminação durante a coleta. Amostras de sedimento do sítio também foram analisadas para verificar a possível contaminação dos microvestígios retidos nos líticos com os microvestígios presentes no sedimento. As análises revelaram fitólitos nos líticos $(\mathrm{n}=19)$ e no sedimento (em todas as amostras), assim como amido na maioria dos líticos $(n=16)$ e em uma única amostra de sedimento. Os morfotipos de fitólitos identificados são diagnósticos dos seguintes táxons de plantas: Aristidoideae, Bambusoideae, Chloridoideae, Arecaceae (palmeiras), Poaceae (gramíneas) incluindo Panicoideae e, dentre essas, Zea mays (milho), Cyperaceae, inclusive Cyperus/Kyllinga sp; Zingiberales e Eudicotiledôneas (arbóreas). Os grãos de amido identificados apresentam semelhanças, embora nem sempre totalmente, com aqueles pertencentes aos táxons: Araceae (taioba), Arecaceae, Poaceae incluindo gramíneas selvagens e Zea mays; Ipomoea batatas (batata-doce), Capsicum sp. (pimenta e pimentão) e Dioscorea sp. (cará). Os resultados indicam que os instrumentos foram usados para processar plantas amiláceas cruas. Na quadra N23 quase todos os fitólitos que estão presentes nos líticos estão presentes também no sedimento (com exceção de Cyperaceae, presentes 
nos líticos, mas não no sedimento). Isso sugere uma possível contaminação dos líticos com os fitólitos do sedimento. Na quadra P11 há fitólitos de dois táxons de plantas (Aristidoideae e Zingiberales) nos líticos que não estão presentes no sedimento. Na quadra AE1 há fitólitos de quatro táxons de plantas (Bambusoideae, Chloridoideae, Cyperus/Kyllinga sp. e Zingiberales) nos líticos, que não estão presentes no sedimento ao redor. A presença exclusiva desses fitólitos nos líticos das quadras P11 e AE1, mas não no sedimento, indica que tais plantas foram, de fato, processadas com os artefatos.

PALAVRAS-CHAVE: Microarqueobotânica, Lagoa Santa, Fitólitos, Amido, Instrumentos Líticos, Holoceno Inicial. 


\begin{abstract}
The karstic region of Lagoa Santa (Minas Gerais state) contains several archaeological sites dating back to the early Holocene with an astonishing number of well-preserved human remains. The Lapa do Santo rockshelter site, in the northern part of the karst, contains more than 30 human interments in which complex funerary rituals were identified, including defleshing, decapitation and intentional teeth removal. The sedimentary matrix containing the skeletal remains is mostly made of ashes from ancient combustion structures, lit within a period of about 3000 years. Several lithic artifacts have been recovered from the site, most of them of small dimensions (length around $22 \mathrm{~mm}$ ). Lithics are mostly flakes (rarely retouched), cores and splinters made from single crystals of hyaline quartz. Previous technological research suggests that lithic artifacts were used to cut and scrape small and soft materials, like plants. To verify whether the lithics from Lapa do Santo were indeed used to process plant resources, analyses of plant microremains (phytoliths and starch) were undertaken in 20 artifacts from the site. The artifacts were recovered from three different excavation units $(1 \mathrm{~m} \times 1 \mathrm{~m})$ and one interment, following a specific protocol to prevent contamination during collection. Sediment samples from the site were also analyzed in order to differentiate between microremains retained in the lithics after their use or incorporated later from the surrounding sediments. The analyses revealed a larger amount of phytoliths in the lithics (19 of them) and sediment (all samples) and starch in most of the artifacts (16 of them) and in one sediment sample. The identified phytolith morphotypes are diagnostic of the following plant taxa: Aristidoideae, Bambusoideae, Chloridoideae, Arecaceae, Poaceae, including Panicoideae and among these, Zea mays (corn), Cyperaceae, including Cyperus/Kyllinga sp; Zingiberales and Eudicots. The starch grains show resemblances (even though not completely sometimes) to those belonging to: Araceae, Arecaceae, Poaceae, including wild grasses and Zea mays, Ipomoea batatas, Capsicum sp. and Dioscorea sp. The results indicate that the instruments were used to process raw (non cooked) starchy plants. Almost every phytolith from the N23 excavation unit that are present in lithics, are also present in the sediment from this unit (except the ones of Cyperaceae, present in lithic but not in the sediment), which strongly suggest contamination of the lithics with the phytoliths and starch from the sediment. From the P11 excavation unit there are phytolithis of two
\end{abstract}


plant taxa (Aristidoideae and Zingiberales) in the lithics that are not present in the sediment. From the AE1 excavation unit there are phytoliths from four plant taxa (Bambusoideae, Chloridoideae, Cyperus/Kyllinga sp. and Zingiberales) in the lithics that are not present in the sediment. This suggests that the phytoliths in these artifacts may have been originated by their use and not by contamination with the sediment.

KEYWORDS: Microarchaeobotany, Lagoa Santa, Phytoliths, Starch, Lithic Artifacts, Early Holocene. 


\section{INTRODUÇÃO}

Esta pesquisa foi realizada no âmbito de um projeto maior de escavação e estudos no sítio arqueológico Lapa do Santo, denominado "As Práticas Mortuárias dos Primeiros Americanos”, coordenado pelo Prof. Dr. André Strauss (Strauss et al; 2016). $\mathrm{O}$ apoio financeiro durante o primeiro ano do mestrado (2016-2017) foi concedido por bolsa do CNPQ (Processo no 134224/2016-7), e no segundo ano (2017-2018) por bolsa da FAPESP em convênio com a CAPES (Processo no 2017/01769-7), com realização de Bolsa de Estágio no Exterior, em Barcelona (BEPE - Processo nº 2017/25020-5).

O projeto maior de escavação ocorre desde 2011 na Lapa do Santo (Figura 1); localizada no município de Matozinhos, estado de Minas Gerais; com suporte do Departamento de Evolução Humana do Instituto Max Planck de Antropologia Evolutiva, do Laboratório de Estudos Evolutivos Humanos ${ }^{1}$ (LEEH-IB/USP) e do Laboratório de Arqueologia e Antropologia Ambiental e Evolutiva ${ }^{2}$ (LAAAE-USP) (Strauss et al; 2016). Os trabalhos de campo referentes a esta pesquisa de mestrado foram realizados em etapa de escavação do ano de 2016 na Lapa do Santo.

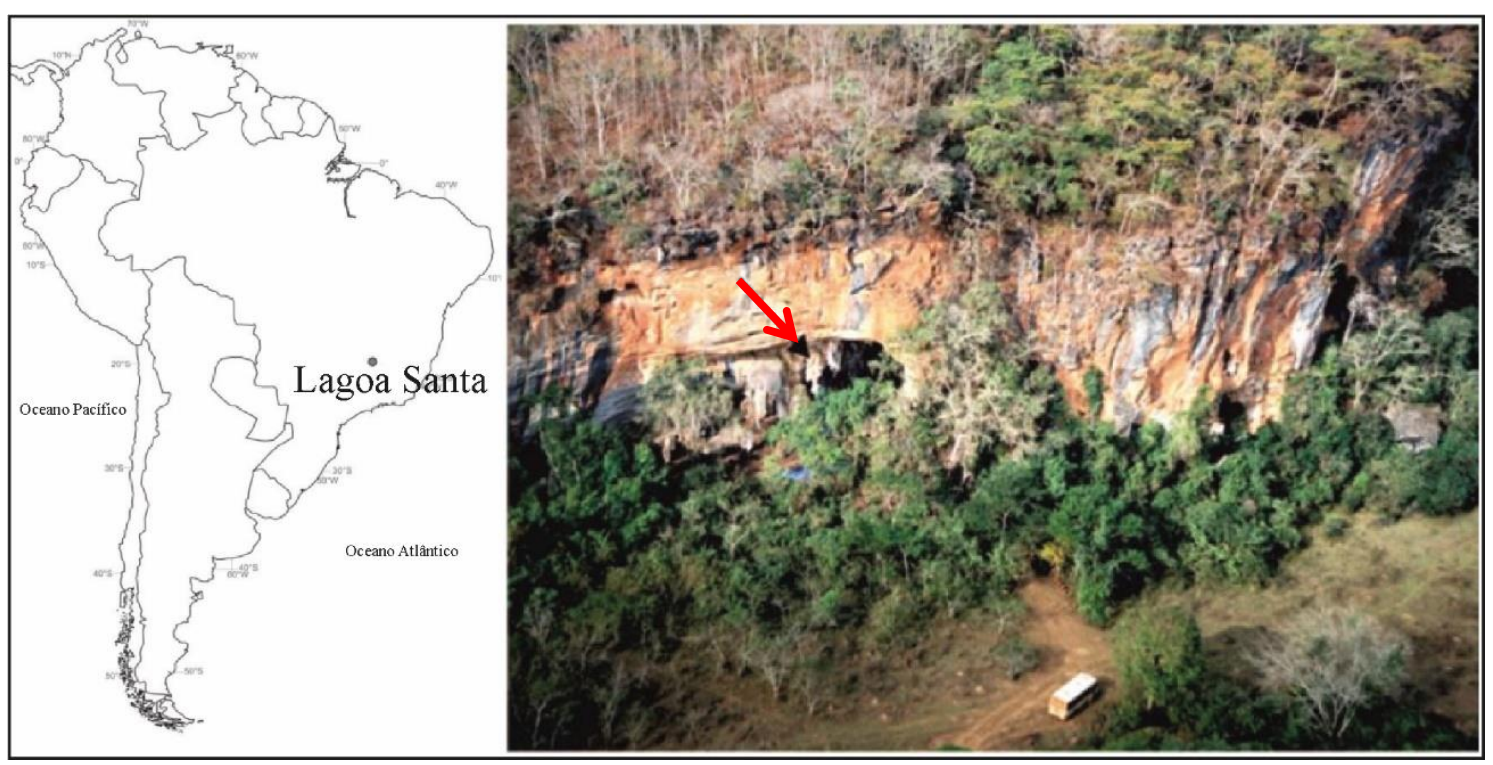

Figura 1. Localização geográfica da região de Lagoa Santa na América do Sul (à esquerda) (fonte: Strauss et al; 2015:6) e fotografia aérea do maciço calcário e da Lapa do Santo (à direita, seta vermelha) (fonte: Strauss et al; 2016:1457).

\footnotetext{
${ }^{1}$ Antes coordenado pelo Dr. Walter Neves e atualmente pela Dra. Mercedes Okumura.

${ }^{2}$ Coordenado pelo Dr. Rui Sérgio Murrieta e pelo Prof. Dr. André Strauss.
} 
O sítio foi inicialmente escavado e estudado de 2001 a 2009 pelo projeto "Origem e microevolução do Homem na América: uma abordagem paleoantropológica" (Projeto Origens), coordenado pelo Dr. Walter Neves (Neves et al; 2007). O suporte foi proporcionado pelo Laboratório de Estudos Evolutivos Humanos (LEEH), do Instituto de Biociências da Universidade de São Paulo (IB/USP), e o apoio financeiro pela FAPESP (Processos n ${ }^{\circ}$ 99/00670-7 e nº4/01321-6) (Neves \& Piló, 2008; Neves et al; 2007; Araujo et al; 2012).

A Lapa do Santo é constituída por um abrigo na entrada de uma caverna (Figura 2), inserida na parte inferior de um maciço calcário de $30 \mathrm{~m}$ de altura, coberto com latossolo e Mata Seca Semi-Decidual ${ }^{3}$ (Figura 1) (Strauss et al; 2016; Hermann et al; 1998).

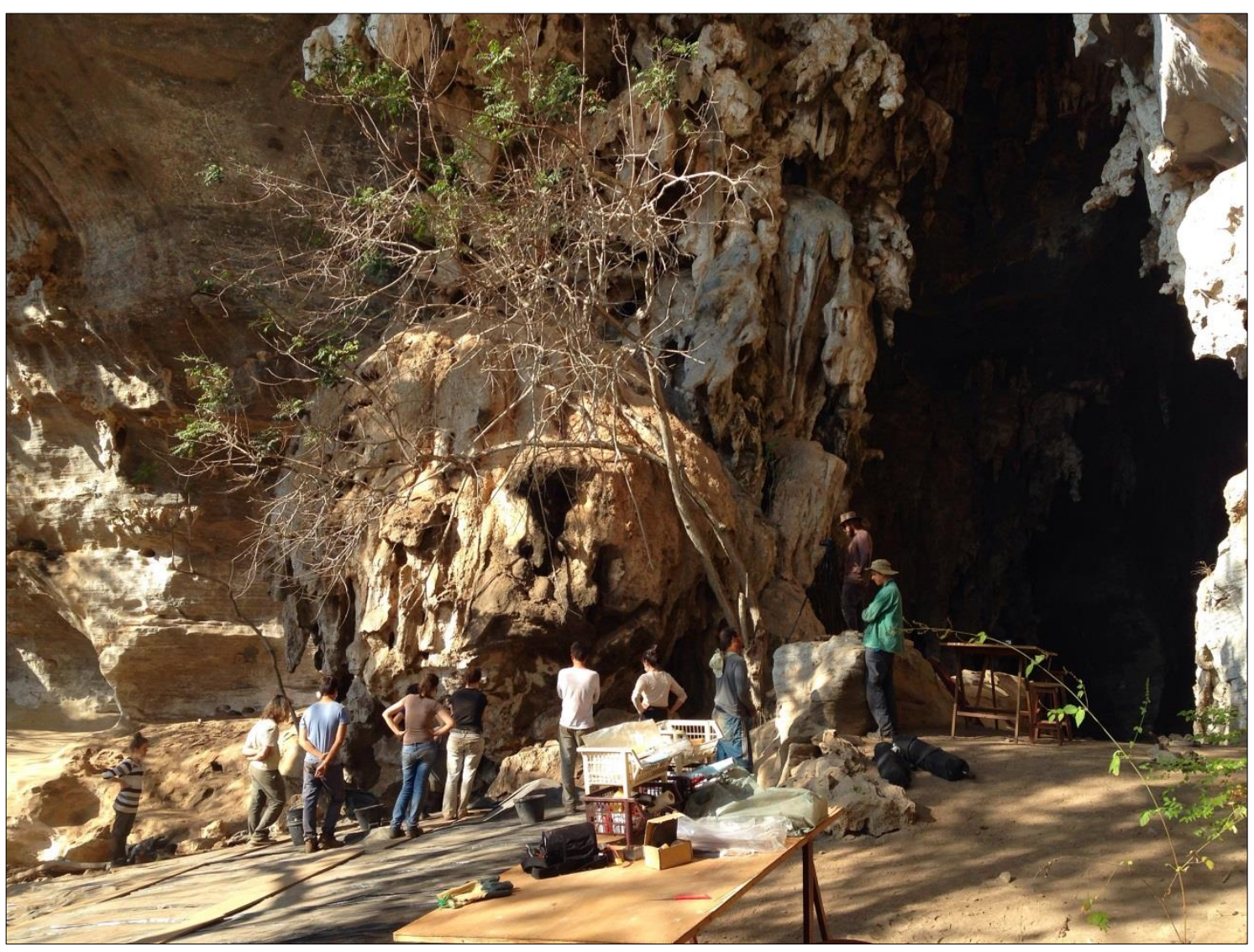

Figura 2. Sítio Lapa do Santo. Etapa de Escavação de 2016.

\footnotetext{
${ }^{3}$ Conhecida como "Mata Seca", a Floresta Estacional Semi-Decidual é uma vegetação de Mata Atlântica, presente entre a zona úmida costeira e o semiárido, possui duas estações bem marcadas com aspecto de floresta na estação chuvosa e a perda de folhas das arbóreas na estação seca (entre $20 \%$ e $50 \%$ das árvores, por isso "semi" decidual) (Hermann et al; 1998).
} 
A parte abrigada da Lapa do Santo possui cerca de $1.300 \mathrm{~m}^{2^{4}}$ (Strauss, 2010; Neves et al; 2014; Strauss et al; 2016; Araujo et al; 2017). A parte sul do abrigo é mais alta e plana e fica em frente à entrada da caverna, onde está a maior concentração de sepultamentos humanos e demais vestígios arqueológicos; há um declive de aproximadamente $10^{\circ}$ em direção à porção norte do abrigo (Strauss et al; 2016; Villagran et al; 2017).

As datações no sítio foram realizadas pelos métodos de radiocarbono, em amostras de carvão e colágeno de ossos humanos, e luminescência opticamente estimulada (optically stimulated luminescence - OSL) em sedimentos (Strauss et al. 2016). Há três períodos de ocupação na Lapa do Santo, com datações calibradas, pertencentes ao Holoceno Inicial ${ }^{5}$, Médio $^{6}$ e $\operatorname{Tardio}^{7}$, respectivamente. A ocupação mais antiga teria ocorrido entre 12.700 e 7900 anos cal. A.P. ${ }^{8}$ (Strauss et al; 2016). O segundo período de ocupação está entre 5400 e 3900 anos cal. A.P; e o terceiro período de ocupação iniciou há 2100 anos cal. A.P. e chegou até cerca do incício do período colonial (Strauss et al; 2016).

Na Lapa do Santo foram escavados sepultamentos humanos considerados entre os mais bem preservados do continente americano (Strauss, 2010; Strauss et al; 2015; Strauss et al; 2016; Strauss \& Oliveira, 2017). Com o estudo de 26 sepultamentos ${ }^{9}$ foram identificados sete padrões funerários ${ }^{10}$, bastante resumidamente caracterizados como: 1) esqueletos em posição fletida; 2) é o mais diverso e é constituído por remanescentes esqueletais que foram talhados e descarnados, com sinal de queima dos tecidos macios; 3) indivíduos enterrados em covas circulares com ossos às vezes desarticulados e quebrados intencionalmente; 4) esqueletos articulados com membros ausentes mas sem marcas de corte; 5) ossos de indivíduo em forma de feixe com marcas de corte; 6) esqueleto cremado; e 7) cova circular com pigmento nos ossos e coberta com blocos (Strauss, 2010; Strauss et al; 2015; Strauss et al; 2016; Strauss \& Oliveira, 2017).

\footnotetext{
${ }^{4} 70 \mathrm{~m}$ de comprimento e $20 \mathrm{~m}$ de largura (Araujo et al., 2018).

${ }^{5}$ O Holoceno Inicial é definido entre 10.000 e 7000 anos A.P. (Ledru et al. 1996).

${ }^{6}$ O Holoceno Médio é definido entre 7000 e 4000 anos A.P. (Ledru et al., 1996).

${ }^{7}$ O Holoceno Tardio é definido entre 4000 anos A.P. até os dias de hoje (Ledru et al., 1996).

${ }^{8}$ Antes do presente (A.P.), considerado como o ano de 1950.

${ }^{9}$ Até o presente momento foram identificados 33 sepultamentos humanos na Lapa do Santo (Villagran et al. 2017).

${ }^{10}$ As datações de cada padrão de sepultamento e detalhamentos serão apresentados no Tópico 1.5.
} 
Os grupos humanos que ocuparam o sítio realizaram no local a combustão de materiais e madeiras em fogueiras, o que fez com que camadas de cinzas fossem acumuladas ao longo do tempo (Araujo et al; 2012; Villagran et al; 2017). Um estudo de análises geoarqueológicas de alta resolução ${ }^{11}$ confirmou que o sedimento do sítio é constituído pelas cinzas, mas também por solo que cai da parte superior do maciço calcário (Villagran et al; 2017). A Lapa do Santo é considerada um lugar que foi ocupado e habitado por grupos humanos, que ali realizaram atividades domésticas e sepultaram os mortos, prática que passou por transformações ao longo do tempo (Strauss et al; 2016). Mais detalhamentos sobre o sítio são apresentados no Capítulo 1.

Na região de Lagoa Santa, as ocupações humanas datam desde o Holoceno Inicial, por grupos caçadores coletores forrageiros (Figura 3) (Neves et al; 2007; Ledru et al; 1996). As datações dos sítios são melhor apresentadas no Capítulo 1 (tópicos $1.1 \mathrm{e}$ 1.4). Populações ceramistas ocuparam a região a partir dos dois últimos milênios (Prous et al; 1998). Os sítios arqueológicos (Figura 3) e paleontológicos da região são conhecidos desde o século XIX com os pioneiros trabalhos de Peter Lund, que propôs a hipótese de coexistência dos seres humanos com os animais extintos da megafauna (Neves et al; 2007; Araujo \& Neves, 2010; Strauss, 2010). Na primeira metade do século XX, foram realizadas outras pesquisas nos sítios de Lagoa Santa, com as primeiras escavações profissionais realizadas pela Missão americano-brasileira, coordenada por Wesley Hurt (Neves et al; 2007; Araujo \& Neves, 2010; Araujo et al; 2012).

Na década de 1970, a Missão franco-brasileira, coordenada por Annette LamingEmperaire, escavou a região de Lagoa Santa, tendo sido encontrado o esqueleto de Luzia, nomeada posteriormente por Walter Neves (Neves et.al; 1999; Neves \& Hubbe, 2005; Neves et al; 2007; Neves et al; 2014; Prous, 2016). O contexto em que Luzia foi encontrada, mas não o esqueleto, foi datado por radiocarbono entre 16.400 e 11.400 anos cal. A.P; e por luminescência (OSL) entre 16.000 e 12.700 anos cal. A.P; sugerindo que ela seja um dos remanescentes humanos mais antigos encontrados no continente americano (Feathers et al; 2010).

\footnotetext{
${ }^{11} \mathrm{O}$ detalhamento do estudo de Villagran et al. (2017) é apresentado no Tópico 1.2.
} 


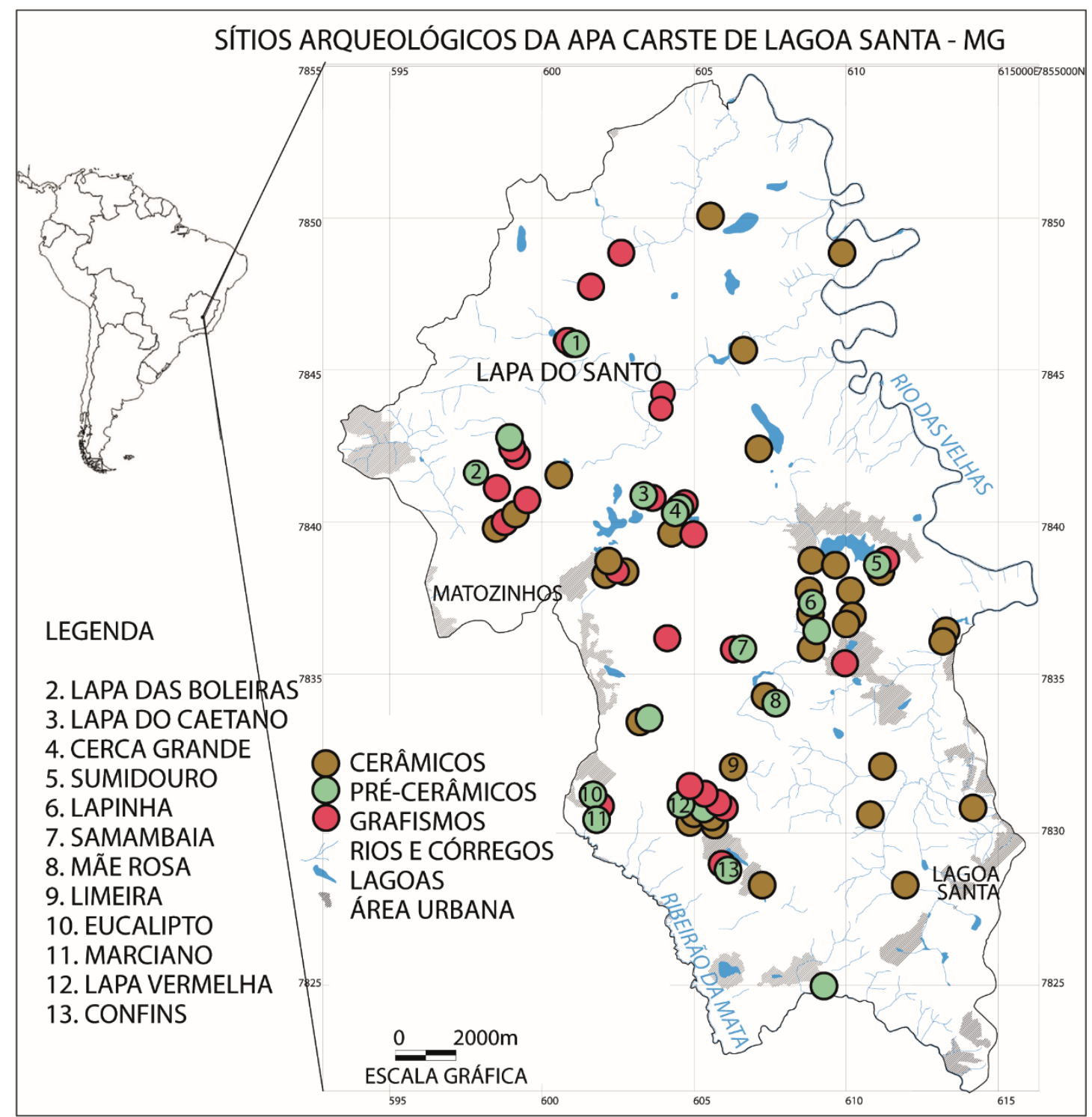

Figura 3. Sítios Arqueológicos do carste de Lagoa Santa. Adaptado de IBAMA-CPRM, Prous et al; (1998) e Villagran et al. (2017).

Além disso, estudos de morfologia craniana de Luzia e de dezenas de outros crânios de Lagoa Santa demonstraram que essas populações possuem uma morfologia definida como paleoamericana, com afinidades com grupos australo-melanésios, caracterizada por crânios longos e estreitos, rostos curtos e estreitos e órbitas e narizes curtos (Neves \& Pucciarelli, 1989; 1991; Neves et al; 1999; Neves et al; 2003; Neves et al; 2004; Neves \& Hubbe, 2005; Neves et al; 2007; Neves et al; 2007; Hubbe et al; 2011; Neves et al; 2013; Strauss et al; 2015b; Neves et al; 2014; Hubbe et al; 2014; Hubbe et al; 2015). 
A morfologia paleoamericana é diferente da observada em populações arqueológicas mais recentes e de grande parte dos grupos indígenas contemporâneos, que possuem uma morfologia craniana denominada ameríndia (Neves \& Pucciarelli, 1989; 1991; Neves et al; 1999; Neves et al; 2004; Neves et al; 2014; Hubbe et al; 2014). Tal morfologia craniana paleoamericana é encontrada em vários sítios arqueológicos do Holoceno Inicial, mais antigos que 7000 anos A.P. no continente americano (Neves et al; 2003; Neves et al; 2004; Neves \& Hubbe, 2005; Neves et al; 2007; Neves et al; 2013).

Dessa forma, foi proposto por Walter Neves e demais autores o "Modelo dos Dois Componentes Biológicos Principais”, segundo o qual o povoamento do continente americano teria ocorrido em dois períodos diferentes, com passagem pela Beríngia (Neves \& Pucciarelli, 1989, 1990, 1991; Neves \& Hubbe, 2005; Neves at. al; 2007; Hubbe et al; 2011). Em um primeiro momento, por uma população com morfologia craniana paleoamericana vinda do sudeste asiático e, em um segundo momento, pelos descendentes dos indígenas atuais com morfologia craniana ameríndia (Neves \& Pucciarelli, 1989, 1991; Neves \& Hubbe, 2005; Neves et al; 2007; Hubbe \& Neves, 2016). O que explicaria as afinidades morfológicas paleoamericanas com as populações australo-melanésias seria uma população ancestral em comum no sudeste asiático, há cerca de 50.000 anos A.P. (Neves \& Pucciarelli, 1989, 1991; Neves \& Hubbe, 2005; Neves et al; 2007; Hubbe et al; 2011; Neves et al; 2014; Hubbe et al; 2015). Os estudos de morfologia craniana e as implicações de Lagoa Santa no cenário internacional sobre evolução humana e o povoamento das Américas são apresentados no Capítulo 1 (tópico 1.1).

Na transição do Pleistoceno para o Holoceno, as populações do Brasil Central possuiriam uma subsistência generalizada com o consumo de recursos vegetais e animais de pequeno e médio porte (Bueno, 2013; Dias, 2004; Scheel-Ybert, 2001; Kipnis, 2002). Esse quadro também é observado em Lagoa Santa, com base em evidências faunísticas dos sítios arqueológicos Grande Abrigo de Santana do Riacho, Lapa do Boquete e Lapa dos Bichos (Figura 3) (Kipnis, 2002). Conforme Kipnis (2002), essas populações consumiriam raízes e frutas, que seriam complementadas pela caça de animais de pequeno e médio porte (Kipnis, 2002; Neves \& Kipnis, 2004). Outros estudos evidenciam também a presença desses animais na dieta dos indivíduos de Lagoa 
Santa (ver Bissaro, 2008; Perez, 2009; Mingatos \& Okumura, 2016 em Capítulo 1, tópico 1.5).

Com relação aos animais de grande porte, como os da megafauna, há evidências de sua existência em Lagoa Santa até o início do Holoceno - tigre dente de sabre (Smilodon sp.) e preguiça gigante (Catonyx cuvieri) (Neves \& Piló, 2003; Hubbe et al; 2013). Entretanto, não há evidências de interação desses animais com os grupos humanos (Hubbe et al; 2013). No entanto, mesmo sem evidências, é possível que os grandes animais da megafauna fossem caçados esporadicamente, mas que não constituíssem a base da dieta (Kipnis, 2002; Neves \& Piló, 2003; Neves \& Kipnis, 2004).

Análises isotópicas foram realizadas em remanescentes ósseos humanos e de fauna nos sítios arqueológicos Lapa do Santo, Lapa das Boleiras e Santana do Riacho (Figura 3) (Hermenegildo, 2009). Os resultados desse estudo indicam que as populações humanas apresentaram uma dieta onívora, com uma forte tendência ao consumo de vegetais desde o início do Holoceno (Hermenegildo, 2009).

Um estudo de saúde bucal, dieta e estilo de vida foi realizado em remanescentes humanos dos sítios a Lapa do Santo, Lapa das Boleiras, Cerca Grande, Harold Walter, Lapa da Amoreira, Lapa de Carrancas, Lapa Mortuária e Santana do Riacho (Figura 3) (Da-Gloria, 2012; Da-Gloria \& Larsen, 2014). Os resultados indicaram um alto índice de cáries, principalmente em indivíduos do sexo feminino (Da-Gloria, 2012; Da-Gloria \& Larsen, 2014). É possível que a combinação de alimentos ricos em amido a fontes de açúcares simples possa potencializar o surgimento de cáries ${ }^{12}$ (Da-Gloria \& Larsen, 2014). Alguns pesquisadores ${ }^{13}$ consideram que o consumo de mel possa causar essa patologia, embora outros autores ${ }^{14}$ argumentem que o mel teria um efeito antibacteriano, a prevenindo (Da-Gloria, 2012; Da-Gloria \& Larsen, 2014). Além disso, os resultados também indicaram baixa mobilidade, infecções e estresse, que são características geralmente presentes em grupos agricultores, mas não há evidências de cultivo em Lagoa Santa no Holoceno Inicial e Médio (Da-Gloria, 2012; Da-Gloria \& Larsen, 2014). Portanto, se propôs que o alto índice de cáries pode ter sido causado por

\footnotetext{
12 ver Lingstrom et al. (2000).

${ }^{13}$ ver Shannon et al. (1979); Bowen \& Lawrence (2005).

${ }^{14}$ ver Molan (2001); English et al. (2004)
} 
uma grande quantidade de carboidrato na dieta, por meio do consumo de tubérculos selvagens, sementes e frutas (Da-Gloria, 2012; Da-Gloria \& Larsen, 2014).

A indústria lítica (artefatos de rochas) de Lagoa Santa do Holoceno Inicial ao Tardio é caracterizada pelo lascamento predominante de cristais de quartzo hialino, sílex e com pouca expressividade outras matérias primas que produzem lascas e núcleos de pequena proporção ${ }^{15}$; e também há aplicação eventual de técnicas de polimento para a produção de lâminas de machado (Pugliese, 2007; Bueno, 2012; Moreno de Sousa, 2014; Moreno de Sousa \& Araujo, 2018: 17).

A funcionalidade desses instrumentos seria adequada à raspagem e ao corte de materiais (Pugliese, 2007; Moreno de Sousa, 2014). Esses materiais poderiam ser plantas e animais de proporção média e pequena, que poderiam estar relacionados à dieta, conforme sugerem Kipnis (2002), Neves \& Kipnis (2004), Pugliese (2007), Hermenegildo (2009), Da-Gloria (2012; 2014), Moreno de Sousa (2014) e Mingatos \& Okumura (2016).

A funcionalidade de um instrumento abarca todas as possibilidades de uso sem relação específica com o material a ser processado, por exemplo: cortar, raspar etc. (Leroi-Gourhan, 1964; Géminard, 1985; Rabardel, 1995; Boëda, 1997; Sigaut, 2002; Moreno de Sousa, 2014). Já a função, é a necessidade que um instrumento atende de acordo com o material a ser processado, por exemplo: cortar vegetais (Leroi-Gourhan, 1964; Sigaut, 2002; Viana, 2005; Fullagar, 2009; Moreno de Sousa, 2014; 2019).

Portanto, para investigar quais materiais poderiam ter sido processados com os líticos, é preciso realizar estudos de microvestígios ou microrresíduos minerais, animais ou botânicos, o que ainda dependeria desses microvestígios serem preservados aderidos aos instrumentos (Fullagar, 2006; 2009; Sandweiss, 2007; Lombard \& Wadley, 2009; Robertson, 2009; Pearsall, 2015).

Na região de Lagoa Santa, foi realizado um estudo de microvestígios botânicos a artefatos líticos do sítio Lapa Grande de Taquaraçu, que identificou grãos de amido e resíduos de sangue, evidências que indicam um caráter multifuncional desses

\footnotetext{
${ }^{15}$ As médias das dimensões dos líticos da Lapa do Santo e Lapa das Boleiras, realizadas por Pugliese (2007) são apresentadas no tópico 1.3 .
} 
instrumentos (Angeles Flores, 2015; Angeles Flores et al; 2016). Esse estudo e o da indústria lítica de Lagoa Santa são apresentados no Capítulo 1 (tópico 1.3).

Os microvestígios botânicos podem ser extraídos de sedimento, cálculo dentário (tártaro), coprólitos e diversos tipos de artefatos arqueológicos (Piperno \& Holst, 1998; Perry, 2001; Torrence \& Barton, 2006; Wesolowski, 2007; Dickau, Ranere, Cooke, 2007; Boyadjian, 2007; 2012; Cascon, 2010). Como parte das análises em artefatos, o estudo de microvestígios de sedimento também é importante, pois permite verificar se as partículas encontradas nas peças são remanescentes diretas do seu uso ou se são decorrentes de processos pós-deposicionais no ambiente (Briuer, 1976; Perry, 2001; Torrence, 2006; Pearsall, 2015).

O estudo da morfologia de fitólitos e de grãos de amido possibilita identificar táxons de plantas em contextos arqueológicos (Pearsall, 2015). Nas últimas décadas, o desenvolvimento de estudos de fitólitos e grãos de amido têm permitido romper com cenários equivocados, nos quais os vegetais eram considerados secundários na dieta de grupos humanos pretéritos e até mesmo de neandertais (Henry et al; 2010; 2014). Estudos de microvestígios botânicos nos Neotrópicos têm demonstrado a antiguidade do desenvolvimento do manejo e da domesticação de plantas nesta região (ver Dickau, Ranere, Cooke, 2007; Perry et al; 2006; Pagán-Jiménez et al; 2015). Uma breve revisão de estudos de fitólitos e amido, inclusive no contexto brasileiro, é apresentada no Capítulo 2 (tópico 2.3).

O estudo de microvestígios botânicos em artefatos líticos é algo inédito na Lapa do Santo, com o potencial de revelar se há evidências de processamento de plantas com esses artefatos. Em vista dos estudos prévios que indicam uma subsistência com importante consumo de recursos vegetais nas populações de Lagoa Santa (Kipnis, 2002; Neves \& Kipnis, 2004; Hermenegildo, 2009; Da-Gloria, 2012; Da-Gloria \& Larsen, 2014; Mingatos \& Okumura, 2016), artefatos líticos com potencial para cortar e raspar materiais vegetais e faunísticos (Pugliese, 2007; Moreno de Sousa, 2014; Angeles Flores, 2015; Angeles Flores et al; 2016), mais o fato da Lapa do Santo ser constituída de cinzas de madeiras queimadas (Villagran et al; 2017), esse sítio possuiria uma grande circulação de plantas com potencial de conter microvestígios botânicos no sedimento e aderidos aos artefatos. 


\section{Metas}

Essa pesquisa busca investigar se os instrumentos líticos da Lapa do Santo foram usados para processar plantas. Dentre essas, as plantas amiláceas, com potencial de terem sido consumidas. Para tanto, se realizou a análise de fitólitos e amido de líticos e sedimentos da Lapa do Santo.

Se buscou responder as seguintes questões: 1) É possível detectar microvestígios botânicos, especialmente fitólitos e grãos de amido, nos artefatos líticos da Lapa do Santo? 2) Os microvestígios são detectados nos sedimentos? 3) Há evidências de que os líticos da Lapa do Santo teriam processado plantas? E plantas amiláceas? 4) Quais são os fitólitos encontrados? 5) Quais são os tipos de amido encontrados? 6) A quais tipos de plantas (táxons) esses microvestígios botânicos podem ser associados? 7) Os grãos de amido identificados apresentam algum dano que possa estar relacionado à preparação de alimentos? 8) As plantas processadas com os líticos estariam relacionadas à dieta? 9) Os líticos da Lapa do Santo e da Lapa Grande de Taquaraçu estudados por Ángeles Flores (2015) apresentariam funções em comum?

\section{Objetivos Gerais}

O objetivo principal deste projeto foi investigar o uso de plantas no sítio arqueológico Lapa do Santo, dentre essas as amiláceas, que seriam consumidas pelos habitantes da região de Lagoa Santa, no início do Holoceno.

\section{Objetivos Específicos}

1. Análise de fitólitos e grãos de amido retidos em instrumentos líticos e em amostras de sedimento arqueológico associadas.

2. Análise da função dos instrumentos líticos da Lapa do Santo no tocante à sua possível relação com o processamento de plantas. 


\section{CONTEXTO ARQUEOLÓGICO: LAGOA SANTA E LAPA DO SANTO}

\subsection{As Pesquisas Arqueológicas em Lagoa Santa}

Os vestígios arqueológicos e paleontológicos da região de Lagoa Santa têm sido pesquisados desde a primeira metade do século XIX, inicialmente com o dinamarquês Peter W. Lund (1801-1880), um dos naturalistas mais importantes do século XIX (Neves et al; 2007; Araujo \& Neves, 2010; Neves et al; 2013; Holten \& Sterll, 2016). Lund realizou viagens ao Brasil com estudos voltados para as ciências naturais e ao saber, pelo fazendeiro Peter Claussen, da existência de fósseis em Lagoa Santa, iniciou a exploração das grutas da região na companhia de assistentes, um deles o artista Peter Brandt (Holten \& Sterll, 2016; Auler \& Piló, 2016).

Lund se estabeleceu no município de Lagoa Santa e trabalhou na região por dez anos e publicou seus estudos na Revista da Sociedade Científica Dinamarquesa em forma de memórias, que foram traduzidas para o português na metade do século $\mathrm{XX}$ (Holten \& Sterll, 2016; Couto, 1950). Os temas abordados se referiam principalmente à tafonomia e à análise de fósseis da fauna antiga nas cavernas, com discussões que envolviam a evolução geológica da Terra e de espécies animais e o catastrofismo para a compreensão da extinção (Neves et al; 2007; Luna Filho, 2007; Neves et al; 2013; Holten \& Sterll, 2016; Auler \& Piló, 2016).

Dentre a totalidade de grutas no carste de Lagoa Santa e arredores, quase todas foram possivelmente visitadas - mais de 800 - por Lund e equipe (Neves et al; 2013; Auler \& Piló, 2016). Algumas dessas grutas foram escavadas e as de maior destaque com relação aos vestígios fósseis são a Gruta de Maquiné, Cerca Grande, Baú, Lapa Vermelha de Lagoa Santa, Escrivânia e Sumidouro (Neves et al; 2013; Auler \& Piló, 2016). No abrigo do Sumidouro, em vista da presença de remanescentes esqueletais humanos associados aos de animais da extinta megafauna pleistocênica na região, Lund propôs a possibilidade da coexistência destes animais e dos primeiros americanos (Neves \& Hubbe, 2005; Neves et al; 2007; Holten \& Sterll, 2016; Auler \& Piló, 2016).

No início do século XX, Cássio U. Lanari, proprietário de fazenda em Lagoa Santa, escavou remanescentes esqueletais humanos de três indivíduos na Lapa do Caetano (Lanari, 1909). Lanari sugeriu estratigraficamente que os indivíduos estivessem associados ao Pleistoceno (Lanari, 1909; Da-Gloria \& Oliveira, 2017). 
Na segunda década do século XX Jorge Padberg-Drenkpol, pesquisador do Museu Nacional do Rio de Janeiro, realizou trabalhos de campo em Lagoa Santa nos quais identificou grande quantidade de remanescentes esqueletais humanos e de megafauna extinta, embora o pesquisador rejeitasse que o material encontrado comprovasse a coexistência de humanos e a megafauna (Neves et al; 2007; Araujo \& Neves, 2010; Strauss, 2010; Neto \& Rodrigues-Carvalho, 2016). A partir da década de 1930, novos trabalhos de campo foram realizados em Lagoa Santa por pesquisadores do Museu Nacional, José de Ávila e Nei Vidal, que identificaram degradação e tráfico de materiais das grutas de Lagoa Santa por parte de aventureiros e pesquisadores em grande parte estrangeiros (Neto \& Rodrigues-Carvalho, 2016).

No centenário de comemoração das pesquisas de Lund em Lagoa Santa foi fundada a Academia de Ciências de Minas Gerais, por Aníbal Mattos, Arnaldo Cathoud e Harold Walter; com o objetivo de dar continuidade aos trabalhos de Lund (Neves et al; 2013; Costa, 2017). Em Confins, foi identificado um crânio humano junto a ossos de mastodonte (Mastodon) e cavalo (Perissodactyla) extintos, porém, devido à falta de análises estratigráficas, tais evidências ainda não comprovaram a coexistência de humanos com os animais extintos (Strauss, 2010; Neto \& Rodrigues-Carvalho, 2016; Prous, 2016).

Na década de 1950, a Missão americano-brasileira coordenada por Wesley Hurt (diretor do Museu da Universidade de South Dakota), Oldemar Blasi, Carlos Couto e Altenfelder Silva realizou escavações mais sistemáticas em Lagoa Santa nos sítios arqueológicos Cerca Grande, Lapa do Ballet e Lapa das Boleiras (Neves et al; 2007; Araujo \& Neves, 2010; Araujo et al; 2012; Neves et al; 2013; Prous, 2016). Nesses trabalhos produziram as primeiras datações absolutas para a região, entre 11.200 e 9700 cal A.P; o que comprovou a presença de grupos humanos entre os mais antigos da América do Sul na região (Araujo et al; 2012).

Na década de 1960 no Museu Nacional, foram estudados cerca de 200 indivíduos de 13 sítios arqueológicos de Lagoa Santa e seus resultados apontaram para confirmar um padrão de morfologia craniana diferenciado e homogêneo em Lagoa Santa, já preliminarmente observado por Lund, Castellanos, (1932) e D’Ávila (1950) (Souza \& Liryo, 2017). 
Visitas a sítios arqueológicos de Lagoa Santa foram realizadas em 1962 por Josaphat Penna, interessado no estudo dos grafismos rupestres, com a arqueóloga francesa Annette Laming-Emperaire (Neves et al; 2007; Prous, 2016). LamingEmperaire realizou e aprofundou pesquisas em sítios arqueológicos com atenção à estratigrafia, cronologia e paleoambiente (Strauss, 2010; Prous, 2016). A Missão foi montada em conjunto com instituições francesas ${ }^{16}$ e o Museu Nacional com pesquisadores de diversas áreas ${ }^{17}$ (Neves et al; 2007; Prous, 2016). Microvestígios vegetais foram estudados por Pascale Prous no laboratório palinológico do Setor de Arqueologia do Museu de História Natural da $\mathrm{UFMG}^{18}$ e carvões de fogueiras foram estudados por Calvino Mainieri (USP) (Prous, 2016).

A Missão franco-brasileira buscou trabalhar em sítios pouco impactados ou não explorados e iniciou os trabalhos em 1971 com a escavação do sítio abrigo Lapa Vermelha IV e posteriormente outros sítios como como Caieiras, Lapa São José, Santana do Riacho, além de sítios cerâmicos a céu aberto associados à Tradição Sapucaí $^{19}$ (Araujo et al; 2012; Prous, 2016). Os trabalhos de campo serviram para o treinamento de arqueólogos devido à exigência do IPHAN $^{20}$ (Prous, 2016). Um dos participantes foi o húngaro Mihály Bányai que continuou a realizar intervenções amadoras em sítios de Lagoa Santa entre 1970 e 1980 e montou uma coleção que constitui o Museu da Lapinha em Pedro Leopoldo (Araujo \& Neves, 2010; Strauss, 2010; Prous, 2016).

Na Lapa Vermelha IV foram escavados pela Missão franco-brasileira cerca de $300 \mathrm{~m}^{2}$ e cerca de $14 \mathrm{~m}$ de profundidade (Laming-Empreraire et al; 1975; Neves et al; 1999; Neves \& Hubbe, 2005; Neves \& Piló, 2008; Neves et al; 2013; Prous, 2016). Foram identificados grafismos rupestres, líticos produzidos em cristais de quartzo hialino, um anzol produzido em osso, assim como mais de uma centena de estruturas de combustão datadas de 6000 anos cal. A.P; contendo conchas de gastrópodes marcas de

\footnotetext{
${ }^{16}$ Ministère des Affaires Etrangères, Unité de Recherche Archéologique e o CNRS (Prous, 2016).

${ }^{17}$ dentre eles Maria Beltrão, André Prous, Aziz Ab’Saber e Agueda Vialou (Prous, 2016).

${ }^{18}$ Universidade Federal de Minas Gerais.

${ }^{19}$ A Tradição Sapucaí foi definida para a cerâmica de grupos do Nordeste e Centro do Brasil, entre 300 a 1800 A.D., com coleções que apresentam vasilhames grandes e espessos, urnas funerárias globulares, assim como vasilhames pequenos de paredes finas e bases perfuradas, e cachimbos tubulares (Dias et al., 1975; Prous, 1992; Schmitz \& Rogge, 2008; Rodrigues \& Gardiman, 2016). Posteriormente foi definida uma Tradição Aratu-Sapucaí devido a semelhança com a Tradição Aratu (Dias Junior et al., 1975; Prous, 1992; Schmitz \& Rogge, 2008; Afonso, 2009).

${ }^{20}$ Instituto do Patrimônio Histórico e Artístico Nacional.
} 
perfuração e pigmentos avermelhados que podem indicar seu uso como alimento e como instrumentos (Prous, 2016).

Além disso, a Missão franco-brasileira escavou o esqueleto de Luzia, indivíduo do sexo feminino que teria vivido entre 20 e 25 anos de idade, estudada e nomeada posteriormente pelo Dr. Walter Neves (Neves et.al; 1999; Neves \& Hubbe, 2005; Neves et al; 2007; Neves \& Piló, 2008; Neves et al; 2013; Neves et al; 2014). Foram econtrados os ossos humanos longos, da bacia e mandíbula de de Luzia, que teria perecido no local provavelmente devido à queda (Neves et.al; 1999; Neves \& Hubbe, 2005; Neves \& Piló, 2008; Neves et al; 2014). Já o seu crânio e um osso longo teriam rolado para uma maior profundidade, onde foram encontrados (Neves et.al; 1999; Neves \& Hubbe, 2005; Neves \& Piló, 2008; Prous, 2016).

Devido à incerteza sobre a integridade estratigráfica do esqueleto de Luzia, desarticulado e com algumas partes espalhadas, foram realizadas datações e análises químicas e de micromorfologia dos sedimentos do sítio (Feathers et al; 2010; Prous, 2016). As datações radiocarbônicas de carvão associado ao esqueleto indicam uma idade entre 11.400 e 16.400 anos cal. A.P; enquanto que as datações de grãos de sedimentos por luminescência (OSL) indicam idades entre 12.700 e 16.000 anos cal. A.P; portanto ambos os métodos confirmam a antiguidade do contexto em que Luzia foi encontrada (Feathers et al; 2010). Entretanto, é possível que Luzia pertença a um contexto mais recente em torno de 9.000 anos A.P. e seus remanescentes tenham declinado ao longo do tempo para a parte datada, mais profunda e mais antiga (Neves et.al; 1999; Feathers et al; 2010).

Segundo Laming-Emperaire, é possível que a Lapa Vermelha IV fosse frequentada por pequenos grupos humanos que passariam a noite no abrigo ao caminharem pela região (Laming-Empreraire et al; 1975; Neves \& Piló, 2008; Prous, 2016). Uma ocupação ceramista foi identificada no sítio e nas proximidades um sítio atribuído à Tradição Sapucaí (Laming-Empreraire et al; 1975; Prous, 2016).

Neves \& Pucciarelli (1989) realizaram um estudo de morfologia craniana de remanescentes esqueletais humanos de Lagoa Santa - sítios Sumidouro, Confins, Lapa do Caetano, Lapa de Carrancas, Cerca Grande e Lapa das Boleiras. Em comparação com coleções esqueletais humanas modernas, se observaram afinidades morfológicas com populações nativas australianas (Neves \& Pucciarelli, 1989). 
Em próximos estudos de morfologia craniana por meio de análise de componentes principais aplicada a 13 variáveis craniométricas, se comparou a mesma coleção de remanescentes esqueletais humanos de Lagoa Santa com coleções arqueológicas da Ásia, Europa, África e Austrália, do período entre 12.000 e 6000 anos A.P. (Neves \& Pucciarelli, 1991). Além de Lagoa Santa, se estudou oito esqueletos de dois sítios arqueológicos de Tequendama, na Colômbia, datados por carbono 14 entre 9000 e 6000 anos A.P. (Neves \& Pucciarelli, 1991). Os resultados indicaram afinidades morfológicas entre as populações sul americanas estudadas, consideradas entre as primeiras ocupações no Holoceno Inicial e as primeiras populações australianas (Neves \& Pucciarelli, 1991). O estudo de morfologia craniana de Luzia também a incluiu nessa morfologia generalizada paleoamericana, caracterizada por crânios longos e estreitos, com rostos curtos e estreitos e órbitas e narizes curtos (Neves et al; 1999). A morofologia craniana não-mongoloide também foi identificada em indivíduos do Holoceno Inicial na América do Norte e as evidências sugeriam a possibilidade de uma ancestralidade em comum entre os primeiros americanos e primeiros australianos (Neves \& Pucciarelli, 1989; 1991; Neves et al. 1999; Powell \& Neves, 1999). Os ancestrais em comum seriam populações do sudeste asiático, pré-mongoloides, o que já era sustentado por estudos genéticos (Neves \& Pucciarelli, 1989; 1991; Neves et al. 1999; Powell \& Neves, 1999).

Até o fim da década de 90, estudos de morfologia craniana suscitavam o interesse científico e da comunidade em geral por Lagoa Santa, importante no debate sobre o povoamento inicial das Américas (Neves \& Pucciarelli, 1989; 1991; Neves et.al; 1999; Powell \& Neves, 1999). Apesar de haver mais de 200 esqueletos humanos exumados dos sítios arqueológicos de Lagoa Santa, ainda eram necessárias datações radiocarbônicas absolutas em contextos mais bem compreendidos (Neves \& Piló, 2008; Prous, 2016).

Visando suprir essa necessidade, entre os anos 2000 e 2009 a região de Lagoa Santa foi pesquisada pelo projeto "Origem e microevolução do Homem na América: uma abordagem paleoantropológica" (conhecido como "Projeto Origens"), coordenado pelo Prof. Dr. Walter Neves (Neves et al; 2007, 2008; Strauss, 2010; Bernardo et al; 2016). O projeto foi realizado pelo Laboratório de Estudos Evolutivos Humanos (LEEH) do Instituto de Biociências da Universidade de São Paulo (IB/USP), com o 
apoio financeiro da Fundação de Amparo à Pesquisa do Estado de São Paulo $\left(\right.$ FAPESP) ${ }^{21}$ (Neves \& Piló, 2008; Strauss, 2010; Bernardo et al; 2016).

Os principais objetivos do Projeto Origens foram gerar um quadro cronológico para as escavações já realizadas no passado, escavar novos sítios com técnicas modernas e buscar sítios arqueológicos fora dos abrigos (Neves et al; 2013). Diversas pesquisas arqueológicas e paleontológicas, interdisciplinares e criteriosas, foram então realizadas em Lagoa Santa, possibilitando um melhor e amplo entendimento paleoambiental e cultural, gerando dezenas de publicações científicas (Neves \& Piló, 2008; Bernardo et al; 2016). Dentre mais de 30 sítios arqueológicos identificados e estudados, cerâmicos e pré-cerâmicos, os principais sítios em abrigo escavados foram a Lapa das Boleiras, Cerca Grande VI, Lapa do Santo e a Lapa Grande de Taquaraçu (Araujo et al; 2012). Também foi escavado o sítio paleontológico Cuvieri (Araujo et al; 2012).

A Lapa do Santo continuou a ser pesquisada a partir de 2011 por um novo projeto denominado "As Práticas Mortuárias dos Primeiros Americanos", coordenado pelo Prof. Dr. André Strauss e pelo Dr. Rodrigo Elias de Oliveira (Strauss, 2010; 2016). O projeto foi realizado em conjunto com o Departamento de Evolução Humana do Instituto Max Planck de Antropologia Evolutiva e o Laboratório de Estudos Evolutivos Humanos (LEEH-IB/USP) (Strauss, 2010). Atualmente, o projeto é realizado em conjunto com o novo Laboratório de Arqueologia e Antropologia Ambiental e Evolutiva (LAAAE-USP), que é coordenado pelo Prof. Dr. Rui Sérgio Murrieta e pelo Prof. Dr. André Strauss.

Do Projeto Origens em diante, os estudos de morfologia craniana e outras análises foram ampliadas e aprimoradas, tornando Lagoa Santa importante nas pesquisas sobre a evolução humana e o povoamento das Américas (Neves et al; 2003; Neves et al; 2004; Neves \& Hubbe, 2005; Neves et al; 2007; Neves et al; 2007; Hubbe et al; 2011; Neves et al; 2013; Strauss et al; 2015b; Neves et al; 2014; Hubbe et al; 2014; Hubbe et al; 2015).

Neves et al. (2007) analisaram a morfologia craniana de 32 indivíduos de Lagoa Santa do período Paleoíndio; 82 indivíduos da costa brasileira do período Arcaico, e 110 indivíduos de sítios do Peru de período agrocerâmico dos últimos séculos antes da

\footnotetext{
${ }^{21}$ (Processos 99/00670-7 e 04/01321-6).
} 
colonização europeia. Os resultados indicam que as amostras de Lagoa Santa apresentam a morfologia paleoamericana e as amostras mais recentes apresentam uma morfologia completamente diferente, ameríndia (Neves et al; 2007).

Neves et al. (2003) realizaram o estudo de morfologia craniana de 6 indivíduos de Santana do Riacho, sítio abrigo com grafismos rupestres, localizado na Serra do Cipó na parte mais ao norte de Lagoa Santa. Foram escavados 28 sepultamentos humanos contendo 40 indivíduos, em sua maioria enterrados em posição fetal e lateral em covas rasas preenchidas com sedimento, carvão e cinzas, em torno de um bloco maior (Neves et al; 2003). Alguns sepultamentos apresentaram artefatos associados como colares de contas de madeira, líticos polidos com pigmentos vermelhos ou amarelos, lascas de quartzo e raspadores (Neves et al; 2003). O sítio foi incialmente ocupado há 11.960 anos A.P; do início do Holoceno até o período colonial e datações de carvão e colágeno de ossos humanos indicam que os sepultamentos estejam entre cerca de 8200 e 9500 anos cal. A.P; e um mais antigo de 11.000 anos A.P. (Neves et al; 2003). O estudo demonstrou que Luzia não era uma exceção, uma vez que esses crânios também apresentaram afinidades morfológicas com crânios australianos e africanos (Neves et al; 2003).

O sítio abrigo Cerca Grande, com grafismos rupestres, em Lagoa Santa, possui sepultamentos humanos datados por associação estratigráfica e datação direta há cerca de 9000 anos A.P. ${ }^{22}$ (Neves et al; 2004). Análises de morfologia foram realizadas em nove crânios e indicam que também possuem a morfologia paleoamericana (Neves et al; 2004; Neves \& Hubbe, 2005).

Neves \& Hubbe (2005) apresentaram os resultados de análises de morfologia de 81 crânios de Lagoa Santa, confirmando que possuem a morfologia paleoamericana com afinidades morfológicas a populações australo-melanésias e africanas subsaarianas. Datações absolutas foram obtidas para 22 dos remanescentes esqueletais desses indivíduos e estão entre 8500 e 7500 anos cal. A.P. (Neves \& Hubbe, 2005). Os indivíduos eram geralmente sepultados em covas rasas cobertas ou envoltas com blocos pequenos de arenito ou quartzo, com uma pequena fogueira adjacente ao topo da cova que era preenchida com carvões (Neves \& Hubbe, 2005). Sepultamentos secundários

\footnotetext{
${ }^{22}$ Datação não calibrada (Neves et al., 2004).
} 
também eram comuns, com aplicação de pigmentos vermelhos aos ossos (Neves \& Hubbe, 2005).

Em 30 crânios humanos do abrigo do Sumidouro, recuperados por Lund, foram aplicadas análises de morfologia craniana (Neves et al; 2007). Os resultados também apontaram para afinidades com a morfologia australo-melanésia, os classificando na morfologia paleoamericana (Neves et al; 2007).

Hubbe et al. (2011) realizaram um vasto estudo de morfologia craniana de indivíduos de sítios arqueológicos dos continentes americano do Holoceno Inicial, europeu do Paleolítico Superior e asiático da Caverna Zhoukoudian. Conforme os resultados obtidos, houve uma diferenciação tardia da morfologia dos humanos modernos, que ocorreu após o povoamento inicial das Américas (Hubbe et al; 2011).

Neves et al. (2013) realizaram análises de morfologia craniana em 20 esqueletos de Savana de Bogotá, na Colômbia, datados entre 11.500 e 6500 anos cal. A.P; e de 100 esqueletos de Lagoa Santa, datados entre 11.500 e 7500 anos cal. A.P. Os resultados demonstram que os indivíduos possuem a morfologia craniana generalizada paleoamericana (Neves et al; 2013).

Análises de morfologia craniana em 7 crânios da Lapa do Santo, de cerca de 9000 e 6000 anos A.P. indicam que não há níveis elevados de variabilidade intragrupal na Lapa do Santo nem em outros conjuntos de Lagoa Santa (Neves et al; 2014). Isso sugere que se trate de uma mesma população biológica com morfologia craniana tipicamente paleoamericana (Neves et al; 2014).

As pesquisas mencionadas contribuíram com o desenvolvimento do "Modelo dos Dois Componentes Biológicos Principais" segundo o qual o continente americano teria sido inicialmente povoado por populações do sudeste asiático com uma morfologia craniana paleoamericana e, posteriormente, por populações com a morfologia craniana ameríndia ou mongoloide (Neves \& Hubbe, 2005; Neves et al; 2007; Neves et al; 2013; Hubbe et al; 2014; Hubbe et al; 2015). A morfologia paleoamericana é caracterizada por neurocrânios longos e estreitos, faces baixas e prognatas, com órbitas e nariz baixos; enquanto que a morfologia ameríndia é definida por é neurocrânios curtos e largos, faces altas e ortognatas, com órbitas e nariz altos (Neves \& Hubbe, 2005; Neves et al; 2007). 
Como apontado antes por Neves \& Pucciarelli (1989, 1991), a morfologia craniana paleoamericana de Lagoa Santa e outros sítios arqueológicos do Brasil e das Américas $^{23}$ possui afinidades com a morfologia craniana de populações australomelanésias (Neves \& Hubbe, 2005; Neves et al; 2007; Neves et al; 2013; Neves et al; 2014; Hubbe et al; 2014; Hubbe et al; 2015). Praticamente todos os sítios arqueológicos com remanescentes esqueletais humanos mais antigos que 7000 anos A.P; na América do Sul e Meosamérica, possuem a morfologia craniana paleoamericana (Neves et al; 2007; Neves et al; 2013).

Conforme o Modelo (Figura 4), isso se deve ao fato de haver uma população ancestral em comum no sudeste asiático, de onde teriam partido ao sul rumo à Austrália, há 50.000 anos A.P; as populações que dariam origem aos australo-melanésios; e rumo ao norte, entre 50.000 e 20.000 A.P, as populações que chegariam ao continente americano, os paleoamericanos (Neves \& Pucciarelli, 1989; 1991; Neves et.al; 2003; Neves \& Hubbe, 2005; Neves et.al; 2007; Hubbe et al; 2011; Neves et al; 2013; Neves et al; 2014; Hubbe et al; 2014; Hubbe et al; 2015). Como durante o Pleistoceno Tardio, entre 65.000 e 11.000 anos A.P; até o início do Holoceno, a Beríngia e América do Norte estavam cobertas por gelo, é provável que os paleoamericanos tenham se movimentado pela costa e entrado no continente americano há cerca de 14.000 anos A.P. (Neves et al; 2003; Neves \& Hubbe, 2005; Hubbe et al; 2011; Neves et al; 2013; Hubbe et al; 2014; Hubbe et al; 2015). Há 12.000 anos A.P. os paleoamericanos já estariam no Brasil (Neves et al; 2003). Com condições climáticas mais amenas na América do Norte no fim do Pleistoceno e início do Holoceno há 11.000 anos A.P; uma segunda população ameríndia teria entrado nas Américas (Neves et al; 2003; Neves et al; 2013; Hubbe et al; 2014; Hubbe et al; 2015).

Portanto, essa população ancestral com morfologia generalizada no sudeste asiático que deu origem aos australo-melanésios e aos paleoamericanos, também deu origem aos ameríndios na Ásia (Neves \& Hubbe, 2005; Neves et al; 2007; Hubbe et al; 2011; Neves et al; 2014; Hubbe et al; 2015). Por essa origem em comum, em termos de estudos de DNA, as populações paleoamericanas e ameríndias podem não ser tão

\footnotetext{
${ }^{23}$ A mofologia paleoamericana também está presente em sítios na Bahia e em São Paulo, assim como em sítios no Chile (Magellan's Strait) Colômbia (Sabana de Bogota), México (Mexico Basin e Baja California) e Estados Unidos (Flórida) (Neves \& Hubbe, 2005; Neves et al., 2013).
} 
diferentes, uma vez que a morfologia craniana teria se diferenciado mas o DNA não tanto (Neves \& Hubbe, 2005; Neves et al. 2007; Neves et al; 2013).

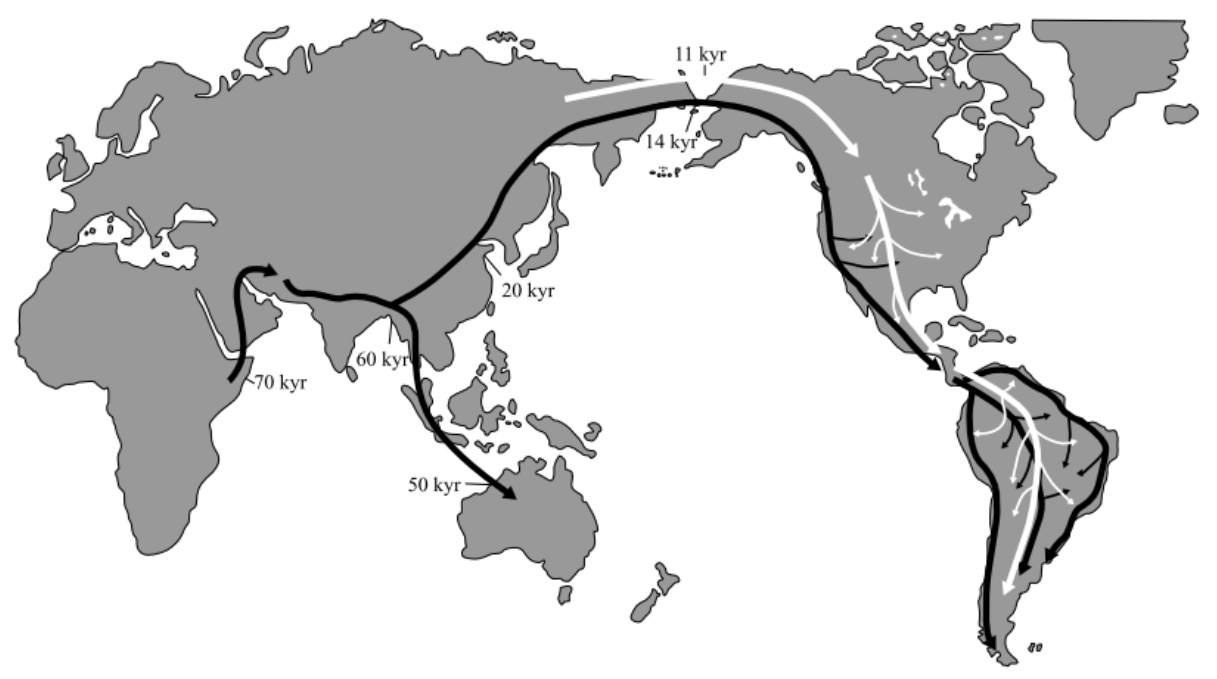

Figura 4. Modelo dos Dois Componentes Biológicos. As rotas pretas representam o componente não-mongoloide e as brancas o componente mongoloide. Fonte: Neves et al. (2003).

É possível que as populações já tenham chegado às Américas com as morfologias cranianas diferenciadas, ao invés de terem ocorrido processos microevolutivos locais nas Américas que teriam por exemplo, desenvolvido a morfologia ameríndia (Neves \& Hubbe, 2005; Neves et al; 2007; Hubbe et al; 2011; Neves et al; 2014; Hubbe et al; 2014; Hubbe et al; 2015).

As populações com morfologia craniana ameríndia prevaleceram a partir do Holoceno Médio até os dias de hoje (Neves et al; 2007; Hubbe et al; 2015). As populações com morfologia craniana paleoamericana foram desaparecendo e possivelmente deixaram descendentes até os dias atuais, ainda que sejam raros os casos em que há essa possibilidade, como os grupos indígenas Macro-Jê denominados pelos colonizadores "Botocudos" (etnias Krenak, Naknenuk, Nakrehé, Etwet e Takruk-krak) (Neves et al; 2007; Strauss et al; 2015b; Neves et al; 2014; Hubbe et al; 2014).

Um estudo recente analisou DNA humano antigo de 49 indivíduos do Brasil, Belize, Andes Central e Cone Sul, datados há cerca de 9000 A.P (Posth et al; 2018). Os resultados indicam que os indivíduos de Lagoa Santa possuem ancestralidade em 
comum com os demais grupos no continente americano (Posth et al; 2018). O estudo defende que uma população ancestral com descendência da Sibéria e do norte da China teria entrado no continente há 17.000 anos A.P; e que a América do Sul teria sido povoada em uma primeira leva entre 15.000 anos A.P. e 11.000 anos A.P; uma segunda leva há 9000 anos A.P; e uma terceira há cerca de 4000 anos A.P. (Posth et al; 2018). Lagoa Santa continua tendo um papel importante na arqueologia mundial.

As pesquisas relacionadas a processos de formação de sítios de Lagoa Santa, tecnologia lítica, a Lapa do Santo e a caracterização ambiental da região, serão apresentadas, respectivamente, nos tópicos a seguir.

\subsection{Processos de Formação dos Sítios de Lagoa Santa}

Os processos de formação de dois sítios a céu aberto, Coqueirinho e Sumidouro, localizados em proximidade à Lagoa do Sumidouro sugerem eventos de erosão e sedimentação seguidos de pedogênese (Araujo et al; 2012; Araujo et al; 2013). No Holoceno Médio foram identificadas altas taxas de acresção de solo, em um ambiente com instabilidade climática, por isso os sítios a céu aberto do Holoceno Inicial estariam em maior profundidade (Araujo et al; 2013). Esse estudo aplicou no sítio a céu aberto Sumidouro datações por OSL e radiocarbônicas, análises de estratigrafia, micromorfológicas, geoquímicas e de distribuição de artefatos líticos (Araujo et al; 2013). Dessa forma, foram detectadas três camadas arqueológicas com preservação da integridade espacial dos artefatos líticos, com datas mais antigas da transição do Pleistoceno ao Holoceno com uma idade máxima por OSL de $14.800 \pm 1100$ anos A.P. e uma idade mínima por radiocarbono de 9240 a 9450 anos cal. A.P. (8310 \pm 40 14C anos A.P.) (Araujo et al; 2013). As camadas intermediárias datam do Holoceno Tardio, há cerca de 2000 anos cal. A.P; e as camadas mais recentes representam a ocupação de grupo com cerâmica associada à Tradição Tupiguarani, ente 632 e 500 anos cal. A.P. (Araujo et al; 2013).

Em Lagoa Santa, ao redor da Lagoa do Sumidouro há outro sítio do mesmo nome, em abrigo, cujo estudo dos processos de formação foram importantes para averiguar a hipótese de Lund sobre a possível contemporaneidade de humanos com a fauna Pleistocênica extinta no sítio, uma vez que os fósseis de ambos, encontrados no 
local, teriam aspecto similar - cor metálica similar a cobre e serem pesados (Piló et al; 2005; Neves et al; 2007; Neves \& Hubbe, 2005; Neves et al; 2013). Piló et al. (2005) realizaram descrições e análises químicas de fluorescência de raios-X em sedimentos, assim como datações por séries de urânio, fluxo de calcita e por radiocarbono em carvão e concha (Piló et al; 2005). As análises indicaram que a formação sedimentar do sítio ocorreu pela introdução natural de sedimento e vestígios arqueológicos pela entrada do teto da caverna e por inundações sazonais pelas demais entradas que teriam misturado parte do material arqueológico (Piló et al; 2005). As datações apontam para uma ocupação humana há cerca de 8400 anos cal. A.P; e, ainda que não tenha sido possível datar os ossos não-humanos devido à falta de preservação de colágeno nos mesmos, segundo outros estudos os animais da megafauna são mais antigos que 9000 anos cal. A.P. (Piló et al. 2005). Portanto, o abrigo do Sumidouro não apresenta evidências de contemporaneidade entre os remanescentes esqueletais humanos e os da fauna extinta (Piló et al. 2005).

Na caverna paleontológica Cuvieri, localizada a $3 \mathrm{~km}$ da Lapa do Santo, foram realizados estudos sedimentares, de taxonomia, cronologia radiocarbônica e processos de deposição dos ossos de fauna e da fauna Pleistocênica extinta (Smilodon populator tigre dentes de sabre sul americano; Valgipes bucklandi - preguiça gigante; e Scelidotheriinae - preguiça gigante) (Hubbe et al; 2011). Duas facies estratigráficas foram identificadas, a mais recente, entre 8580 anos cal. A.P. até o presente, é constituída por silte marrom escura e é mais arenosa (Hubbe et al; 2011). A mais antiga data da transição Pleistoceno/Holoceno entre 13.600 e 10.660 anos cal. A.P. e é constituída por silte marrom escuro avermelhado e possui mais sílica, alumínio e ferro, e menos cálcio que a facies mais recente (Hubbe et al; 2011). Na facies mais antiga foram depositados os animais da megafauna, enquanto que os raros remanescentes desses animais que aparecem na camada mais recente são oriundos de processos de mistura com a camada mais antiga (Hubbe et al; 2011).

Na Lapa Vermelha IV, análises micromorfológicas e químicas em sedimentos identificaram no sítio precipitações de carbonato de cálcio, interpretadas como oriundas de cinzas (Feathers et al; 2010). Tais cinzas teriam sido possivelmente originadas em fogueiras, em uma camada de ocupação humana, produzidas próximas à entrada e à linha de gotejamento do abrigo (Feathers et al; 2010). Entretanto, a presença desses sedimentos antropogênicos ocorre em finas lentes em meio aos sedimentos 
predominantes que são argilosos, vermelhos e amarelados de origem de fora do síto (Neves \& Piló, 2008).

Nos sítios Lapa do Santo, Lapa das Boleiras e Lapa Grande de Taquaraçu têm sido observadas e estudadas grandes concentrações de cinzas nos sedimentos dos sítios arqueológicos (Neves \& Piló, 2008; Araujo et al; 2008; Araujo \& Neves, 2010; Araujo et al; 2012; Villagran et al; 2017; Araujo et al; 2017). Tais cinzas foram originadas devido a atividades humanas de combustão de madeiras nos sítios, por isso os sedimentos possuem um caráter antropogênico (Araujo et al; 2008; Araujo \& Neves, 2010; Villagran et al; 2017; Araujo et al; 2017).

O sítio abrigo Lapa das Boleiras foi ocupado entre 11.800 anos cal. A.P. e 8400 anos cal. A.P. e possui grandes quantidades de sedimentos acumulados de origem antropogênica, principalmente nos períodos mais antigos quando a ocupação foi mais intensa, constituídos em grande parte por cinzas da queima de plantas em fogueiras (Araujo et al; 2008; Araujo \& Neves, 2010). Um hiato de vestígios no sítio durante o Holoceno Médio, entre 7500 e 800 anos A.P; pode sugerir que tenha havido uma queda nas ocupações na região nesse período, que estaria mais seco (Araujo et al; 2008; Araujo \& Neves, 2010). Análises micromorfológicas na Lapa das Boleiras identificaram sedimentos vermelhos coluvionares e argilosos presentes em todos os estratos e principalmente nos períodos intermediários da estratigrafia; assim como sedimentos calcíticos cinza claros com presença de carvão, material vegetal, fitólitos, e fragmentos de ossos, relacionados às ocupações humanas (Araujo et al; 2008; Araujo \& Neves, 2010). Um terceiro tipo de sedimentos também estão associados à ocupações humanas, são orgânicos e marrom escuros, constituídos por cinzas, matéria orgânica, fragmentos de carvão e ossos, e fitólitos (Araujo et al; 2008). Análises de difratometria de raios-x, fluorescência de raios-x e espectrometria de emissão atômica por plasma acoplado indutivamente (ICP-AES) indicaram que os sedimentos avermelhados, possuem $\mathrm{Si}, \mathrm{Fe}$, Al e Ti, similar aos solos caoliníticos presentes na região e são de origem coluvionar (Araujo et al; 2008). Já os sedimentos acinzentados possuem $\mathrm{Ca}, \mathrm{Mg}$ e $\mathrm{P}$, correlacionados à decomposição de matéria orgânica e óssea e à dissolução de carbonatos de cálcio derivados de cinzas de plantas queimadas e foram originados pela queima de material vegetal em fogueiras (Araujo et al; 2008). 
No sítio abrigo Lapa Grande de Taquaraçu, escavações e estudos geoarqueológicos realizados indicam que os sedimentos sejam antropogênicos, compostos quase totalmente de cinzas da queima de madeiras, com pouco silte e argilominerais em alguns níveis, provenientes do rio adjacente (Araujo et al; 2012; Villagran, 2013; Araujo et al; 2017). As datações radicarbônicas realizadas demarcam idades entre 11.750 a 11.250 anos cal. A.P. e entre 9050 a 8990 anos cal. A.P. para as ocupações humanas no sítio (Araujo et al; 2012; Araujo et al; 2017).

$\mathrm{Na}$ Lapa do Santo, análises geoarqueológicas de alta resolução micromorfologia, $\mu$ FTIR (espectrômetro no infravermelho por transformada de Fourier acoplado a um microscópio) e petrologia orgânica - indicaram que cinzas de fogueira são o componente principal do depósito, com aporte também de agregados de solo que caem da parte superior abrigo (Villagran et al; 2017). As análises foram aplicadas a amostras coletadas das superfícies de escavação e perfis estratigráficos entre $10 \mathrm{~cm}$ e 90 $\mathrm{cm}$ de profundidade, onde se concentra a maior quantidade de sepultamentos humanos datados do Holoceno inicial, com o objetivo de compreender sua natureza e forma de acumulação (Villagran et al; 2017). O estudo também realizou experimentações com solos e cupinzeiros locais e uma fogueira produzida próxima ao sítio, para identificar os efeitos do aquecimento no solo (Villagran et al; 2017). A fogueira experimental atingiu a temperatura máxima de $875^{\circ} \mathrm{C}$ com média de $650{ }^{\circ} \mathrm{C}$ e os cupinzeiros adicionados à mesma mantiveram o calor por mais tempo e obtiveram uma cor alaranjada (Villagran et al; 2017). Para obtenção de referência com relação a alteração termal, se aqueceu amostras em múfla, montadas em lâmina de micromorfologia, onde foi aplicada $\mu$ FTIR (Villagran et al; 2017).

Nas análises micromorfológicas se identificou que os sedimentos da Lapa do Santo são constituídos, além das cinzas, por agregados de argilominerais vermelhos, alaranjados, amarelos e marrom escuros (Villagran et al; 2017). Além disso, há menos de $5 \%$ de carvão, fragmentos de calcário proveniente das paredes do abrigo, micro lascas de quartzo, minerais opacos e grãos de quartzo, ossos - em sua maioria de peixes - e fragmentos de concha frequentemente queimados, tecidos parcialmente carbonizados e fitólitos (Villagran et al; 2017). Alguns agregados de argilominerais possuem revestimentos e infiltrações límpidas e laminadas que sugerem que originários de um horizonte $\mathrm{Bt}$ de solo fora do abrigo (Villagran et al; 2017). Cinzas recristalizadas, misturadas com cristais de cinzas com bordas retas e desconexão com a 
matriz pulverulenta circundante sugerem que tenha havido remobilização lateral dos subprodutos das fogueiras, possivelmente para cobrir os sepultamentos (Villagran et al; 2017).

Conforme Villagran et al. (2017), as cinzas são oriundas de fogueiras realizadas próximas aos sepultamentos, circundados por resíduos de combustão, e as cinzas seriam despejadas nas covas para acomodar e cobrir os remanescentes humanos. Também foi detectado que haveria uma lenta passagem de água através dos sedimentos e/ou episódios de saturação de água e secagem, além de pouco grau de bioturbação (Vilagran et al; 2017).

De um total de 44 micro-facies identificadas, Villagran et al. (2017) apresenta três principais. A mais representativa ( $85 \%$ das micro-facies) é constituída por cinzas distribuídas aleatoriamente e articuladas, agregados de argilominerais e remanescentes orgânicos de carvão, ossos e tecidos não identificados (Villagran et al; 2017). A segunda (10\% das micro-facies) é composta de uma micromassa compactada de cor cinza escura com cinzas e fosfatos (Villagran et al; 2017). A terceira (5\% das microfacies) se trata de material oriundo de latossolo vermelho (Villagran et al; 2017).

Os resultados de $\mu$ FTIR apontam que a maioria dos agregados de argilominerais analisados da Lapa do Santo tenham sido aquecidos acima de $500-600{ }^{\circ} \mathrm{C}$ e abaixo de $800{ }^{\circ} \mathrm{C}$ (Villagran et al. 2017). Os resultados de petrologia orgânica confirmam que os tecidos de planta sejam componentes dos sedimentos, aleatoriamente incorporados na matriz cinzenta com tamanhos que variam entre $1 \mu \mathrm{m}$ e $200 \mu \mathrm{m}$ (Villagran et al; 2017). Os tecidos lenhosos são mais presentes que os herbáceos e os vestígios de plantas são em sua maioria permineralizados, com substituição de fosfato, óxido de $\mathrm{Mn}$ e silicificação (Villagran et al; 2017). Pequenos tecidos de plantas como detritos celulares também foram encontrados dentro dos agregados de argilominerais, o que confirma sua associação com material do solo (Villagran et al; 2017). Por serem similares em composição, cor e estrutura com os latossolos locais, é possível que os agregados de argilominerais sejam provenientes do latossolo vermelho existente na parte superior do abrigo (Villagran et al; 2017).

A maioria dos detritos de plantas presentes nos sedimentos da Lapa do Santo parecem oxidados e/ou degradados por fungos e apesar da sua pouca reflectância indicativa de umidade - eles não apresentam fluorescência e ocorrem juntos com as 
partículas de carvão e cinzas (Villagran et al; 2017). É possível que esses detritos se tratem de partículas de carvão com pouca reflectância, produzidas após a combustão incompleta da madeira (Villagran et al; 2017). A presença de preenchimentos de célula vegetal (secretinite) isolados nos sedimentos ou dentro de carvão e de tecido permineralizado, mais a aparência inchada das paredes celulares, que possuem rachaduras por encolhimento e bordas corroídas, indicam que o tecido tenha passado por uma umidificação avançada antes da carbonização (Villagran et al; 2017). Esses preenchimentos e paredes celulares também possuem marcas de ataques de fungos, o que sugere intemperismo biológico da madeira antes da queima (Villagran et al; 2017). Portanto, a maioria da madeira utilizada para combustão estaria já em estado de decomposição, como galhos caídos na mata por exemplo (Villagran et al; 2017).

Outro estudo realizado especificamente nas unidades denominadas com a letra "M" da Lapa do Santo, localizadas em área plana na porção sul, concordam com que a formação de sedimentos seria decorrente das atividades humanas de combustão de madeiras e produção de cinzas (Araujo et. al; 2017). Isso se deveria à constatação de um hiato de 4280 anos, durante o qual não haveria sido observado processos de sedimentação no sítio (Araujo et.al; 2017). Uma vez que datações radiocarbônicas indicam uma primeira ocupação no Holoceno Inicial - de 12.460 a 8700 anos cal. A.P. - em seguida o hiato na estratigrafia e, a segunda ocupação no Holoceno Médio - de 5100 a 4200 anos cal. A.P. - sem mudanças observadas nos vestígios culturais analisados (sedimentos, remanescentes de fauna, artefatos líticos e em osso) (Araujo et. al; 2017).

\subsection{Tecnologia Lítica}

As primeiras observações mais consistentes sobre os vestígios líticos de Lagoa Santa ocorreram principalmente a partir da segunda metade do século XX (ver Mattos, 1938; Walter, 1958; Hurt \& Blasi, 1969; Beltrão, 1974). Uma primeira tipologia dos líticos de Lagoa Santa foi realizada por Harold Walter na década de 1950, com abordagem evolutiva, mas faltava embasamento em informações contextuais (Bueno \& Isnardis, 2016). Na década de 1960, Hurt e Blasi formularam uma nova tipologia com base na forma, propuseram inferências funcionais e caracterizaram a indústria como predominantemente de lascas em quartzo cristalino, que seriam os próprios 
instrumentos (Bueno \& Isnardis, 2016). A Missão franco-brasileira realizou a coleta de superfície e em escavação de considerável quantidade de vestígios líticos, analisados por Maria Beltrão e considerados como uma indústria simples (Beltrão, 1974; Bueno \& Isnardis, 2016; Moreno de Sousa \& Araujo, 2018). Estudos dos líticos do Grande Abrigo de Santana do Riacho abordaram a tecnologia de confecção, métodos de debitagem e lascamento bipolar (Prous, 1991; Prous \& Lima 1986).

Com o Projeto Origens, novas análises da indústria lítica de Lagoa Santa foram realizadas (Pugliese, 2007; Bueno, 2012; Moreno de Sousa, 2014; Moreno de Sousa \& Araujo, 2018). Pugliese (2007) realizou o estudo das indústrias líticas da Lapa do Santo e da Lapa das Boleiras. Análises dos líticos da Lapa das Boleiras também são apresentadas por Araujo \& Pugliese (2010) ${ }^{24}$.

Na Lapa do Santo há dezenas de milhares de líticos coletados (Strauss et al; 2016). Parte desse material foi analisada por Pugliese (2007) e por Moreno de Sousa (2014).

Pugliese (2007) analisou 212 líticos plotados (com coordenadas x, y e z) da quadra F13, que representam as faixas de 12.700 a 11.700 anos cal. A.P. e de 8300 a 8000 anos cal. A.P. (Strauss et al; 2016). Foram analisados mais 697 líticos plotados de trincheira cujas quadras são M3, M4, M5 e M6; além de 4920 líticos provenientes de peneira e flotação da quadra F13; e 1536 líticos de peneira e flotação da quadra M6 (Pugliese, 2007).

Na Lapa das Boleiras foram analisados 1895 líticos plotados das quadras D39, E41, H20, H25, H30, I12, I23, J11, J12, J25, K10, K11, K12, K25, L10, L11, L17, L25, N10, N11 e O11 (Pugliese, 2007). E mais 7981 líticos provenientes de peneira e flotação das quadras J11, J12, K11 e K12 (Pugliese, 2007).

Na Lapa do Santo e Lapa das Boleiras, as lascas são predominantes em comparação a outros tipos de líticos e é rara a presença de instrumentos formais (Pugliese, 2007; Araujo \& Pugliese, 2010). O conceito de expedient core technology ${ }^{25}$ foi utilizado para designar os instrumentos como "não formais", produzidos com técnicas de lascamento nas quais não haveria o controle das lascas produzidas, nem a

\footnotetext{
${ }^{24}$ referentes às quadras $\mathrm{J} 11, \mathrm{~J} 12, \mathrm{~K} 10, \mathrm{~K} 11, \mathrm{~K} 12, \mathrm{~L} 10$ e L11, localizadas ao sul do abrigo e consideradas mais completas estratigraficamente e em relação a datações.

${ }^{25}$ de Parry \& Kelly (1987).
} 
preparação dos núcleos (Pugliese, 2007). Sob essa perspectiva e devido a uma baixa presença de retoques, o autor defende que os instrumentos seriam produzidos para um uso imediato e descartados sem reavivamento dos gumes para reutilização (Pugliese, 2007).

As lascas inteiras da Lapa do Santo apresentam dimensões com média de 24,32 $\mathrm{mm}$ de comprimento; 21,60 $\mathrm{mm}$ de largura e 7,79 $\mathrm{mm}$ de espessura (Pugliese, 2007). Os núcleos da Lapa do Santo apresentam uma média de $36,12 \mathrm{~mm}$ de comprimento; 26,53 mm de largura e 18,62 mm de espessura (Pugliese, 2007).

As lascas inteiras da Lapa das Boleiras apresentam dimensões com média de 19,33 $\mathrm{mm}$ de comprimento; 17,42 $\mathrm{mm}$ de largura e 6,02 $\mathrm{mm}$ de espessura (Pugliese, 2007). Os núcleos da Lapa das Boleiras apresentam uma média de 29,50 mm de comprimento; 21,78 mm de largura e 15,88 mm de espessura (Pugliese, 2007).

A matéria-prima predominante dos líticos da Lapa do Santo e Lapa das Boleiras é sempre o quartzo hialino e com menor expressividade o sílex, silexito, quartzito, quartzo leitoso e arenito silicificado (Pugliese, 2007; Araujo \& Pugliese, 2010). Nos níveis mais antigos dos sítios, esses outros tipos de matéria prima não predominantes são mais recorrentes que nos níveis mais recentes (Pugliese, 2007; Araujo \& Pugliese, 2010).

Os líticos em silexito representam apenas 5\% do conjunto da Lapa do Santo e de Lapa das Boleiras e 90\% desses líticos foram produzidos no período entre 12.500 e 10.200 anos cal. A.P. (Pugliese, 2007; Araujo et al; 2018). Ainda que haja essa diferença inicialmente, ela ocorre apenas em termos de matéria prima, uma vez que a tecnologia aplicada é exatamente a mesma aplicada ao quartzo (Pugliese, 2007; Araujo et al; 2018).

Na Lapa do Santo, essas matérias primas não predominantes deixam de ser utilizadas há cerca de $9900 \pm 500$ anos A.P. e a partir desse momento só aparece o quartzo hialino (Pugliese, 2007; Strauss et al; 2016). Pugliese (2007) considera o quartzo hialino como uma matéria prima local e as demais matérias primas não locais. A redução das matérias primas não locais e o foco somente no quartzo hialino é interpretada por Strauss et al. (2016) como tendo relação com o início de um modo de vida menos móvel e mais local no carste. 
Uma análise preliminar de marcas de $\mathrm{uso}^{26}$ foi aplicada a nove líticos da Lapa do Santo, tendo sido identificadas cicatrizes de arranhamento e fraturas por pressão (Pugliese, 2007; Strauss et al; 2016). Isso pode indicar que as lascas tenham sido usadas para cortar materiais macios como couros, carne e gramíneas (Pugliese, 2007; Strauss et al; 2016). Também se observou que as lascas que teriam sido utilizadas possuem dimensões mais robustas que as que não apresentam indícios de terem sido utilizadas (Pugliese, 2007; Strauss et al; 2016). É sugerido que a funcionalidade dos instrumentos da Lapa do Santo (e Lapa das Boleiras) seria adequada à raspagem e ao corte de materiais, como plantas e animais de proporção média e pequena relacionados à dieta (Pugliese, 2007).

Estudos de marcas de uso também foram realizados nos líticos do sítio Santana do Riacho. De 69 artefatos líticos, foram identificadas marcas de uso por processamento de madeira em quatro raspadores, processamento de material pigmentado em dois raspadores e demais marcas não identificadas em 25 raspadores (Prous et al; 1991 apud Neves et al; 2003). A indústria lítica do sítio Santana do Riacho é caracterizada por lascas líticas em quartzo hialino, localmente disponíveis entre 1 e $2 \mathrm{~km}$ do sítio (Prous et al; 1991 apud Neves et al; 2003).

Pugliese (2007) considerou haver um baixo grau de variabilidade artefatual intra e inter-sítio, o que não caracterizaria os sítios como residenciais, mas de atividades específicas. Entretanto, Bueno (2012) retoma os estudos dos líticos da Lapa do Santo e da Lapa das Boleiras, mais os líticos dos sítios a céu aberto Coqueirinho e Sumidouro, também do Holoceno Inicial, entre 10 e 8 mil anos. Foi identificada uma considerável variabilidade artefatual, devido à diversidade tecnológica aplicada na produção dos mesmos: lascas e fragmentos de quartzo e lâminas de machado com diferentes graus de polimento e lascamento (Bueno, 2012). Dessa maneira, o autor defende que os sítios em

\footnotetext{
${ }^{26} \mathrm{O}$ estudo é preliminar porque não se trata de uma análise de traceologia propriamente dita. Foram utilizadas lupa de mão com aumentos de 10x e 20x e lupa binocular com aumento de 100x, além de um microscópio Nikon SMZ 800 com alcance de aumento de 10-120x (Pugliese, 2007). A traceologia desenvolvida por Sergei Semenov (1957) se refere ao estudo das marcas de uso mecânicas em superfícies de artefatos, como estrias, polimento, traços de atrito e demais modificações. Muito antes em 1892 Flaxman Spurrel realizou as primeiras experimentações de marcas de uso de polimento em diferentes matérias-primas (Hayden \& Kamminga, 1977). Em 1930, Eliot C. Curwen contribuiu com mais trabalhos experimentais de marcas de uso em materiais (Hayden \& Kamminga, 1977). Em 1957, a publicação de Semenov se tornou a grande referência nos estudos de marcas de uso (Hayden \& Kamminga, 1977). Contudo, o termo traceologia é muitas vezes susbtituído por "estudos funcionais" e isso seria um problema porque restringe o conceito de Semenov, que não teria discriminado outras abordagens e questões para a Tecnologia Pré-Histórica (Hayden, 1977). Além disso, a traceologia somente abarca o funcionamento e a funcionalidade dos artefatos, não a função.
} 
abrigo seriam compatíveis com sítios residenciais, nos quais ocorreriam atividades cotidianas diversificadas e regulares, enquanto que os sítios a céu aberto estariam relacionados a atividades específicas para obtenção de recursos (Bueno, 2012).

Bueno (2012) discorda que a indústria lítica lagoassantense não apresente instrumentos formais, argumentando que, para além das lâminas de machado, há uma ponta de projétil bifacial, raspadores e algumas lascas com retoques nos gumes (Bueno, 2012).

Nos sítios a céu aberto as matérias primas líticas utilizadas seriam locais, com os instrumentos utilizados e descartados no sítio, entretanto, não foram identificadas todas as etapas da cadeia operatória referentes à produção dos instrumentos (Bueno, 2012). Já nos sítios em abrigo, além de matérias primas locais, há matérias primas não locais que eram transportadas ao sítio, às vezes em estado bruto, e os instrumentos seriam ali produzidos, utilizados e descartados ou até mesmo transportados para uso em áreas externas (Bueno, 2012). Grande parte das lascas são menores que $3 \mathrm{~cm}$ e como há artefatos que possivelmente foram encabados, conforme Bueno (2012) há a possibilidade de que houvesse mais artefatos compostos, como por exemplo com a incrustação das pequenas lascas em hastes ou suportes de madeira ou osso.

As lâminas de machado encontradas nesses sítios do Holoceno Inicial estão entre as mais antigas evidências de polimento de líticos no continente (Araujo et al; 2008; Bueno, 2012; Araujo et al; 2018). Conforme Bueno (2012), é possível que as lâminas, tanto polidas quanto lascadas, tenham sido encabadas em madeira, e a eles é atribuída uma funcionalidade de corte ou poda de árvores de diferentes portes, o que possibilitaria uma maior intervenção humana na paisagem.

Moreno de Sousa (2014) realizou a análise tecnológica de indústrias líticas do Holoceno Inicial no Brasil: a Lagoassantense; a $\mathrm{Umbu}^{27}$ presente no Sul do país; e a Itaparica $^{28}$, presente no Centro-Oeste e Nordeste brasileiros. Lagoa Santa parece ter uma

\footnotetext{
${ }^{27}$ A Tradição Umbu foi definida por Eurico Miller para designar uma indústria lítica do Holoceno Inicial; presente no Sul do Brasil, no Estado de São Paulo, no Uruguai, no Paraguai e na Argentina; caracterizada principalmente pela presença de pontas bifaciais pedunculadas (Okumura \& Araujo 2013; Moreno de Sousa, 2014). A tese recém publicada de Moreno de Sousa (2019) identifica heterogeneidades tecnológicas e desconstrói a suposta unicidade de uma Tradição Umbu.

${ }^{28}$ A Tradição Itaparica (ver Schmitz, 1980) ou Tecnocomplexo Itaparica (ver Lourdeau, 2010) se trata de uma indústria lítica do Holoceno Inicial presente no Centro-Oeste e Nordeste brasileiros, caracterizada principalmente pela presença de instrumentos unifaciais plano-convexos (lesmas) (Schmitz, 1980) ou, em outra definição, artefatos façonados unifacialmente a uma face plana (Lourdeau, 2010). Rodet et al.
} 
indústria lítica local que não possui similaridades com as demais indústrias contemporâneas mencionadas (Moreno de Sousa, 2014; Moreno de Sousa \& Araujo, 2018).

O material analisado da Lapa do Santo, 422 líticos, é proveniente das quadras F12, F13, G12 e G13; e foram incluídas nas análises resíduos de lascamento (Moreno de Sousa, 2014). Os níveis estudados são os mais antigos do Holoceno Inicial do sítio, níveis 28 a 40 para os plotados e níveis 32 a 39 para os coletados em peneira (Moreno de Sousa, 2014).

As lascas residuais possuem grande semelhança entre si, principalmente aquelas cujo suporte é o cristal de quartzo hialino; e segundo o autor, isso se deveria às pequenas dimensões dos suportes, o que não possibilitaria uma diversidade nas feições (Moreno de Sousa, 2014). Devido às pequenas proporções dos núcleos e das lascas identificadas, o autor afirma se tratar de uma indústria microlítica (Moreno de Sousa, 2014).

O estudo da cadeia operatória ${ }^{29}$ indica a debitagem de pequenas lascas quadriláteras, circulares ou laminares, de perfil plano ou côncavo, cuja matéria prima é o quartzo hialino em cristal; e o sílex; com eventual aplicação de polimento às demais matérias primas (Moreno de Sousa, 2014). O lascamento em sílex é similar ao quartzo hialino, mas é menos utilizado, os líticos são um pouco maiores e há muito mais marcas da ação do fogo nas peças, que teria ocorrido após terem sido descartadas (Moreno de Sousa, 2014). Geralmente não há façonagem e Moreno de Sousa (2014) concorda com Pugliese (2007) em que as lascas teriam sido provavelmente utilizadas sem ou com poucos retoques para ativar o gume, ainda que sejam necessários estudos específicos sobre a função dos instrumentos (Moreno de Sousa, 2014).

Os núcleos da Lapa do Santo se apresentam bastante esgotados e possuem dimensões variadas, entre 10 e 50 mm de comprimento; 12 e 42 mm de largura; e 8 a 34

(2011) revisitam a Tradição e identificam heterogeneidade tecnológica e morfológica dentre a mesma, apontando as limitações dessa classificação.

${ }^{29}$ Cadeia operatória é um conceito usado para descrever um processo técnico que conduz de uma matériaprima bruta a um produto acabado e envolve um encadeamento de atos, gestos e instrumentos que perpassam por escolhas técnicas e culturais (Cresswell, 1989., Lemonnier, 1993., Balfet, 1991., Marchand, 1999). É através da cadeia operatória que se pode compreender a lógica interna de uma determinada atividade (Balfet, 1991). Cada cadeia operatória se apresenta com um certo número de etapas e pode se desenvolver em diferentes lugares uma vez que a atividade pode envolver deslocamentos se for sazonal ou permanente, próxima ou distante do local de habitação (Balfet, 1991). 
mm de espessura (Moreno de Sousa, 2014). Ainda assim, 90\% desses núcleos possuem córtex, o que demonstra bastante aproveitamento volumétrico do cristal (Moreno de Sousa, 2014).

Instrumentos líticos formais que são exceções foram encontrados na Lapa do Santo, como uma ponta de projétil e lâminas de machado (AStrauss et al; 2016; Araujo et al.; 2018). A ponta de projétil da Lapa do Santo foi encontrada abaixo ${ }^{30}$ de um nível datado em 10.000 anos cal. A.P; foi produzida em calcário silicificado e apresenta façonagem, retoques bifaciais, e polimento em uma das faces (Moreno de Sousa, 2014; Strauss et al; 2016). É possível que essa seja a evidência mais antiga de polimento em lítico nas Américas (Moreno de Sousa, 2014).

Uma lâmina de machado é proveniente de uma camada datada em aproximadamente 10.400 anos cal. A.P. e foi produzida em uma lasca de óxido de ferro (hematita), apresenta polimento e picoteamento no gume e nos bordos (Moreno de Sousa, 2014; Strauss et al; 2016). Algumas partes indicam atrito com material vegetal, sugerindo o encabamento com madeira (Strauss et al; 2016). Demais lâminas de machado da Lapa do Santo foram analisadas, duas pertencem ao Holoceno Inicial e duas ao Holoceno Médio (Moreno de Sousa \& Araujo, 2018). As matérias-primas são a hematita e rocha ígnea e foram aplicadas técnicas de lascamento e polimento (Moreno de Sousa \& Araujo, 2018).

Moreno de Sousa (2014) defende que a debitagem dos pequenos cristais de quartzo hialino, matéria prima com volume limitado, é mais complexa do que se fosse aplicada a outras matérias primas, como seixos disponíveis na região. Na localidade da Lapa do Santo há raras fontes de cristais de quartzo hialino e a sua busca e escolha é prioritária, em vista do resultado final que poderia ser alcançado com outras matérias primas e as mesmas técnicas (Moreno de Sousa, 2014; Araujo et al.; 2018). Os instrumentos teriam a funcionalidade de cortar e raspar (Moreno de Sousa, 2014).

Moreno de Sousa \& Araujo (2018) apresentam novos dados e discutem sobre os líticos dos sítios Lapa do Santo, Lapa das Boleiras, Lapa de Taquaraçu, Coqueirinho e Sumidouro. Para a Lapa do Santo, foram analisados cerca de 600 líticos das quadras F12, F13, G12 e G13, dos níveis do Holoceno Inicial entre 310 e $390 \mathrm{~cm}$ de profundidade (Moreno de Sousa \& Araujo, 2018).

\footnotetext{
${ }^{30}$ Quadra G12 nível 28 (Strauss et al., 2016).
} 
Os resultados para a Lapa do Santo indicam que nos níveis mais antigos que 8800 anos cal. A.P. $72 \%$ da matéria prima é quartzo hialino e $22 \%$ é sílex; enquanto que nos níveis mais recentes que essa data, $80 \%$ é quartzo hialino e $12 \%$ é sílex, tendo sido esse padrão observado em outros sítios de Lagoa Santa (Moreno de Sousa \& Araujo, 2018).

As indústrias de artefatos líticos da Lapa do Santo não teriam se alterado ao longo das ocupações, com exceção do desaparecimento das matérias primas que não o quartzo hialino (Araujo et al; 2018). Mas os tipos de suportes, a presença de córtex e os tipos de bulbo teriam sido mantidas na mesma proporção ao longo do tempo (Araujo et al; 2018).

Com relação aos métodos aplicados aos líticos da Lapa do Santo, a debitagem dos núcleos parece ser sistemática, com a exploração dos cristais de quartzo hialino pelo método de fatiamento e de planos oposto (Moreno de Sousa \& Araujo, 2018). Esses métodos podem ter sido aplicados devido à limitação do volume e estrutura dos pequenos cristais, mas os métodos persistem porque também foram aplicados a outros tipos de matérias primas (Moreno de Sousa \& Araujo, 2018).

De acordo com Strauss et al. (2016), os cristais de quartzo ocorrem na área do carste de Lagoa Santa, enquanto que outras matérias primas (sílex, quartzito e arenito silicificado) não estão presentes mas são encontradas nas proximidades como o rio Jaboticatubas a $25 \mathrm{~km}$ e nas Montanhas Espinhaço a $60 \mathrm{~km}$.

Segundo Moreno de Sousa \& Araujo (2018), não existem fontes conhecidas de quartzo hialino em Lagoa Santa. Fontes abundantes de quartzito em seixos e blocos são encontradas no Rio das Velhas a $10 \mathrm{~km}$ da Lapa do Santo (Moreno de Sousa \& Araujo, 2018). Ao lado da Lapa Grande de Taquaraçu, no rio Jaboticatubas, há seixos e blocos de boa qualidade e abundantes, mas no sítio só há quartzo hialino, não existente no local (Moreno de Sousa \& Araujo, 2018).

Dessa maneira, os autores argumentam que a insistente escolha pelos cristais de quartzo hialino não é utilitária, mas sim próxima a uma "obsessão" que poderia ser explicada pelas características visuais de translucidez e brilho (Moreno de Sousa \& Araujo, 2018). Os autores também apontam que é possível que as pontas bifaciais sejam 
oriundas de trocas e que não componham a indústria de Lagoassantense (Moreno de Sousa \& Araujo, 2018).

A cadeia operatória da indústria lítica de Lagoa Santa seria definida pela 1) aquisição de matéria prima, 2) debitagem por fatiamento diagonal e métodos de planos opostos, 3) (para algumas raras peças) a redução e retoque dos gumes ativos para tornárlos mais côncavos e denticulados, 4) uso multifuncional, 5) descarte nos abrigos (Moreno de Sousa, 2014; Moreno de Sousa \& Araujo, 2018).

Os autores defendem que a indústria de Lagoa Santa não seria simples e nem complexa, mas sim uma forma estável e eficaz de se lidar com a matéria prima desejada, o cristal de quartzo (Moreno de Sousa \& Araujo, 2018). Portanto, a definição mais atualizada para a indústria lítica de Lagoa Santa seria “[...] uma indústria microlítica baseada no lascamento de quartzo e sílex e eventual aplicação de técnicas de polimento, incluindo a produção de lâminas polidas, que persistem durante o Holoceno Inicial até o Tardio" (Moreno de Sousa \& Araujo, 2018: 17).

Segundo Moreno de Sousa \& Araujo (2018), a indústria lítica de Lagoa Santa poderia ser considerada complexa se tomarmos em conta que haveria um padrão sistemático e estruturado de produção dos artefatos, mesmo assim, o argumento é insuficiente porque algo simples não implica que seja assistemático (ver Moreno de Sousa, 2014). A indústria poderia ser considerada simples se levarmos em conta que a maioria dos instrumentos passaria por poucas etapas de produção para o produto final, basicamente a maioria só seria debitada e já diretamente utilizada (Moreno de Sousa \& Araujo, 2018).

\subsection{Cronologia e Sepultamentos da Lapa do Santo}

Como mencionado no tópico "1.2 Processos de Formação dos Sítios de Lagoa Santa", datações radiocarbônicas realizadas nas unidades "M" na Lapa do Santo, indicam uma ocupação no Holoceno Inicial, de 12.460 a 8700 anos cal. A.P; e outra ocupação no Holoceno Médio, de 5100 a 4200 cal BP. Conforme Araujo et al. (2018) o grupo teria inicialmente ocupado a Lapa do Santo e se deslocado geograficamente, devido provavelmente a alterações ambientais e depois retornado ao sítio. O grupo teria mantido a maneira de produzir a cultura material intacta ao longo desse hiato, 
equivalente a 160 gerações, o que implicaria em uma forte tradição oral e manutenção do saber-fazer (Araujo et al; 2018). Apesar das ocupações na Lapa do Santo iniciarem há 12.500 anos cal. A.P; a prática de sepultar as pessoas no sítio começaria somente 2500 anos depois (Araujo et al; 2018).

O estudo de padrões dos sepultamentos e datações dos mesmos, assim como datações em demais localidades da Lapa do Santo indicam três períodos de ocupação (Strauss et al; 2016). As datações foram realizadas em sedimento ${ }^{31}$ por OSL e em carvão e colágeno de ossos humanos por radiocarbono e indicam três períodos diferentes de ocupação que correspondem em certa parte com o Holoceno Inicial, Médio e Tardio (Strauss et al; 2016).

O Período 1, com intervalo de $68.2 \%$, inicia há 12.500 e vai até 8100 anos cal. A.P. Com intervalo de $95.4 \%$ o período 1 vai de 12.700 a 8000 anos cal. A.P. Esse período está abaixo do valor de z 0.137 m na profundidade do sítio.

O período 2, com intervalo de 68,2\%, inicia há 5.002 e vai até 4000 anos cal. A.P. Com intervalo de $95.4 \%$, o Período 2 vai de 5400 a 3900 anos cal. A.P. Esse período está entre os valores de z 0.137 m e 0.947 m de profundidade.

O período 3, com intervalo de $68.2 \%$, inicia há 1100 e vai até 700 anos cal. A.P. Com intervalo de 95,4\%, o Período 3 inicia há 2100 anos cal. A.P. e vem até séculos antes da colonização europeia. Esse período está acima do valor de $0.947 \mathrm{~m}$ na profundidade do sítio.

Com relação aos sepultamentos da Lapa do Santo (Figura 5), estudos de morfologia em sete crânios $^{32}$ foram realizados e comparados com a morfologia de indivíduos de outros sítios de Lagoa Santa da Colômbia e demais bancos de dados (Neves et al; 2014). Os resultados indicam que os indivíduos da Lapa do Santo possuem um padrão morfológico paleoamericano e representam uma mesma população biológica em Lagoa Santa (Neves et al; 2014; Neves et al; 2013).

\footnotetext{
${ }^{31}$ Em 21 amostras de sedimento, duas fora do abrigo e as demais nas quadras Q48, F13, M6 e na trincheira (Strauss et al., 2016).

${ }^{32}$ Sepultamentos $1,5,11,14,17,21$ e 26 . O crânio do sepultamento 17 é uma exceção a ser melhor investigada (Strauss et al., 2016).
} 


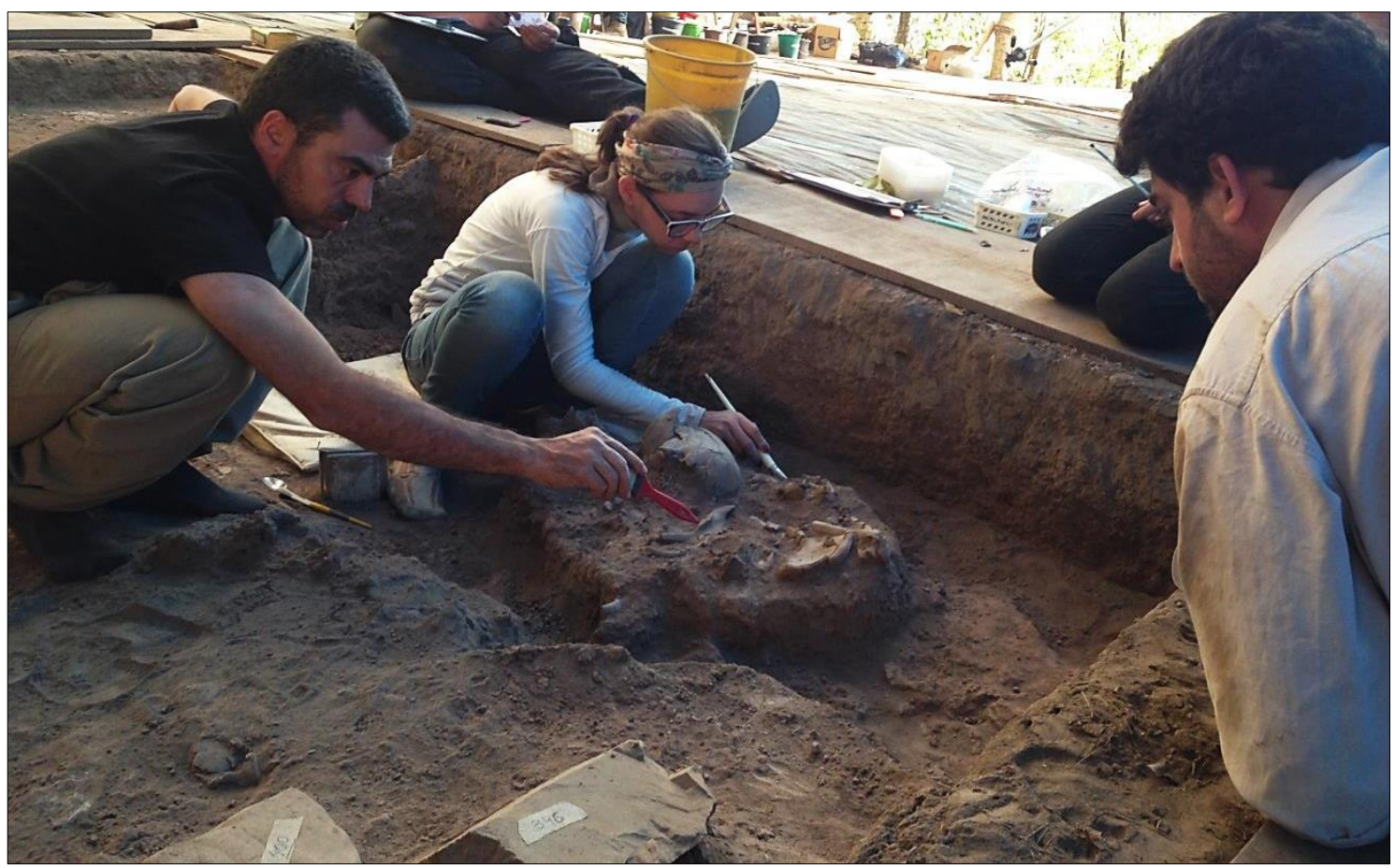

Figura 5. Escavação de um sepultamento na Lapa do Santo durante etapa de campo em 2016. Pesquisadores: Dr. Rodrigo Elias de Oliveira, Dr. André Strauss e arqueóloga Lycia Macley.

Até o momento foram escavados 33 sepultamentos na Lapa do Santo (Villagran et al; 2017). Com o estudo de 26 desses sepultamentos, Strauss (2010) os classificou em 7 padrões. O Padrão 1, definido para os sepultamentos 1 e 27 , consiste em esqueletos articulados e em posição fletida, cujo enterramento foi primário e estão entre 10.600 e 9700 anos cal. A.P. (Strauss, 2010; 2016; Strauss et al; 2016). O sepultamento 1 se refere a um indivíduo adulto do sexo masculino e a cova estava coberta por grandes blocos (40 cm de comprimento) de calcário (Strauss, 2010; 2016). O sepultamento 27 se refere a uma criança de aproximadamente 8 anos de idade, em posição sentada com joelhos próximos ao crânio e mandíbula aberta indicando que a cova não havia sido completamente preenchida, sem blocos. Este esqueleto foi diretamente datado por colágeno de osso entre 10545 e 10270 e é o diretamente datado mais antigo do Brasil (Strauss, 2016).

O Padrão 2 consiste em sepultamentos com ossos talhados e descarnados com sinal de queima de tecidos macios, cuja cronologia está entre 9400 e 9600 anos cal. A.P; e foi subclassificado em três grupos (Strauss, 2010; 2016; Strauss et al; 2016).

O Padrão 2A é representado pelos sepultamentos 21 e 26 que são partes de esqueletos articulados com marcas de corte e talhagem de partes intencionalmente 
removidas (Strauss, 2010; 2016; Strauss et al; 2016; Strauss \& Oliveira, 2017). As diáfises da tíbia e da fíbula do sepultamento 21 foram talhadas e removidas (Strauss, 2010; 2016; Strauss et al; 2016). No sepultamento 26 a cabeça foi decapitada com as seis primeiras vértebras cervicais articuladas, as mãos estão amputadas sobre a cabeça e falta o osso hióide (Figura 6) (Strauss, 2010; 2016; Strauss et al; 2015; Strauss et al; 2016). Análises de marcas de corte nos ossos com microscopia eletrônica de varredura e microscopia confocal evidenciam estrias micro paralelas e perfil em $\mathrm{V}$ transversal o que indica o uso de lascas líticas como instrumento cortante dos corpos ainda com os tecidos muscular e cartilaginoso presentes (Strauss et al; 2015; Strauss et al; 2016; Strauss \& Oliveira, 2017).

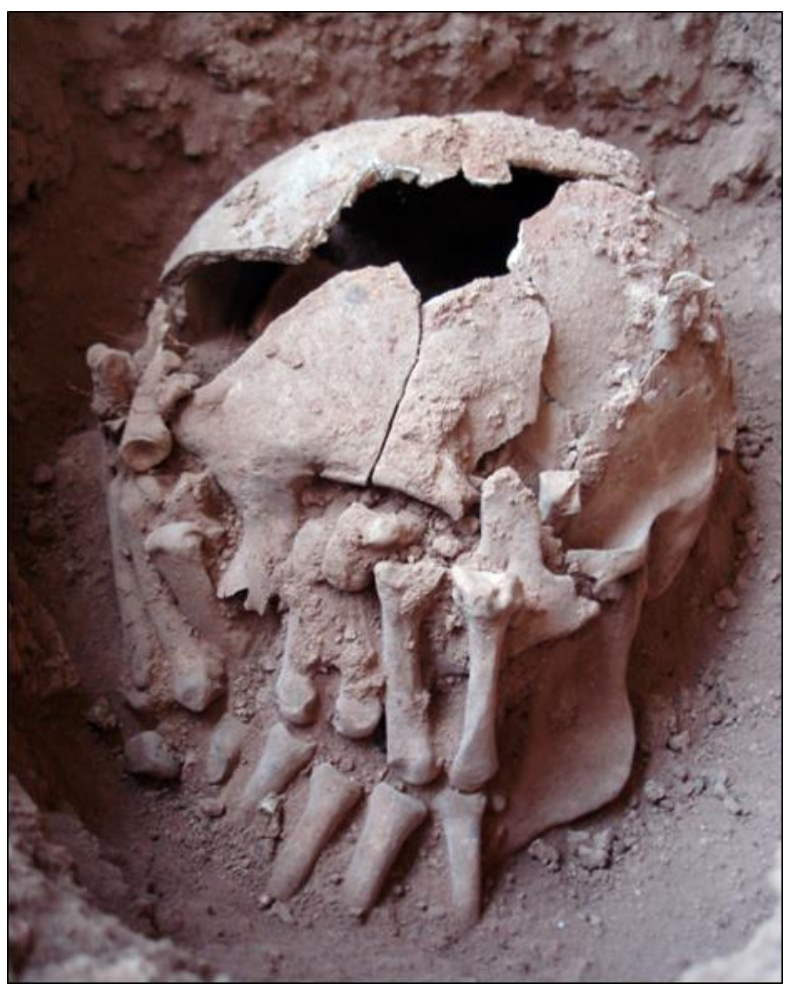

Figura 6. Crânio do sepultamento 26 da Lapa do Santo. Fonte: Strauss et al. (2015:13).

O Padrão de Sepultamento 2B se trata de covas preenchidas com ossos desarticulado de mais de um indivíduo, até cinco, com a seleção de partes anatômicas específicas e inclui os sepultamentos 9, 14, 17, 18 e 23 (Strauss, 2010; 2016, Strauss et al; 2016). Em alguns sepultamentos há ossos que apresentam marcas de exposição ao fogo, corte, talhagem, descarnamento, resíduos vermelhos de pigmento aplicado e a remoção intencional de dentes (Strauss, 2010; 2016, Strauss et al; 2016). É possível que 
haja sepultamentos similares ao Padrão 2B em Cerca Grande, Lapa das Limeiras e Lapa da Samambaia (Strauss et al; 2016).

Os sepultamentos 14, 17 e 18 compreendem um conjunto de ossos de pelo menos um indivíduo subadulto ao lado do crânio de um indivíduo adulto (Strauss, 2010; 2016, Strauss et al; 2016). Os ossos longos foram talhados e divididos em extremidades e diáfises, algumas queimadas e talhadas em seções menores (Strauss, 2010; Strauss et al; 2016). No sepultamento 17 a parte superior do crânio foi disposta como um recipiente, com ossos talhados, alguns com marcas de corte por descarnamento e marcas de queima, algumas delas apenas na parte anterior (da frente) do crânio indicam que a exposição ao fogo ocorreu quando ainda havia tecidos macios no rosto (Strauss, 2010; Strauss et al; 2016; Strauss \& Oliveira, 2017). No sepultamento 17 os dentes do indivíduo adulto foram removidos e os processos coronoides perfurados (Strauss, 2010; Strauss et al; 2016). Os sepultamentos 14 e 18 apresentam pigmentação vermelha (Strauss, 2010; Strauss et al; 2016). No sepultamento 23 a parte superior do crânio foi preenchida com 54 dentes permanentes e 30 não-permanentes (de leite), alguns do sepultamento 17 (Strauss, 2010; 2016; Strauss et al; 2016). No sepultamento 9 há o crânio de uma criança próximo à pélvis de outra, os dentes de leite foram removidos e um conjuntos de dentes e diáfises talhadas foram colocadas próximo ao sepultamento (Strauss, 2010; 2016; Strauss et al; 2016).

O Padrão 2C é constituído por ossos isolados com marcas de queima e corte (Strauss, 2010; 2016; Strauss et al; 2016). Alguns ossos possuem marcas de roedores, o que sugere que não tenham sido rapidamente enterrados (Strauss et al; 2016). Em Confins, em Lagoa Santa, foram identificados ossos queimados isolados semelhantes ao Padrão 2c (Strauss et al; 2016).

O Padrão 3 consiste em covas circulares, rasas (com cerca de $20 \mathrm{~cm}$ de profundidade), bastante preenchidas com ossos de um indivíduo por cova e fora da posição anatômica, a maioria desarticulados, e os de indivíduos adultos quebrados ao meio (Strauss, 2010; 2016; Strauss et al; 2016). A cronologia desse padrão está entre 8600 e 8200 anos cal. A.P. e compreende os sepultamentos 6, 7, 10, 11, 12, 13, 15, 19 e 22. Os sepultamentos 6, 12, 15, e 19 apresentam cobertura circular de blocos de calcário (Strauss, 2010; 2016; Strauss et al; 2016). Ossos fragmentados por rochas em Lapa da 
Mãe Rosa, Lapa da Limeira, Terraço do Sumidouro, Cerca Grande 5 e 6 sugerem que sejam similares ao Padrão 3 (Strauss et al; 2016).

O Padrão 4, classificado com base nos sepultamentos 2 e 3 , se trata de esqueletos de indivíduos adultos articulados cujos membros estão ausentes e os ossos não apresentam marcas de corte (Strauss, 2010; 2016; Strauss \& Oliveira, 2017). O sepultamento 3 é de um indivíduo do sexo masculino e não há ambos os membros superiores e inferiores (Strauss, 2010; 2016). O sepultamento 2 é de indivíduo do sexo feminino e não há os membros superiores, tendo uma datação realizada por colágeno de osso que indica idade entre 9029 e 8798 anos cal. A.P. (Strauss, 2016).

O Padrão 5, representado pelo sepultamento de mesmo número, contém ossos de um único indivíduo adulto do sexo feminino organizados em forma de feixe, com marcas de corte nos ossos longos (Strauss, 2010; 2016). Não há datação direta, mas está acima do Padrão 2 na estratigrafia e pode ser supostamente mais recente que esse (Strauss, 2010; 2016).

O Padrão 6 representa o sepultamento 8, cujo esqueleto de apresenta ter sido totalmente cremado, ocorrência única na Lapa do Santo, e possivelmente, de Lagoa Santa (Strauss, 2010; 2016). O esqueleto é de um indivíduo adulto em cova circular, sem carvões, o que indica que a calcinação não tenha ocorrido dentro da cova (Strauss, 2010; 2016).

O Padrão 7, definido para sepultamento 4, é uma cova circular coberta por blocos de quartzito e preenchida com ossos de um indivíduo subadulto de aproximadamente 5 a 7 anos de idade (Strauss, 2010; 2016). Os ossos apresentam pigmento vermelho (Strauss, 2010; 2016).

Demais remanescentes ósseos humanos foram recuperados e classificados como casos isolados (Strauss, 2010; 2016). Esse é o caso do sepultamento 24 em que há dentes permanentes, alguns ossos e blocos, localizado entre os padrões 2 e 3 (Strauss, 2010; 2016). Também é o caso do sepultamento 25, localizado acima do Padrão 1 , em que há poucos ossos bastante fragmentados de um recém nascido de cerca de seis meses de idade (Strauss, 2010; 2016).

Conforme Strauss Strauss et al; 2016, a Lapa do Santo era um espaço doméstico e um lugar para sepultar os mortos segundo conceitos cosmológicos e sociais que 
realçariam a comunicação visual das cerimônias (Strauss et al; 2016). As transformações observadas na forma de sepultar os mortos revelam como esses grupos eram dinâmicos ao longo do tempo (Strauss et al; 2016).

\subsection{Demais Vestígios da Lapa do Santo}

Um estudo palinológico não publicado, acessado pelo LAAAE-IB/USP, foi realizado por Johnica Morrow em 2014, em amostras de perfil oeste da área de escavação na Lapa do Santo, e foram identificadas plantas representativas de vegetação tropical (Morrow, 2014). Entre 6 e $12 \mathrm{~cm}$ de profundidade, foi encontrado pólen de Arecaceae, Chenopodiaceae/Amaranthaceae, Asteraceae, Malpighiaceae, Melastomataceae, Myrtaceae e Poaceae (Morrow, 2014). Entre 12 e $30 \mathrm{~cm}$ foram identificadas Euphorbiaceae, Malpighiaceae, Malvaceae (Hibiscus ver), Melastomataceae, Myrtaceae, Nyctagenaceae e Poaceae. Entre 30 e $36 \mathrm{~cm}$ o pólen se encontrou tafonomizado e por isso não foi identificado (Morrow, 2014). E entre 48 a 60 cm não foi detectado pólen (Morrow, 2014). O sedimento alcalino do sítio, dentre outros processos tafonômicos como bioturbação, pode ser uma das principais causas para a baixa preservação de pólen no sítio à medida que aumenta a profundidade (Morrow, 2014).

Na parte norte do abrigo há marcas d'água nas paredes calcárias, em altura de 4 m, o que sugere uma área de acumulação de água (Villagran et al; 2017). Para verificar se esse lago afetou o depósito arqueológico, foram realizadas análises de diatomáceas em 12 amostras de sedimento arqueológico, tendo sido identificadas diatomáceas em 70\% das amostras, mas em baixa frequência (Strauss, et al; 2016). O tipo mais comum foi Eunotia, gênero que prefere pântanos, rios e lagos. E Hantzschia amphioxis que habita águas periódicas e efêmeras (Strauss et al; 2016). Ainda que exista ao norte do abrigo marcas de água no paredão que indiquem a existência de uma lagoa em algum momento, a existência dessa água no sítio não se confirma devido à baixa frequência de diatomáceas. As poucas diatomáceas encontradas poderiam ter sido trazidas em algum contexto pelos grupos humanos desde lagos vizinhos (Strauss et al; 2016).

Com relação a artefatos em osso de fauna da Lapa do Santo, foram classificadas 198 peças que consistem em espátulas (71\%), perfuradores $(25 \%)$ e anzóis $(0,01 \%)$ (Strauss et al; 2016; Araujo et al; 2018). Esses instrumentos foram produzidos em sua 
maioria com ossos de cervídeos (Mazama sp.) e tatus (Dasypus e Euphractus) (Santos, 2011; Araujo et al; 2018). Araujo et al. (2018) apresentam a classificação de uma amostra menor desses artefatos, 56 deles, provenientes das unidades F12, F13, G12 e G13 e unidades M, datados entre 10.060 e 4510 anos cal. A.P. As camadas mais recentes apresentam maiores quantidades de perfuradores e as camadas mais antigas maiores frequências de espátulas (Araujo et al; 2018).

Análises zooarqueológicas foram realizadas em ossos de Mazama sp. (cervídeos) da Lapa do Santo, provenientes dos contextos sul e norte do abrigo (Bissaro, 2008). Na parte norte do abrigo está o contexto de habitação e funerário do sítio e a parte sul é considerada uma área de descarte de restos alimentares e de material lítico, com sedimento erodido da parte norte, mais alta, para a mais baixa (Bissaro, 2008; Perez, 2009). De um total de 320 ossos, 21,86\% apresentam marcas de terem sido queimados não aleatoriamente e 3,13\% apresentam marcas de corte (Bissaro, 2008). Bissaro (2008) comparou índices de fragmentação dos ossos de Mazama sp. da Lapa do Santo com os do sítio paleontológico Cuvieri e concluiu que a fragmentação presente nos ossos da Lapa do Santo não é resultado de um processo aleatório, mas sim da interferência humana, provavelmente para a exploração alimentar do tutano (Bissaro, 2008). Na etnografia é comum que ocorra o corte e desmembramento de animais de grande porte no local do abate, o que deixa elevados índices de desmembramento e marcas de corte nas articulações, o que não foi observado em Mazama sp. na Lapa do Santo (Bissaro, 2008). Como propôs Kipnis (2002) para os sítios do Brasil Central, na Lapa do Santo os animais de pequeno e médio porte seriam levados inteiros para o sítio sem escolha de partes anatômicas (Bissaro, 2008).

Um estudo zooarqueológico com abordagem paleoambiental foi realizado em elementos ósseos faunísticos da Lapa do Santo, no total 1708 peças, das quadras L4, L5, L7 L8, L9, L10, M3, M4, M5 e M6 (Perez, 2009; Strauss et al; 2016). Os resultados apresentam um conjunto faunístico com predomínio de animais de pequeno e médio porte como répteis, pássaros e peixes; e em menor quantidade a presença de animais de maior porte como veados e queixadas (Perez, 2009; Strauss et al. 2016). Nos períodos do Holoceno Inicial, com datações por radiocarbono em carvão e osso entre $9900 \pm 40$ e $8230 \pm 40$ anos A.P.; e do Holoceno Médio, com datações por radiocarbono em carvão entre $4070 \pm 60$ anos A.P. e $3820 \pm 100$ anos A.P.; foram identificados carnívoros, primatas, quelônios, répteis, peixes, Dasypus novemcinstus, marsupiais, Euphractus 
sexcinctus, aves, Silvylagus brasiliensis, pequenos roedores, anfíbios, Tayassu sp; Cuniculus paca e Mazama sp. (Perez, 2009). No período Holoceno Tardio, com datações radiocarbônicas em carvão entre $960 \pm 60$ anos A.P. e $910 \pm 60$ anos A.P.; se detectou carnívoros, quelônios, répteis, peixes, Dasypus novemcinctus, aves, pequenos roedores, anfíbios, Tayassu sp. e Mazama sp. (Perez, 2009).

Outras análises de remanescentes faunísticos da Lapa do Santo foram realizadas em 984 peças provenientes das quadras F12, F13, G12 e G13 em níveis do Holoceno Inicial, e nas quadras M3, M4, M5, M6 e M7 em níveis do Holoceno Inicial e Médio (Mingatos \& Okumura, 2016; Mingatos, 2017). Os resultados ${ }^{33}$ sugerem uma dieta generalizada com o consumo de mamíferos de médio porte, com alto consumo de cervídeos (Mazama sp.), mas também paca e macacos; e de mamíferos de pequeno porte como tatu, preá e mocó; em menor expressividade peixes, anfíbios e aves (Mingatos \& Okumura, 2016; Mingatos, 2017).

Análises de isótopos de carbono e nitrogênio aplicadas a 8 ossos humanos e 22 de fauna da Lapa do Santo, do Holoceno Inicial, sugerem para ambos um predomínio de uma dieta baseada em plantas $\mathrm{C}_{3}$ (Hermenegildo, 2009; Strauss et al; 2016). Valores altos de nitrogênio em indivíduo humano infantil sem dentição permanente pode sugerir amamentação (Hermenegildo, 2009; Strauss et al; 2016). Baixos valores de nitrogênio na população humana adulta é algo distintivo de carnívoros e similar a dieta de herbívoros, o que significaria a ocorrência de uma dieta altamente baseada no consumo de plantas $\mathrm{C}_{3}$ e complementada com o consumo de fauna (Hermenegildo, 2009; Strauss et al; 2016). Contudo, os humanos apresentaram uma porcentagem de plantas de origem $\mathrm{C}_{4}$ (como o milho) relativo a $19,6 \pm 1,6 \%$, interpretado pelo autor como um número baixo que seria provavelmente proveniente de contaminação, uma vez que haveria o desconhecimento da presença de espécies $\mathrm{C} 4$ na região no Holoceno Inicial (Hermenegildo, 2009).

\footnotetext{
${ }^{33}$ Os táxons identificados foram Mazama sp. (veado), Dasypus novemcinctus (tatu-galinha), Euphractus sexcinctus (tatu-peba), Cavia aperea (preá), Tayassu sp. (porco do mato), Kerodon rupestres (mocó), Bagre sp., Anura (sapo), Tapirus terrestris (anta), Teiidae (lagarto), Testudines (tartarugas), Didelphidae (gambá), macacos, roedores pequenos, demais tatus, jacarés, pacas e cobras (Mingatos \& Okumura, 2016).
} 
Análises de estrôncio em 23 amostras de esmalte de dentes humanos da Lapa do Santo indicam que os indivíduos teriam vivido em um mesmo ambiente, no caso a região de Lagoa Santa devido à similaridade da assinatura de estrôncio (Strauss et al. 2016). Portanto, haveria baixa mobilidade territorial com estratégia de subsistência regional (Strauss et al. 2016).

Um estudo de saúde bucal, dieta e estilo de vida em remanescentes humanos dos sítios arqueológicos Lapa do Santo e de demais sítios de Lagoa Santa ${ }^{34}$, identificou um alto índice de cáries nos dentes, principalmente em indivíduos do sexo feminino (DaGloria, 2012; Da-Gloria \& Larsen, 2014). Segundo Lingstrom et al. (2000) a combinação de alimentos ricos em amido a fontes de açúcares simples pode potencializar o surgimento de cáries (Da-Gloria \& Larsen, 2014). O consumo de mel seria outra possiblidade para o alto índice de cáries, tendo em vista que há pesquisadores $^{35}$ que o consideram causador desta patologia, embora outros autores ${ }^{36}$ argumentem que o mel teria um efeito antibacteriano, a prevenindo (Da-Gloria, 2012; Da-Gloria \& Larsen, 2014). Além disso, os indivíduos de Lagoa Santa também apresentam indicadores de baixa mobilidade, infecções e estresse, que são características presentes em grupos humanos agricultores (Da-Gloria, 2012; Da-Gloria \& Larsen, 2014). Contudo, não haveria evidências conhecidas de domesticação de plantas ou do consumo de plantas domesticadas no início do Holoceno na região central do Brasil (Da-Gloria \& Larsen, 2014). Portanto, se propôs que o alto índice de cáries pode ter sido causado por uma grande quantidade de carboidrato na dieta por meio do consumo de tubérculos selvagens, sementes e frutas (Da-Gloria, 2012; Da-Gloria \& Larsen, 2014).

A Lapa do Santo apresenta grafismos rupestres em forma de pintura e petroglifos (comumente com a técnica de picoteamento), ambos com motivos geométricos e antropomorfos filiformes curtos, alongados e arredondados; e pinturas zoomorfas como aves, cervídeos e quadrúpedes (Baeta, 2011). Os grafismos são identificados parietalmente nos tetos, pisos e laterais de condutos ou patamares (Baeta, 2011). Em escavação a 4 m de profundidade no mesmo nível do piso natural da caverna, na unidade FG-13/14, foi encontrado um petroglifo considerado o mais antigo do

\footnotetext{
${ }^{34}$ Lapa das Boleiras, Cerca Grande, Harold Walter, Lapa da Amoreira, Lapa de Carrancas, Lapa Mortária e Santana do Riacho (Da-Gloria, 2012).

35 ver Shannon et al. (1979); Bowen \& Lawrence (2005).

${ }^{36}$ ver Molan (2001); English et al. (2004)
} 
continente americano (Neves et al; 2012). Datações radicarbônicas contextuais indicam uma idade mínima entre 10.700 a 10.500 anos cal. A.P. (9370 \pm 640 anos A.P.) e datações por luminescência (OSL) de sedimento da mesma camada estratigráfica indicam que o grafismo se situa entre $11.700 \pm 800$ anos cal. A.P. (Neves et al. 2012). O grafismo se trata de uma figura produzida por picoteamento que mede $30 \mathrm{~cm}$ de comprimento e $20 \mathrm{~cm}$ de largura, antropomorfa, filiforme, com três dígitos, um falo e uma cabeça em forma de "c" (Baeta, 2011; Neves et al. 2012).

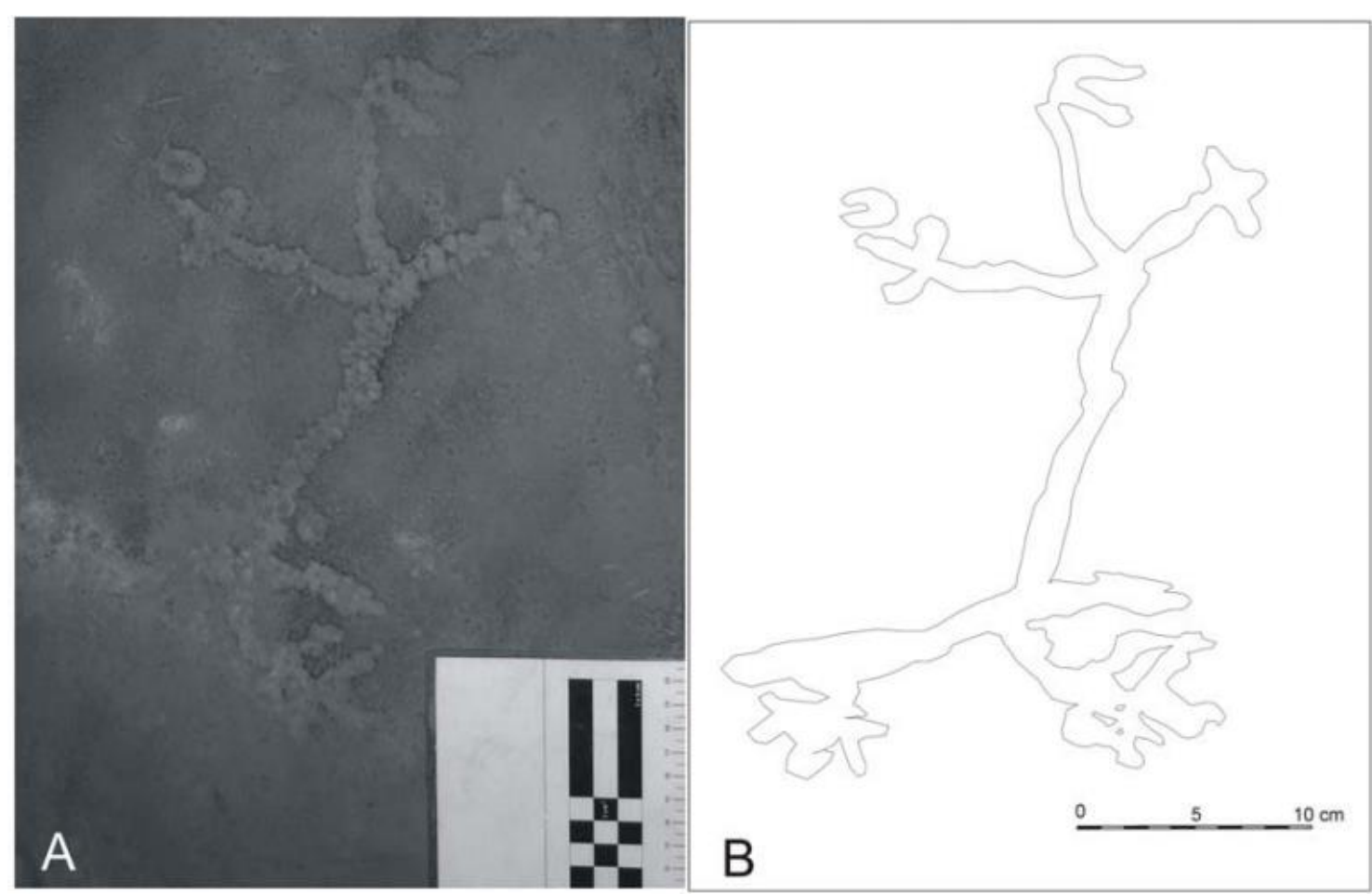

Figura 7. Fotografia do petroglifo (A) e ilustração do contorno (B). Fonte: Neves et al. (2012:2).

Estudos de georadar (ground-penetrating radar - GPR) na Lapa do Santo indicaram a presença de anomalias no pacote sedimentar, que representaram a presença de potenciais vestígios arqueológicos (Porsani et al; 2010). A escavação de alguns desses pontos foi realizada, tendo sido encontradas fogueiras e artefatos nos locais sinalizados (Porsani et al; 2010). 


\subsection{Caracterização ambiental}

\subsubsection{Atual}

A Área de Proteção Ambiental (APA) do Carste de Lagoa Santa ${ }^{37}$ se localiza a aproximadamente $46 \mathrm{~km}$ ao norte de Belo Horizonte, no estado de Minas Gerais (Figura 3) (Araujo \& Neves, 2010). A APA possui 35.900 hectares e abarca 35 municípios como Lagoa Santa, Pedro Leopoldo, Confins, Matozinhos e Funilândia (Viana et al; 1998; Hermann et al; 1998).

A base geológica da região é um complexo metamórfico de rochas gnáissicas, granitóides e migmatíticas (Viana et al; 1998). Sobre este há as formações do Grupo Bambuí - Sete Lagoas e Serra de Santa Helena - do período Pré-Cambriano Superior ou Neoproterozóico, entre cerca de 1 bilhão e 541 milhões de anos atrás (Dardenne, 1978; Auler, 1994, 2009; Viana et al; 1998; Vieira, 2007). Na Formação Sete Lagoas se configuram os abrigos rochosos calcários da região (Araujo \& Neves, 2010). Nesta formação há o Membro Pedro Leopoldo com predomínio de calciossiltitos e sobre este o Membro Lagoa Santa com calciarenitos e veios de calcita e quartzo (Viana et al; 1998; Araujo \& Neves, 2010). Sobre esta está a Formação Serra de Santa Helena na qual há latossolos que são identificados nas partes superiores dos abrigos, onde há vegetação (Piló, 1998; 2000; Viana et al; 1998).

Os solos da região são Latossolo Vermelho-Escuro, Vermelho-Amarelo, Podzólico Vermelho-Escuro, Cambissolos e Glei Pouco Húmido (Shinzato \& Lumbreras, 1998). O relevo apresenta áreas planas com várzeas sujeitas a inundações e planaltos forte ondulados e ondulados com feições típicas como abrigos, cavernas, dolinas, uvalas, poljes, sumidouros, surgências e ressurgências (Auler, 1994, 2009; Shinzato \& Lumbreras, 1998; Patrus, 1998). A drenagem é constituída por águas de superfície e subterrâneas inter-relacionadas, assim como lagoas, inserido na sub-bacia do Rio das Velhas, que pertence à bacia do Rio São Francisco (Patrus, 1998).

O clima atual na região é quente e úmido, com regime pluviométrico tropical uma vez que é seco no inverno - maio a setembro - com concentração de chuvas no verão - novembro a janeiro (Auler, 1994; Patrus, 1998). Entre os anos 1961 a 1990 a temperatura média anual foi $21,4^{\circ} \mathrm{C}$, com o mês mais frio (julho) apresentando entre

\footnotetext{
${ }^{37}$ IBAMA/Decreto n ${ }^{\circ} 98.881$.
} 
$18,1^{\circ} \mathrm{C}$ e $12,5^{\circ} \mathrm{C}$; e o mês mais quente (março) com média de $23,2{ }^{\circ} \mathrm{C}$ e média das máximas de $29,3^{\circ} \mathrm{C}$ (Patrus, 1998).

Vegetação

A vegetação apresenta remanescentes de Cerrado e Mata Seca Semi-Decidual (Fig. 2) (Hermann et al; 1998). A área está drasticamente antropizada devido ao desmatamento para pecuária, agricultura, expansão urbana e a degradação de formações rochosas (grutas, por exemplo) pela mineração (Auler, 1994; Hermann et al; 1998).

Ao final do século XIX, o botânico dinamarquês Eugenius Warming coletou e documentou cerca de 2.593 espécies de plantas em Lagoa Santa (Warming, 1892; 1908). O estudo de Warming (1892; 1908) identificou táxons de Mata Seca SemiDecídua e Cerrado na região, embora hoje muitas áreas se encontrem antropizadas e desmatadas (Raczka, 2009).

Em estudo mais recente na APA foram identificadas 600 espécies vegetais de 95 famílias botânicas (Hermann et al; 1998). O Anexo I apresenta os táxons botânicos contemporâneos identificadas em Lagoa Santa. Esses incluem espécies de Mata Seca Semidecidual nas matas Lagoa da Cauaia (localidade do sítio Lapa do Santo), Lapinha, Castelo da Jaguara e Vargem Comprida; Mata Seca Decidual ${ }^{38}$ na Mata Poções e Mata da Horta; Transição mata-cerrado na Mata Infraero; Cerrado no Sumidouro, Império, Infraero e Promissão (Hermann et al; 1998).

A Mata Lagoa da Cauaia apresentou melhor estado de conservação, mas menor diversidade em relação a outras matas, devido a presença de espécies dominantes, como a Myracrodruon urundeuva (aroeira) (Hermann et al; 1998).

Na Lagoa dos Mares, no município de Lagoa Santa, se observou uma riqueza de espécies de macrófitas aquáticas - como Eicchornia azurea, Hydrocleis nymphoides e Nymphaea ampla - sendo a mais frequente a Salvinia herzogii que têm tomado ${ }^{39}$ cerca de 50\% da superfície da lagoa, em interação com Cyperus sp. (Reis \& Barbosa, 1993).

\footnotetext{
${ }^{38}$ Possui a mesma ocorrência da Floresta Estacional Semi-Decidual de Mata Atlântica, entre a zona úmida costeira e o semiárido, com duas estações bem marcadas, uma com aspecto de floresta na estação chuvosa e uma com perda de folhas das arbõreas na época seca, mas a "Decidual" perde mais de $50 \%$ das folhas das árvores, enquanto que a Semi-Decidual perde entre 20\% e 50\% (Hermann et al; 1998).

${ }^{39}$ Provavelmente devido à atividades antrópicas locais (Reis \& Barbosa, 1993).
} 
Na Lagoa Olhos D’água, no mesmo município, foi estudada a interação ecológica positiva entre Myzus persicae (Heteroptera, Aphidae), Samea multiplicalis (Lepidoptera, Pyralidae) e Salvinia molesta, que são fonte de alimento para herbívoros (Pelli \& Barbosa, 2011). Na área do município de Sete Lagoas, próximo mas exterior à área da APA, foram identificadas espécies vegetais de Cerrado, Mata seca, vegetação sobre rochas calcárias, mata pluvial e pasto (Tannús, 1996).

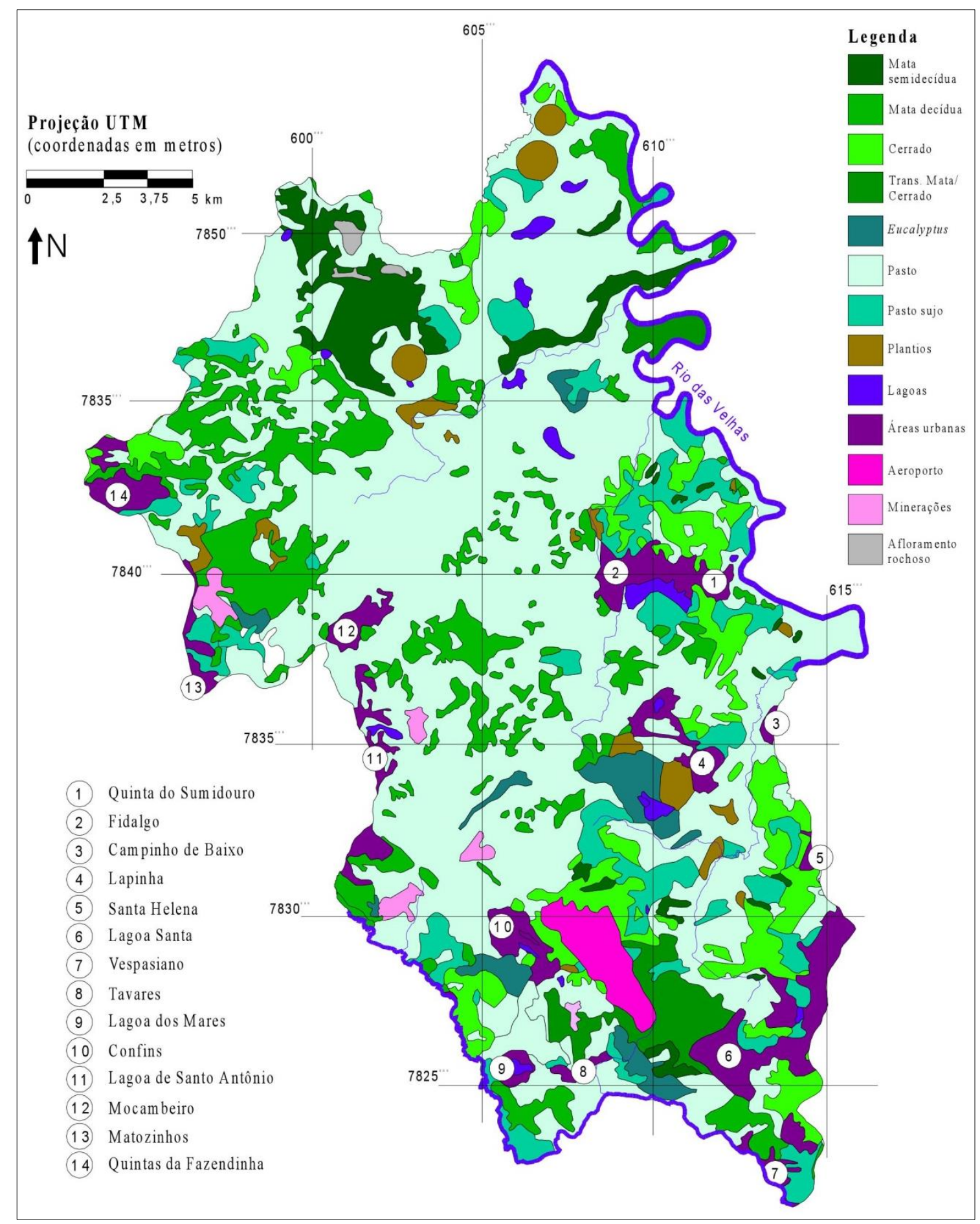


Figura 3. Mapa da vegetação atual na APA Carste de Lagoa Santa próximo ao sítio Lapa do Santo. Fonte: Hermann et al. (1998).

\subsubsection{Do Pleistoceno Tardio ao Holoceno}

No Pleistoceno Tardio havia baixas temperaturas e um clima semiárido mais seco que o atual no Brasil Central (Ferraz-Vicentini \& Salgado-Labouriau, 1996; Ledru et al; 1996; Barberi, 2001). Nesse período foi identificado em Lagoa Santa pólen de plantas arbóreas de floresta úmida e fria (Podocarpus e Araucaria) associadas a um gênero de árvore do cerrado (Caryocar), que sugerem a existência de um mosaico de floresta e savana com clima frio e úmido e temperaturas entre $5^{\circ} \mathrm{C}$ e $6{ }^{\circ} \mathrm{C}$ mais baixas que as atuais (Raczka, 2009). A identificação de Cyperaceae ao fim desse período indica aumento de umidade (Raczka, 2009).

Com a transição para o Holoceno Inicial (entre 10.000 e 7.000 anos A.P.), em Lagoa Santa teria ocorrido um acréscimo de umidade com o surgimento de lagoas, veredas com buritis (Mauritia), vegetação arbórea do cerrado e matas de galeria, junto com densas ocupações humanas (Ledru et al; 1996).

Entre 12.600 a 5500 anos A.P. foi detectado na região um aumento de pólen de Caryocar e de outras árvores do cerrado (como Bombax, Pseudobombax, Kielmeyera, Qualea, Vochysia e Stryphnodendron), assim como de florestas tropicais (como Daphnopsis, Protium, Rubiaceae e Roupala) (Raczka, 2009). A oscilação entre Asteraceae, Cyathea, Lycopodium e Zygnema (ocorrente em brejo) indica uma alta sazonalidade na região nesse período (Raczka, 2009).

No Holoceno Médio (entre 7000 e 4000 anos A.P.) o clima estaria mais seco que o atual em Lagoa Santa (Parizzi et al; 1998; Ledru et al; 1996; Behling, 2003; Meyer et al; 2014). Neste período haveria um clima sazonal e seria estabelecida uma vegetação de Cerrado, Mata Ciliar e Mata Seca Semidecidual e Decidual na região, que teriam permanecido similar e sem alterações significantes (Ledru et al; 1996; Freire, 2011).

Eventos de seca e baixa humidade durante o Holoceno Médio no Brasil Central teriam sido responsáveis por um abandono e deslocamento das populações humanas (Araujo et al; 2003). Essa hipótese é conhecida como o "Hiato do Arcaico" (Araujo et al; 2003; 2005). Em regiões como Lagoa Santa, um período de pouca pluviosidade seria 
suficiente para secar as lagoas, principais fontes de água para as populações humanas (Araujo et al; 2003).

Em contraponto, um estudo de fósseis de mamíferos do sítio paleontológico Cuvieri e do sítio arqueológico Lapa do Santo indica ausência de mudanças ambientais severas durante o Holoceno Inicial e Médio, com possibilidade de ter ocorrido um clima homogêneo na região e com aumento da umidade a partir do Holoceno Médio (Perez, 2009). Um estudo de folhas fósseis de cerrado do Holoceno Médio do sítio paleontológico RMT-1, em Lagoa Santa, indicou que o clima nesse período deveria ser sazonal ao invés de ter passado por um uma seca severa como sugere a hipótese do Hiato do Arcaico (Nakamura, 2011). Autores sustentam a ocorrência de oscilações climáticas durante o Holoceno Médio em Lagoa Santa, mas elementos polínicos identificados não seriam característicos de clima seco (Raczka, 2009; Raczka, 2013). Em concordância com um período de instabilidade climática e não uma grande seca, um estudo no abrigo do Sumidouro identificou períodos de erosão e sedimentação que indicariam instabilidade e períodos de pedogênese que indicariam estabilidade (Araujo et al; 2013).

No Holoceno Tardio (entre 4000 anos A.P. até os dias atuais) teria ocorrido aumento na umidade em Lagoa Santa (Ledru et al; 1996; Freire, 2011). Entre 5500 A.P e 3000 anos A.P. dados de palinologia indicam aumento de Melastomataceae, Moraceae, redução de Caryocar e Zygnema, que indicariam um clima mais úmido (Raczka, 2009). Entre o período de 3000 A.P e 500 anos A.P. em Lagoa Santa foi identificado pólen de plantas arbóreas como Arecaceae (alguns similares a Acrocomia), Ilex, Melastomataceae e Myrtaceae e plantas herbáceas de Asteraceae, Poaceae e Cyperaceae (Raczka, 2009). A partir de 2000 anos A.P; pólen identificado em Lagoa Santa indica a presença de táxons botânicos como Asteraceae, Poaceae, Apocynaceae, Arecaceae, Melastomataceae, Alchornea, Cecropia, Ficus, Mimosa, Peixotoa e Sebastiana (Raczka, 2009).

Conforme estudo de palinologia na lagoa que nomeia a região, Lagoa Santa, entre 6100 a 5400 anos A.P. esporos de Lycopodium e algas indicam um aumento de umidade (Parizzi et al; 1998). Ao final do Holoceno Médio, entre 5400 e 4600 anos A.P., pólen, esporos e algas (Gramineae/hoje Poaceae, Compositae/hoje Asteraceae e Portulacaceae) indicam a presença de um pântano intermitente e um clima mais seco 
que o atual (Parizzi et al; 1998). Em amostra datada de 4600 anos A.P. o pólen é abundante, principalmente de origem arbórea, além de que os esporos de Lycopodium são substituídos pelos de samambaia de ambiente úmido (Parizzi et al; 1998). Isso indica que o pântano foi substituído pela lagoa permanente e se formou um mosaico de florestas e Cerrado ao redor, com clima quente e semi-húmido similar ao do presente (Parizzi et al; 1998).

Análises polínicas e de carvão da Lagoa Nova, ao nordeste de Minas Gerais, sugerem a existência de cerrado entre 10.170 e 8560 anos A.P. e entre 7560 e 6060 anos A.P. na região (Behling, 2003). A precipitação anual seria menor e a época de seca dois meses mais extensa que hoje em dia (Behling, 2003). Incêndios naturais seriam frequentes e a área de cerrado seria mais ampla do que atualmente (Behling, 2003). O cerrado atual do Centro-Oeste brasileiro seria resquício desse passado do Holoceno Inicial (Behling, 2003). Entre 8560 e 7560 anos A.P. haveria em Lagoa Nova uma fase úmida com expansão de floresta de galeria (Behling, 2003). No Holoceno Tardio ainda haveria remanescentes de cerrado e somente a partir de 600 anos A.P. e com maior umidade na região, se desenvolveria a Mata Seca Semi-Decídua presente hoje (Behling, 2003).

Estudos no Ribeirão da Mata sugerem que a vegetação do passado holocênico seja similar à atual na região, com mata e cerrado (ver Freire, 2011; Nakamura, 2011) (Bernardo et al; 2016). Também é possível que o Holoceno Médio e Tardio apresentassem assembleias florísticas similares (Freire, 2011; Raczka, 2009). Entretanto, outros pesquisadores defendem que mudanças no passado teriam alterado a configuração da vegetação nessa macrorregião (ver De Oliveira, 1992; De Oliveira et al; 1999) (Bernardo et al; 2016). A tabela abaixo (Tabela 1) apresenta a relação de táxons botânicos identificados no Pleistoceno Tardio e Holoceno Inicial, Médio e Tardio, segundo cada autor em cada período especificado.

Tabela 1.Táxons Botânicos em Lagoa Santa no passado

\begin{tabular}{|c|l|}
\hline & Podocarpus \\
Pleistoceno & Myrsine \\
Tardio & Araucaria \\
& Caryocar \\
& Cyperaceae \\
& (Raczka, 2009) \\
\hline
\end{tabular}




\begin{tabular}{|c|c|}
\hline & $\begin{array}{l}\text { Entre } 12.000 \text { e } 5500 \text { anos A.P. } \\
\text { (Pleistoceno Tardio, Holoceno Inicial e Médio) } \\
\text { Cerrado: } \\
\text { Caryocar } \\
\text { Bombax } \\
\text { Pseudobombax } \\
\text { Pseudobombax } \\
\text { Qualea } \\
\text { Vochysia } \\
\text { Floresta tropical: } \\
\text { Daphnopsis } \\
\text { Protium } \\
\text { Rubiaceae e } \\
\text { Roupala } \\
\text { Brejos ou pântanos: } \\
\text { Asteraceae, } \\
\text { Cyathea, } \\
\text { Lycopodium } \\
\text { Zygnema } \\
\text { (Raczka, 2009) }\end{array}$ \\
\hline Holoceno Inicial & $\begin{array}{l}\text { Mauritia (Ledru et al; 1996) } \\
\text { Myrsine } \\
\text { Araucaria } \\
\text { Cyathea } \\
\text { Lycopodium } \\
\text { (Raczka, 2009) }\end{array}$ \\
\hline Holoceno Médio & $\begin{array}{l}\text { Nectandra cf. leucantha (Lauraceae) } \\
\text { Byrsonima sp. (Malpighiaceae, cf. Malpighiaceae), } \\
\text { Prunus myrtifolia (Rosaceae) } \\
\text { Celtis cf. pubescens (Cannabaceae) } \\
\text { Matayba cf. guianensis (Sapindaceae) } \\
\text { Cupania vernalis (Sapindaceae) } \\
\text { Allophylus cf. petiolulatus (Sapindaceae) } \\
\text { Platypodium cf. elegans (Leguminosae - Papilionoideae) } \\
\text { cf. Erythroxylum sp. (Erythroxylaceae) } \\
\text { cf. Tachigali aurea (Leguminosae - Caesalpinioideae) } \\
\text { Dalbergia sp. (Leguminosae - Papilionoideae) } \\
\text { cf. Abutilon sp. (Malvaceae) } \\
\text { Machaerium cf. hirtum (Leguminosae - Mimosoideae) } \\
\text { cf. Andira sp. (Leguminosae - Papilionoideae) } \\
\text { cf. Antonia sp. (Loganiaceae) } \\
\text { Callisthene cf. major (Vochysiaceae) } \\
\text { cf. Calophylum sp. (Clusiaceae) } \\
\text { Cassia cf. ferriginea (Leguminosae - Caesalpinioideae), } \\
\text { cf. Enterolobium sp. (Leguminosae - Mimosoideae), } \\
\text { cf. Jacaranda sp. (Bignoniaceae) }\end{array}$ \\
\hline
\end{tabular}




\begin{tabular}{|c|c|}
\hline & $\begin{array}{l}\text { Pera } \text { cf. glabratal/obovata (Euphorbiaceae) } \\
\text { Senna cf. macranthera (Leguminosae - Caesalpinioideae) } \\
\text { Stryphnodendron cf. adstringes (Leguminosae - Mimosoideae) } \\
\text { Swartzia cf. acutifolia (Leguminosae - Papilionoideae) Tapirira } \\
\text { sp. (Anacardiaceae) } \\
\text { Trichillia pallida (Meliaceae) } \\
\text { Sapindaceae, cf. Urticaceae } \\
\text { cf. Euphorbiaceae } \\
\text { (Nakamura, 2011) } \\
\text { Entre } 6100 \text { e } 5400 \text { anos A.P. } \\
\text { Poaceae } \\
\text { Asteraceae } \\
\text { Portulacaceae } \\
\text { (Parizzi } \text { et al; } 1998 \text { ) }\end{array}$ \\
\hline Holoceno Tardio & $\begin{array}{l}\text { Entre } 5500 \text { e } 3000 \text { anos A.P. } \\
\text { Melastomataceae, } \\
\text { Moraceae, } \\
\text { Caryocar } \\
\text { Zygnema } \\
\text { (Raczka, 2009) } \\
\text { Entre anos } 3000 \text { e } 500 \text { anos A.P. } \\
\text { Arecaceae } \\
\text { Melastomataceae } \\
\text { Myrtaceae } \\
\text { Asteraceae } \\
\text { Poaceae } \\
\text { Cyperaceae } \\
\text { Acrocomia Ilex } \\
\text { (Raczka, 2009) } \\
\text { De 2000 anos A.P. em diante } \\
\text { Arecaceae } \\
\text { Melastomataceae } \\
\text { Apocynaceae } \\
\text { Alchornea } \\
\text { Cecropia, Ficus } \\
\text { Mimosa } \\
\text { Peixotoa } \\
\text { Sebastiana } \\
\text { (Raczka, 2009). }\end{array}$ \\
\hline
\end{tabular}




\section{MICROVESTÍGIOS BOTÂNICOS}

Os microvestígios de origem botânica podem ser fitólitos, amido, pólen, dentre outros. A Microarqueobotânica é a área de estudo dos mesmos quando encontrados em contexto arqueológico (Scheel-Ybert, 2016). Esses microvestígios podem se preservar por milhares de anos, tanto em sedimentos quanto em artefatos (Barton \& Mathews, 2006).

\subsection{Fitólitos}

Fitólitos ${ }^{40}$ são corpos de sílica formados no tecido das plantas, que, ao absorver água, também adquirem sílica e outros sais minerais do susbtrato (Piperno, 1998; Piperno, 2006). A sílica pode ser depositada em estruturas intracelulares e extracelulares das plantas, formando os fitólitos (Piperno, 1998; Piperno, 2006; Pearsall, 2015). Os fitólitos estão presentes em caules, folhas, raízes e demais partes das plantas (Piperno, 1998; Piperno, 2006; Pearsall, 2015).

Dessa maneira, como alguns fitólitos são depositados nas células das plantas, podem ser formados com as formas de células específicas de plantas, que são diferentes entre alguns táxons e por isso eles podem ser diagnósticos de gêneros de plantas e em alguns casos até mesmo espécies (Piperno, 2006). Piperno (2006:7) apresenta uma tabela com a relação das inúmeras famílias de plantas que produzem morfotipos específicos de fitólitos e suas atribuições taxonômicas.

Após a decomposição das plantas, como partículas inorgânicas, os fitólitos ficam depositados no substrato (Piperno, 2006; Pearsall, 2015). Madella \& Lancelotti (2012) definem três processos tafonômicos que ocorrem no contexto cultural e arqueológico com os fitólitos. O primeiro seria a necrólise, quando ocorre a desagregação e decomposição da planta morta (Madella \& Lancelotti, 2012). O segundo é a bioestratinomia e se refere aos processos pós-deposicionais após a morte da planta mas anteriores ao enterramento do fitólito (Madella \& Lancelotti, 2012). O terceiro é a diagênese fóssil, após o enterramento, com os efeitos cumulativos de processos físicos, químicos e biológicos, como a bioturbação, que podem alterar ou destruir o registro fitolítico (Madella \& Lancelotti, 2012).

\footnotetext{
${ }^{40}$ O termo "fitólito" tem origem na língua grega e significa "pedra de planta" (Piperno, 1988:11).
} 
Contudo, é importante ter em conta que plantas produzem mais fitólitos que outras, assim como há plantas que não produzem fitólitos, como aróides (Arecacea), Amaranthaceae, Chenopodiaceae, cará (Dioscorea sp.), árvores de várias famílias e a maioria das cactáceas (Piperno, 2006). Portanto, a ausência dessas plantas no registro arqueológico não implica necessariamente que não estiveram no contexto cultural no passado (Piperno, 1998; Piperno, 2006).

\section{Métodos de análise em fitólitos das cruzes associados à Zea mays (milho)}

Os fitólitos cujo morfotipo é cross (cruz) são produzidos pelas Poaceas e algumas delas podem ser diagnósticas das folhas de Zea mays (Pearsall e Piperno, 1990). A análise de fitólitos em amostras de sedimento de sítios no Equador, região de Real Alto e Província de Santa Elena, demonstrou que o tamanho do morfotipo de cruzes poderia indicar a presença de milho (domesticado) (Pearsall, 1978). O estudo utilizou como material comparativo folhas de nove raças de milho e dez gêneros de gramíneas selvagens (Pearsall, 1978). O tamanho das cruzes foi classificado da seguinte forma: as extra grandes com largura entre $20.61 \mu \mathrm{m}$ e $25.19 \mu \mathrm{m}$; as grandes com largura entre $16.03 \mu \mathrm{m}$ e $20.56 \mu \mathrm{m}$; as medianas com largura entre $11.45 \mu \mathrm{m}$ e $15.98 \mu \mathrm{m}$; as pequenas com largura entre $6.87 \mu \mathrm{m}$ e $11.40 \mu \mathrm{m}$ (Pearsall, 1978; Pearsall, 1984). Foi constatado que o milho poderia ser distinguido por produzir cruzes grandes e extra grandes, que não ocorrem em gramíneas selvagens, que produzem cruzes pequenas e medianas (Pearsall, 1978). Dessa maneira foi identificado milho há pelo menos 4450 A.P na região (Pearsall, 1978).

Um próximo estudo dos fitóltitos em cruzes, realizado no Panamá, analisou além do tamanho a morfologia tridimensional dos mesmos e reforçou a possibilidade de diferenciação entre milho e gramíneas selvagens inclusive teosinto - um ancestral do milho domesticado (Piperno, 1984). Para a aprimoração do método, se analisou amostras contemporâneas de 20 raças de milho, 4 raças de teosinto anual, 2 espécies de teosinto perene e 40 gramíneas de Panicoideae e Bambusoideae (Piperno, 1984). Foram definidas oito variantes de cruzes com base na sua morfologia tridimensional, sendo a 
do milho a variante $1^{41}$ característica do milho, as variantes 2 e 6 características de teosinto, as variantes 3, 8 e 10 características de Bambusoideae e na variante 5 estão as gramíneas exceto milho (Piperno, 1984, Piperno, 2006). O método foi aplicado a amostras de sedimento de quatro sítios arqueológicos no Panamá e se constatou a presença de milho há 2500 anos A.P; o que foi corroborado com estudos polínicos existentes (Piperno, 1984).

Para a formalização do método de identificação das cruzes de milho, foi aplicada uma abordagem estatística existente denominada "Função Discriminante" Starczak, 1985; Piperno, 1988). A estatística foi aplicada 36 especies de Panicoideae, entre raças de milho e gramíneas selvagens contemporâneas do Panamá e em resultado o milho e as gramíneas selvagens foram separados em dois grupos (Piperno, 1988). Se observou que nenhuma gramínea selvagem produz cruzes grandes e extra grandes nem quantidades significativas de variante 1 (Piperno, 1988; Pearsall \& Piperno, 1990). Além disso, nenhuma cruz variante 1 que excedesse $20.5 \mu \mathrm{m}$ (extra grande) foi identificada em gramíneas selvagens, enquanto que elas ocorrem em muitas raças de milho (Piperno, 1988; Pearsall \& Piperno, 1990). A função discriminante foi aplicada a amostras de sedimento de sítios arqueológicos no Panamá e se constatou que as frequências de fitólitos sugerem grandes diferenças no uso de plantas e cultivo nos abrigos rochosos (Piperno, 1988). Isso estaria relacionado à diferenças na confiuguração ecológica dos sítios, nas práticas de subsistência, sazonalidade de ocupação e especialização funcional do uso das plantas (Piperno, 1988).

As análises das cruzes com seu tamanho, morfologia tridimensional e função discriminante foi aplicada a sedimento de sítios arqueológicos no Equador - sítios da Tradição Las Vegas (pré-cerâmica com ocupações de 10.000 a 6600 anos A.P.) na península de Santa Elena e o sítios Real Alto (cerâmico, tradição Valdivia, desde 5200 a 3500 anos A.P.). O milho foi identificado em ambos os contextos e já estava presente há pelo menos 7000 A.P. (Pearsall \& Piperno, 1990).

O método de Piperno e Pearsall (1998, 1990) para identificação de milho por meio dos fitólitos em cruzes foi aplicado no Uruguai a plantas contemporâneas - 35

\footnotetext{
${ }^{41}$ Ambos os lados da Cruz Variante 1 possuem a mesma forma e são imagens refletidas (mirror image) um do outro (Piperno, 1984).

${ }^{42}$ Fisher's Linear Discriminant Function Analysis (Piperno \& Starczak, 1985).
} 
gramíneas de Panicoideae, cinco Oryzoideae e uma Bambusoideae - e a 9 amostras de sedimento modernas (Iriarte, 2003). Em resultado as gramíneas selvagens não apresentaram cruzes extra grandes maiores que $20.60 \mu \mathrm{m}$ de largura, dessa forma o autor confirma que a presença de cruzes extra grandes seria suficiente para provar a presença de milho em um contexto arqueológico (Iriarte, 2003: 1092). Segundo o autor, muitas gramíneas selvagens produzem variante 1 também como o milho, mas só o milho produz as cruzes grandes e extra grandes (Iriarte, 2003). As gramíneas estudadas apresentaram também grande quantidade (39\%) de cruzes variantes 5 e 6 (Iriarte, 2003). O milho não foi detectado nas amostras de sedimento modernas (Iriarte, 2003).

A análise das cruzes e função discriminante também foram aplicadas a sítios arqueológicos de campos de cultivo (camellones) em Llanos de Moxos, na Bolívia (Dickau et al; 2016). A construção de alguns campos ocorreu por volta de 2400 anos A.P. e outros em 570 A.D. A função discriminante não foi aplicada a amostras com menos de 20 cruzes (Iriarte, 2003). Em resultado foi detectado o milho como um dos cultivos presentes, antes da construção dos campos a vegetação era savana com plameiras e o declínio nas frequências de fitólitos de plantas arbóreas indica a transformação humana na paisagem (Iriarte, 2003).

\subsection{Grãos de Amido}

O amido está presente principalmente em partes comestíveis das plantas - os órgãos de reserva de energia - como sementes, frutas, raízes, tubérculos e caules, por isso seu estudo tem um potencial informativo sobre a dieta (Robyt, 2001; Torrence, 2006b). O amido compreende $65 \%$ da fonte de calorias na dieta humana e está presente em vegetais, frutos e cereais utilizados na alimentação (Robyt, 2001).

As raízes fixam as plantas e absorvem água e minerais do meio, as raízes tuberosas são ideais para a dieta, pois, possuem reserva de energia em forma de amido, são exemplos: batata-doce, mandioca e beterraba (Raven, 2014). Caules subterrâneos também podem apresentar essa reserva de energia, são os tubérculos, como a batatainglesa (Raven, 2014). 
O amido é produzido na célula vegetal com a fotossíntese (Robyt, 2001). Dentro do cloroplasto, a energia do Sol faz com que a molécula de água se fragmente em hidrogênio e oxigênio (Robyt, 2001; Gott et al; 2006). A combinação do hidrogênio com o dióxido de carbono absorvido forma a glicose - açúcar simples (Gott et al; 2006). Transportada para o amiloplasto, a glicose é polimerizada e são produzidas a amilose e a amilopectina, que são os componentes que formam um grão de amido (Gott et al; 2006; Pearsall, 2015). Caso necessário, o amido é convertido em açúcar e transferido para a parte da planta onde é requisitado (Gott et al; 2006).

Em um grão de amido a taxa de amilose e amilopectina, que depende de fatores genéticos e ambientais, influencia na sua morfologia e propriedades físicas, como a gelatinização - processo no qual há a quebra da estrutura do grão, quando exposto a temperatura superior a $50^{\circ}$ ou devido a reações químicas (Gott et al; 2006; Pearsall, 2015).

A formação de um grão de amido inicia no hilo, um ponto central de onde são formadas camadas adicionais e sucessivas - as lamelas (Loy, 1994). Com o crescimento do grão, a quantidade de amilose pode aumentar (Gott et al; 2006). A caracterização da forma do grão, a localização e região do hilo, dentre outros aspectos, podem ser diagnósticos de táxons de plantas (Loy, 1994).

$\mathrm{O}$ amido possui birrefringência, que é a propriedade na qual alguns objetos afetam a direção e velocidade da luz polarizada (Gott et al; 2006). Portanto, quando exposto a luz polarizada cruzada em microscópio, o grão de amido exibe uma cruz negra chamada cruz de interferência, enquanto que as outras partes ficam com aspecto brilhante (Loy, 1994; Gott et al; 2006).
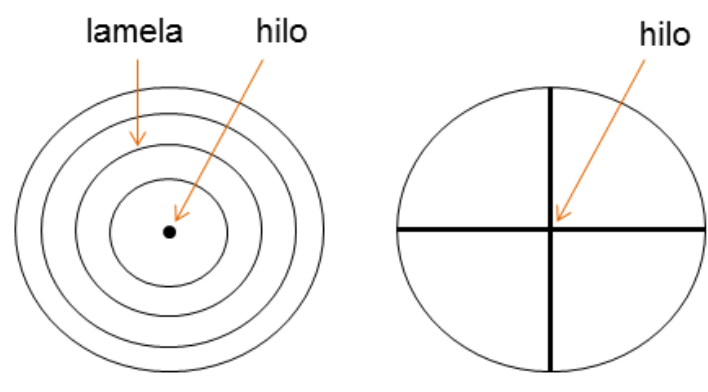

cruz de inteferência

Figura 8. Características básicas de um grão de amido. Adaptado de Fiona Roberts (Gott et al; 2006:40). 
Essas características morfológicas podem ser diagnósticas de grãos de amido nativos, que são aqueles que não possuem alterações estruturais (Samuel, 2006). Já os grãos modificados ou danificados apresentam modificações em sua estrutura causadas por processos físicos e químicos, como a mencionada gelatinização, e podem não exibir um aspecto definido nem apresentar birrefringência (Samuel, 2006; Babot, 2003; 2006; Crowther, 2012). Os grãos de amido danificados podem ser indicativos de processos de preparação de alimentos, como o cozimento (Samuel, 2006; Babot, 2003; 2006; Crowther, 2012).

\subsection{Breve Histórico e Potencial dos Estudos de Amido e Fitólitos}

As primeiras ilustrações publicadas de grãos de amido são da primeira metade do século XVIII, de autoria de Anton Leewenhoek, construtor de microscópios (Pearsall, 2015). Mais de um século depois, Julius Fritzsche foi o primeiro a considerar a forma dos grãos de amido como um elemento importante na sua identificação (Pearsall, 2015). Na metade do século XIX, Matthias Schleiden fez a primeira chave taxonômica de classificação de amido tendo identificado 22 tipos, que foram alguns anos depois revistos em somente 17 tipos por Carl Nägeli, que aprimorou a classificação (Piperno, 1988).

Ao fim do século XIX, Julius L. Meyer propôs uma classificação baseada na formação dos grãos de amido, que não alcançou a popularidade da de Nägeli que era mais facilmente aplicável (Pearsall, 2015). Em 1905 John Muter acrescenta a importância do uso de luz polarizada em sua identificação e caracteriza grãos de grandes grupos de plantas: batata, legume, trigo, sagu e arroz (Pearsall, 2015). No ano seguinte, Andrew L. Winton e Kate G. B. Winton produziram uma tipologia de amido com base na forma dos grãos, que mesmo possuindo inúmeras variações, poderiam ser agrupados em categorias gerais (Winton \& Winton, 1932). Nas décadas seguintes tiveram importantes contribuições na temática de microscopia de alimentos vegetais (Winton \& Winton, 1945; 1981).

Na primeira década do século XX, Henry Kraemer passou a considerar não somente a forma, mas também o tamanho e a textura dos grãos de amido (Piperno, 
1988). Mas o trabalho mais reconhecido em taxonomia do amido veio em 1913 com Edward T. Reichert, com uma descrição detalhada e muitas fotos de amido de mais 350 espécies de plantas selvagens e cultivadas (Pearsall, 2015). O estudo de Reichert foi reorganizado em 1930 por James B. McNair, de maneira a tornar a aplicação desse estudo mais acessível, possibilitando o uso desse trabalho para a distinção do amido de diferentes espécies e gênero (Pearsall, 2015).

Os fitólitos foram inicialmente observados em plantas em 1835 por Struve, botânico alemão. Seu conterrâneo, Christian G. Ehrenberg foi o primeiro a desenvolver um sistema de classificação para fitólitos em 1854, com o qual ele reconheceu 12 tipos de fitólitos, alguns dos quais haviam sido enviados a ele por Darwin para análise, como uma "poeira" nos instrumentos de laboratório (Piperno, 1988). Ainda no século XIX, outros cientistas como William Gregory (1855) e Franz J. Ruprecht (1866) identificaram a ocorrência de fitólitos em plantas e solo. Anton DeBary em 1887 publicou um guia de pesquisa sobre a silicificação de fitólitos, trabalho incrementado por Fritz Netolitzky em 1929 (Piperno, 1988). As publicações sobre fitólitos estavam limitadas à língua alemã e com a Segunda Guerra Mundial, as pesquisas botânicas paralisaram (Piperno, 1988).

Fitólitos e amido de contextos arqueológicos podem ser considerados como uma cultura material, por mais que sejam produtos da natureza, eles passaram por uma seleção ou escolha cultural que envolve um universo simbólico (Madella \& Lancelotti, 2012). Os fitólitos e amido encontrados em um contexto arqueológico podem estar incluídos em atividades humanas e cadeias operatórias que envolvem o uso de plantas na dieta, usos farmacêuticos, como material construtivo, ornamental, dentre outros. Também envolve desde a concepção e produção de um instrumento lítico (com escolhas técnicas do objetivo da forma de que necessita para o fim idealizado, matéria prima, suporte, tecnologia de lascamento etc.), seu uso para processar plantas (aquelas de interesse cultural) e o seu descarte.

Em contextos arqueológicos, é possível que Ludwig Wittmack tenha sido o primeiro a identificar amido, no início do século $\mathrm{XX}$, em fornos antigos no Peru e também identificou amido com iodo no que seria um fragmento de pão de um túmulo do Egito Antigo (Pearsall, 2015). Em 1961, a arqueóloga americana Margaret E. A. 
Towle, identificou e publicou desenhos de grãos de amido enquanto estudava macrorrestos vegetais arqueológicos do Peru (Pearsall, 2015).

Na década de 1930, Harry Godwin aplicou análises de pólen à arqueologia na Inglaterra (Trigger, 2004). Métodos sobre análise de pólen publicados em 1964 por Iversen \& Faegri motivaram as aplicações em contextos arqueológicos. O estudo de grãos de pólen e esporos está fortemente relacionado à reconstrução de ambientes do passado - vegetação e clima - e à detecção de atividades humanas (Dimbleby, 1967; Pearsall, 2015).

Mas os primeiros estudos de microvestígios em artefatos arqueológicos foram realizados por Briuer (1976), em líticos de um abrigo nos Estados Unidos, nos quais foram identificados tecidos de plantas microscópicos. Em 1978 o livro Plants and Archaeology de Geoffrey W. Dimbleby se torna referência para a arqueobotânica, mas ainda não incluiria o amido como elemento de análise. Em 1979 Harry J. Shaffer e Richard G. Holloway estudaram resíduos orgânicos visíveis de 11 líticos do Texas. Eles encontraram fibras de plantas, amido, fitólitos e pêlos, tendo interpretado as evidências como materiais processados no uso dos instrumentos (Pearsall, 2015).

A partir da década de 1980, Thomas Loy e Richard Fullagar, na Austrália, impulsionaram as pesquisas sobre diversos tipos de microvestígios arqueológicos minerais (e.g. ocre), animais (e.g. pelos) e botânicos (pólen, fitólitos e amido), com o objetivo de compreender o uso dos artefatos e as atividades realizadas nos sítios (Loy, 1994; Lombard \& Wadley, 2009; Fullagar, 2009; Pearsall, 2015).

Apesar de conhecidos desde o início do século XX, a identificação de grãos de amido em artefatos arqueológicos acontece a partir da década de 1980, com base no conhecimento de que a sua morfologia poderia indicar identidades taxonômicas de plantas específicas (ver Banks \& Greenwood, 1975; Czaja, 1978).

Em 1981, Donald Ugent, Thomas e Sheila Pozorski demonstraram que o amido seria útil para ajudar a identificar macrovestígios fragmentados (Pearsall, 2015). A partir da década de 1980, Thomas Loy e Richard Fullagar, na Austrália, impulsionaram as pesquisas sobre diversos tipos de microvestígios arqueológicos minerais (e.g. ocre), animais (e.g. pelos) e botânicos (pólen, fitólitos e amido), com o objetivo de 
compreender o uso dos artefatos e as atividades realizadas nos sítios (Loy, 1994; Lombard \& Wadley, 2009; Fullagar, 2009; Pearsall, 2015).

No Brasil, um dos primeiros estudos de amido em contexto arqueológico consiste em uma análise realizada em macrovestígios de milho (Zea mays) e de mandioca (Manihot esculenta) dos sítios Lapa do Boquete e Lapa da Hora, no Vale no Peruaçu, em Minas Gerais, em contextos que datam entre 1010 e 570 anos A.P. (Freitas, 2004). O estudo dos grãos obteve a confirmação de que os macrovestígios se tratassem de milho e de mandioca.

Também pioneiro em microvestígios botânicos de fitólitos e amido foi o estudo realizado em cálculo dentário de indivíduos recuperados em sambaquis do litoral norte de Santa Catarina (Wesolowski, 2007; Wesolowski et. al, 2007; Wesolowski et al; 2010). Os sítios analisados são o Sambaqui Morro do Ouro (datado de $4030 \pm 40$ anos A.P.), Sambaqui Forte Marechal Luz (datado entre $1110 \pm 100$ e $850 \pm 100$ anos A.P.), e os sítios cerâmicos Sambaqui Enseada 1 (datado de $1390 \pm 40$ anos A.P.) e Itacoara (datado em $550 \pm 55$ anos A.P.) (Wesolowski et. al, 2007). Os resultados indicaram a presença de fitólitos de Poaceae e alguns semelhantes a Arecaceae e Araucaria angustifolia (pinhão); assim como grãos de amido possivelmente de milho, batata-doce, Arecaceae e Dioscorea sp; dentre outros não identificados (Wesolowski et. al, 2007). No sítio Morro do Ouro se observou que a presença de maiores prevalências e frequências de cáries dentais com menor variabilidade de grãos de amido e fitólitos no cálculo, indicam um foco no consumo de poucas espécies de plantas, comportamento indicativo de horticultura (Wesolowski et. al, 2007). Nos sítios Forte Marechal Luz, Enseada 1 e Itacoara foi observada maior variabilidade de morfologias de amido e fitólitos no cálculo, com menores frequências e prevalências de cáries, sugerindo ênfase no consumo de plantas coletadas (Wesolowski et. al, 2007). Em ambos os grupos sem cerâmica e com cerâmica foi identificado o consumo de plantas amiláceas e a menor diversidade de fontes de carboidrato à dieta estaria relacionada a uma maior ocorrência de cáries (Wesolowski et. al, 2007).

Um outro estudo de microvestígios botânicos em cálculo dentário humano foi realizado no sambaqui Jabuticabeira II, em Santa Catarina, datado entre $2880 \pm 75$ e $1805 \pm 65$ anos A.P.; e no sambaqui Moraes, em São Paulo, com sepultamentos humanos datados entre $5895 \pm 45$ e $4511 \pm 32$ anos A.P. (Boyadjian, 2007). Ambos os 
sítios apresentaram evidências do consumo de plantas amiláceas, como Dioscorea sp. (cará), Araceae (taioba) e Ipomoea batatas (batata-doce), sem distinções desse consumo entre os sexos dos indivíduos (Boyadjian, 2007).

Um próximo estudo focou na identificação de microvestíigios botânicos de cálculo dentário do sambaqui Jabuticabeira II (Boyadjian, 2012; Boyadjian et al; 2016). Os resultados identificaram grãos de amido que podem ser de Dioscorea sp; Arecaceae (inhame e taioba), batata-doce (Ipomoea batatas), Myrtaceae (possivelmente pitanga) e milho (Zea mays), assim como fitólitos que podem ser de Calathea sp. e Poaceae (Boyadjian, 2012; Boyadjian et al; 2016). O estudo indica que tais plantas fariam parte da dieta do grupo sambaquieiro, e que plantas domesticadas como o milho podem sugerir o seu cultivo ou também trocas com outros grupos do interior (Boyadjian, 2012; Boyadjian et al; 2016). A identificação de grãos de amido danificados podem sugerir que os alimentos eram moídos ou macerados com artefatos líticos polidos existentes no contexto, assim como há sinais de que alguns grãos teriam sido processados em decorrência da produção de farinha (Boyadjian, 2012; Boyadjian et al; 2016).

Na Amazônia, no sítio Hatahara, foram realizadas análises de microvestígios botânicos em fragmentos cerâmicos e uma laterita (Cascon, 2010; Caromano et al; 2013). Foram identificados fitólitos de palmeiras dos gêneros Astrocaryum, Attalea, Bactris, Euterpe, Mauritia, e Oenocarpus; de Cyperaceae e possivelmente de milho (Zea mays) (Cascon, 2010; Caromano et al; 2013). Os grãos de amido identificados podem ser de Dioscorea sp. e de milho (Cascon, 2010; Caromano et al; 2013). Se observou que os vasilhames cerâmicos seriam multifuncionais e utilizados para processar as plantas, algumas com potencial para terem sido consumidas na dieta (Cascon, 2010; Caromano et al; 2013).

Um estudo com abordagem etnoarqueológica com a etnia indígena Asurini do Rio Xingu, aplicou análises de microvestígios botânicos ao processamento de mandioca (Manihot esculenta Crantz) (Cascon, 2017). O estudo identificou diferentes tipos de danificações causadas nos grãos de amido referentes à diferentes etapas da produção de farinha e outros produtos feitos com mandioca (Cascon, 2017). Em alimentos produzidos com mandioca e em pilão utilizado para processá-la, foram identificados fitólitos de outras plantas, como de árvores dicotiledôneas, de Arecaceae, Clusiaceae, Cyperaceae, Marantaceae, Poaceae e Zingiberaceae (Cascon, 2017). Amostras de 
sedimento de fogueira relacionada a atividades alimentares também foram analisadas e se encontrou grãos de amido e fitólitos de árvores dicotiledôneas e Arecaceae, dentre outros (Cascon, 2017).

O estudo de fitólitos, dentre outras análises, foram realizadas em sedimentos dos geoglifos Tequinho e Sol de Maio, no Acre, além de demais amostras de sedimento da região (Watling, 2014). O sítio Tequinho está datado entre e 572-666 A.D. e 25-129 A.D. e o sítio Sol de Maio datado do período de 1300 A.D. (Watling et al; 2016). Nos sítios arqueológicos, foram identificados táxons de plantas como Heliconia, Strelitziaceae, Annonaceae, milho e Cucurbita sp. (abóboras).

Em continuidade, próximos estudos incluíram, além desses dois sítios, os geoglifos Fazenda Iquiri II (datado em AD 1400-1600 A.D.), Campo Esperança (ocupado há 1400 A.D.), El Círculo (datado entre 1270 cal AD. e 1400 cal AD), Las Palmeras (datado entre 1507-1799 A.D. e 116-340 cal A.D.), Chacra Telería (datado em 21-222 cal. A.D.) e Tumichuchua (datado cal. 200 A.C. e 192 A.D.) (Watling et al; 2015; Watling et al; 2016; Watling et al; 2016b). As análises de fitólitos foram realizadas em amostras de artefatos líticos relacionados a moagem, vasilhames cerâmicos e sedimento (Watling et al; 2015; Watling et al; 2016). Por meio da análise de amostras de referência do presente na região, esses estudos também conseguiram identificar que determinados conjuntos fitolíticos são representativos de diferentes tipos de floresta (Watling, 2014; Watling et al; 2015; Watling et al; 2016). Os sítios estariam inseridos em áreas já alteradas por atividades humanas e a vegetação no passado seria constituída por floresta de bambu e por palmeiras manejadas; sendo a estratégia de subsistência dos grupos constituída por plantas selvagens e domesticadas, como milho, abóboras e palmeiras (Watling, 2014; Watling et al; 2015; Watling et al; 2016; Watling et al; 2016b).

Ainda no contexto amazônico, no sítio Teotônio, ocupado de 9000 a 5000 anos cal. A.P; foram encontrados amido e fitólitos de sedimentos e instrumentos líticos pequenas lascas (cerca de $9 \mathrm{~mm}$ de comprimento) e núcleos em quartzo hialino e leitoso (Watling et al; 2018). Os táxons de plantas identificadas demonstram a presença de mandioca (Manihot esculenta), abóbora (Curcubita sp.), feijões (Phaseolus sp.), pequi (Caryocar sp.), goiabeira (Psidium sp.), dentre outras; sendo essas umas das evidências 
mais antigas de cultivo de plantas na região, provavelmente do incío dessa prática (Watling et al; 2018).

Na região de Lagoa Santa, foi realizado um estudo pioneiro para o contexto brasileiro, de microarqueobotânica em artefatos líticos (Angeles Flores, 2015). Os artefatos analisados são provenientes do sítio sítio Lapa Grande de Taquaraçu, abrigo calcário com datações desde Holoceno Inicial (entre $11.360 \pm 110$ e $1100 \pm 80$ anos cal. A.P; com hiato ocupacional entre $9000 \pm 70$ e $1100 \pm$ anos cal. A.P.) localizado a $20 \mathrm{~km}$ da Área de Proteção Ambiental (APA) de Lagoa Santa, no município de Jaboticatubas (Angeles Flores, 2015; Angeles Flores et al; 2016). Um estudo faunístico nesse sítio identificou que os grupos que o ocuparam possuiriam uma subsistência generalista como sugerida para a região, e que também eram pescadores (Chim, 2018).

Angeles Flores (2015) analisou grãos de amido e resíduos para teste de presença de sangue de 11 instrumentos líticos da Lapa Grande de Taquaraçu, destes, 9 lascas ou resíduos de lascamento em quartzo hialino ou leitoso, um bloco de calcário e uma lesma. A identificação taxonômica do amido alcançou semelhanças à inhame, Ipomoea batatas (batata-doce) e à família Arecaceae (palmeiras). Os instrumentos seriam multifuncionais no tocante ao processamento de recursos vegetais e animais (Angeles Flores, 2015). A lesma, semelhante às associadas à indústria lítica Itaparica, foi encontrado em contexto mais antigo que 11.500 anos A.P; e nela foram identificados grãos de amido nas partes ativas, enquanto que os microvestígios não estavam presentes nas partes proximais com potencial preensivo (Angeles Flores et al; 2016).

Na Lapa do Santo, além da pesquisa apresentada nesta dissertação, está sendo desenvolvido um estudo microarqueobotânico em cálculo dentário de remanescentes humanos da Lapa do Santo pela Dra. Célia Boyadjian. 


\section{MATERIAIS E MÉTODOS}

Os trabalhos de campo realizados nesta pesquisa ocorrem na etapa de 2016. Com os propósitos desta pesquisa, no tocante a realizar uma coleta que evitasse contaminação e favorecesse a análise de microvestígios, foram coletados 101 líticos e 32 amostras de sedimento (Tópico 3.2 e Tópico 3.4.1). O material é proveniente das unidades N23, P11, AE1, um lítico coletado na parte inferior do crânio humano do Sepultamento 39, e três amostras de sedimento de fora do sítio (Figura 9 e Figura 10). De todas as amostras coletadas, foram analisados 21 líticos e quatro amostras de sedimento (uma de cada quadra e uma localizada acima do maciço calcário e portanto, fora do sítio).

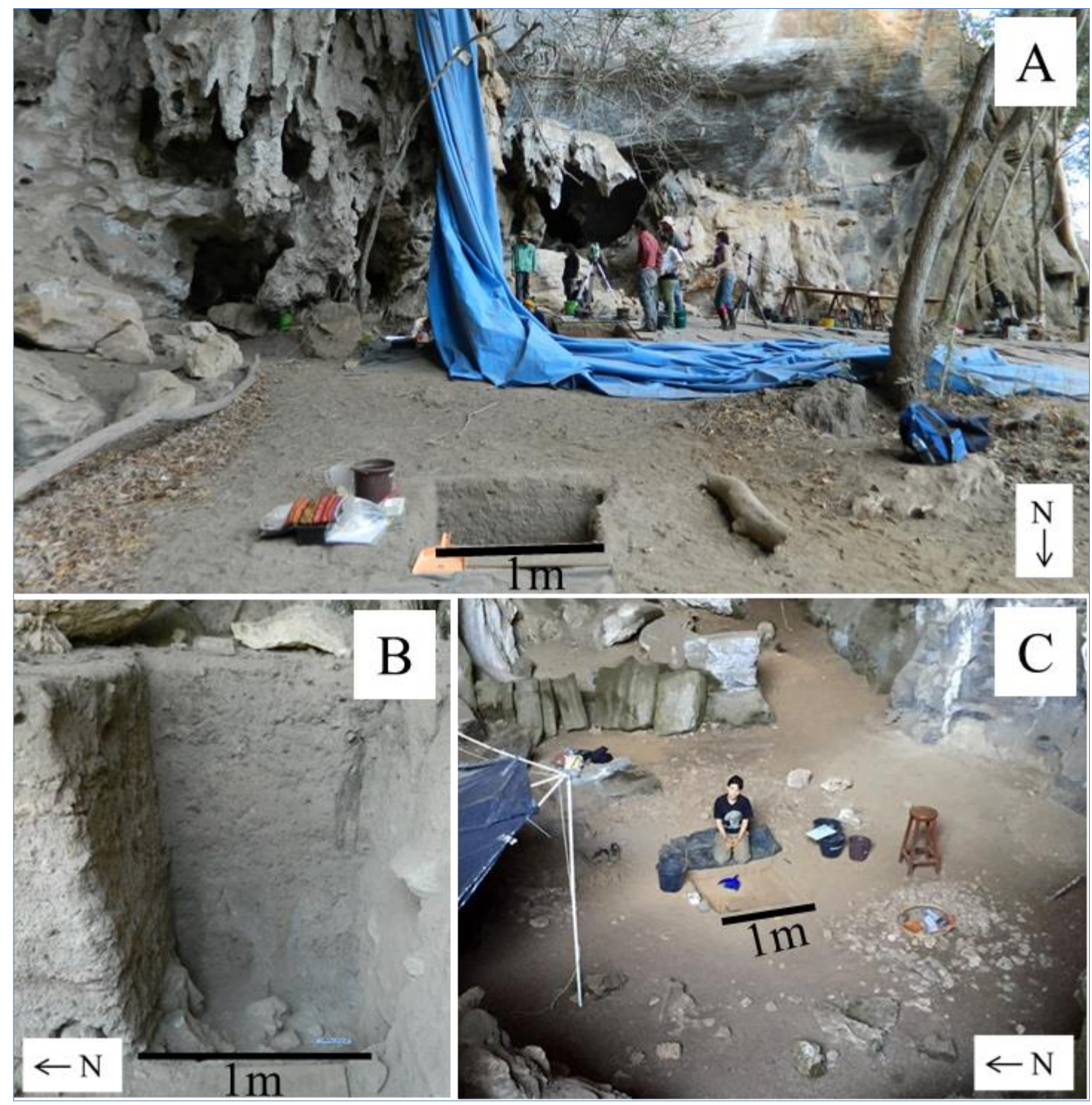

Figura 9. Unidades de Escavação. A) N23, B) P11 e C) A.E.1. Lapa do Santo, 2016. 


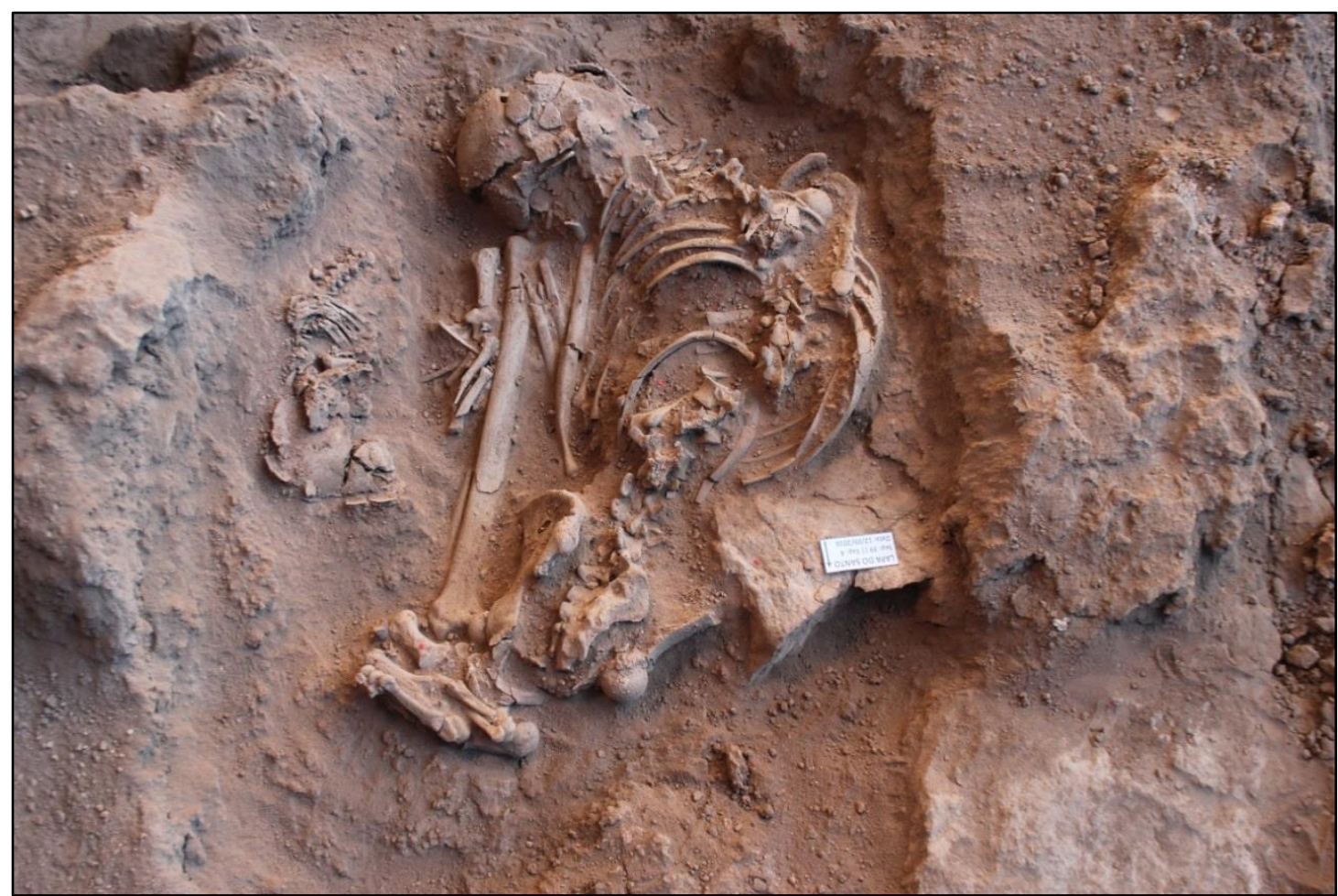

Figura 10. Sepultamento 39. Autoria da foto: Projeto "As Práticas Mortuárias dos Primeiros Americanos".

A Figura 11 apresenta a localização das quadras analisadas N23, P11 e AE1, além da localização das áreas de escavação da etapa de pesquisa de 2001 a 2009, e da etapa de pesquisa de 2001 a 2014. Os dados das novas unidades de escavação da etapa de 2016 não foram ainda publicados. O declive do sítio pode ser observado na Figura 12, assim como a diferença de profundidade entre as quadras P11 ( $\mathrm{z}$ com cerca de $-1,2$ na camada mais profunda) e N23 (z com cerca de $-3,4$ na camada mais profunda.). Pela localização da quadra AE1, ela não poderia ser visualizada na Figura 12. 


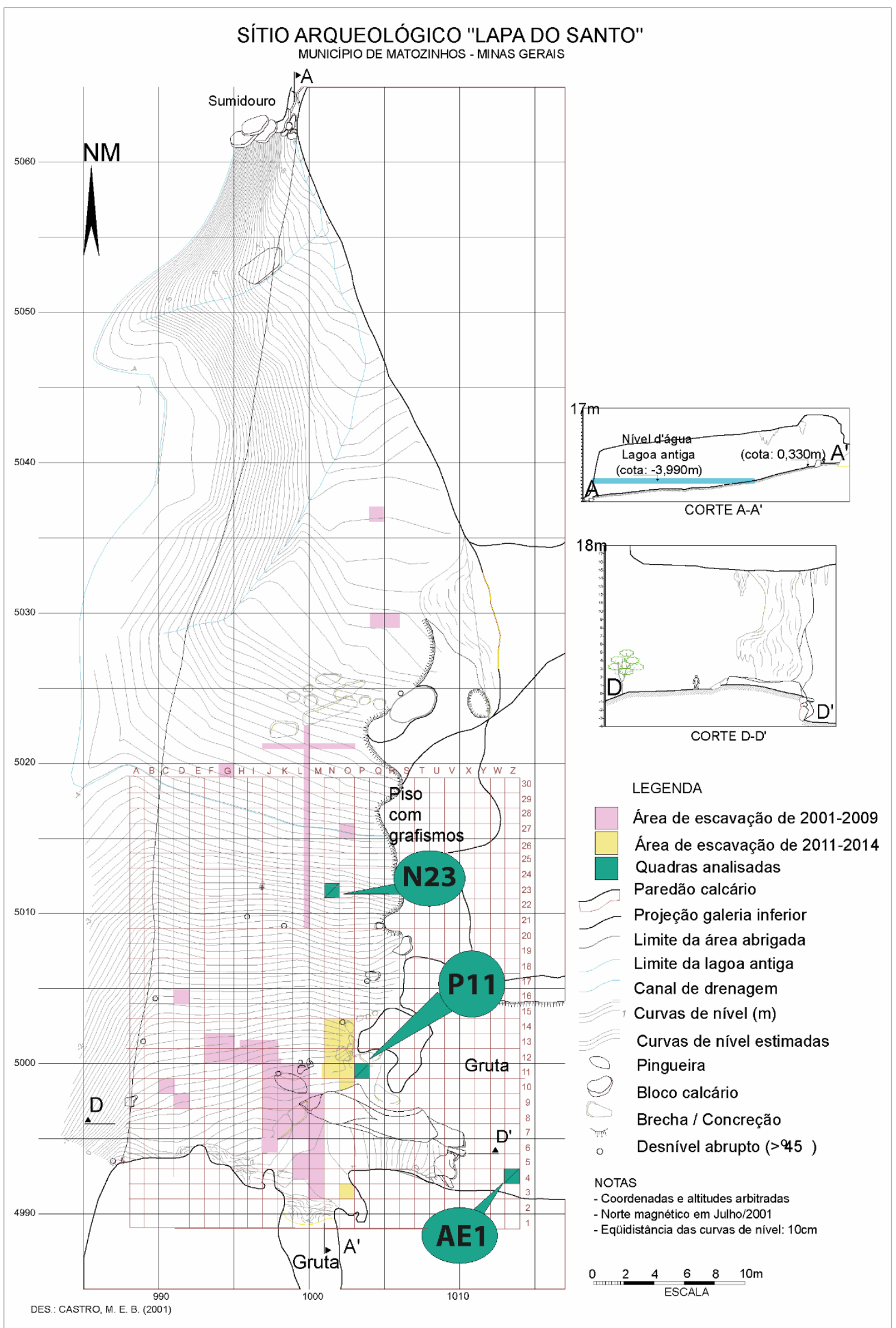

Figura 11. Localização em planta das quadras escavadas na Lapa do Santo. 


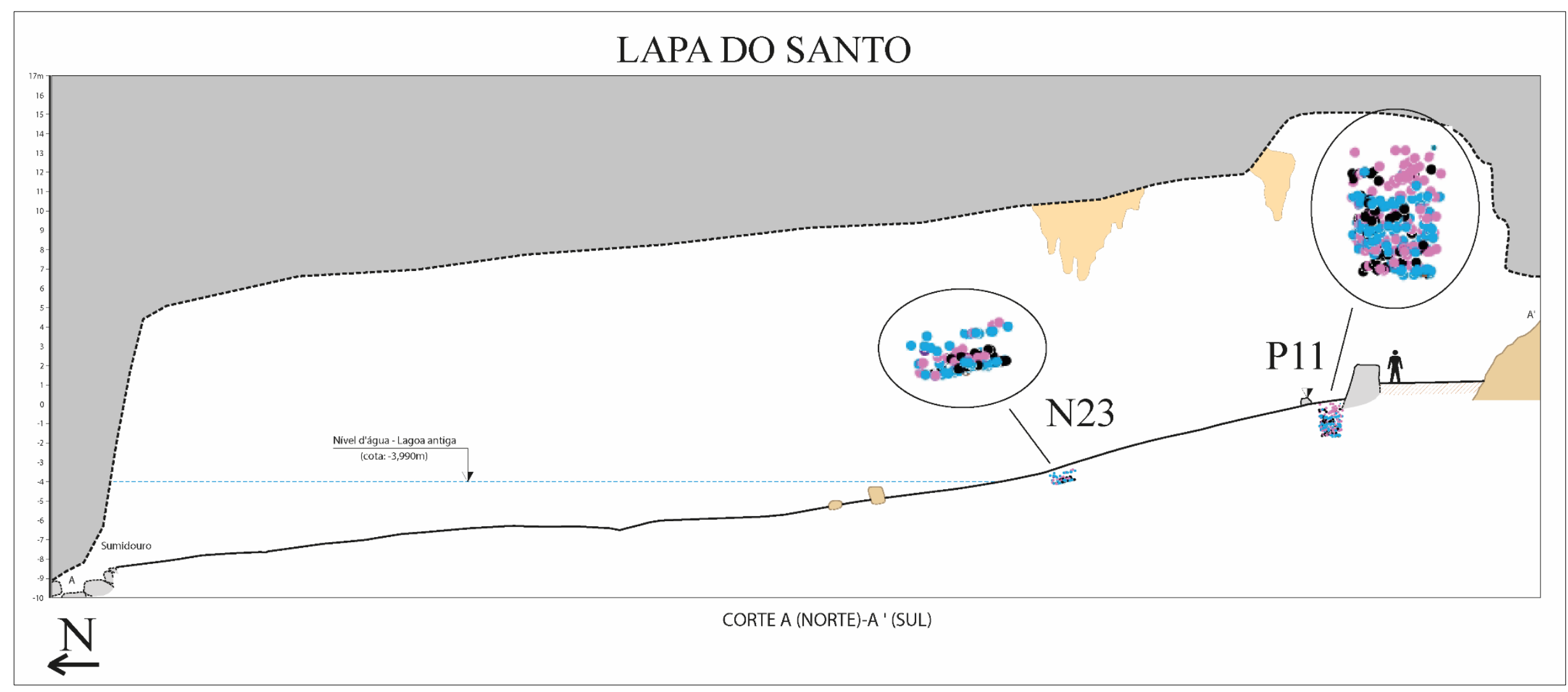

Figura 12. Localização e proporções de escala aproximadas das quadras N23 e P11. Os pontos coloridos indicam o material arqueológico em todas as camadas escavadas até $\mathrm{o}$ ano de 2016. Os pontos são, preto=carvão, azul=lítico, rosa=fauna. 


\subsection{Escavação e coleta do material arqueológico}

Previamente à realização dos trabalhos de campo, foi elaborado um protocolo (Tópico 3.1.1) de escavação e coleta de artefatos líticos especificamente para viabilizar a análise de microvestígios retidos nos mesmos. O objetivo do protocolo é evitar a contaminação das amostras por amido contemporâneo (Crowther et al; 2014). Este protocolo foi desenvolvido com base em propostas apresentadas por vários especialistas: Fernández, 1980; Bryant \& Hall, 1993; Loy, 1994; Piperno \& Holst, 1998; Renfrew \& Bahn, 1998; Kealhofer et al; 1999; Perry, 2001; Hardy et al; 2001; Gallay, 2002; Green \& Tolmie, 2004; Bicho, 2006; Fullagar, 2006; Torrence, 2006; Domingo et al; 2007; Charles et al; 2009; Perry, 2010; Wesolowski, 2013 e Pearsall, 2015 .

Durante o trabalho de campo, não houve a circulação de alimentos no sítio arqueológico. Demais aspectos (Tópico 3.1.1) do protocolo foram aplicados somente pela autora deste trabalho, responsável pela escavação e coleta do respectivo material lítico a ser estudado (Figura 13). A única exceção foi a coleta de um lítico realizada no Sepultamento 39, escavado pelo Dr. Rodigo Elias, tendo a coleta do lítico sido realizada pela autora deste trabalho. Para além dos cuidados do protocolo, as minhas roupas foram trocadas sempre ao entrar na área do sítio arqueológico, trocadas antes do horário de almoço e as roupas limpas vestidas novamente para voltar ao sítio, para que não fossem levados restos alimentares que pudessem contaminar as amostras.

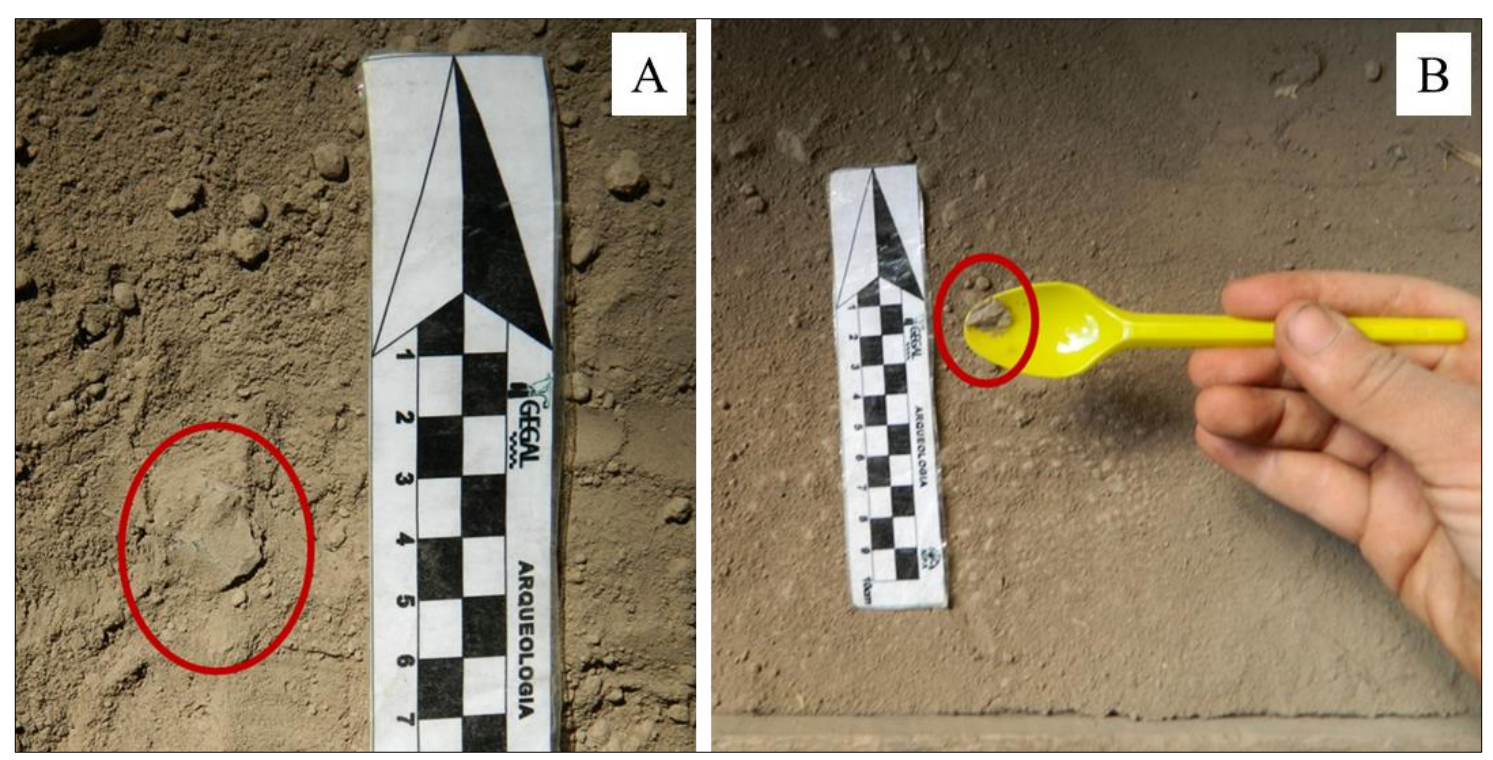

Figura 13. A) Lítico detectado durante a escavação. B) Lítico coletado com colher plástica. Sondagem N23, Lapa do Santo, 2016. 


\subsubsection{Protocolo De Escavação e Coleta de Artefatos e Sedimento para Análise de Microvestígios Botânicos}

\section{Escavar e expor os artefatos in situ.}

2. Coletar cada artefato com o máximo de sedimento aderido possível, transferi-lo imediatamente para um saco plástico limpo e identificá-lo. Esse procedimento deve ser feito com auxílio de um instrumento descartável como espátula ou colher de plástico, que deve ser substituído a cada artefato coletado. Deve-se evitar a manipulação exacerbada dos artefatos e nenhum tipo de higienização dos artefatos deve ser feita em campo para que os microvestígios não sejam eliminados.

3. Coletar amostras de sedimento de cada camada estratigráfica onde estão os artefatos. Definir quantidade entre $30 \mathrm{~g}$ e $100 \mathrm{~g}$.

4. Cada amostra de sedimento deve ser coletada com um instrumento descartável (espátula ou colher de plástico) e limpo e transferida imediatamente para um saco plástico limpo, devidamente identificado. O instrumento utilizado deve ser substituído a cada nova coleta para evitar contaminação.

5. Registrar (fotografias e croqui ou estação total) os procedimentos realizados e a localização do material arqueológico identificado e coletado.

Observações:

1. Orientar a equipe a não circular na área de escavação com alimentos, bebidas ou cigarros a fim de evitar a contaminação das amostras com microvestígios contemporâneos.

2. A escavação deve proceder normalmente até o momento de se evidenciar e coletar um artefato ou sedimento. Nesses casos, se deve utilizar pás e pincéis novos e/ou limpos para a manipulação de cada artefato ou coleta de sedimento e evitar assim a contaminação de um para o outro.

3. A coleta do material arqueológico deve ocorrer rapidamente para evitar a contaminação por partículas do meio. 
4. Os sacos plásticos utilizados para acondicionamento de cada amostra ou artefato devem ser do tipo "zip-lock" para serem bem vedados. Devem ser identificados com etiquetas ou marcador. Etiquetas de papel nunca devem ser colocadas diretamente junto à amostra, é preciso que estejam dentro de sacos plásticos para evitar que elas sejam agentes de contaminação e que se deteriorem.

5. Para o contexto da Lapa do Santo em que há pouca umidade, se fechou os sacos imediatamente à coleta. Para contextos úmidos indica-se a secagem antes do fechamento.

Para assegurar a integridade das amostras coletadas, todas foram acondicionadas em dois sacos plásticos zip-lock e encaminhadas ao laboratório separadamente do material coletado em campo (que não utilizou o protocolo para microvestígios). Todos os líticos e sedimentos se encontram acondicionados no LAAAE-IB/USP.

\subsection{Líticos Coletados}

Foram coletados 101 líticos nesta pesquisa (Tabela 2), seguindo o protocolo que evita a contaminação e favorece a análise de microvestígios (Tópico 3.1). Os dados de $\mathrm{x}, \mathrm{y}$ e $\mathrm{z}$ foram coletados com estação total, exceto para a quadra AE1 em que se utilizou trena (Tabela 2).

Tabela 2. Total de líticos coletados

\begin{tabular}{|c|c|c|c|c|c|c|}
\hline Quadra & PN & Nível $(\mathbf{c m})$ & Facies & $\mathbf{X}$ & $\mathbf{Y}$ & $\mathbf{Z}$ \\
\hline N23 & 13014 & $6(50-60 \mathrm{~cm})$ & 7 & 13,871 & 22,481 & $-3,377$ \\
\hline N23 & 14017 & $6(50-60)$ & 8 & 13,818 & 22,313 & $-3,436$ \\
\hline N23 & 13067 & $6(50-60)$ & 7 & 13,451 & 22,472 & $-3,445$ \\
\hline N23 & 13885 & $6(50-60)$ & 9 & 13,721 & 22,713 & $-3,493$ \\
\hline N23 & 14029 & $6(50-60)$ & 8 & 13,440 & 22,388 & $-3,444$ \\
\hline N23 & 13120 & $6(50-60)$ & 8 & 13,595 & 22,205 & $-3,372$ \\
\hline N23 & 13962 & $6(50-60)$ & 9 & 13,292 & 22,596 & $-3,491$ \\
\hline N23 & 13431 & $6(50-60)$ & 7 & 13,198 & 22,775 & $-3,494$ \\
\hline P11 & 14292 & $15(140-150)$ & 14 & 15,480 & 10,521 & $-1,173$ \\
\hline P11 & 14385 & $16(150-160)$ & 14 & 15,795 & 10,261 & $-1,247$ \\
\hline P11 & 14391 & $16(150-160)$ & 14 & 15,347 & 10,472 & $-1,204$ \\
\hline P11 & 14410 & $16(150-160)$ & 14 & 15,365 & 10,309 & $-1,209$ \\
\hline
\end{tabular}




\begin{tabular}{|c|c|c|c|c|c|c|}
\hline Quadra & PN & Nível (cm) & Facies & $\mathbf{X}$ & $\mathbf{Y}$ & $\mathbf{Z}$ \\
\hline $\mathrm{P} 11$ & 14469 & $16(150-160)$ & 14 & 15,550 & 10,120 & $-1,232$ \\
\hline $\mathrm{P} 11$ & 14369 & $16(150-160)$ & 14 & 15,524 & 10,282 & $-1,216$ \\
\hline AE1 & 14267 & $2(10-20)$ & 0 & $\underline{61}$ & $\underline{85}$ & $\underline{20}$ \\
\hline AE1 & 14236 & $2(10-20)$ & 0 & $\underline{72}$ & $\underline{74}$ & $\underline{20}$ \\
\hline AE1 & 14355 & $3(20-30)$ & 0 & $\underline{96}$ & $\underline{98}$ & $\underline{25}$ \\
\hline AE1 & 14335 & $3(20-30)$ & 0 & $\underline{9}$ & $\underline{48}$ & $\underline{25}$ \\
\hline AE1 & 14353 & $3(20-30)$ & 0 & $\underline{28}$ & $\underline{79}$ & $\underline{25}$ \\
\hline AE1 & 14297 & $3(20-30)$ & 0 & $\underline{29}$ & $\underline{13}$ & $\underline{25}$ \\
\hline Sep. 39 & 14192 & $13(120-130)$ & $\begin{array}{c}\text { Exposição } \\
2 \\
\end{array}$ & 14,602 & 13,948 & $-1,242$ \\
\hline $\mathrm{N} 23$ & 13013 & 6 & 7 & 13,204 & 22,234 & $-3,34$ \\
\hline N23 & 13035 & 6 & 7 & 13,119 & 22,229 & $-3,323$ \\
\hline $\mathrm{N} 23$ & 13038 & 6 & 7 & 13,093 & 22,149 & $-3,322$ \\
\hline $\mathrm{N} 23$ & 13132 & 6 & 8 & 13,881 & 22,126 & $-3,373$ \\
\hline $\mathrm{N} 23$ & 13252 & 6 & 8 & 13,104 & 22,138 & $-3,342$ \\
\hline $\mathrm{N} 23$ & 13289 & 6 & 8 & 13,356 & 22,124 & $-3,372$ \\
\hline $\mathrm{N} 23$ & 13308 & 6 & 8 & 13,561 & 22,065 & $-3,353$ \\
\hline N23 & 13320 & 6 & 8 & 13,586 & 22,14 & $-3,368$ \\
\hline $\mathrm{N} 23$ & 13329 & 6 & 8 & 13,404 & 22,251 & $-3,387$ \\
\hline $\mathrm{N} 23$ & 13334 & 6 & 8 & 13,503 & 22,355 & $-3,421$ \\
\hline N23 & 13351 & 6 & 8 & 13,6 & 22,221 & $-3,397$ \\
\hline $\mathrm{N} 23$ & 13363 & 6 & 8 & 13,295 & 22,335 & $-3,415$ \\
\hline $\mathrm{N} 23$ & 13442 & 6 & 7 & 13,267 & 22,57 & $-3,468$ \\
\hline N23 & 13461 & 6 & 7 & 13,129 & 22,613 & $-3,494$ \\
\hline $\mathrm{N} 23$ & 13909 & 6 & 9 & 13,709 & 22,626 & $-3,505$ \\
\hline $\mathrm{P} 11$ & 13911 & 13 & 11 & 15,444 & 10,473 & $-0,967$ \\
\hline P11 & 13932 & 13 & 11 & 15,927 & 10,235 & $-0,942$ \\
\hline $\mathrm{N} 23$ & 13934 & 6 & 9 & 13,222 & 22,417 & $-3,436$ \\
\hline N23 & 13937 & 6 & 9 & 13,156 & 22,456 & $-3,466$ \\
\hline N23 & 13938 & 6 & 9 & 13,271 & 22,604 & $-3,498$ \\
\hline $\mathrm{N} 23$ & 13940 & 6 & 9 & 13,303 & 22,584 & $-3,492$ \\
\hline $\mathrm{P} 11$ & 13941 & 13 & 11 & 15,476 & 10,137 & $-0,958$ \\
\hline $\mathrm{P} 11$ & 13947 & 13 & 11 & 15,219 & 10,401 & $-0,955$ \\
\hline P11 & 13948 & 13 & 11 & 15,286 & 10,407 & $-0,966$ \\
\hline $\mathrm{P} 11$ & 13961 & 13 & 11 & 15,146 & 10,642 & $-0,98$ \\
\hline N23 & 13977 & 6 & 9 & 13,386 & 22,506 & $-3,478$ \\
\hline $\mathrm{P} 11$ & 14007 & 13 & 11 & 15,218 & 10,333 & $-0,988$ \\
\hline
\end{tabular}




\begin{tabular}{|c|c|c|c|c|c|c|}
\hline Quadra & PN & Nível (cm) & Facies & $\mathbf{X}$ & $\mathbf{Y}$ & $\mathbf{Z}$ \\
\hline P11 & 14027 & 13 & 11 & 15,588 & 10,803 & $-0,998$ \\
\hline P11 & 14074 & 14 & 11 & 15,173 & 10,793 & $-1,01$ \\
\hline P11 & 14221 & 15 & 11 & 15,251 & 10,584 & $-1,1$ \\
\hline AE1 & 14237 & 2 & 0 & 0 & 0 & 0 \\
\hline AE1 & 14244 & 2 & 0 & 0 & 0 & 0 \\
\hline AE1 & 14255 & 2 & 0 & 0 & 0 & 0 \\
\hline AE1 & 14256 & 2 & 0 & 0 & 0 & 0 \\
\hline AE1 & 14261 & 2 & 0 & 0 & 0 & 0 \\
\hline AE1 & 14268 & 2 & 0 & 0 & 0 & 0 \\
\hline AE1 & 14269 & 2 & 0 & 0 & 0 & 0 \\
\hline AE1 & 14298 & 3 & 0 & 0 & 0 & 0 \\
\hline P11 & 14301 & 15 & 14 & 15,713 & 10,691 & $-1,21$ \\
\hline AE1 & 14317 & 3 & 0 & 0 & 0 & 0 \\
\hline AE1 & 14323 & 3 & 0 & 0 & 0 & 0 \\
\hline AE1 & 14324 & 3 & 0 & 0 & 0 & 0 \\
\hline AE1 & 14325 & 3 & 0 & 0 & 0 & 0 \\
\hline AE1 & 14334 & 3 & 0 & 0 & 0 & 0 \\
\hline AE1 & 14354 & 3 & 0 & 0 & 0 & 0 \\
\hline AE1 & 14371 & 3 & 0 & 0 & 0 & 0 \\
\hline P11 & 14378 & 16 & 14 & 15,665 & 10,204 & $-1,222$ \\
\hline P11 & 14392 & 16 & 14 & 15,227 & 10,212 & $-1,181$ \\
\hline AE1 & 14393 & 3 & 0 & 0 & 0 & 0 \\
\hline AE1 & 14394 & 3 & 0 & 0 & 0 & 0 \\
\hline P11 & 14399 & 16 & 14 & 15,338 & 10,258 & $-1,201$ \\
\hline P11 & 14401 & 16 & 14 & 15,298 & 10,475 & $-1,187$ \\
\hline P11 & 14403 & 16 & 14 & 15,35 & 10,147 & $-1,201$ \\
\hline P11 & 14413 & 16 & 14 & 15,2 & 10,198 & $-1,183$ \\
\hline P11 & 14417 & 16 & 14 & 15,226 & 10,31 & $-1,187$ \\
\hline AE1 & 14418 & 3 & 0 & 0 & 0 & 0 \\
\hline AE1 & 14419 & 3 & 0 & 0 & 0 & 0 \\
\hline AE1 & 14420 & 3 & 0 & 0 & 0 & 0 \\
\hline AE1 & 14421 & 3 & 0 & 0 & 0 & 0 \\
\hline AE1 & 14422 & 3 & 0 & 0 & 0 & 0 \\
\hline P11 & 14425 & 16 & 14 & 15,358 & 10,241 & $-1,216$ \\
\hline P11 & 14429 & 16 & 14 & 15,304 & 10,151 & $-1,203$ \\
\hline AE1 & 14433 & 3 & 0 & 0 & 0 & 0 \\
\hline AE1 & 14434 & 3 & 0 & 0 & 0 & 0 \\
\hline & & & & & & \\
\hline
\end{tabular}




\begin{tabular}{|c|c|c|c|c|c|c|}
\hline Quadra & PN & Nível (cm) & Facies & $\mathbf{X}$ & $\mathbf{Y}$ & $\mathbf{Z}$ \\
\hline P11 & 14445 & 16 & 14 & 15,174 & 10,723 & $-1,189$ \\
\hline AE1 & 14455 & 3 & 0 & 0 & 0 & 0 \\
\hline P11 & 14458 & 16 & 14 & 15,775 & 10,382 & $-1,251$ \\
\hline P11 & 14459 & 16 & 14 & 15,124 & 10,317 & $-1,201$ \\
\hline AE1 & 14487 & 3 & 0 & 0 & 0 & 0 \\
\hline AE1 & 14488 & 3 & 0 & 0 & 0 & 0 \\
\hline AE1 & 14489 & 3 & 0 & 0 & 0 & 0 \\
\hline AE1 & 14498 & 3 & 0 & 0 & 0 & 0 \\
\hline AE1 & 14500 & 3 & 0 & 0 & 0 & 0 \\
\hline AE1 & 14501 & 3 & 0 & 0 & 0 & 0 \\
\hline AE1 & 14520 & 3 & 0 & 0 & 0 & 0 \\
\hline AE1 & 14521 & 3 & 0 & 0 & 0 & 0 \\
\hline AE1 & 14524 & 3 & 0 & 0 & 0 & 0 \\
\hline AE1 & 14529 & 3 & 0 & 0 & 0 & 0 \\
\hline AE1 & 14530 & 3 & 0 & 0 & 0 & 0 \\
\hline AE1 & 14574 & 3 & 0 & 0 & 0 & 0 \\
\hline
\end{tabular}

\subsection{Líticos Analisados}

Dos 101 líticos coletados, 21 foram analisados nesta pesquisa (Tabela 3). A seleção da quantidade dos mesmos buscou um equilíbrio de distribuição entre as quadras selecionadas e levou em consideração o tempo disponível para a realização do trabalho. A seleção de quais líticos seriam analisados foi em parte aleatória e em parte guiada pelo aspecto de líticos (ainda sujos) que tivessem gume ou retoques, o que poderia aumentar as chances de análise de líticos que tivessem sido utilizados. Ainda sim, líticos sem esse aspecto também poderiam ter sido utilizados. Os líticos analisados são lascas sem retoque e com retoque, fragmentos de lasca e peças com córtex e negativos. A descrição tecnológica preliminar é apresentada nos Resultados.

Os líticos foram analisados em duas etapas. Na Etapa 1 (Método Step-Wise) foram analisados oito líticos da quadra N23 (Tópico 0). Na Etapa 2 (Tópico 3.7) foram analisados vinte líticos: os mesmos líticos da quadra N23, com exceção do lítico 13431, ou seja, sete líticos da N23; mais seis líticos da quadra P11; mais seis líticos da quadra AE1 e um lítico coletado na parte inferior do crânio humano do Sepultamento 39 (Figura 
14). O lítico 13431 não seguiu para a análise na Etapa 2 porque aparentemente toda a superfície foi amostrada na Etapa 1, tendo em conta que possui menos que $2 \mathrm{~cm}$ (Figura $33)$.

Tabela 3. Total de líticos analisados e sua proveniência.

\begin{tabular}{|c|c|c|c|c|c|c|c|}
\hline Quadra & PN & Nível (cm) & Facies & $\mathbf{X}$ & $\mathbf{Y}$ & $\mathbf{Z}$ & $\begin{array}{c}\text { Foto } \\
\text { (Figura } \\
\text { 14) }\end{array}$ \\
\hline N23 & 13014 & $\begin{array}{c}6(50-60 \\
\mathrm{cm})\end{array}$ & 7 & 13,871 & 22,481 & $-3,377$ & A \\
\hline N23 & 14017 & $6(50-60)$ & 8 & 13,818 & 22,313 & $-3,436$ & $\mathrm{C}$ \\
\hline $\mathrm{N} 23$ & 13067 & $6(50-60)$ & 7 & 13,451 & 22,472 & $-3,445$ & $\mathrm{E}$ \\
\hline $\mathrm{N} 23$ & 13885 & $6(50-60)$ & 9 & 13,721 & 22,713 & $-3,493$ & $\mathrm{G}$ \\
\hline $\mathrm{N} 23$ & 14029 & $6(50-60)$ & 8 & 13,440 & 22,388 & $-3,444$ & B \\
\hline N23 & 13120 & $6(50-60)$ & 8 & 13,595 & 22,205 & $-3,372$ & $\mathrm{D}$ \\
\hline N23 & 13962 & $6(50-60)$ & 9 & 13,292 & 22,596 & $-3,491$ & $\mathrm{~F}$ \\
\hline N23 & 13431 & $6(50-60)$ & 7 & 13,198 & 22,775 & $-3,494$ & $\begin{array}{l}\text { Figura } \\
33\end{array}$ \\
\hline $\mathrm{P} 11$ & 14292 & $\begin{array}{c}15(140- \\
150)\end{array}$ & 14 & 15,480 & 10,521 & $-1,173$ & $\mathrm{H}$ \\
\hline $\mathrm{P} 11$ & 14385 & $\begin{array}{c}16(150- \\
160)\end{array}$ & 14 & 15,795 & 10,261 & $-1,247$ & $\mathrm{~K}$ \\
\hline P11 & 14391 & $\begin{array}{c}16(150- \\
160)\end{array}$ & 14 & 15,347 & 10,472 & $-1,204$ & M \\
\hline $\mathrm{P} 11$ & 14410 & $\begin{array}{c}16(150- \\
160)\end{array}$ & 14 & 15,365 & 10,309 & $-1,209$ & I \\
\hline P11 & 14469 & $\begin{array}{c}16(150- \\
160)\end{array}$ & 14 & 15,550 & 10,120 & $-1,232$ & $\mathrm{~J}$ \\
\hline P11 & 14369 & $\begin{array}{c}16(150- \\
160)\end{array}$ & 14 & 15,524 & 10,282 & $-1,216$ & $\mathrm{~L}$ \\
\hline AE1 & 14267 & $2(10-20)$ & 0 & 61 & 85 & 20 & $\mathrm{~N}$ \\
\hline AE1 & 14236 & $2(10-20)$ & 0 & 72 & 74 & 20 & $\mathrm{O}$ \\
\hline AE1 & 14355 & $3(20-30)$ & 0 & 96 & 98 & 25 & $S$ \\
\hline AE1 & 14335 & $3(20-30)$ & 0 & 9 & 48 & 25 & $\mathrm{P}$ \\
\hline AE1 & 14353 & $3(20-30)$ & 0 & 28 & 79 & 25 & $\mathrm{R}$ \\
\hline AE1 & 14297 & $3(20-30)$ & 0 & 29 & 13 & 25 & Q \\
\hline Sep. 39 & 14192 & $\begin{array}{c}13(120- \\
130)\end{array}$ & $\begin{array}{c}\text { Exposição } \\
2\end{array}$ & 14,602 & 13,948 & $-1,242$ & $\mathrm{~T}$ \\
\hline
\end{tabular}




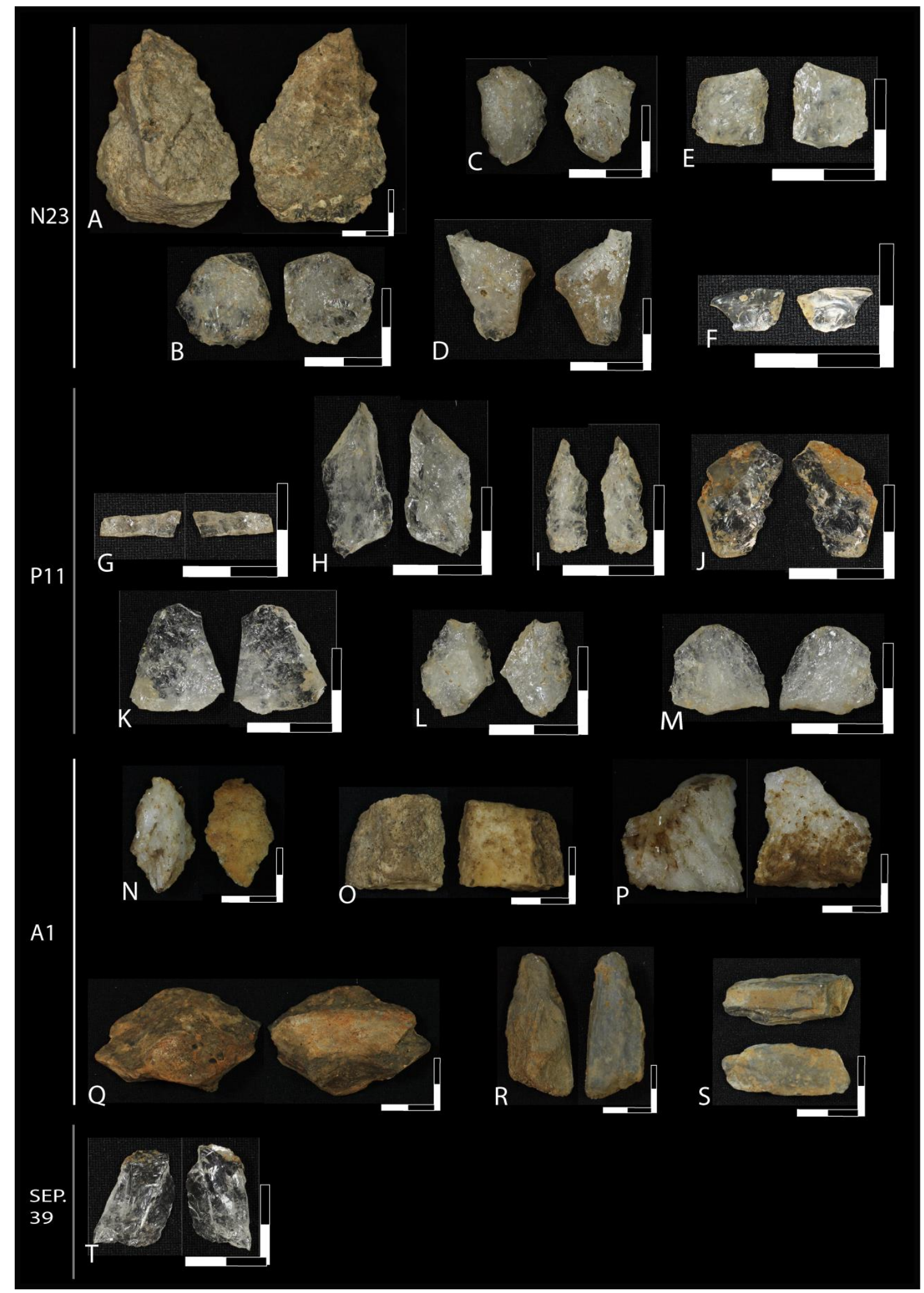

Figura 14. Líticos analisados. Líticos da quadra N23: A) 13014, B) 14029, C) 14017, D) 13120, E) 13067, F) 13962, G) 13885. Líticos da quadra P11: H) 14292, I) 14410, J) 14469, K) 14385 , L) 14369, M) 14391. Líticos da quadra A1: N) 14267, O) 14236, P) 14335, Q) 14297, R) 14353, S) 14355. Lítico do Sepultamento 39: T) 14192. 


\subsection{Amostras de Sedimentos para controle de contaminação}

Com a decomposição de plantas e o seu processamento pelos seres humanos, grãos de amido e fitólitos são depositados no ambiente, ou podem ficar retidos em objetos que tenham entrado em contato com plantas ou mãos contendo seus resíduos (Barton, 2006).

O estudo dos microvestígios de sedimentos é necessário como parte das análises em artefatos, porque possibilita verificar ou controlar se as partículas encontradas nas peças são remanescentes diretos do seu uso ou se são decorrentes de processos pósdeposicionais no ambiente e outros tipos de contaminação por sacos plásticos, por exemplo, e em laboratório (Briuer, 1976; Kealhofer et al; 1999; Perry, 2004; Torrence, 2006b; Barton, 2006; Williamson, 2006, Crowther et al; 2014; Pearsall, 2015). Artefatos que foram usados para processar plantas devem conter mais grãos de amido e fitólitos do que os sedimentos circundantes em um sítio arqueológico (Barton, 2006). Caso os microvestígios botânicos dos artefatos resultem de contato secundário dos mesmos com o ambiente do sítio, os artefatos e sedimentos analisados devem conter quantidades equivalentes de microvestígios (Barton, 2006).

Em um estudo de amido em artefatos líticos do sítio FAO na Papua Nova Guiné, para controle de contaminação e interpretação dos resultados foram realizadas análises em amostras de sedimento do sítio arqueológico (Barton et al; 1998). Os resultados demonstraram que a contaminação nos líticos (pelo ambiente/sedimento e em laboratório) pode ser identificada e quantificada, uma vez que nos artefatos que apresentam marcas de uso há maior quantidade de amido do que nos sedimentos do sítio (Barton et al; 1998). A menor quantidade de amido nos sedimentos é equivalente à quantidade de amido na maioria dos artefatos que não apresentam marcas de uso e portanto não teriam sido usados para processar plantas (Barton et al; 1998).

A coleta de sedimentos é um importante elemento de controle de análise das amostras líticas, uma vez que os microvestígios retidos nos líticos podem ser tanto decorrentes do seu uso, quanto de processos pós-deposicionais (Kealhofer, Torrence, Fullagar, 1999; Perry, 2001; Torrence, 2006; Charles et al; 2009). 


\subsubsection{Amostras de Sedimento Coletadas}

Amostras de sedimento foram coletadas nas unidades escavadas em proximidade aos líticos coletados (Tabela 4). Alguns artefatos contaram com uma coleta de sedimento abaixo do artefato, a $5 \mathrm{~cm}$ do artefato e a $10 \mathrm{~cm}$ do artefato (Figura 15).

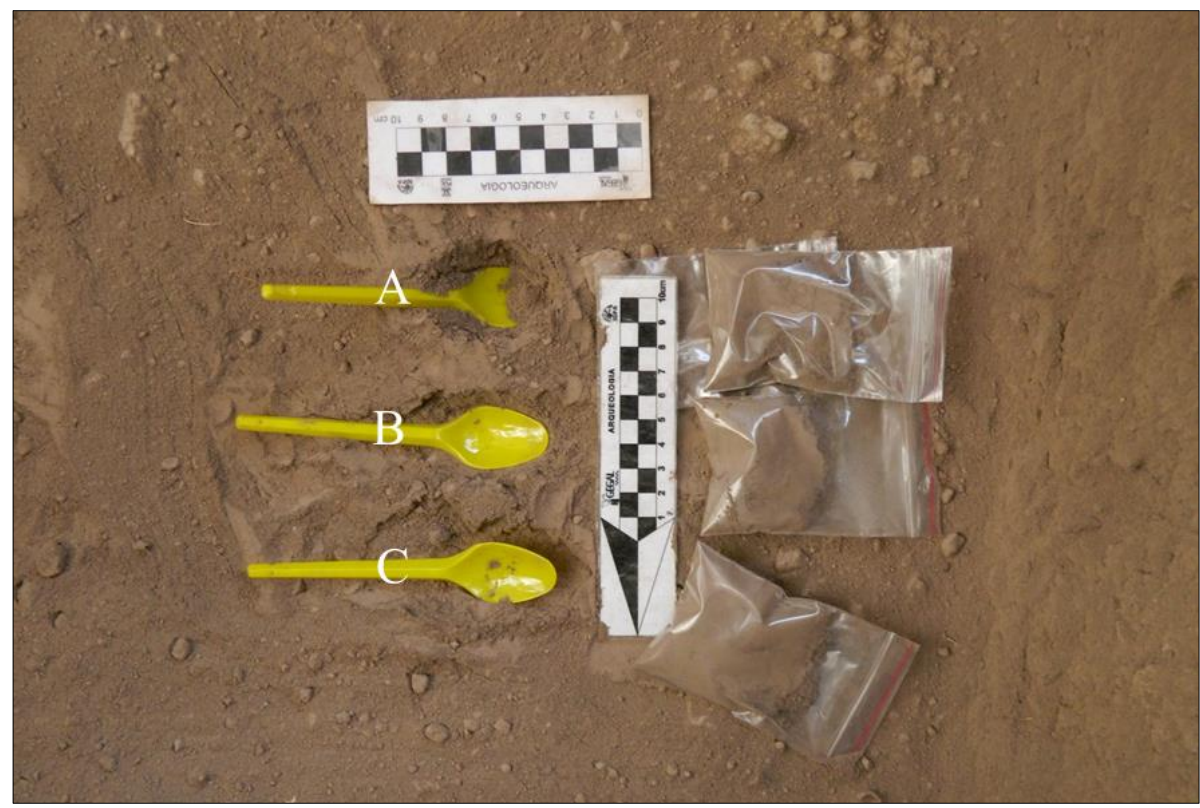

Figura 15. A) Lítico e sedimento coletado abaixo do mesmo. B) Sedimento coletado a $5 \mathrm{~cm}$ do lítico. C) Sedimento coletado a $10 \mathrm{~cm}$ do lítico.

Além disso, foram coletadas amostras de sedimento de três localidades fora do sítio (Tabela 4). Essas amostras podem ser utilizadas para identificação de táxons de plantas presentes no sedimento natural, cujo objetivo pode ser a comparação com o que é encontrado nos artefatos e assim ter um melhor controle da contaminação com o meio. Essas amostras de sedimento foram coletadas a $30 \mathrm{~cm}$ de profundidade em três áreas fora do sítio arqueológico: sobre o abrigo (C2) (Figura 16); em um paleolago a sul do abrigo (C3) (Figura 17); e em um perfil exposto ao norte da área de escavação (C1) (Figura 18).

Tabela 4. Total de sedimentos coletados

\begin{tabular}{|c|c|c|c|c|c|c|}
\hline Quadra & PN & Nível (cm) & Facies & X & Y & $\mathbf{Z}$ \\
\hline N23 & 14030 & $6(50-60)$ & 8 & 13,442 & 22,392 & $-3,469$ \\
\hline P11 & 14398 & $16(150-160)$ & 14 & 15,309 & 10,227 & $-1,217$ \\
\hline AE1 & 14358 & $3(20-30)$ & 0 & 51 & 84 & 25 \\
\hline $\begin{array}{c}\text { Acima do } \\
\text { abrigo }\end{array}$ & C2 & $3(20-30)$ & 0 & & & \\
\hline
\end{tabular}




\begin{tabular}{|c|c|c|c|c|c|c|}
\hline Quadra & PN & Nível $(\mathrm{cm})$ & Facies & $\mathbf{X}$ & $\mathbf{Y}$ & $\mathbf{Z}$ \\
\hline $\begin{array}{l}\text { Perfil ao } \mathrm{N} \text { da } \\
\text { área de escav. }\end{array}$ & $\mathrm{C} 1$ & $3(20-30)$ & 0 & & & \\
\hline Paleolago & $\mathrm{C} 3$ & $3(20-30)$ & 0 & & & \\
\hline $\mathrm{N} 23$ & 12998 & 6 & 7 & 13,847 & 22,802 & $-3,476$ \\
\hline $\mathrm{N} 23$ & 13115 & 6 & 7 & 13,188 & 22,219 & $-3,373$ \\
\hline N23 & 13124 & 6 & 8 & 13,299 & 22,124 & $-3,366$ \\
\hline $\mathrm{N} 23$ & 13134 & 6 & 8 & 13,881 & 22,126 & $-3,373$ \\
\hline $\mathrm{N} 23$ & 13254 & 6 & 8 & 13,109 & 22,131 & $-3,345$ \\
\hline N23 & 13255 & 6 & 8 & 13,202 & 22,14 & $-3,365$ \\
\hline $\mathrm{N} 23$ & 13335 & 6 & 8 & 13,507 & 22,356 & $-3,423$ \\
\hline $\mathrm{N} 23$ & 13336 & 6 & 8 & 13,504 & 22,417 & $-3,428$ \\
\hline N23 & 13364 & 6 & 8 & 13,298 & 22,333 & $-3,417$ \\
\hline $\mathrm{N} 23$ & 13365 & 6 & 8 & 13,304 & 22,411 & $-3,424$ \\
\hline $\mathrm{N} 23$ & 13432 & 6 & 7 & 13,185 & 22,775 & $-3,5$ \\
\hline N23 & 13433 & 6 & 7 & 13,2 & 22,724 & $-3,486$ \\
\hline $\mathrm{N} 23$ & 13878 & 6 & 9 & 13,46 & 22,703 & $-3,531$ \\
\hline $\mathrm{N} 23$ & 13890 & 6 & 9 & 13,717 & 22,709 & $-3,503$ \\
\hline N23 & 13891 & 6 & 9 & 13,721 & 22,658 & $-3,485$ \\
\hline $\mathrm{N} 23$ & 13892 & 6 & 9 & 13,734 & 22,779 & $-3,521$ \\
\hline $\mathrm{N} 23$ & 13963 & 6 & 9 & 13,298 & 22,599 & $-3,507$ \\
\hline N23 & 13964 & 6 & 9 & 13,295 & 22,7 & $-3,52$ \\
\hline $\mathrm{N} 23$ & 13965 & 6 & 9 & 13,297 & 22,656 & $-3,519$ \\
\hline $\mathrm{N} 23$ & 14018 & 6 & 8 & 13,816 & 22,313 & $-3,46$ \\
\hline N23 & 14019 & 6 & 8 & 13,709 & 22,316 & $-3,453$ \\
\hline $\mathrm{N} 23$ & 14031 & 6 & 8 & 13,448 & 22,303 & $-3,444$ \\
\hline P11 & 14071 & 14 & 11 & 15,457 & 10,488 & 1,023 \\
\hline $\mathrm{P} 11$ & 14258 & 15 & 11 & 15,597 & 10,229 & $-1,185$ \\
\hline AE1 & 14284 & 2 & 0 & 0 & 0 & 0 \\
\hline P11 & 14293 & 15 & 14 & 15,38 & 10,495 & $-1,174$ \\
\hline P11 & 14304 & 15 & 14 & 15,38 & 10,301 & $-1,185$ \\
\hline P11 & 14368 & 16 & 14 & 15,567 & 10,376 & $-1,237$ \\
\hline P11 & 14379 & 16 & 14 & 15,667 & 10,197 & $-1,258$ \\
\hline
\end{tabular}



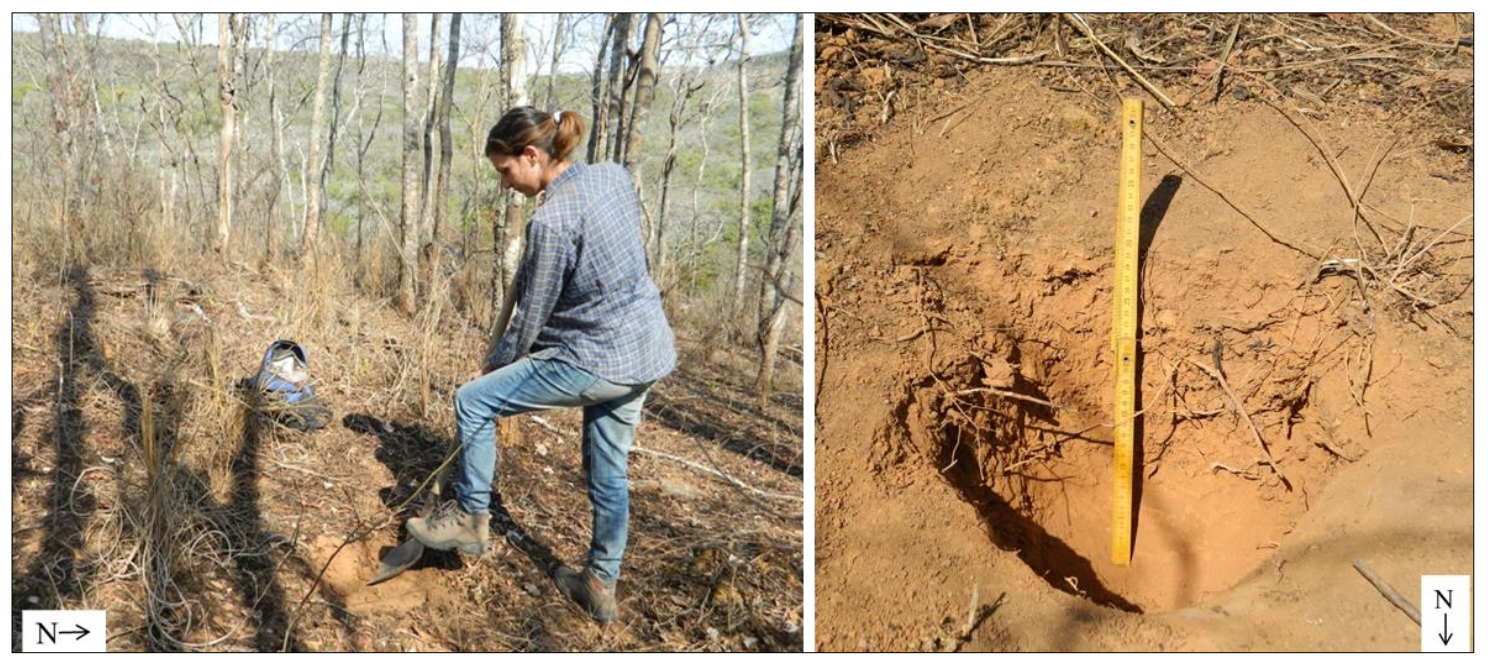

Figura 16. Coleta de sedimento na parte superior do abrigo (C2), pela Dra. Ximena Villagran.

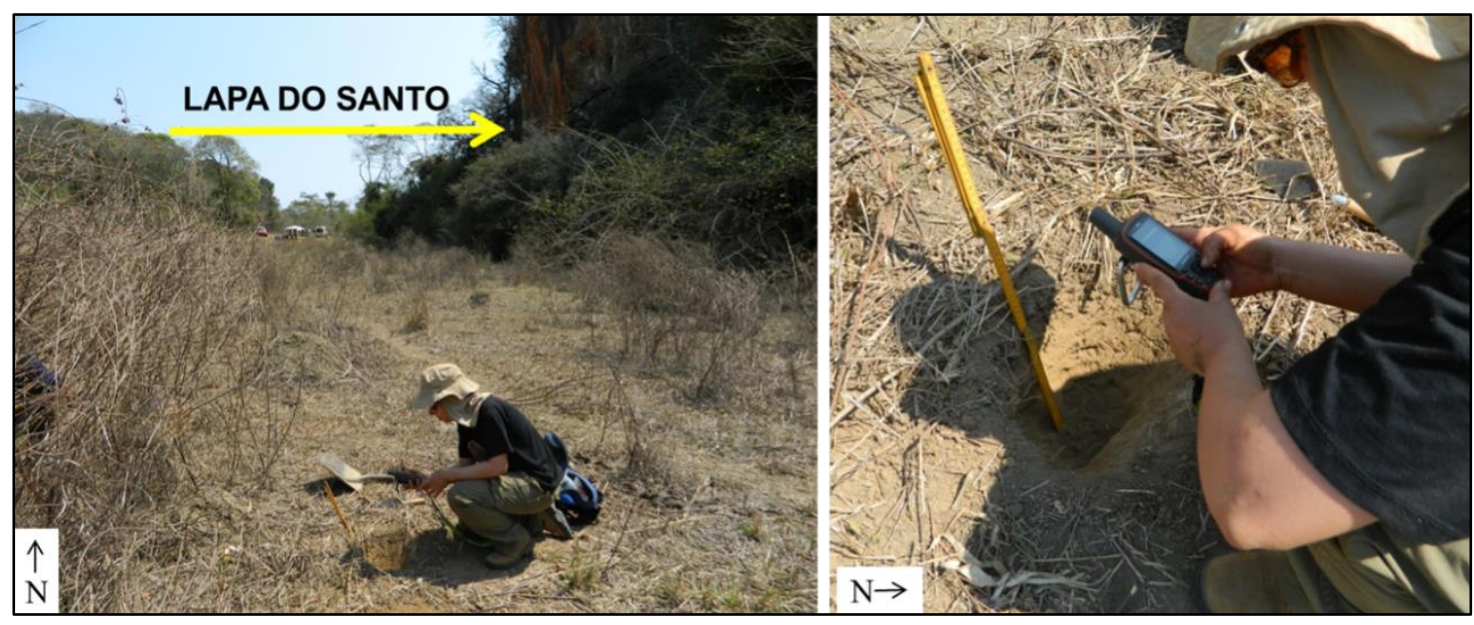

Figura 17. Coleta de sedimento em paleolago ao sul do abrigo (C3).
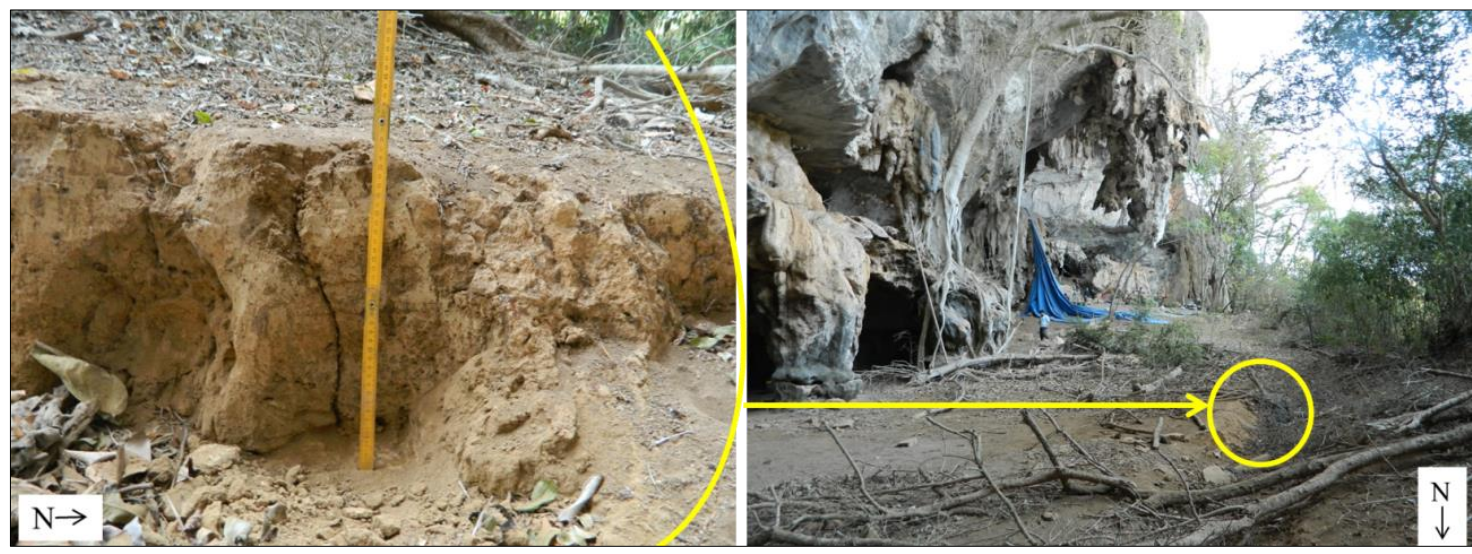

Figura 18. Coleta de sedimento em perfil ao norte da área de escavação do sítio (C1). 


\subsubsection{Amostras de Sedimento Analisadas}

As amostras de sedimento analisadas foram uma da quadra N23, uma da quadra P11, uma da quadra AE1 e uma de fora do sítio (Amostra C2) (Tabela 5).

Tabela 5. Sedimentos analisados.

\begin{tabular}{|c|c|c|c|c|c|c|}
\hline Quadra & PN & Nível (cm) & Facies & X & Y & $\mathbf{Z}$ \\
\hline N23 & 14030 & $6(50-60)$ & 8 & 13,442 & 22,392 & $-3,469$ \\
\hline P11 & 14398 & $16(150-160)$ & 14 & 15,309 & 10,227 & $-1,217$ \\
\hline AE1 & 14358 & $3(20-30)$ & 0 & 51 & 84 & 25 \\
\hline C2 & C2 & $3(20-30)$ & 0 & & & \\
\hline
\end{tabular}

\subsection{Localização das amostras na planta e perfis das quadras analisadas}

O material analisado das quadras N23 e P11 está nas camadas mais profundas (e últimas escavadas), o que pode ser observado nos croquis (Figura 19 e Figura 20). Os dados foram plotados em estação total, exceto para a quadra AE1 (Figura 21), dentro da caverna, em que se utilizou trena. 


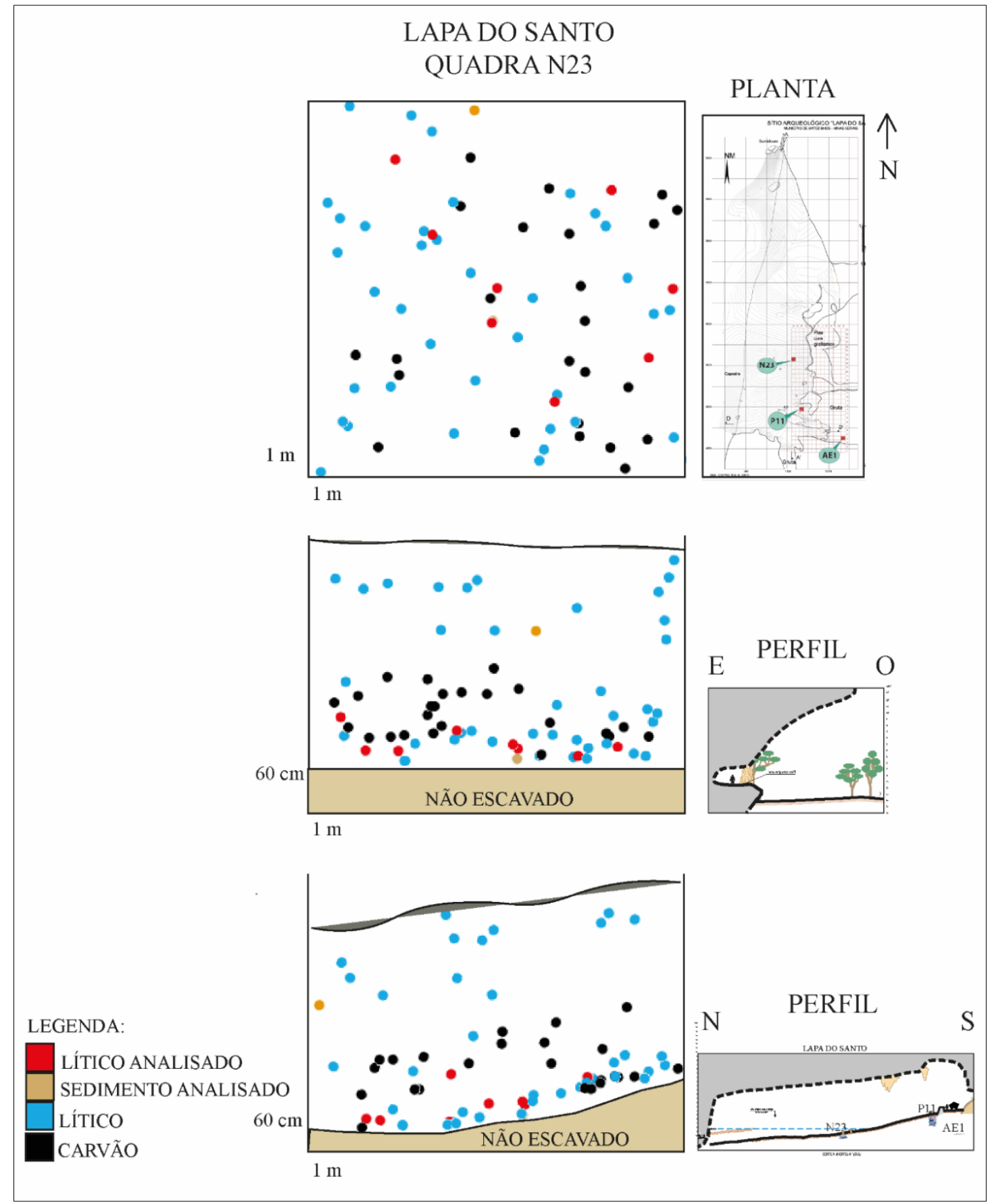

Figura 19. Croquis em planta e perfis da quadra N23. 


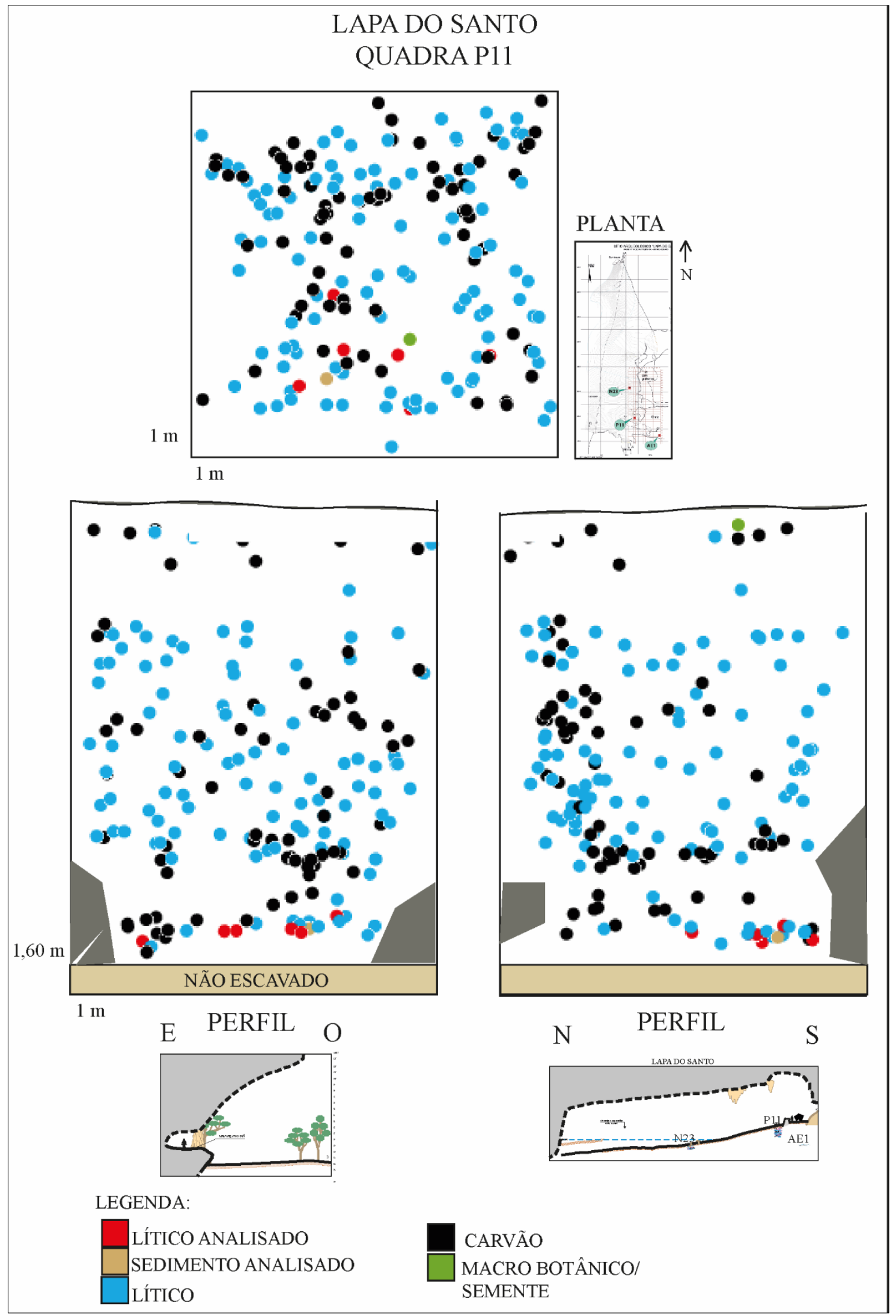

Figura 20. Croquis em planta e perfis da quadra P11. 


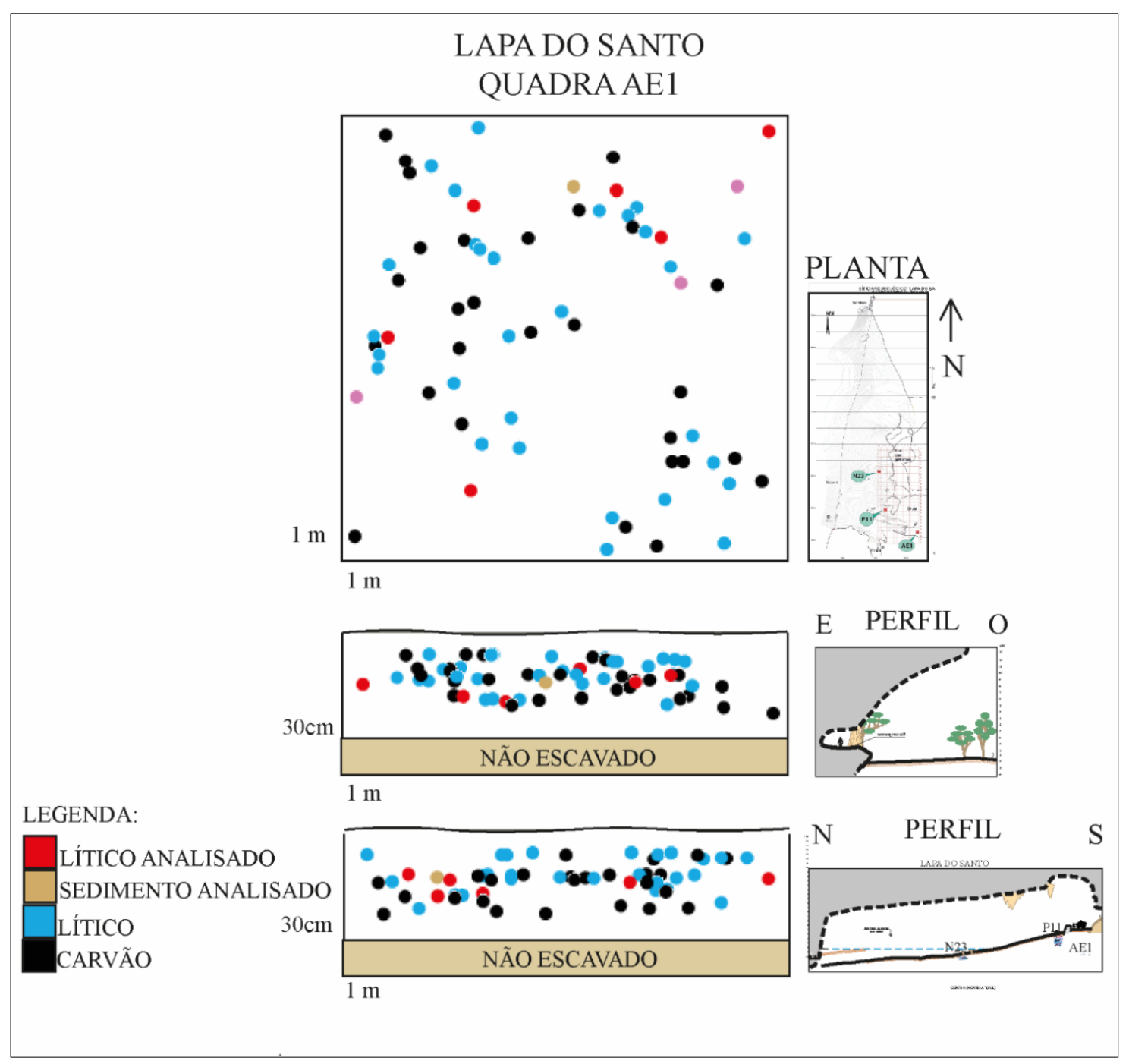

Figura 21. Croquis em planta e perfis da quadra AE1. 


\subsubsection{Antiguidade dos Contextos Analisados}

Como mencionado no Tópico 1.5, as datações na Lapa do Santo indicam três períodos de ocupação humana bem definidos. O Período 1 inicia há 12.700 e vai até 8000 anos cal. A.P. e se sabe que esse período possui profundidade abaixo do valor $\mathrm{z}$ de $0.137 \mathrm{~m}$ no sítio (Figura 22). O Período 2 vai de 5400 a 3900 anos cal. A.P. e sua profundidade está entre os valores de z $0.137 \mathrm{~m}$ e $0.947 \mathrm{~m}$ (Figura 22). O Período 3 inicia há 2100 anos cal. A.P. e vem até pouco antes do período colonial, estando nas camadas acima do valor de z de 0.947 m na profundidade do sítio (Figura 22).

\begin{tabular}{|llll|}
\hline \multicolumn{2}{|c}{ Table 1. Chronological periods for the 2001-2009 excavations in Lapa do Santo. } \\
\hline & $\mathbf{6 8 . 2} \%$ interval & $\mathbf{9 5 . 4 \%}$ interval & $\begin{array}{l}\text { Vertical interval } \\
\text { (z-value in meters) }\end{array}$ \\
\hline Lapa do Santo Period 3 & $0.7-1.1 \mathrm{cal} \mathrm{kyBP}$ & $0-2.1 \mathrm{cal} \mathrm{kyBP}$ & $>0.947$ \\
Lapa do Santo Period 2 & $4.0-5.2 \mathrm{cal} \mathrm{kyBP}$ & $3.9-5.4 \mathrm{cal} \mathrm{kyBP}$ & $0.137-0.947$ \\
Lapa do Santo Period 1 & $8.1-12.5 \mathrm{cal} \mathrm{kyBP}$ & $8.0-12.7 \mathrm{cal} \mathrm{kyBP}$ & $<0.137$ \\
\hline
\end{tabular}

Figura 22. Períodos cronológicos da Lapa do Santo para as escavações de 2001 a 2009. Fonte: Strauss (2016:133-tese)

Partindo desse raciocínio, podemos verificar, com a profundidade dos contextos analisados nesta pesquisa, à qual período cronológico da Lapa do Santo eles pertencem. Com base na Tabela 6, com dados já apresentados da profundidade das unidades estudadas (Tabela 3 e Tabela 5), se percebe que o material analisado da quadra N23, da quadra P11 e do Sep. 39 se encontram no Período 1. Os valores para a quadra AE1 não foram tomados com estação total, mas sim com trena (valores em centímetros), a partir da superfície inicial da escavação, por isso esses valores não podem ser comparados com os dados de z para as demais quadras.

Tabela 6. Profundidade dos contextos analisados

\begin{tabular}{|c|c|c|c|c|c|}
\hline Quadra & Material & PN & Nível $(\mathbf{c m})$ & $\mathbf{Z}$ & Período \\
\hline N23 & Lítico & 13014 & $6(50-60 \mathrm{~cm})$ & $-3,377$ & 1 \\
\hline N23 & Lítico & 14017 & $6(50-60)$ & $-3,436$ & 1 \\
\hline N23 & Lítico & 13067 & $6(50-60)$ & $-3,445$ & 1 \\
\hline N23 & Lítico & 13885 & $6(50-60)$ & $-3,493$ & 1 \\
\hline N23 & Lítico & 14029 & $6(50-60)$ & $-3,444$ & 1 \\
\hline
\end{tabular}




\begin{tabular}{|c|c|c|c|c|c|}
\hline Quadra & Material & PN & Nível (cm) & $\mathbf{Z}$ & Período \\
\hline N23 & Lítico & 13120 & $6(50-60)$ & $-3,372$ & 1 \\
\hline N23 & Lítico & 13962 & $6(50-60)$ & $-3,491$ & 1 \\
\hline N23 & Lítico & 13431 & $6(50-60)$ & $-3,494$ & 1 \\
\hline N23 & Sedimento & 14030 & $6(50-60)$ & $-3,469$ & 1 \\
\hline P11 & Lítico & 14292 & $15(140-150)$ & $-1,173$ & 1 \\
\hline P11 & Lítico & 14385 & $16(150-160)$ & $-1,247$ & 1 \\
\hline P11 & Lítico & 14391 & $16(150-160)$ & $-1,204$ & 1 \\
\hline P11 & Lítico & 14410 & $16(150-160)$ & $-1,209$ & 1 \\
\hline P11 & Lítico & 14469 & $16(150-160)$ & $-1,232$ & 1 \\
\hline P11 & Lítico & 14369 & $16(150-160)$ & $-1,216$ & 1 \\
\hline P11 & Sedimento & 14398 & $16(150-160)$ & $-1,217$ & 1 \\
\hline AE1 & Lítico & 14267 & $2(10-20)$ & $20 \mathrm{~cm}^{*}$ & - \\
\hline AE1 & Lítico & 14236 & $2(10-20)$ & $20 \mathrm{~cm}^{*}$ & - \\
\hline AE1 & Lítico & 14355 & $3(20-30)$ & $25 \mathrm{~cm}^{*}$ & - \\
\hline AE1 & Lítico & 14335 & $3(20-30)$ & $25 \mathrm{~cm}^{*}$ & - \\
\hline AE1 & Lítico & 14353 & $3(20-30)$ & $25 \mathrm{~cm}^{*}$ & - \\
\hline AE1 & Lítico & 14297 & $3(20-30)$ & $25 \mathrm{~cm}^{*}$ & - \\
\hline AE1 & Sedimento & 14358 & $3(20-30)$ & $25 \mathrm{~cm}^{*}$ & - \\
\hline Sep. 39 & Lítico & 14192 & $13(120-130)$ & $-1,242$ & 1 \\
\hline
\end{tabular}

As datações mais próximas da quadra N23, com valor de $\mathrm{z}$ aproximado aos da quadra N23 (cerca de -3,4), estão ao sul da mesma: quadra G13 com carvão (z -3,74) datado em 10.573 anos cal. A.P. ${ }^{43}$; e quadra F13 com carvão (z -3,755) datado em $9662^{44}$ anos cal. A.P.

As datações mais próximas da quadra $\mathrm{P} 11$, com valor de $\mathrm{z}$ aproximado aos da quadra P11 (cerca de -1,2), são: A quadra G12, com carvão (z -1,303) datado em 9463 anos cal. A.P $P^{45}$. A quadra, G13 com carvão (z -1900) datado em 9913 anos cal. A.P ${ }^{46}$. E a quadra M6 com carvão (z 1,512) datado também em 9913 anos cal. A.P ${ }^{47}$.

A quadra AE1 e o Sepultamento 39 ainda não foram datados.

\footnotetext{
${ }^{43}$ (intervalo de 95,4\%) Strauss et al., 2016.

${ }^{44}$ (intervalo de 95,4\%) Strauss et al., 2016.

45 (intervalo de 95,4\%) Strauss et al., 2016.

46 (intervalo de 95,4\%) Strauss et al., 2016.

47 (intervalo de 95,4\%) Strauss et al., 2016.
} 


\subsection{Extração de Microvestígios Botânicos}

Inicialmente, foram aplicados dois protocolos para análise de oito líticos da quadra N23 (Etapa 1), sendo eles: Extração com Pipeta (step-wise sample) (Etapa 1a) e sonicação sem aplicação de reagentes e sem flotação com líquido pesado (Etapa 1b) (Tópico 3.6.1).

Devido a resultados insatisfatórios na recuperação de microvestígios botânicos (Tópico 4.1 e Tópico 5.1), apresentados na avaliação de qualificação, se optou por, a partir de então, aplicar um terceiro protocolo utilizado no laboratório do Prof. Marco Madella, na Universitat Pompeu Fabra (Etapa 2) (Tópico 3.7).

\subsubsection{Etapa 1a: Pipeta ou Método Step-Wise}

O processamento inicial das amostras para o estudo dos microvestígios foi realizado no Laboratório de Antropologia Biológica do IB/USP, coordenado pela Profa. Dra. Sabine Eggers, sob a orientação e supervisão da Dra. Célia Boyadjian. O procedimento de sonicação dos líticos foi realizado no Laboratório de Arqueologia, Antropologia Ambiental e Evolutiva (LAAAE-IB/USP) ${ }^{48}$, coordenado pelos Profs. Drs. Rui Murrieta e André Strauss, com instrução do Dr. Leandro Cascon e da Dra. Caroline Caromano.

O primeiro protocolo de extração aplicado é realizado com pipeta (Método StepWise) (Perry, 2001) (Figura 23) consiste nas seguintes etapas: 1) aplicar com pipeta, sob a superfície do artefato, entre 20 e $30 \mu \mathrm{l}$ de água ultrapura; 2) após deixar a água na superfície por alguns minutos, coletar com a pipeta; 3) transferir o resíduo para uma lâmina de microscopia óptica; 4) cobrir o resíduo com lamínula e selar com esmalte de unhas (Perry, 2001; Loy \& Fullagar, 2006). As lâminas foram montadas com glicerol (concentração 25\%), meio móvel que permite a rotação dos microvestígios botânicos e, assim, a visualização de seu aspecto tridimensional, o que possibilita sua melhor identificação (Field, 2006; Boyadjian, 2012: 59).

\footnotetext{
${ }^{48}$ Até o ano de 2017 era denominado Laboratório de Estudos Evolutivos Humanos (LEEH-USP) ${ }^{48}$ e até então coordenado pelo Prof. Dr. Rui Murrieta e o Prof. Dr. Walter Neves.
} 


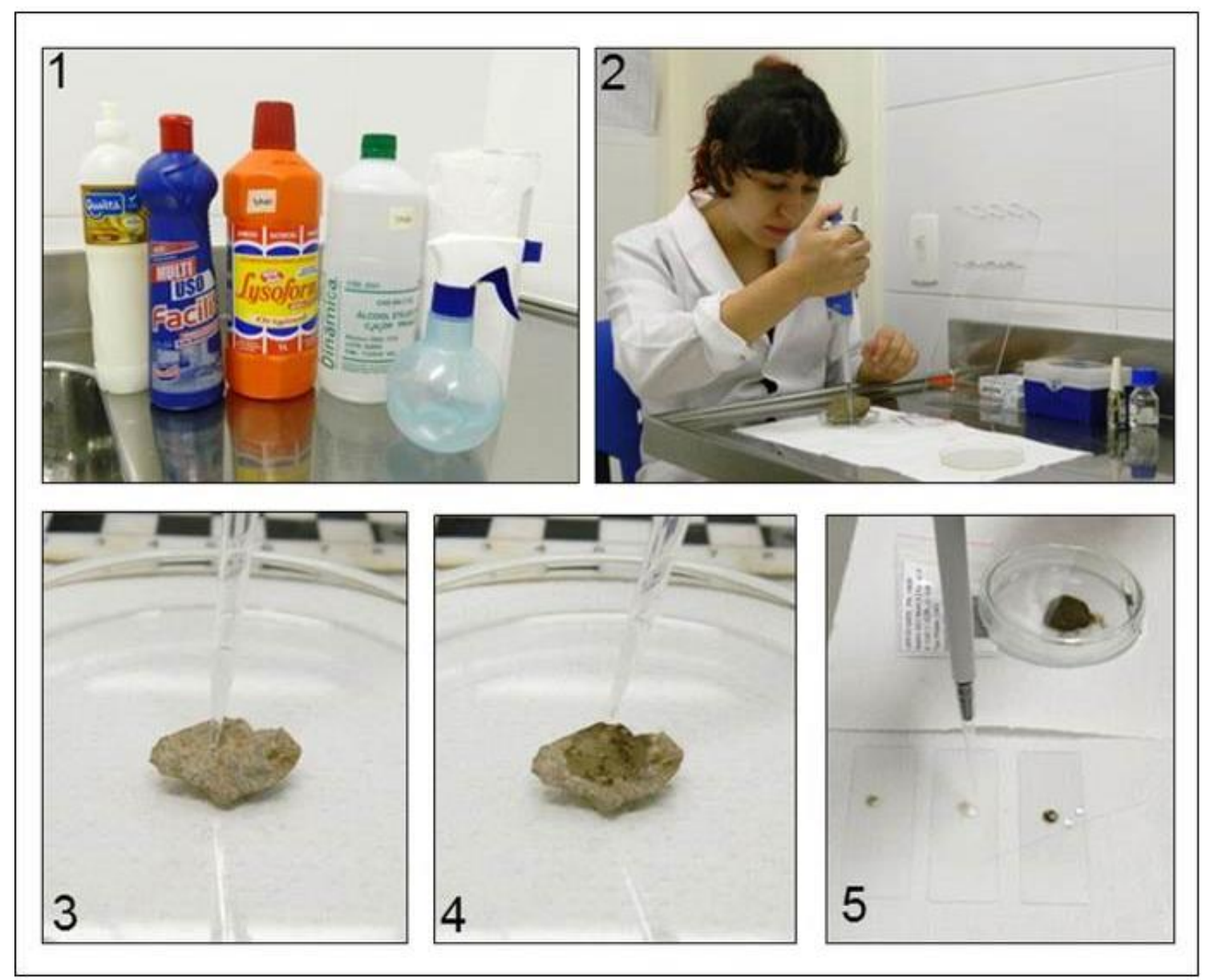

Figura 23. Método de extração de microvestígios com pipeta. 1) Materiais utilizados na higinenização do laboratório. 2) Extração. 3-4) Aplicação da gota de água. 5) Montagem das lâminas.

Esse protocolo não sugere a prévia escovação dos líticos. Dessa maneira, foram aplicadas três gotas de água (uma de cada vez) que resultaram na montagem de três lâminas de um mesmo ponto no lítico. A intenção é de que a primeira gota aplicada no local seja considerada uma amostra dos microvestígios presentes no ambiente do sítio arqueológico. A segunda gota seria intermediária e a terceira gota seria aquela a ser analisada. Foram amostrados oito líticos da quadra N23 cujos locais de coleta estão circulados na Figura 24. 


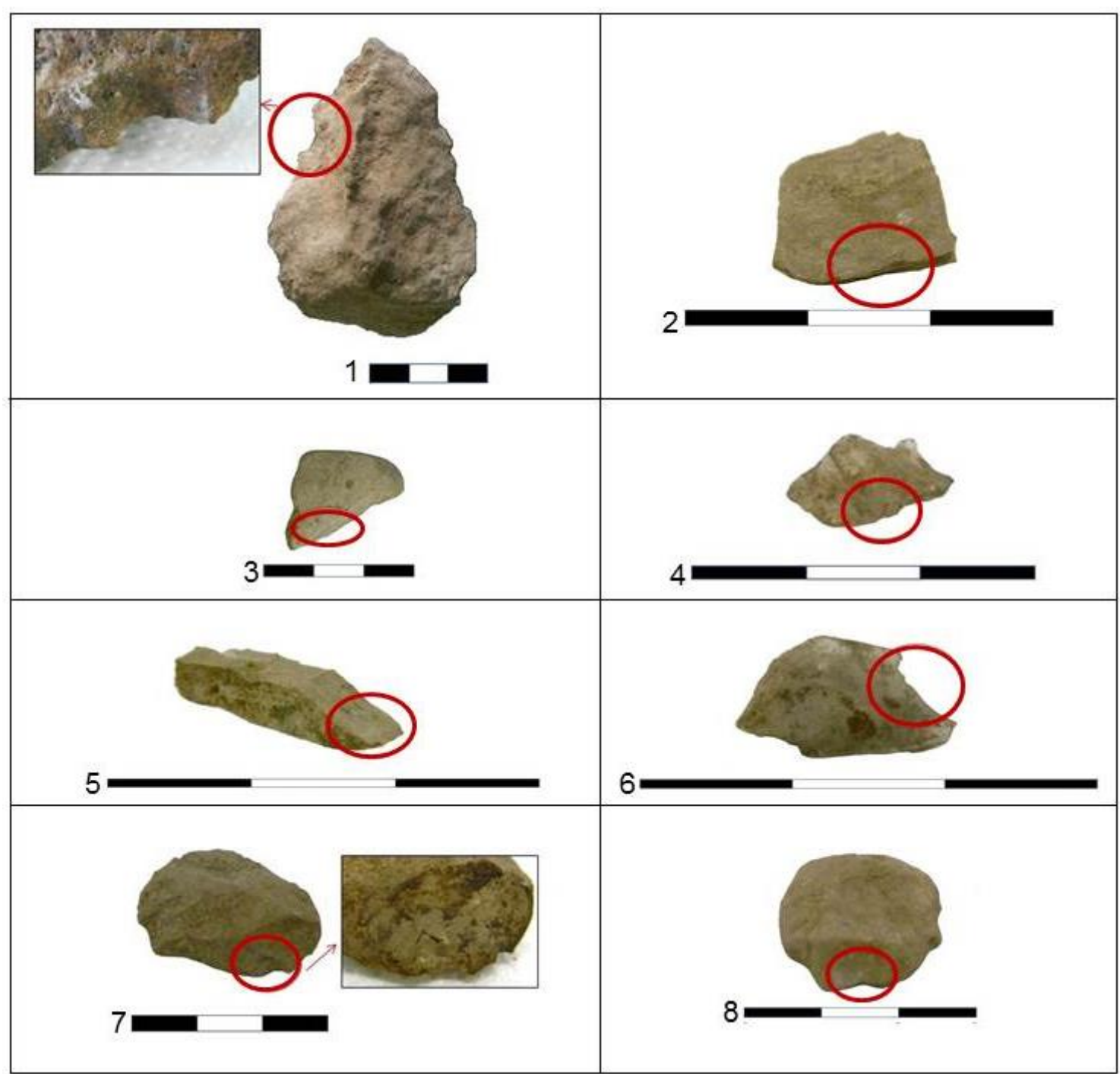

Figura 24. Locais onde as amostras foram extraídas nos oito líticos da quadra N23. 1) Lítico PN: 13014, 2) PN: 13067, 3) PN: 13120, 4) PN: 13431, 5) PN: 13885, 6) PN: 13962, 7) PN: 14017, 8) PN: 14029.

\subsubsection{Etapa 1b: Técnica de Escovação e Sonicação}

Após a Etapa 1a (aplicação da técnica da pipeta ou método step-wise) os oito líticos foram escovados e sonicados. A escovação foi feita com escova interdental sobre papel alumínio (Figura 11). O sedimento escovado foi recolhido e acondicionado caso seja necessário futuramente.

A técnica de sonicação busca desagregar os microvestígios aderidos ao artefato através de um aparelho denominado banho de ultrassom (Pearsall, 2015; Lombardo et al; 2016). O artefato é colocado dentro de um becker ou tubo falcon ${ }^{49}$ com água destilada que, por sua vez, é imerso em água dentro do aparelho, que emitirá ondas

\footnotetext{
${ }^{49}$ De $15 \mathrm{ml}$ ou $50 \mathrm{ml}$ dependendo das dimensões do lítico.
} 
sonoras que vibrarão na água, o que desagregará o resíduo dos líticos (Pearsall, 2015; Lombardo et al; 2016). Cada lítico foi sonicado por 10 minutos (Figura 35). A solução resultante da sonicação foi centrifugada por 3 minutos a 3000rpm (Cascon, 2010). Com uma pipeta, os microvestígios do fundo de cada tubo centrifugado foram recolhidos e montados em duas lâminas para microscopia.

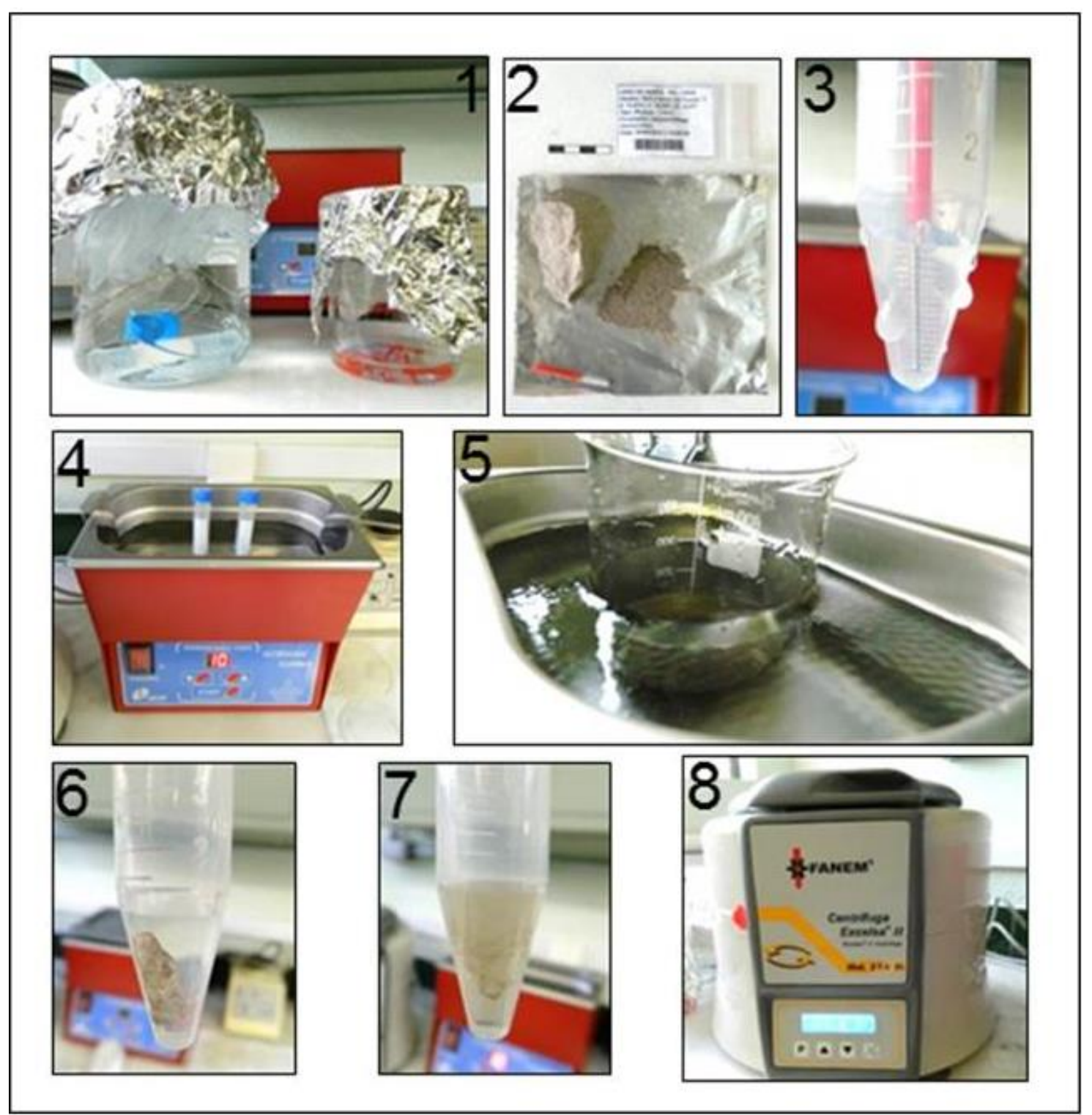

Figura 17. Extração com banho de ultrassom. 1) Materiais imersos em solução de água sanitária com água destilada. 2) Lítico escovado. 3) Amostra de possíveis resíduos na escova para controle de contaminação. 4-5) Banho de ultrassom. 6) Lítico antes do banho de ultrassom. 7) Lítico após banho de ultrassom, com material desagredado. 8) Centrífugação.

Os beckers de laboratório, tubos de centrífuga, placas de petri e escovas interdentais foram lavados com água destilada, imersos por um dia em solução de hipoclorito de sódio (água sanitária) para eliminar microrganismos e finalmente 
enxaguados com água destilada antes de sua utilização. Não foram usadas luvas no procedimento, mas as mãos foram sempre lavadas com detergente, secas com papel toalha depois limpas com álcool 70. A bancada e superfícies eram higienizadas com papel toalha e limpador multiuso, desinfetante lysoform e álcool 70. Para o controle de uma possível contaminação contemporânea, se fizeram lâminas com amostras das vidrarias, escovas e tubos utilizados, assim como do papel toalha, esmalte de unhas e glicerina utilizados (segundo o protocolo de Crowther et al; 2014).

Parte da solução sonicada foi amostrada diretamente em lâminas e observadas em microscópio. Os resultados da amostragem com pipeta e sonicação (Etapa 1) são apresentados no Tópico 4.1 e discutidos no Tópico 5.1.

Parte da solução sonicada dos primeiros oito líticos foi acondicionada para ser analisada na Etapa 2 (Tópico 3.7). Antes da Etapa 2 se realizou também a escovação e sonicação de mais 13 líticos: seis da quadra P11, seis da quadra AE1 e o lítico associado ao Sep. 39. (Tabela 3).

\subsection{Etapa 2: Método com Sonicação e Aplicação de Reagentes}

Sete, dos oito líticos sonicados que foram analisados na Etapa $1 \mathrm{~b}$ foram analisados também na Etapa 2. Um dos líticos (PN 13431) não seguiu para a Etapa 2 porque durante a aplicação das gotas de água quase toda a sua superfície foi amostrada, uma vez que esse lítico é muito pequeno (menor que $2 \mathrm{~cm}$ ), ainda que tenham aparecido microvestígios na Etapa 1b (Figura 27). Além desses sete da quadra N23 foram analisados na Etapa 2: seis líticos da quadra P11; seis da quadra AE1; e um lítico coletado no Sepultamento 39. Para a Etapa 2, todos os líticos passaram pela escovação e sonicação (como na Etapa 1b) e em seguida pela aplicação de reagentes.

Em 2018 foi realizado um estágio no laboratório do grupo de pesquisa CaSES (Complexity And Socio-Ecological Dynamics), sob orientação do Prof. Marco Madella, na Universitat Pompeu Fabra, em Barcelona. Foi realizado um treinamento para identificação microscópica de fitólitos e amido, que incluiu o processamento das amostras e o seu estudo posterior em microscópio. Durante o estágio se completou o processamento de todas as amostras contempladas nesta pesquisa. 
As amostras oriundas do processo de sonicação dos líticos, bem como o sedimento coletado no sítio foram processados de acordo com métodos apresentados por Madella et al; (1998), Therin \& Lentfer (2009:159-161), Barton \& Torrence (2006) e Lombardo, Ruiz-Pérez \& Madella (2016). Os protocolos aplicados e demais procedimentos de laboratório realizados estão descritos a seguir:

\subsubsection{Protocolo Usado para Processamento das Amostras e Recuperação de Fitólitos e Amido}

\section{$\underline{\text { Pesagem e secagem inicial das amostras }}$}

1. Escrever os códigos de laboratório daas amostras nos tubos falcon de $50 \mathrm{ml}$.

2. Pesar os tubos vazios (com tampa).

3. Colocar o sedimento em seu respectivo tubo ( $4 \mathrm{~g}$ cuando há e menos se não há quantidade suficiente).

4. Secar a amostra de sedimento do tubo em forno a $40^{\circ} \mathrm{C}$ sem tampa (Figura 25).

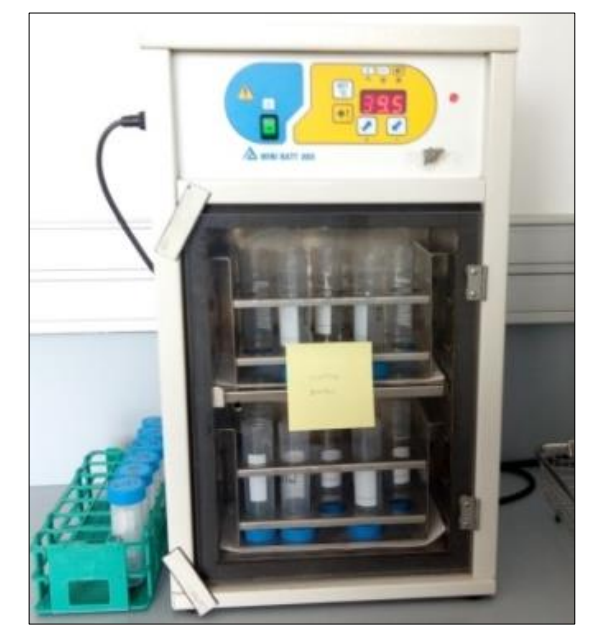

Figura 25. Amostras secando em forno.

5. Pesar os tubos fechados com as amostras de sedimento secas.

\section{Preparação de Sodium Hexametaphosphate (Calgon) em Concentração 5\%}

1. Adicionar $50 \mathrm{~g}$ de sodium hexametaphosphate $5 \%$ em pó (Figura 26A) a um becker. Antes, não esquecer de zerar a tara da balança com o becker. 


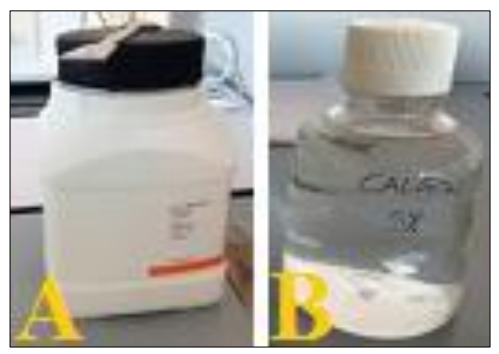

Figura 26. Preparação de Calgon. Calgon em pó (A) e Calgon 5\% (B).

2. Adicionar $950 \mathrm{ml}$ de água destilada a outro becker.

3. Colocar o becker com a água na placa para agitação HYCC (SH-2 magnetic stirrer), colocar um ímã no becker e iniciar a agitação.

4. Adicionar os $50 \mathrm{~g}$ de sodium hexametaphosphate $5 \%$ lentamente na água em movimento.

5. Quando a solução estiver homogênea, está pronto (Figura 26B).

\section{Disperção Inicial de Sedimentos}

(Adicionar Sodium Hexametaphosphate 5\% às amostras para limpá-las)

1. Adicionar sodium hexametaphosphate 5\% aos tubos com as amostras secas.

2. [Para flotar almido antes de flotar fitólitos]. Centrifugar a $2500 \mathrm{rpm}$ por 1 minuto

3. Remover o sobrenadante dos tubos com pipeta descartável.

4. Repetir o processo quantas vezes necessário até que o sobrenadante esteja limpo ou claro.

\section{Enxágue}

1. Adicionar água destilada aos tubos e centrifugar a $2500 \mathrm{rpm}$ por dois minutos.

2. Repetir esse processo três vezes.

\section{$\underline{\text { Secagem e Pesagem de Amostras Depois do Sodium Hexametaphosphate 5\% }}$}

1. Secar as amostras em forno a $40^{\circ} \mathrm{C}$.

2. Pesar as amostras despois de limpá-las com sodium hexametaphosphate 5\% e estiverem secas. 
Flotação do amido com Sodium Polytungstate (SPT) na gravidade específica de

\section{$1.6 \mathrm{~g} / \mathrm{cm} 3$}

1. Adicionar SPT pela primeira vez com pipeta descartável ao tubo com a amostra seca até a marca de $15 \mathrm{ml}$.

2. Passar os tubos em um agitador.

3. Colocar os tubos em banho de ultrassom a $20^{\circ} \mathrm{C}$ por dez minutos.

4. Centrifugar a $2500 \mathrm{rpm}$ por dez minutos (Figura 27).

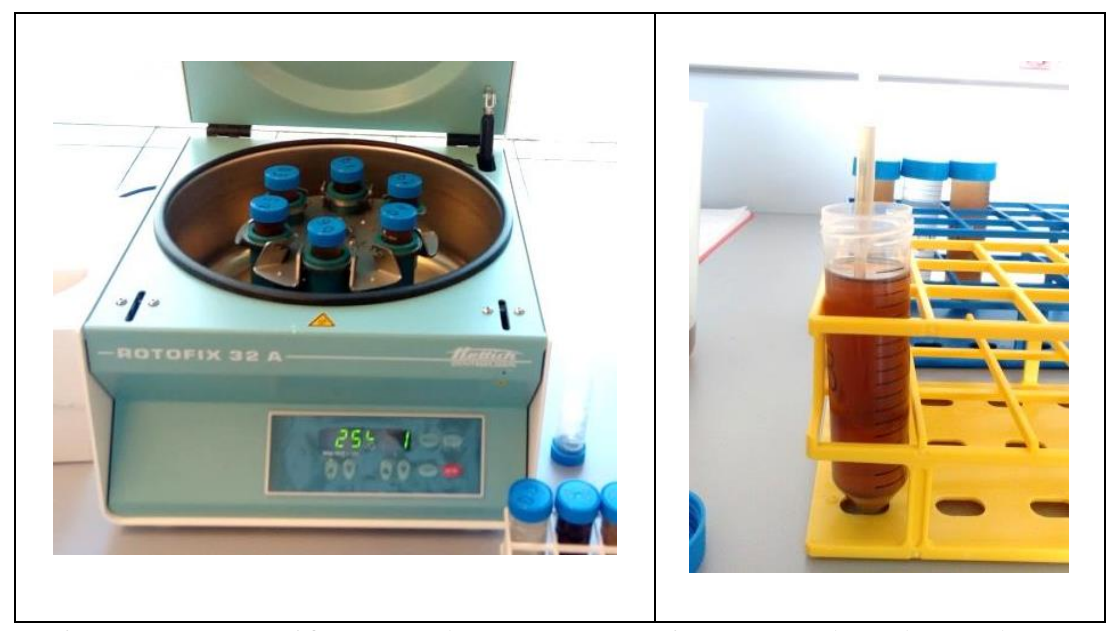

Figura 27. Centrifugação de amostras e pipetagem do sobrenadante.

5. Preparar tubos-cópia para acondicionar amido flotado e uma pipeta de vidro para cada tubo. Observação: as mesmas pipetas de vidro e pipetador de borracha são utilizados para ss duas etapas de flotação (primeira e segunda vez com SPT).

6. Recuperar amido flotado com pipetas de vidro (Figura 28).

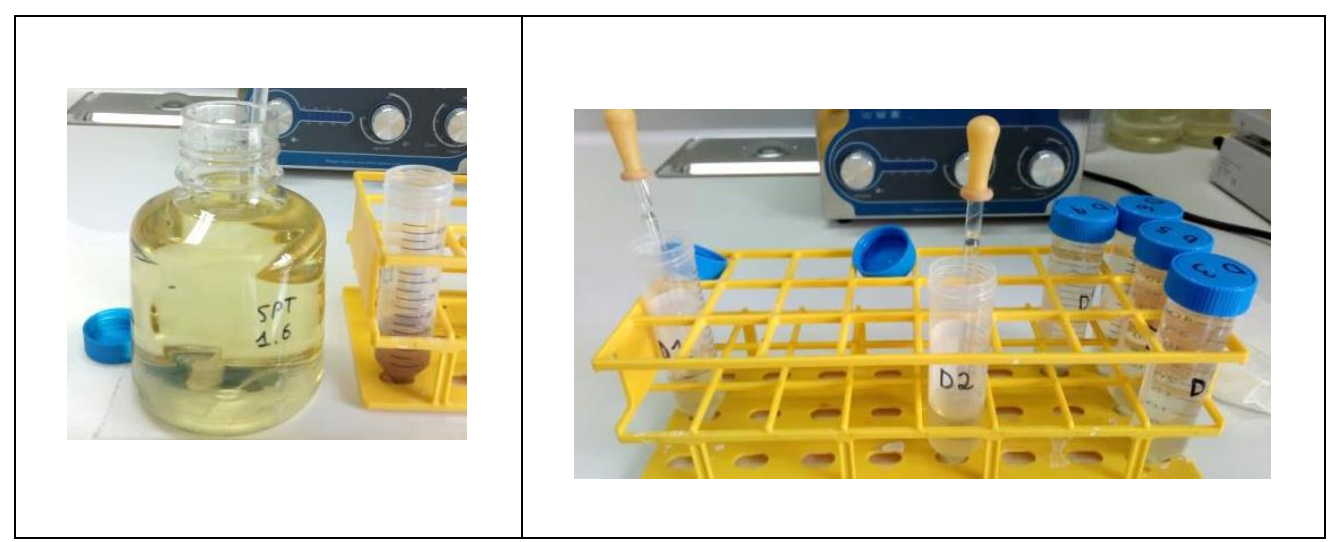

Figura 28. SPT 1.6 e flotação de amido.

7. Adicionar SPT 1.6 pela segunda vez até a marca de $10 \mathrm{ml}$ no tubo.

8. Centrifugar a $2500 \mathrm{rpm}$ por 10 minutos novamente.

9. Ao fim da flotação pela segunda vez, limpar a pipeta de vidro com água destilada 
dentro do tubo para que não se perda amostra.

Limpeza de SPT em gravidade específica de $1.6 \mathrm{~g} / \mathrm{cm} 3$ dos tubos-cópia com amido flotado

1. Adicionar água destilada ao tubo.

2. Centrifugar os tubos a $3000 \mathrm{rpm}$ por dez minutos. Observação: sempre agitar os tubos e se necessário utilizar um agitador.

3. A primeira solução pipetada com SPT depois de centrifugadas as amostras se coloca para reciclagem.

4. Pipetar pela primeira vez até a metade do tubo.

5. Adicionar água destilada ao tubo até encher novamente.

6. Centrifugar a $3000 \mathrm{rpm}$ por cinco minutos. Repetir o processo três vezes.

\section{Acondicionamento do amido nos frascos pequenos, secagem e pesagem}

1. Acondicionar amido nos frascos pequenos. Fazer com jato de água destilada de uma garrafa, do tubo para o frasco, com cuidado.

2. Colocar os frascos com almidón para secar ao horno.

3. Pesar os frascos secos com amido (sem a tampa).

\section{Limpeza do SPT dos tubos originais que serão preparados para fitólitos}

1. Adicionar água destilada aos tubos.

2. Centrifugar a $2500 \mathrm{rpm}$ por dois minutos. Repetir o processo quatro vezes. Observação: a primeira pipetagem de SPT é para reciclagem.

\section{Eliminação dos carbonatos para flotação dos fitólitos ${ }^{50}$}

1. Las muestras necesitan estar secas. Pesar.

2. Adicionar ácido clorídrico $(\mathrm{HCl}) 10 \%^{51}$ aos tubos originales con fitólitos hasta 1 marca de $5 \mathrm{ml}$.

3. Pasal los tubos con fitólitos y ácido clorídrico $(\mathrm{HCl}) 10 \%$ en agitador.

4. Añadir hasta más ácido clorídrico $(\mathrm{HCl}) 10 \%$ hasta la marca de $10 \mathrm{ml}$ si la muestra sigue reaccionando.

\footnotetext{
${ }^{50}$ Colocar luvas, óculos de proteção, e máscaras se necessário. Realizar o processo na capela.

${ }^{51} \mathrm{O}$ ácido clorídrico $(\mathrm{HCl})$ comprado tem concentración de 35\%. Mas se necesita o $\mathrm{HCl}$ com concentração de 10\%. Para preparar $\mathrm{HCl} 10 \%$ de um $\mathrm{HCl} 35 \%$, é necessário adicionar $285 \mathrm{ml}$ de $\mathrm{HCl}$ $35 \%$ e completar com água destilada até $1 \mathrm{~L}$ de solución.
} 
5. Cuando las muestras paran de reaccionar la solucción en el tubo se queda verde, en general (Figura 29).

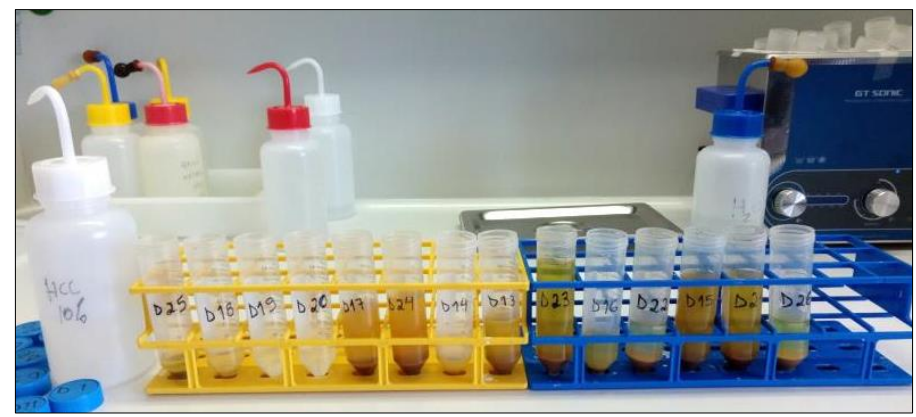

Figura 29. Amostras reagindo com $\mathrm{HCl} 10 \%$.

Limpeza do ácido clorídrico $(\mathrm{HCl}) 10 \%$ dos tubos ${ }^{52}$

1. Adicionar água destilada aos tubos com amostras que já reagiram com ácido clorídrico.

2. Centrifugar a $2500 \mathrm{rpm}$ por dois minutos. Repetir o processo quatro vezes.

\section{Eliminação da matéria orgânica ${ }^{53}$}

1. Adicionar peróxido de hidrogênio $\left(\mathrm{H}_{2} \mathrm{O}_{2}\right)$ aos tubos (que recibieron $\mathrm{HCl} 10 \%$ e já foram lavados) até a marca de $10 \mathrm{ml}$.

2. Pasar os tubos em agitador.

3. Colocar os tubos abertos sem tampa em banho de ultrassom por 30 minutos a $60{ }^{\circ} \mathrm{C}$ (Figura 30).

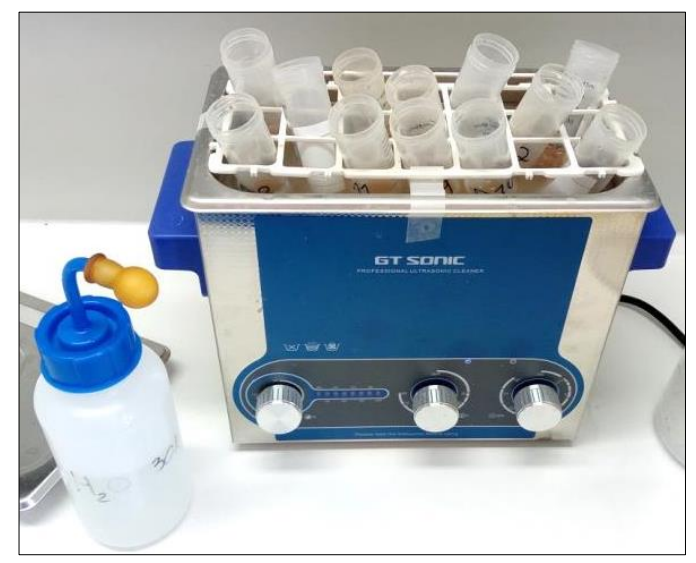

Figura 30. Amostras com o peróxido de hidrogênio em banho de ultrassom.

4. Retirar do banho de ultrassom e deixar descansar por 30 minutos.

\footnotetext{
${ }^{52}$ Colocar luvas, óculos de proteção, e máscaras se necessário. Realizar o processo na capela.

${ }^{53}$ Colocar luvas, óculos de proteção, e máscaras se necessário. Realizar o processo na capela.
} 
5. Passar os tubos em agitador.

6. Se as amostras ainda reagem, adicionar mais $\mathrm{H}_{2} \mathrm{O}_{2}$.

7. Se necessário, trocar o $\mathrm{H}_{2} \mathrm{O}_{2}$ das muestras. Para isso, adicionar água destilada aos tubos e centrifugar a $2500 \mathrm{rpm}$ por dois minutos. Pipetar e colocar mais $\mathrm{H}_{2} \mathrm{O}_{2}$.

\section{Limpeza de peróxido de hidrogêno $\left(\mathrm{H}_{2} \underline{\mathrm{O}}_{2}\right)$ dos tubos ${ }^{54}$}

1. Adicionar água destilada aos tubos.

2. Centrifugar a $2500 \mathrm{rpm}$ por dois minutos. Repetir o processo quatro vezes.

3. Adicionar sodium hexametaphosphate $5 \%$ aos tubos.

4. Colocar em banho de ultrassom a $60^{\circ} \mathrm{C}$ por dez minutos.

5. Centrifugar a $1500 \mathrm{rpm}$ por três minutos.

6. Pipetar.

7. Se o sobrenadante não está limpo, adicionar mais sodium hexametaphosphate 5\% aos tubos. Nesse caso, repetir o processo de banho de ultrassom, centrifugar e pipetar.

8. Limpar o sodium hexametaphosphate 5\% dos tubos. Adicionar água destilada aos tubos. Centrifugar a $2500 \mathrm{rpm}$ por dois minutos. Repetir esse processo de limpeza quatro vezes.

9. Secar as amostras em forno.

Flotação dos fitólitos com SPT em gravidade específica $2.3 \mathrm{~g} / \mathrm{cm}^{355}$

1. Pesar amostras secas.

2. Adicionar o SPT 2.3 aos tubos até a marca de $15 \mathrm{ml}$.

3. Colocar os tubos em agitador.

4. Colocar os tubos em banho de ultrassom a $60{ }^{\circ} \mathrm{C}$ por dez minutos.

5. Preparar tubos-cópia e pipetas de vidro.

6. Centrifugar a $3000 \mathrm{rpm}$ por cinco minutos.

7. Pipetar (ou flotar) os fitólitos até a marca de $5 \mathrm{ml}$ no tubo e colocá-los nos tuboscópia.

8. Adicionar mis SPT até a marca de $10 \mathrm{ml}$.

9. Colocar os tubos em agitador.

10. Centrifugar a $3000 \mathrm{rpm}$ por cinco minutos.

\footnotetext{
${ }^{54}$ Colocar luvas, óculos de proteção, e máscaras se necessário. Realizar o processo na capela.

${ }^{55}$ Colocar luvas, óculos de proteção, e máscaras se necessário. Realizar o processo na capela.
} 
11. Pipetar até a marca de $5 \mathrm{ml}$.

12. Encher com água os tubos-cópia com fitólitos. Limpar a pipeta no tubo para não perder amostra.

13. Centrifugar tubos-cópia com fitólitos a $3000 \mathrm{rpm}$ por dez minutos.

14. Recuperar SPT dos tubos-cópia com fitólitos pipetando até a marca de $5 \mathrm{ml}$..

15. Lavar tubos-cópia com fitólitos quatro vezes a $2500 \mathrm{rpm}$ por dois minutos na centrífuga.

16. Para recuperar SPT dos tubos originais, se deve adicionar água e centrifugar a 3000 rpm por três minutos.

\section{Acondicionamento dos fitólitos, secagem e pesagem}

1. Acondicionar fitólitos em frascos pequenos. Fazer com jato de água destilada de uma garrafa, do tubo para o frasco.

2. Colocar os frascos com fitólitos para secar no forno.

3. Pesar frascos com fitólitos (sem tampa).

As lâminas com amostras de amido foram preparadas com meio de montagem glicerol (concentração 25\%) e as lâminas com amostras de fitólitos foram montadas com Entellan ${ }^{\circledR}$. As lâminas preparadas foram analisadas sob microscópio petrográfico Leica DM2700P em luz plana polarizada (PPL) e luz polarizada cruzada (XPL) (essencial para a detecção e análise do amido).

\subsubsection{Amostras de materiais utilizados em laboratório para controle de}

\section{contaminação}

Amostras de materiais de laboratório foram montadas em lâmina e visualizadas ao microscópio. Seis lâminas de água destilada foram analisadas, dentre elas três ficaram por $24 \mathrm{~h}$ abertas ao ar livre no laboratório, para que que coletassem partículas do ar também. O papel toalha é utilizado em todas as etapas de laboratório, para higienização das bancadas e das lâminas (com álcool), secagem de utensílios e das mãos, por isso duas lâminas com papel toalha macerado e picotado foram analisadas. E foi analisada uma lâmina com esmalte da marca colorama, utilizado para montagem das lâminas de amido. 


\subsection{Análise dos Microvestígios Botânicos}

Em 2018 foi realizado um estágio no Laboratório de Arqueobotânica e Paisagem (LAP), Setor de Arqueologia, Departamento de Antropologia do Museu Nacional da Universidade Federal do Rio de Janeiro (UFRJ), coordenado pela Profa. Dra. Rita Scheel-Ybert, sob a orientação da Profa. Dra. Célia Boyadjian. No estágio se obteve treinamento em análise de microvestígios botânicos com foco na identificação de grãos de amido e se analisaram algumas amostras.

As análises de microscopia foram realizadas no Laboratório de Microarqueologia (LABMICRO) do MAE/USP (processo FAPESP 2015/19405-6) coordenado pela Profa. Dra. Ximena S. Villagran, com orientação da Dra. Célia Boyadjian, do Ms. Javier Ruiz-Pérez e do Dr. Marco Madella durante sua visita ao MAE em dezembro de 2018.

A descrição dos grãos de amido e a sua identificação taxonômica foram realizadas a partir da observação de características morfométricas e de aspectos como a forma e a visibilidade da cruz de interferência, a presença e localização do hilo, a visibilidade das lamelas, a presença de fissuras e elementos da superfície (Torrence, 2006). A identificação dos morfotipos de fitólitos segue a bilbiografia especializada no tema, tais como: Pearsall (2015), Piperno (2006), Pagán-Jimenez (2015) e Madella, Alexandre \& Ball (2005). Gráficos foram gerados com o uso do software C2.

\section{Medição das cruzes variante 1 neste trabalho}

Como regra geral, as cruzes de Zea mays possuem a morfologia variante $1 \mathrm{e}$ estima-se que possuam entre $16 \mu \mathrm{m}$ a $21 \mu \mathrm{m}$ de tamanho, sendo maiores que as de outras Poaceas que não ultrapassariam os $16 \mu \mathrm{m}$ de tamanho ${ }^{56}$ (Pearsall e Piperno, 1990; Piperno, 2006:56,200). Mais seguramente se atribui à Zea mays cruzes com tamanho superior $20.5 \mu \mathrm{m}$ (Pearsall \& Piperno, 1990). Portanto, neste trabalho como há no total apenas 21 cruzes variante 1 e outras cruzes associadas à categoria "outras

\footnotetext{
${ }^{56}$ Pode haver variações regionais (Pearsall e Piperno, 1990:327).
} 
variantes", não foi possível aplicar a função discriminante. Mas a largura das cruzes variante 1 foi medida para verificar se podem ser associadas a milho.

\subsection{Descrição Tecnológica Preliminar dos Artefatos Líticos}

Este trabalho realizará uma descrição tecnológica preliminar dos artefatos líticos, para que dê suporte à interpretação dos resultados e discussões. Não se trata de uma análise tecnológica.

Alguns traços tecnológicos ${ }^{57}$ serão descritos, como: a classe da peça (lasca, fragmento), matéria-prima, presença de talão, ponto de impacto, bulbo, ondas de propagação, lancetas e negativos, localização dimensão e morfologia dos retoques, acidentes de lascamento, produção de suporte com a debitagem, se há configuração do instrumento $^{58}$ com a façonangem e se há produção ou modificação da região do gume com retoque (Dauvois, 1976, Balfet, 1991, Pelegrin, 1988; Inizan et al; 1995, Boëda, 1997; Fogaça, 2001). A debitagem, a partir de um núcleo e por meio do lascamento, tem como objetivo a produção de lascas suporte que serão utilizadas ou trabalhadas (Pelegrin, 1988). A façonagem, a partir de lascamentos sucessivos de um fragmento de rocha ou suporte, busca configurar um instrumento (Pelegrin, 1988). O retoque busca a configuração da região do gume (Inizan et al; 1995, Marchand, 1999).

Existe uma relação - não determinante - entre a morfologia de um instrumento e os seus possíveis usos e funções (Marchand, 1999). Determinados tipos de gume serão preferidos e mais eficientes para cortar e outros para raspar, por exemplo (Marchand, 1999). A extremidade do gume é denominada plano de bico, é a área do instrumento que entra em contato direto com a matéria a ser processada (Boëda, 1997; Viana, 2005; Moreno de Sousa, 2014; Ramos, 2016). Logo atrás está o plano de corte do instrumento com a superfície do mesmo, direciona e estabiliza a ação e pode ou não entrar em contato com a matéria a ser processada (Boëda, 1997; Viana, 2005; Moreno de Sousa, 2014, Ramos, 2016). Gumes com ângulo entre $70^{\circ}$ e $90^{\circ}$ estariam relacionados à funcionalidade de raspar e gumes com ângulo entre $40^{\circ}$ e $60^{\circ}$ estariam aptos a funcionalidade de cortar (Boëda, comunicação pessoal, 2004 apud Viana, 2005).

\footnotetext{
57 A tecnologia é o estudo dos métodos e técnicas de realização de uma atividade, o que envolve o conhecimento e a escolha dos agentes (Cresswell, 1989a., Balfet, 1991).

${ }^{58} \mathrm{Um}$ instrumento pode ser entendido como aquilo que permite transformar uma matéria por meio da força humana (Cresswell, 1989b., Rabardel, 1995).
} 


\section{RESULTADOS}

\subsection{Etapa 1: Microvestígios Extraídos Pelo Método da Pipeta (Etapa 1a, Método Step-Wise) e Sonicação (Etapa 1b)}

Este método foi aplicado a oito líticos e no total foram detectados 17 fitólitos e cinco grãos de amido (Tabela 7). Além destes, também foram observados 21 outros elementos como espículas, células longas e itens não identificados.

Tabela 7. Quantidade absoluta de fitólitos e amido presente nas amostras de líticos

\begin{tabular}{|c|c|c|c|c|c|c|}
\hline & & & \multicolumn{2}{|c|}{ FITÓLITOS } & \multicolumn{2}{c|}{ AMIDO } \\
\hline QD. & PN & NÍV. & PIPETA & SONICAÇÃO & PIPETA & SONICAÇÃO \\
\hline N23 & 13014 & 6 & 0 & $\mathbf{2}$ & 0 & 0 \\
\hline N23 & 14017 & 6 & 0 & $\mathbf{1}$ & 0 & 0 \\
\hline N23 & 13067 & 6 & $\mathbf{4}$ & $\mathbf{5}$ & 0 & 0 \\
\hline N23 & 13885 & 6 & 0 & $\mathbf{2}$ & 0 & $\mathbf{1}$ \\
\hline N23 & 14029 & 6 & 0 & $\mathbf{2}$ & 0 & 0 \\
\hline N23 & 13120 & 6 & 0 & 0 & 0 & 0 \\
\hline N23 & 13962 & 6 & 0 & 0 & 0 & $\mathbf{3}$ \\
\hline N23 & 13431 & 6 & 0 & $\mathbf{1}$ & 0 & $\mathbf{1}$ \\
\hline Total & - & - & $\mathbf{4}$ & $\mathbf{1 3}$ & 0 & $\mathbf{5}$ \\
\hline
\end{tabular}

\section{Fitólitos}

A classificação dos morfotipos de fitólitos será apresentada adiante no item 4.2.2. "fitólitos identificados" junto com os resultados da Etapa 2. Na Etapa 1 foram identificados 11 bilobates (alguns de Panicoideae), um bulliform de Poaceae, um stippled polygonal cone de Cyperaceae, dois globular granulates e um semelhante a rondel wavy-top.

\section{Amido}

Os grãos de amido foram encontrados em três líticos. No lítico 13431 é possível que o item $3(4,5 \mu \mathrm{m})$ seja um amido devido a presença de cruz de interferência, entretanto, a visibilidade não permite confirmar (Figura 33). 
As imagens 5 e 6 do lítico 13885 são de um amido de forma poligonal, com facetas de pressão, hilo cêntrico e fissuras ao redor. Possui borda dupla e superfície ondulada. A cruz de interferência é distorcida com braços finos (Figura 34).

O lítico 13962 apresentou 3 grãos de amido (Figura 37). Um deles, representado nas imagens 2 e $3(13 \mu \mathrm{m})$, apresenta forma irregular e ovalada, superfície lisa, hilo visível aberto com fissura e cruz de interferência simétrica com braços espessos. Nas imagens 4 e 5 há um amido $(8,8 \mu \mathrm{m})$ redondo e achatado devido a uma depressão que pode ser natural ou um sinal de danificação. A superfície é lisa, a cruz de interferência é simétrica com braços espessos e o hilo é cêntrico e invisível.

O amido das imagens 6 e 7 do lítico $13962(6 \mu \mathrm{m})$ possui forma ovalada e cruz de interferência sem visibilidade suficiente para classificá-la (Figura 37).

\section{Microvestígios identificados em cada lítico}

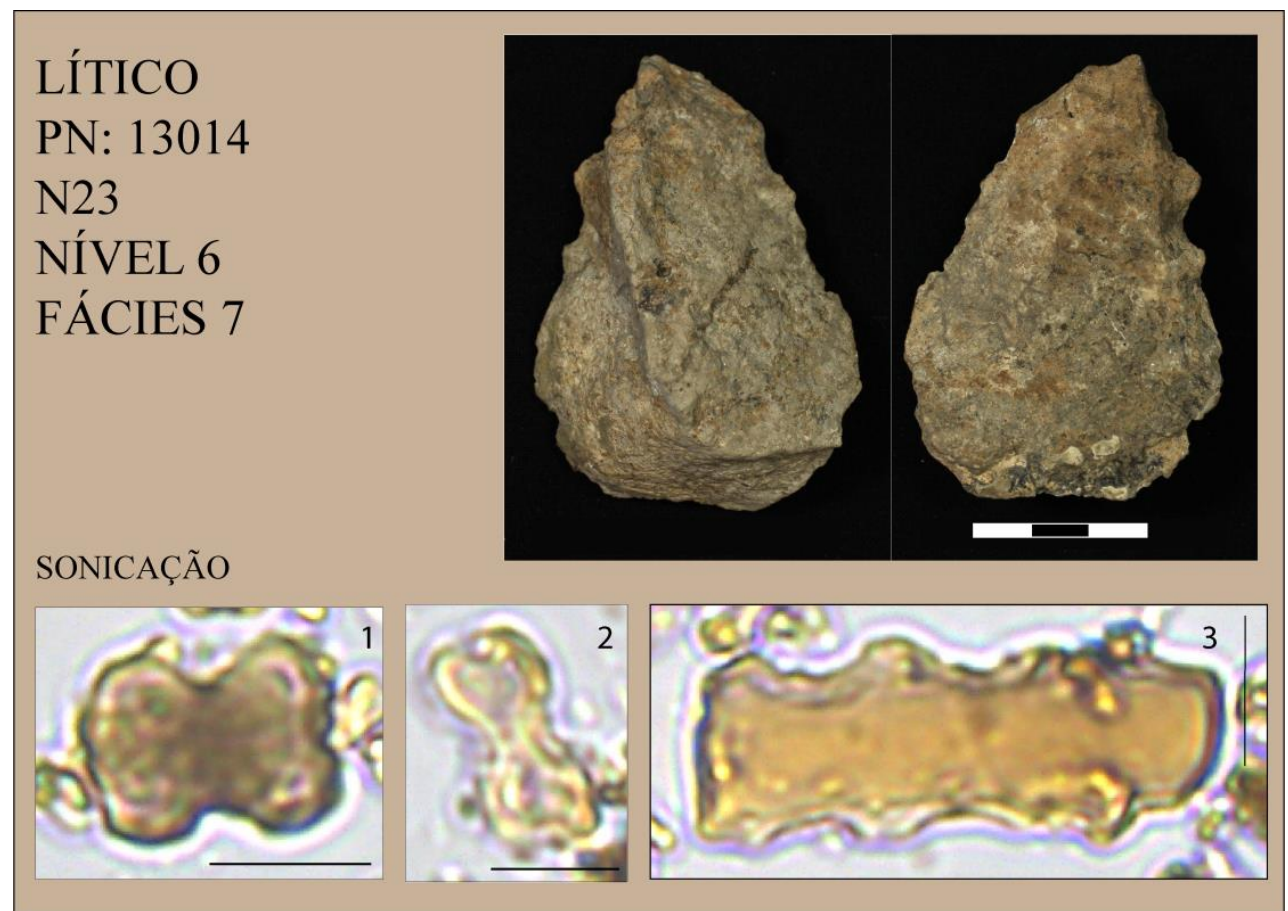

Figura 31. Microvestígios do lítico 13014. Não foram detectados microvestígios nas amostras coletadas com pipeta. Estes são provenientes de amostra sonicada. Fitólitos: 1) cross de Poaceae; 2) bilobate; 3) célula longa. Escala $10 \mu \mathrm{m}$. 


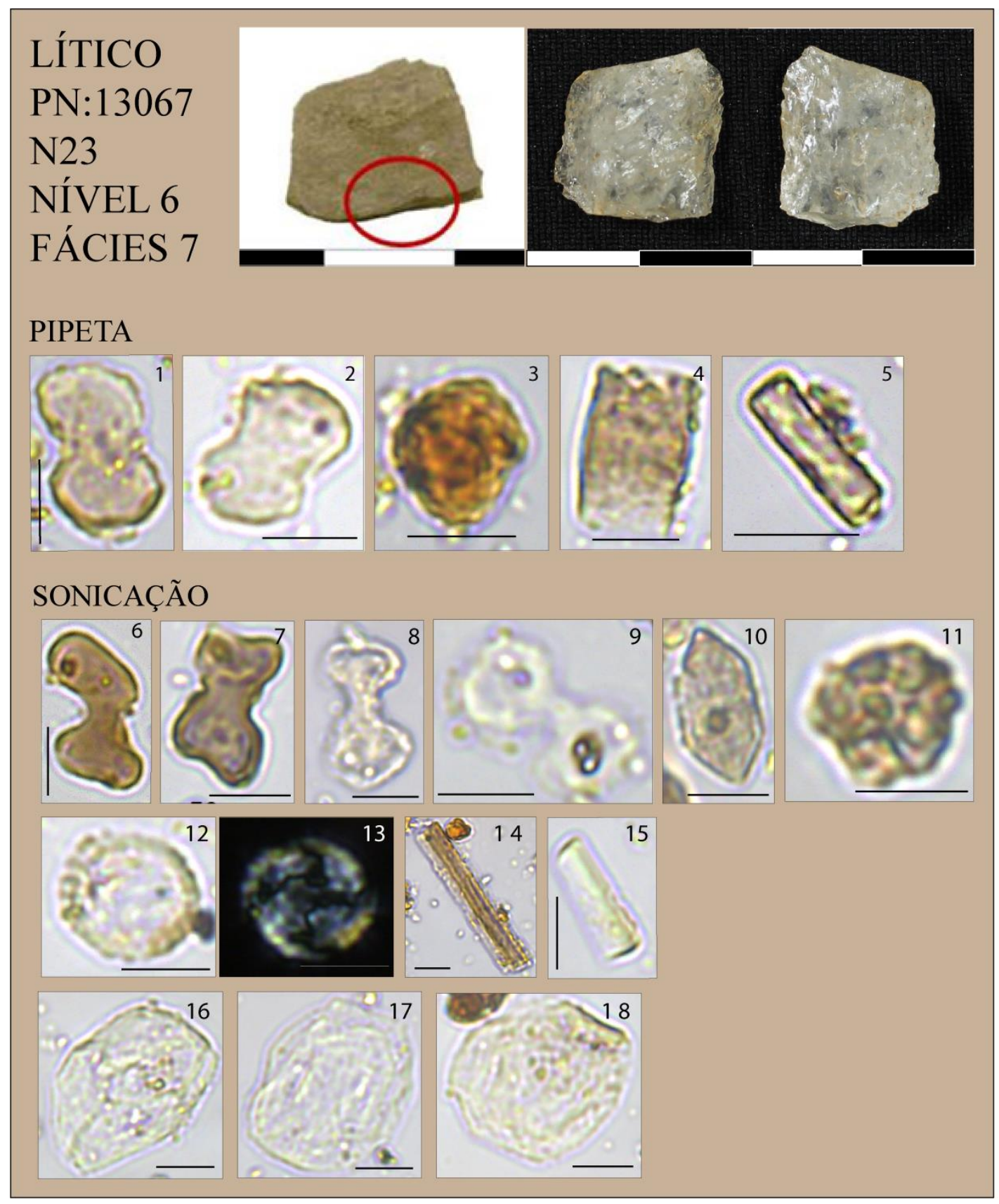

Figura 32. Microvestígios do lítico 13067. Fitólitos coletados com pipeta: 1) bilobate de Panicoideae; 2) não identificado; 3) globular granulate; 4) bulliform de Poaceae; 5) célula longa. Fitólitos provenientes de sonicação: 6, 7, ,8 e 9) bilobate de Poaceae; 10) stippled polygonal cone de Cyperaceae; 11) não identificado; 15) célula longa. 14) espícula de esponja. 16, 17 e 18) não identificados. 12-13) não identificado. Escala $10 \mu \mathrm{m}$. 


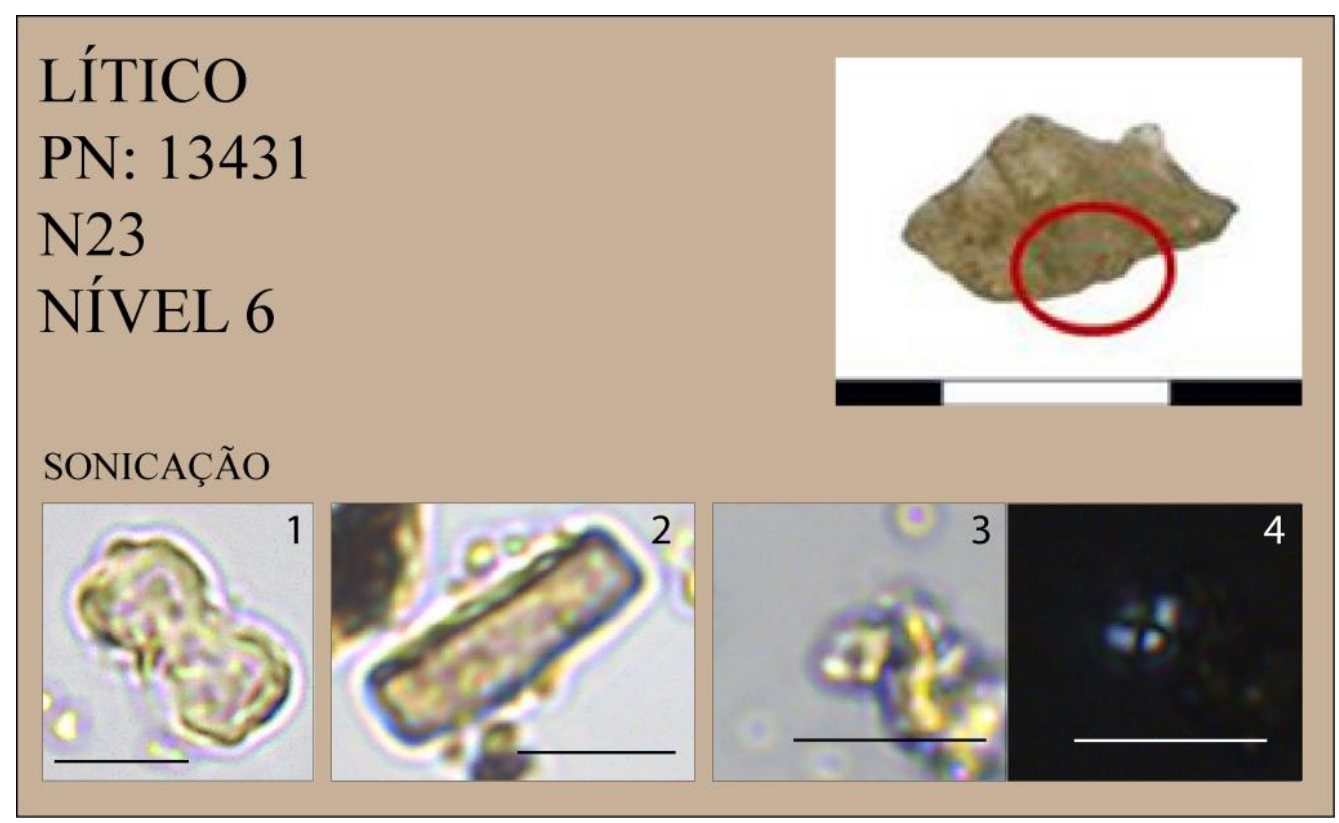

Figura 33. Microvestígios do lítico 13431. Fitólito proveniente de sonicação: 1) bilobate. 2) célula longa. 3-4) possível amido proveniente de sonicação. Escala $10 \mu \mathrm{m}$.

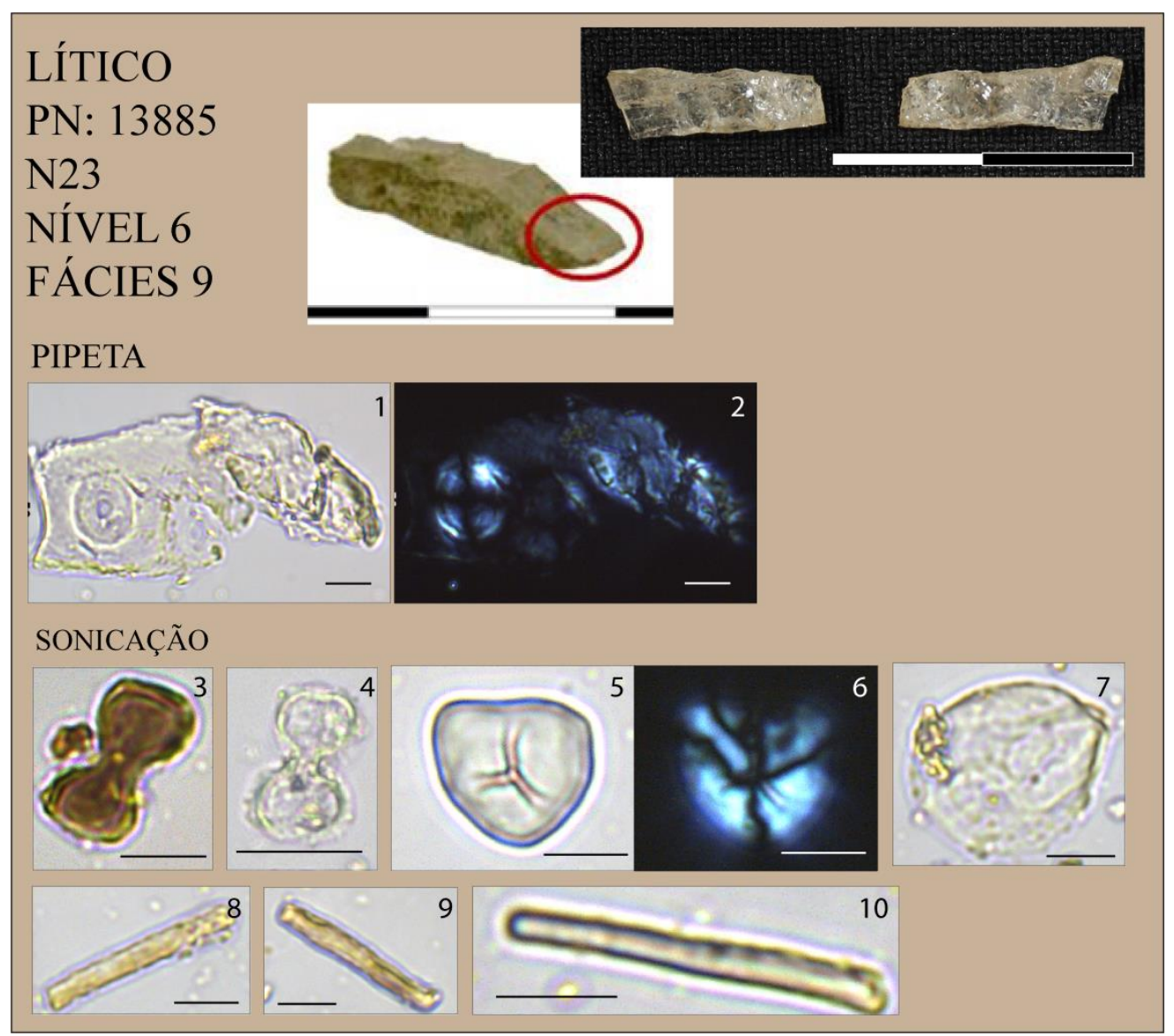

Figura 34. Microvestígios do lítico 13885. Provenientes de coleta com pipeta: 1-2) pontoações areoladas. Fitólitos de sonicação: 3) bilobate de Panicoideae; 4) bilobate. 8, 9 e 10) células longas. 7) não identificado. Amido de sonicação: 5 e 6. Escala $10 \mu \mathrm{m}$. 


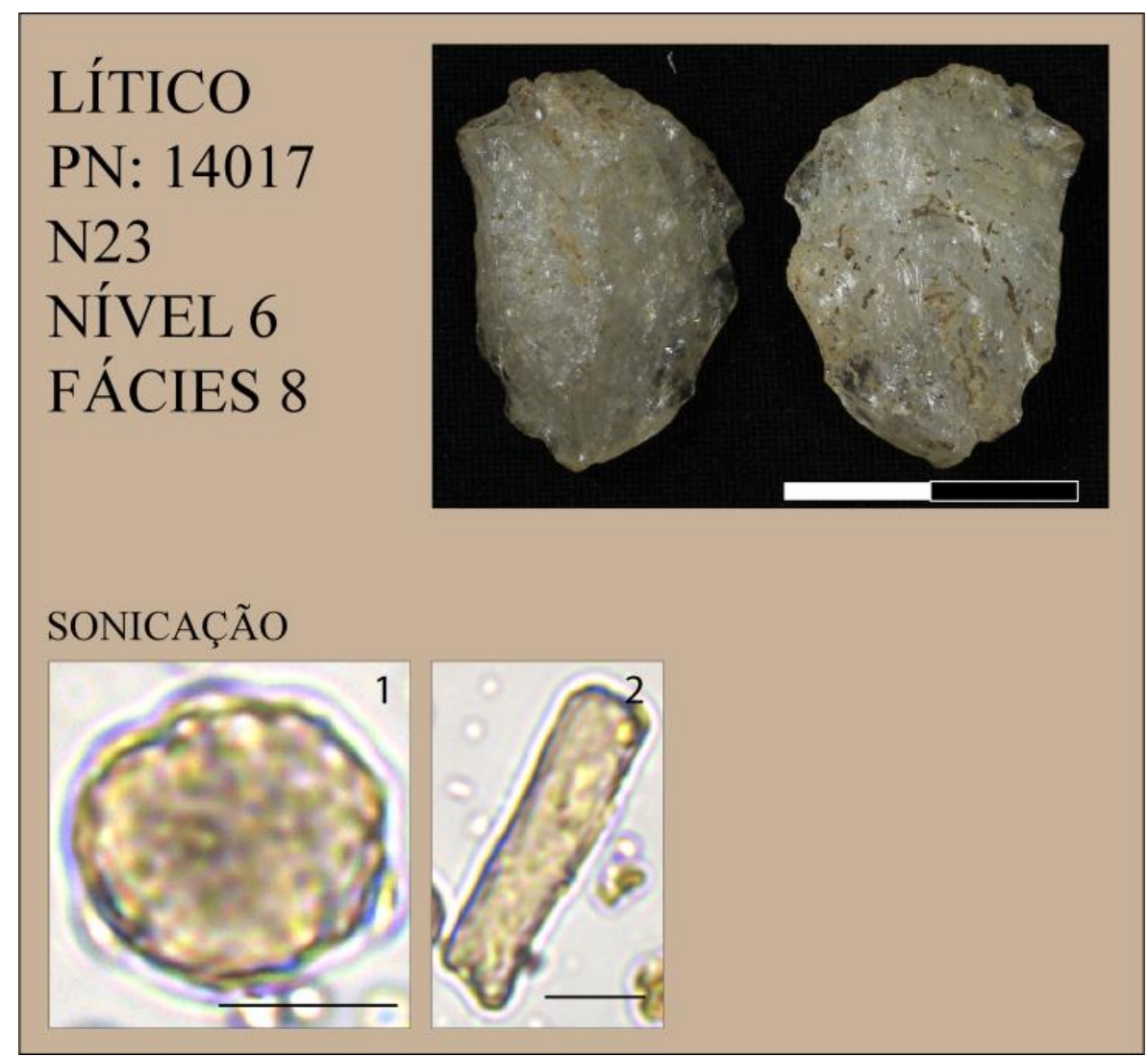

Figura 35. Microvestígios do lítico 14017. Escala $10 \mu \mathrm{m}$. Fitólito proveniente de sonicação: 1) globular granulate; 2) célula longa. Escala 10 $\mu \mathrm{m}$.

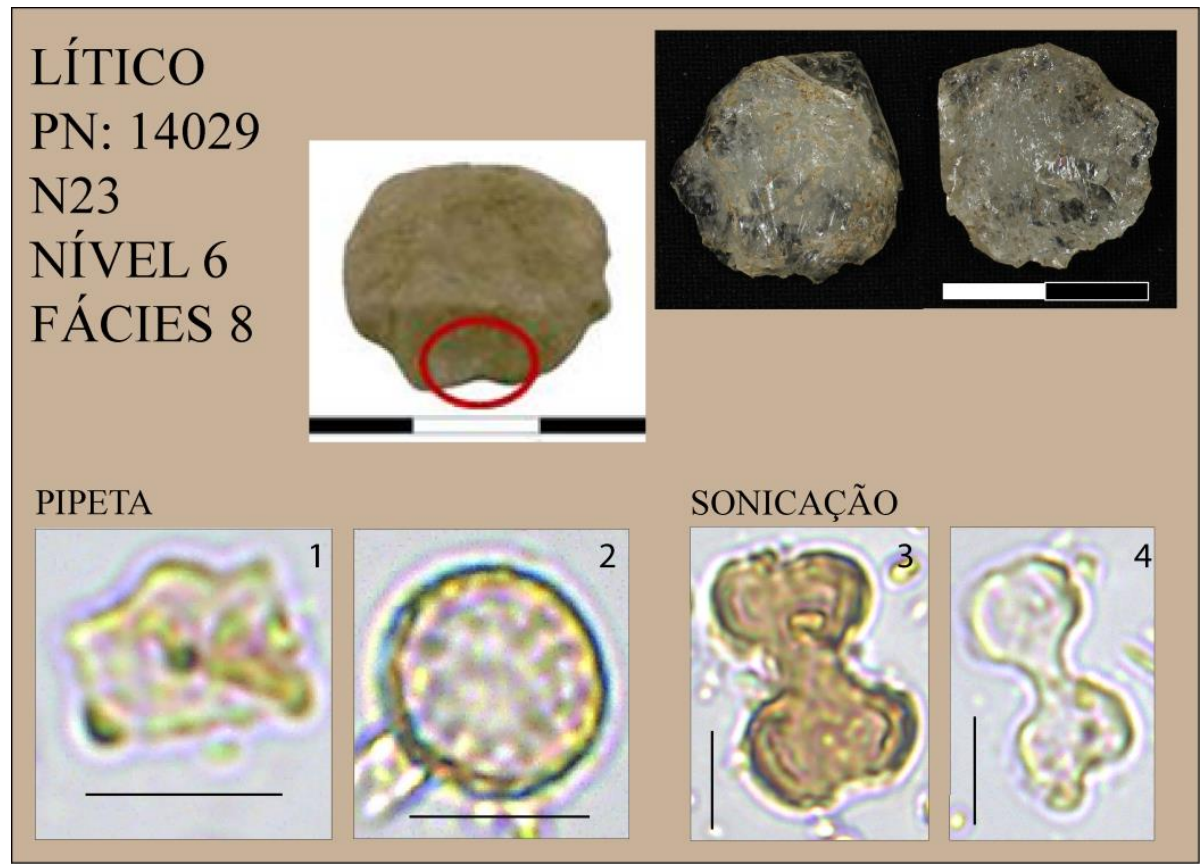

Figura 36. Microvestígios do lítico 14029. Escala $10 \mu \mathrm{m}$. Provenientes de coleta com pipeta: 1) se assemelha a rondel wavy-top mas é achatado e quase plano; 2) não identificado. Fitólitos provenientes de sonicação: 3 e 4) bilobates de Panicoideae. Escala $10 \mu \mathrm{m}$. 


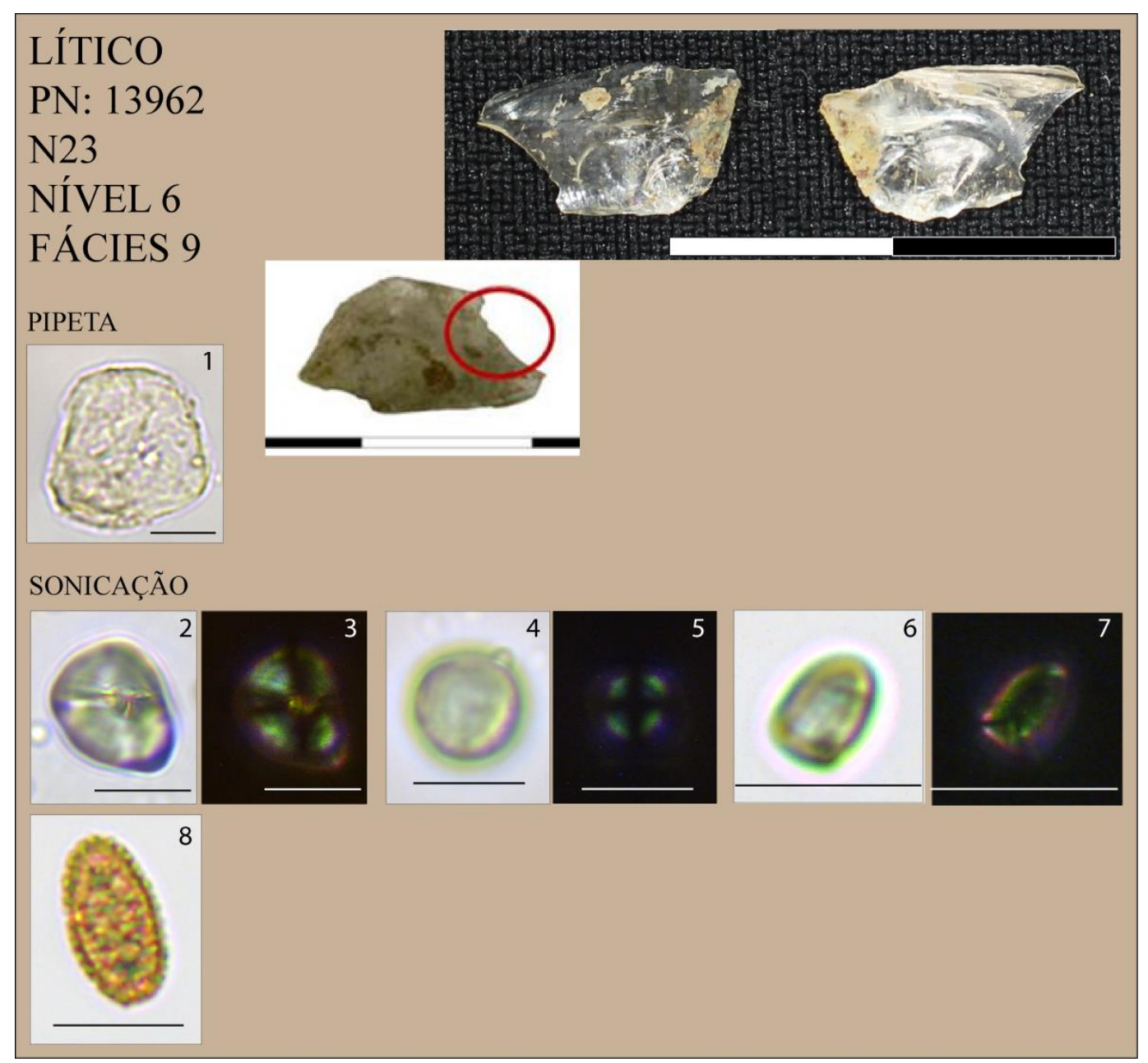

Figura 37. Microvestígios do lítico 13962. Proveniente de pipeta: 1) não identificado. Provenientes de sonicação: 2-3) amido não identificado; 4-5) amido não identificado; 6-7) amido não identificado. 8) estrutura não identificada. Escala $10 \mu \mathrm{m}$.

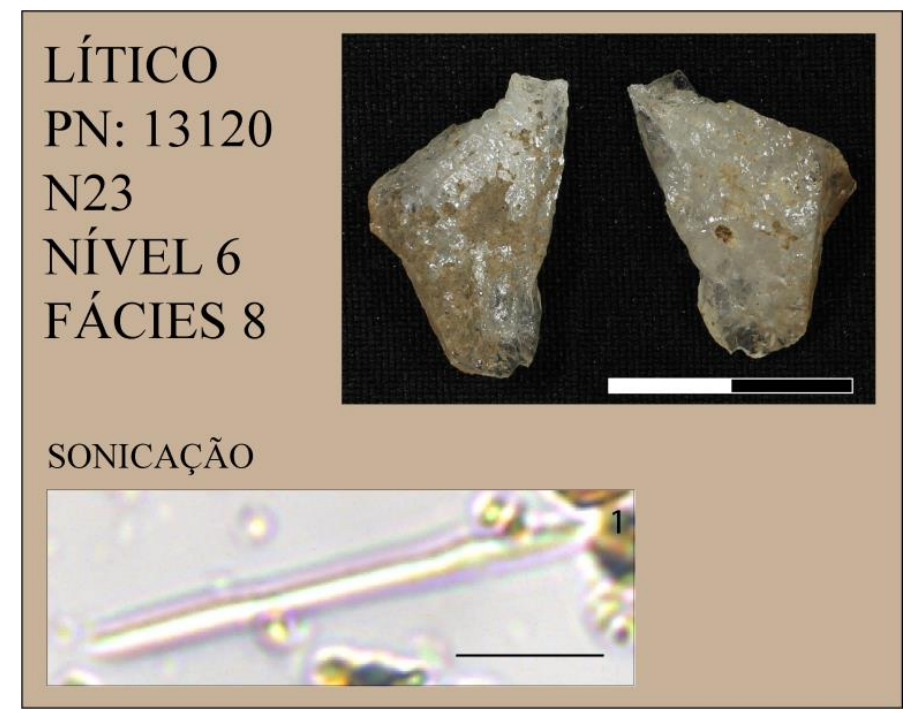

Figura 38. Microvestígios do lítico 13120. Possível célula longa proveniente de amostra sonicada. Escala $10 \mu \mathrm{m}$. 


\subsection{Etapa 2: Microvestígios extraídos de líticos e sedimento pelo método da}

sonicação/escovação e aplicação de reagentes

\subsubsection{Relação da presença de microvestígios nos líticos e no sedimento de referência}

A tabela abaixo (Tabela 8) mostra o número de fitólitos e de grãos de amido recuperados das amostras oriundas tanto de sonicação quanto de sedimento escovado dos líticos. Os fitólitos foram observados em $82,05 \%$ do total de amostras analisadas, enquanto que os grãos de amido foram recuperados de 53,84\% delas. É possível perceber, também, que esses microvestígios foram mais recorrentes no sedimento escovado. Os fitólitos são presentes em $75 \%$ das amostras sonicadas e em $89,47 \%$ das amostras escovadas. O amido é presente em $45 \%$ das amostras sonicadas e $63,16 \%$ das amostras escovadas.

Tabela 8. Quantidade Absoluta de Fitólitos e Amido Presente nas Amostras de Líticos

\begin{tabular}{|c|c|c|c|c|c|c|}
\hline & & & \multicolumn{2}{|c|}{ FITÓLITOS } & \multicolumn{2}{|c|}{ AMIDO } \\
\hline QD. & PN & NíV. & SONICADO & ESCOVADO & SONICADO & ESCOVADO \\
\hline $\mathrm{N} 23$ & 13014 & 6 & 66 & 110 & 5 & 1 \\
\hline $\mathrm{N} 23$ & 14017 & 6 & 9 & 23 & 2 & 0 \\
\hline $\mathrm{N} 23$ & 13067 & 6 & 1 & 263 & 0 & 0 \\
\hline $\mathrm{N} 23$ & 13885 & 6 & 1 & 4 & 0 & 0 \\
\hline $\mathrm{N} 23$ & 14029 & 6 & 5 & 100 & 1 & $\mathbf{1}$ \\
\hline N23 & 13120 & 6 & 0 & 11 & 0 & 0 \\
\hline $\mathrm{N} 23$ & 13962 & 6 & 0 & 26 & 0 & 1 \\
\hline P11 & 14292 & 15 & 3 & 36 & 1 & 1 \\
\hline P11 & 14385 & 16 & 0 & 0 & 0 & 1 \\
\hline P11 & 14391 & 16 & 6 & 63 & 1 & 5 \\
\hline P11 & 14410 & 16 & 3 & 3 & 0 & 0 \\
\hline P11 & 14469 & 16 & 1 & 85 & 0 & 1 \\
\hline $\mathrm{P} 11$ & 14369 & 16 & 0 & 12 & 1 & 0 \\
\hline A1 & 14267 & 2 & 0 & 19 & 0 & 7 \\
\hline A1 & 14236 & 2 & 1 & 27 & 0 & 1 \\
\hline A1 & 14355 & 3 & 1 & 3 & 2 & 2 \\
\hline
\end{tabular}




\begin{tabular}{|c|c|c|c|c|c|c|}
\hline & & & \multicolumn{2}{|c|}{ FITÓLITOS } & \multicolumn{2}{c|}{ AMIDO } \\
\hline QD. & PN & NÍV. & SONICADO & ESCOVADO & SONICADO & ESCOVADO \\
\hline A1 & 14335 & 3 & $\mathbf{1}$ & 0 & 0 & 0 \\
\hline A1 & 14353 & 3 & $\mathbf{1}$ & $\mathbf{5 4}$ & $\mathbf{4}$ & $\mathbf{4}$ \\
\hline A1 & 14297 & 3 & $\mathbf{1}$ & $\mathbf{1 0}$ & 0 & $\mathbf{2}$ \\
\hline $\begin{array}{c}\text { SEP. } \\
39\end{array}$ & 14192 & 13 & $\mathbf{1}$ & - & $\mathbf{3}$ & - \\
\hline Total & - & - & $\mathbf{1 0 1}$ & $\mathbf{8 4 9}$ & $\mathbf{2 0}$ & $\mathbf{2 7}$ \\
\hline
\end{tabular}

Com relação ao sedimento analisado de cada quadra, todas apresentam fitólitos em seu contexto e só aparece amido na quadra P11 (Tabela 9). Além disso, o número de grãos de amido observado nesta amostra é baixo $(n=2)$.

Tabela 9. Quantidade Absoluta de Fitólitos e Amido Presentes em Sedimento

\begin{tabular}{|c|c|c|c|c|}
\hline QD. & PN & NÍV. & FITÓLITOS & AMIDO \\
\hline N23 & 14030 & 6 & $\mathbf{2 2 5}$ & 0 \\
\hline P11 & 14398 & 16 & $\mathbf{5 6}$ & $\mathbf{2}$ \\
\hline A1 & 14358 & 3 & $\mathbf{2 0 2}$ & 0 \\
\hline C2 & $\begin{array}{c}\text { Acima } \\
\text { do } \\
\text { Abrigo }\end{array}$ & $30 \mathrm{~cm}$ & $\mathbf{2 9 5}$ & $\mathbf{2}$ \\
\hline Total & - & - & $\mathbf{7 7 8}$ & 0 \\
\hline
\end{tabular}

\subsubsection{Identificação dos Fitólitos}

Os fitólitos são os microvestígios botânicos mais abundantes nas amostras de líticos e de sedimento. Os morfotipos de fitólitos identificados estão associados aos táxons de plantas que os produzem. Essa relação é apresentada abaixo (Tabela 10). Além dos fitólitos, a análise também detectou demais estruturas silicosas provenientes de 
diatomáceas e esponjas $^{59}$ (ver Batista \& Volkmer-Ribeiro, 2002; Volkmer-Ribeiro \& Machado, 2007; Costa et al; 2010).

Um exemplo de cada morfotipo é apresentado na Figura 39. Em seguida, são apresentados os resultados quantitativos de três tipos de amostras: sonicadas dos líticos (Gráfico 1), escovadas dos líticos (Gráfico 2) e do sedimento (Gráfico 3).

Dois fitólitos do conjunto analisado possuem partes semelhantes a ondulações do morfotipo rondel wavy-top, um tipo que é diagnóstico de Zea mays (milho) e estão presentes no sabugo (Piperno, 2009). Entretanto, como a rotação e identificação tridimensional não foram suficientemente nítidas para os classificar como wavy-top, eles foram desclassificados da análise e não entram em outra categoria (Figura 40).

Tabela 10. Fitólitos e Associação Taxonômica

\begin{tabular}{|c|c|c|c|c|}
\hline $\begin{array}{c}\text { Morfotipos de } \\
\text { Fitólitos } \\
\text { Identificados }\end{array}$ & Foto (Figura 39) & \multicolumn{3}{|c|}{ Táxons } \\
\hline $\begin{array}{c}\text { Bilobate (long and } \\
\text { thin shaft) }\end{array}$ & 1 & Aristidoideae & \multirow{10}{*}{ Poaceae } & \multirow{10}{*}{ Monocot. ${ }^{60}$} \\
\hline $\begin{array}{c}\text { Bilobate (blocky } \\
\text { ou spiked) }\end{array}$ & 2 & \multirow{3}{*}{ Bambusoideae } & & \\
\hline Collapsed saddle & 8 & & & \\
\hline 3-spiked rondel & 7 & & & \\
\hline Saddle & 9 & Chloridoideae & & \\
\hline Bilobate & 3 & Panicoideae & & \\
\hline Cross - Variante 1 & 4 & Zea mays & & \\
\hline Bulliform & 10 & \multirow{3}{*}{$\begin{array}{l}\text { Poaceae não } \\
\text { diagnóstica }\end{array}$} & & \\
\hline $\begin{array}{c}\text { Cross - Outras } \\
\text { Variantes }\end{array}$ & 5 & & & \\
\hline Rondel & 6 & & & \\
\hline
\end{tabular}

\footnotetext{
${ }^{59}$ Algumas esponjas são calcáreas e não silicosas (Coradin et al., 2004). As estruturas silicosas aparecem nesta análise devido aos protocolos aplicados, para recuperação dos fitólitos, que são silicosos (Lombardo et al., 2016).

${ }^{60}$ As plantas Monocotiledôneas ou Monocot. possuem três elementos (em geral) nas partes florais, pólen monoaperturados (com um poro ou sulco), apenas um cotilédone, venação foliar frequentemente paralela, feixes vasculares primários no caule em arranjo disperso e raro crescimento secundário verdadeiro com câmbio vascular (Raven, 2014).
} 


\begin{tabular}{|c|c|c|c|}
\hline $\begin{array}{l}\text { Morfotipos de } \\
\text { Fitólitos } \\
\text { Identificados }\end{array}$ & Foto (Figura 39) & & Táxons \\
\hline Globular echinate & 11 & \multirow{3}{*}{\multicolumn{2}{|c|}{ Arecaceae }} \\
\hline $\begin{array}{c}\text { Globular echinate } \\
\text { elongate }\end{array}$ & 12 & & \\
\hline $\begin{array}{c}\text { Globular echinate } \\
\text { with short acute } \\
\text { projections }\end{array}$ & 13 & & \\
\hline $\begin{array}{l}\text { Stippled polygonal } \\
\text { cone }\end{array}$ & 14 & $\begin{array}{c}\text { Cyperus/Kyllinga } \\
\text { sp. }\end{array}$ & \multirow{2}{*}{ Cyperaceae } \\
\hline Polygonal stippled & 15 & $\begin{array}{c}\text { Cyperaceae não } \\
\text { diagnóstica }\end{array}$ & \\
\hline Globular nodular & 16 & \multicolumn{2}{|c|}{ Zingiberales } \\
\hline $\begin{array}{l}\text { Globular } \\
\text { granulate }\end{array}$ & 17 & \multirow{3}{*}{\multicolumn{2}{|c|}{ Eudicot. $^{61}$}} \\
\hline Jigsaw & 18 & & \\
\hline Globular psilate & 19 & & \\
\hline
\end{tabular}

\footnotetext{
${ }^{61}$ As Eudicotiledôneas ou Eudicots são arbóreas, apresentam quatro ou cinco elementos (em geral), pólen triaperturados (com três poros ou sulcos), dois cotilédones, venação foliar frequentemente reticulada, feixes vasculares primários no caule com arranjo em anel e com crescimento secundário verdadeiro com câmbio vascular comumente presente (Raven, 2014).
} 


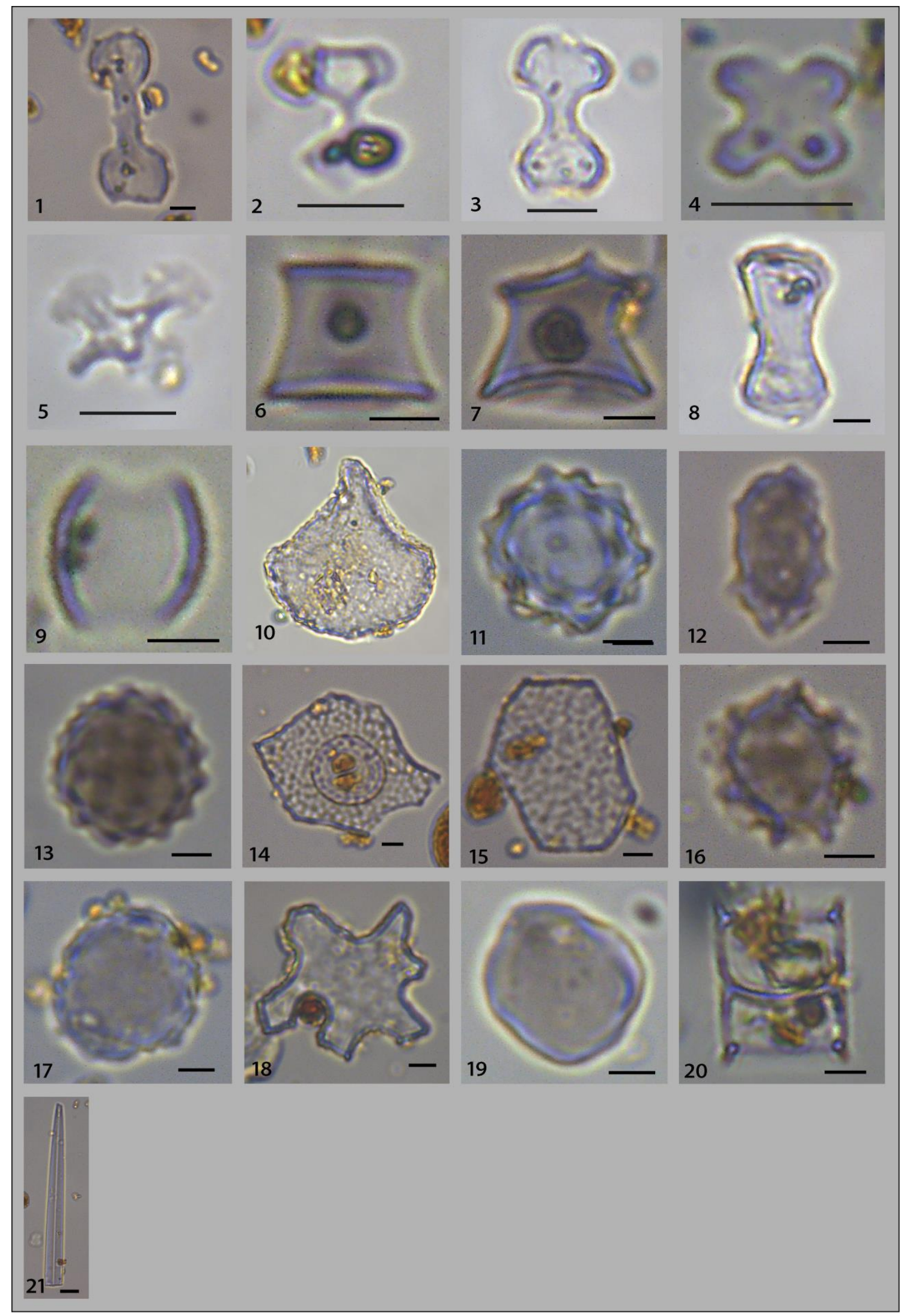

Figura 39. Exemplos para ilustrar cada morfotipo de fitólito e outros elementos identificados nas análises provenientes de líticos e sedimento arqueológicos da Lapa do Santo. 1) bilobate de Aristidoideae, 2) bilobate de Bambusoideae, 3) bilobate de Panicoideae, 4) cross de Poaceae "variante 1", 5) cross de Poaceae "outras variantes", 6) rondel de Poaceae, 7) 3-spiked rondel de Bambusoideae, 8) collapsed saddle de Bambudoideae, 9) saddle de Chloridoideae, 10) 
bulliform de Poaceae, 11) globular echinate de Arecaceae (palmeira), 12) globular echinate elongate de Arecaceae, 13) globular echinate de Arecaceae with short acute projections, 14) stippled polygonal cone de Cyperus/Kyllinga sp; 15) polygonal stippled de Cyperaceae, 16) globular nodular de Zingiberales, 17) globular granulate de Eudicotiledônea (arbóreas), 18) jigsaw de Eudicotiledônea, 19) globular psilate de Eudicotiledônea, 20) diatomácea, 21) espícula de esponja. Escala $10 \mu \mathrm{m}$.

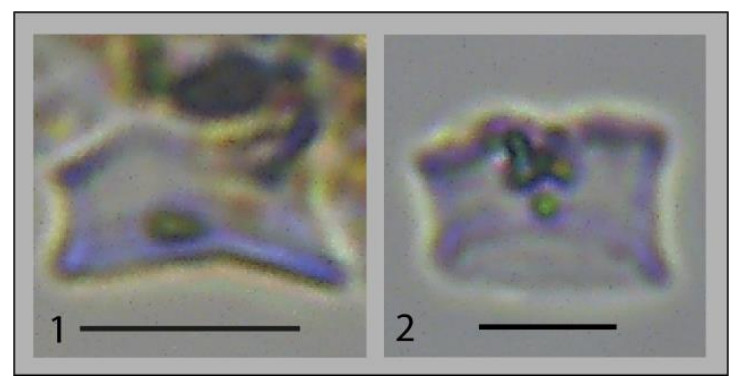

Figura 40. 1-2) Estes dois fitólitos do conjunto são o mofotipo rondel, com aparente, mas não confirmada, ondulação característica do rondel tipo wavy-top (Zea mays). Escala $10 \mu \mathrm{m}$. 


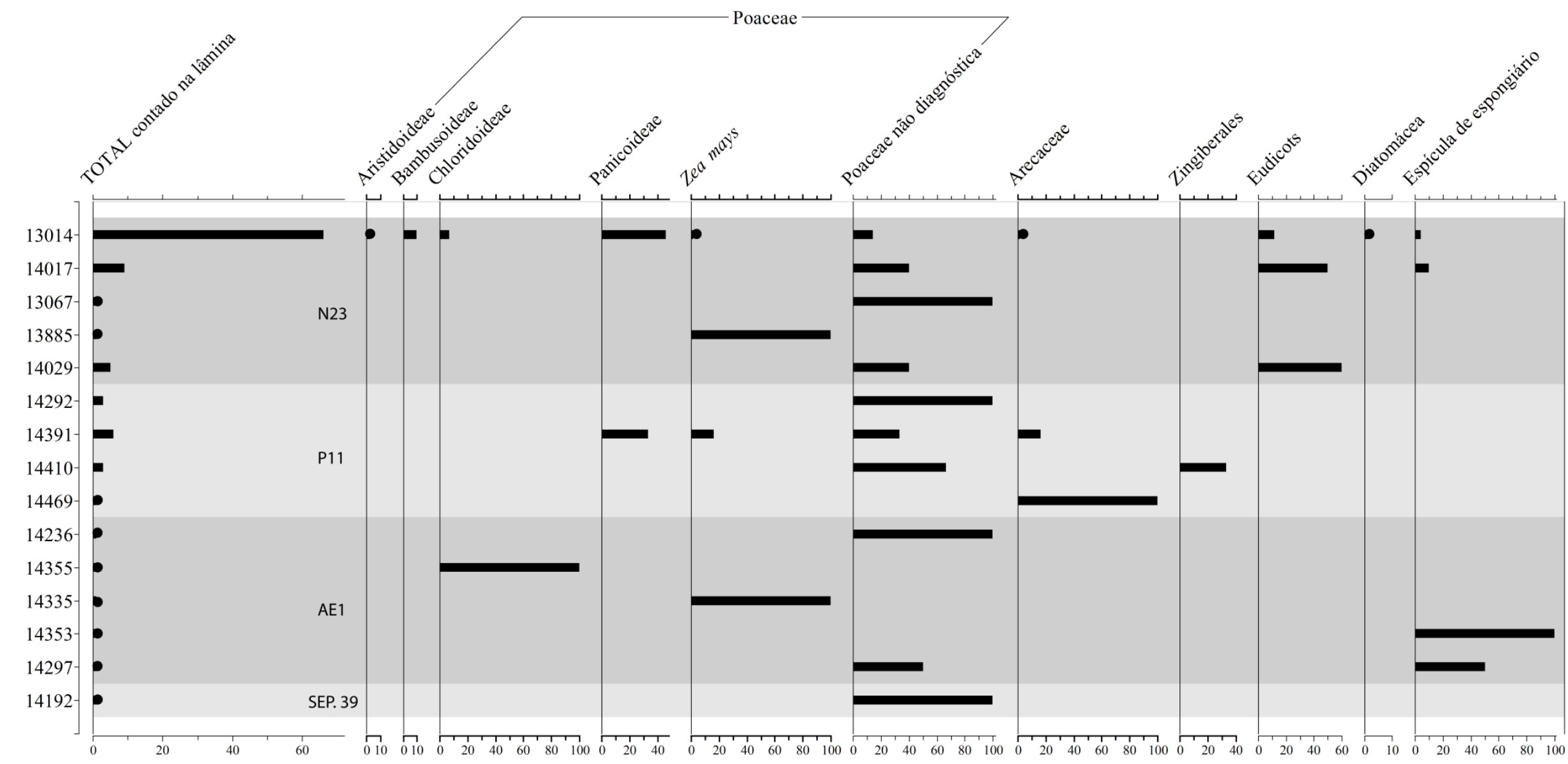

Gráfico 1. Diagrama da proporção relativa (\%) dos grupos taxonômicos botânicos identificados a partir da análise fitolítica das amostras provenientes de sonicação (Etapa 2) de líticos das quadras N23, P11, AE1 e do Sepultamento 39. O total de elementos contados na lâmina estão em valor absoluto. 


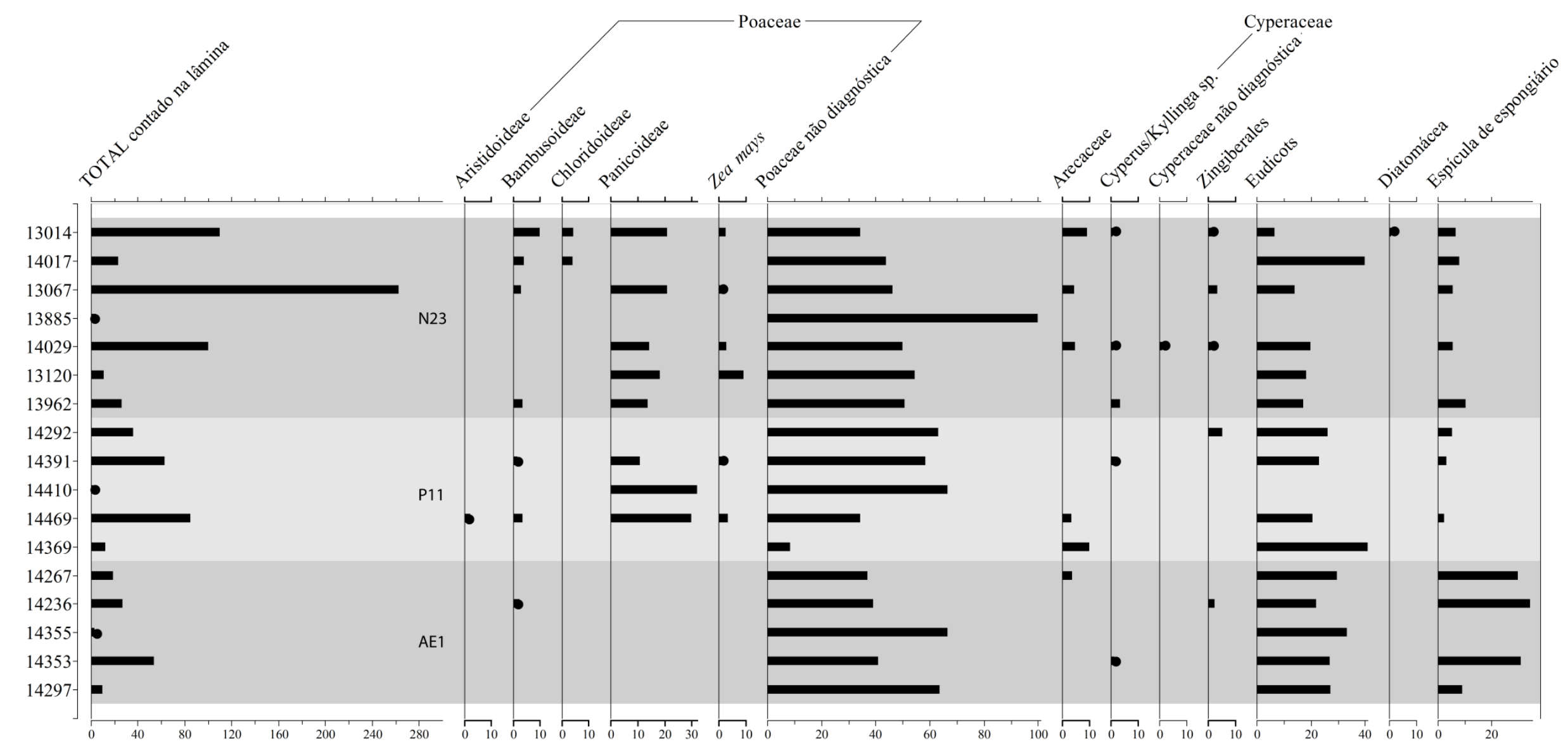

Gráfico 2. Diagrama da proporção relativa (\%) dos grupos taxonômicos botânicos identificados a partir da análise fitolítica das amostras provenientes de escovação (Etapa 2) de líticos das quadras N23, P11, AE1 e do Sepultamento 39. O total de elementos contados na lâmina estão em valor absoluto. 


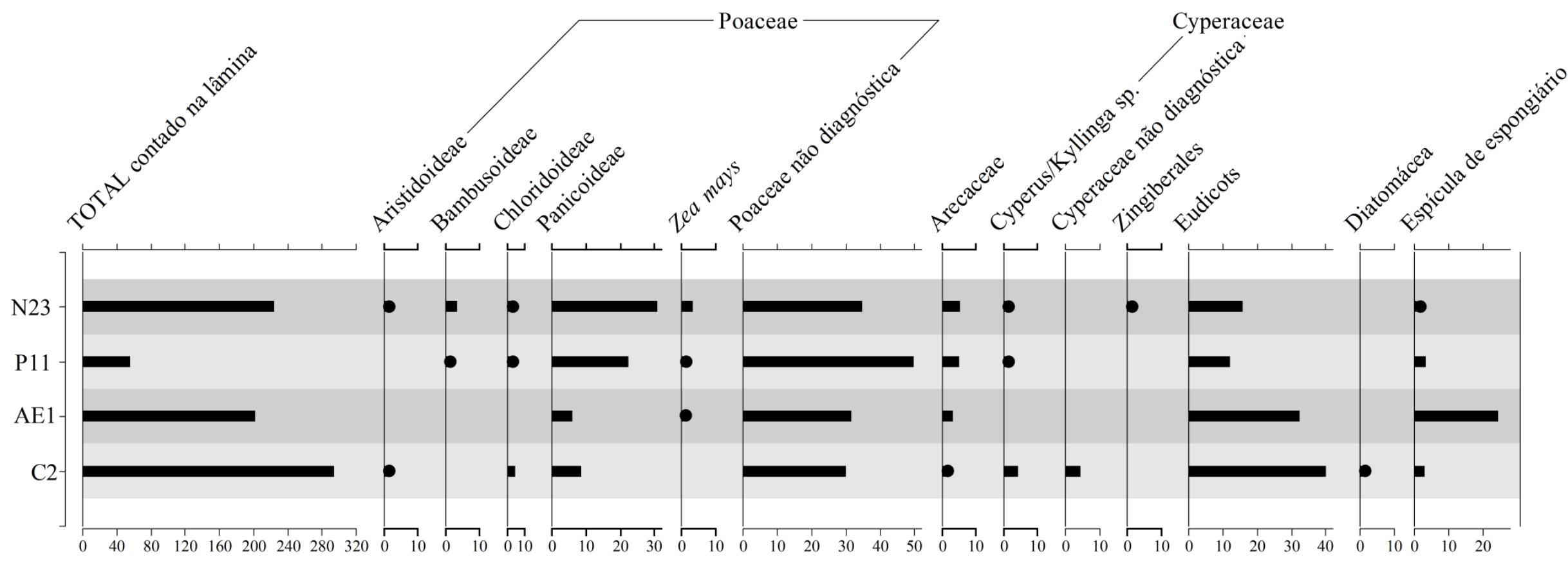

Gráfico 3. Diagrama da proporção relativa (\%) dos grupos taxonômicos botânicos identificados a partir da análise fitolítica das amostras de sedimento arqueológico coletado das quadras N23, P11, AE1 e de fora do sítio (C2) (Etapa 2). O total de elementos contados na lâmina estão em valor absoluto. 


\subsubsection{Medição das Cruzes}

Foram realizadas medições das larguras das cruzes em fitólitos cujo morfotipo é cross (cruz), diagnósticos das folhas de Zea mays, que podem ser associadas a variante 1 (cruzes planas e pouco espessas e geralmente mais simétricas), com a classificação das dimensões segundo os critérios de Pearsall (1978) e de Piperno (1984). Os resultados são apresentados na

Tabela 11, e na Figura 41, em ordem decrescente.

Tabela 11. Medição das Cruzes

\begin{tabular}{|c|c|}
\hline Largura $(\mu \mathrm{m})$ & Classificação do Tamanho das Cruzes \\
\hline 37,55 & \multirow{12}{*}{ Extra grandes (acima de $20.61 \mu \mathrm{m}$ ) } \\
\hline 35,3 & \\
\hline 34,61 & \\
\hline 28,51 & \\
\hline 26,75 & \\
\hline 25,58 & \\
\hline 25,16 & \\
\hline 24,51 & \\
\hline 22,93 & \\
\hline 22,28 & \\
\hline 21,65 & \\
\hline 20,7 & \\
\hline 20,59 & \multirow{6}{*}{ Grandes (entre 16.03 e $20.56 \mu \mathrm{m}$ ) } \\
\hline 18,65 & \\
\hline 18,3 & \\
\hline 17,93 & \\
\hline 17,34 & \\
\hline 16,33 & \\
\hline 14,28 & \multirow{3}{*}{ Medianas (entre 11.45 a $15.98 \mu \mathrm{m}$ ) } \\
\hline 14,12 & \\
\hline 13,2 & \\
\hline
\end{tabular}




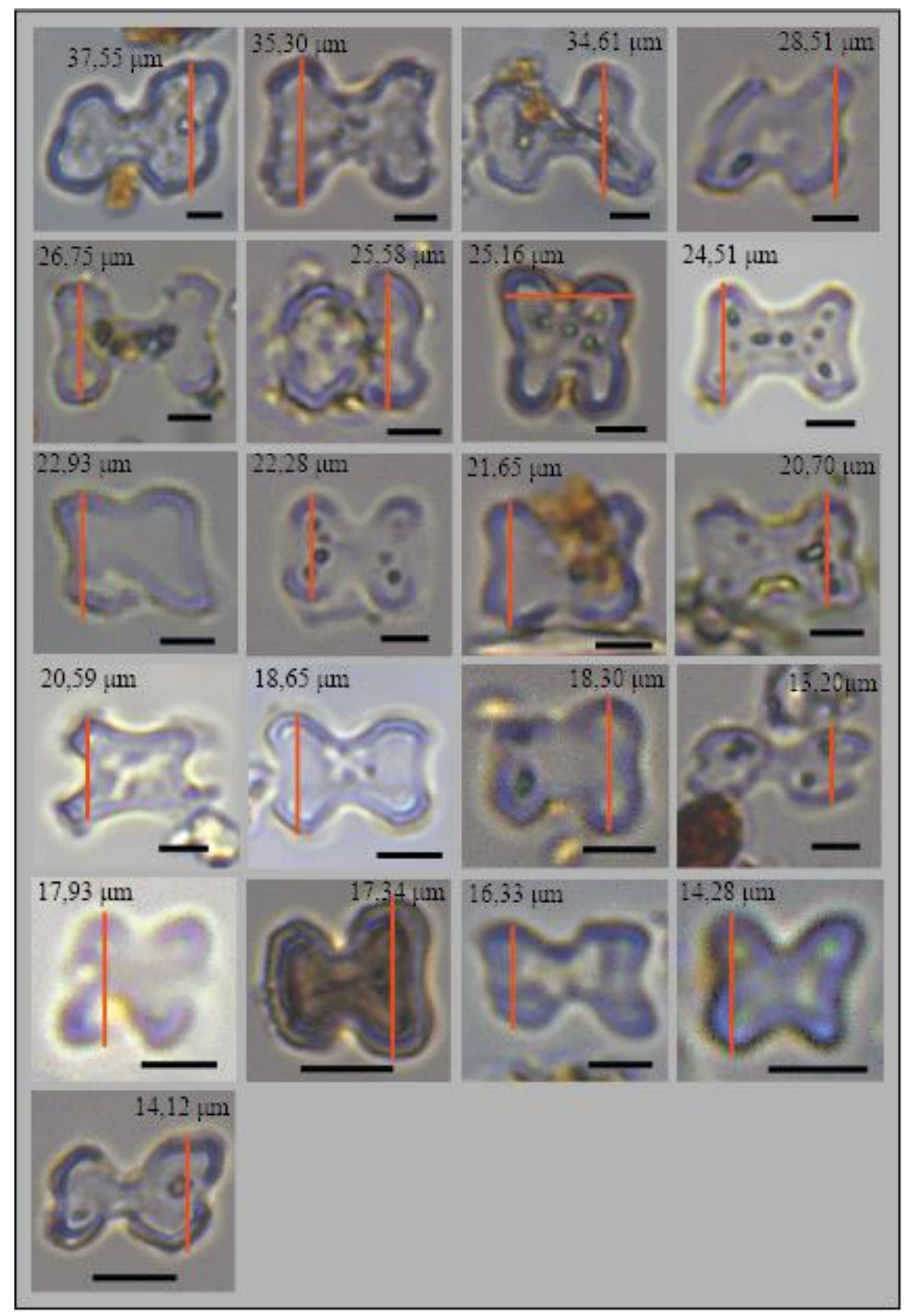

Figura 41. Medição da largura das cruzes. Escala $10 \mu \mathrm{m}$. 


\subsubsection{Identificação dos Grãos de Amido}

Foram observados 47 grãos de amido no total de amostras (sonicadas e escovadas) provenientes dos líticos estudados e dois grãos na amostra de sedimento da quadra P11. Esses grãos foram agrupados em oito morfotipos segundo características em comum e diagnósticas (que possibilitam a atribuição de a táxons aos grãos).

\section{Morfotipo A (n=18)}

Os grãos desse morfotipo são irregulares, poligonais ou poliédricos, com hilo cêntrico e fissuras de várias formas: ramificadas, em linha reta ou curvas e em forma de X ou Y (Figura 42). A cruz de interferência é distorcida ou simétrica, com braços finos. A superfície pode ser lisa ou áspera. O menor grão possui $16,39 \mu \mathrm{m}$ e o maior $27,73 \mu \mathrm{m}$ de comprimento.

\section{Milho vs. Gramíneas Selvagens (Wild Grasses)}

Os grãos de amido de milho (Zea mays) e gramíneas selvagens (wild grasses) podem ser similares no tocante a formas poliédricas e irregulares, com facetas de pressão e vários tipos de fissuras, como radiais, em X, Y e transversais que são comuns no milho (Holst et al; 2007; Piperno et al; 2009: 5020; Musaubach et. al, 2013). Entretanto, eles podem ser diferenciados com relação a sua morfologia e tamanho (Holst et al; 2007). Os grãos de gramíneas selvagens podem medir aproximadamente de 3 a $11 \mu \mathrm{m}$ de comprimento médio, atingindo comprimento máximo 2 a $18 \mu \mathrm{m}$ (Holst et al; 2007; Musaubach et. al, 2013). Os grãos de milho podem ser maiores e medem de em torno de 8 a $25 \mu \mathrm{m}$ de comprimento máximo (Holst et al; 2007; Musaubach et. al, 2013). Por isso, grãos maiores que $18 \mu \mathrm{m}$ seriam certamente de milho (Holst et al; 2007).

Além disso, grãos alongados em forma de sino (bell-shaped), ovais e redondos são muito mais comuns em gramíneas selvagens, assim como grãos com uma borda dupla, muito raramente com fissuras transversais (Holst et al; 2007; Musaubach et. al, 2013). Grãos irregulares e facetados constituem a maioria dos grãos de milho e em 
menos proporções em gramíneas selvagens, eles não têm forma tridimensional definida e suas superfícies são ásperas (Holst et al; 2007). As facetas de pressão do milho são mais definidas e destacadas que as de gramíneas selvagens, que são mais suaves (Holst et al; 2007). As fissuras em milho e gramíneas selvagens são semelhantes, exceto a do tipo transversal que corta grande parte do grão, ela é considerada abundante e característica de milho e é rara em gramíneas selvagens (Holst et al; 2007). O hilo é semelhante em milho e gramíneas selvagens, é cêntrico e pode ser fechado ou aberto, mas em gramíneas selvagens há mais grãos com cavidade no hilo (Holst et al; 2007).

Conforme Holst et al. (2007), a presença do milho é sugerida se o conjunto estudado apresentar respostas positivas para as afirmações a seguir: 1) Grãos irregulares dominam a assembleia; 2) Não há grãos (ou são raros) em forma de sino (bell-shaped); 3) Se grãos com fissuras transversais são comuns; 4) Há grãos com facetas de pressão bem definidas; 5) Há grãos maiores que $18 \mu \mathrm{m}$.

Com cautela, Musaubach et al. (2013) advertem para a espécie de gramínea selvagem Sorghastum pelitum que pode ser confundida com o milho por ser grande, podendo atingir até no máximo $20 \mu \mathrm{m}$.

\section{Milho vs. batata-doce}

Os grãos de batata-doce (Ipomoea batatas) podem ser poliédricos, esféricos e hemisféricos, com fissuras nos grãos maiores (Boyadjian, 2012: 194). Grãos de amido de milho e de batata-doce podem ser bastante semelhantes, por serem facetados com grãos angulares e mesmos tamanhos (Chinique de Armas, 2015: 6). O diferencial é que os grãos de batata-doce medem entre 5 a $40 \mu \mathrm{m}$ (com uma média de $18 \mu \mathrm{m}$ ) e grãos com mais de $25 \mu \mathrm{m}$ podem ser considerados como sendo de batata-doce e não de milho (Pagán-Jimenez, 2007:202; Chinique de Armas, 2015:6). Entretanto, é difícil diferenciar grãos com menos de $25 \mu \mathrm{m}$ (Chinique de Armas, 2015).

Em suma, grãos menores que $18 \mu$ m podem ser gramíneas selvagens, teosinte, milho e batata-doce (Holst et al; 2007; Musaubach et. al, 2013; Chinique de Armas, 2015:6). Grãos entre $18 \mu \mathrm{m}$ e $25 \mu \mathrm{m}$ podem ser de milho ou batata-doce (Holst et al; 2007; Musaubach et. al, 2013; Chinique de Armas, 2015:6). E grãos maiores que $25 \mu \mathrm{m}$ provavelmente serão batata-doce (Holst et al; 2007; Musaubach et. al, 2013; Chinique de Armas, 2015:6). 


\section{Identificação}

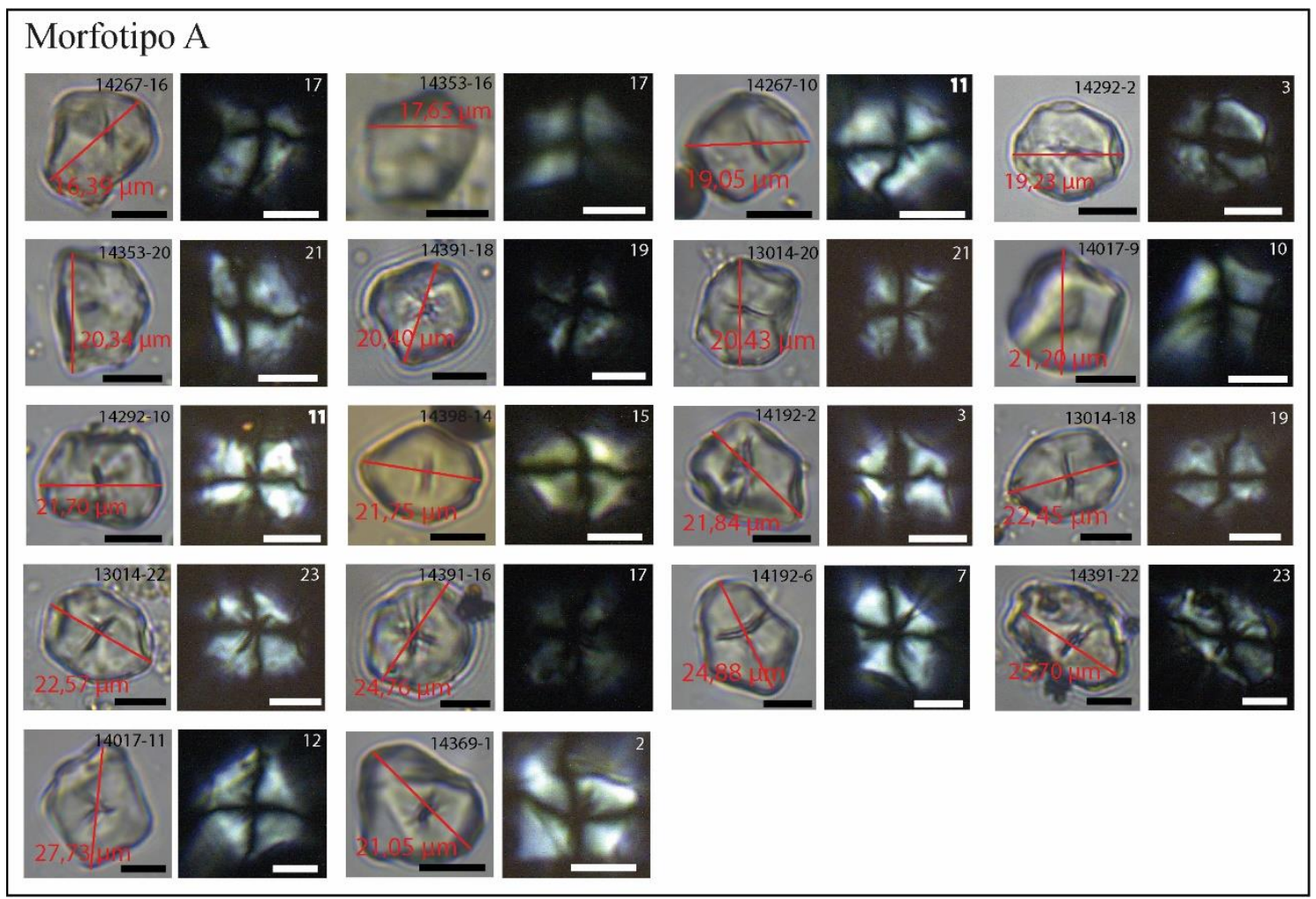

Figura 42. Grãos de amido classificados como Morfotipo A.

O grão 16 do lítico $14267(16,39 \mu \mathrm{m})$ possui comprimento menor que $18 \mu \mathrm{m}$ e sua fissura parece ser transversal (ver Holst et al; 2007: 17610; Musaubach et al; 1191). Sua forma se assemelha à batata-doce em Chinique de Armas (2013:7), exceto pelo hilo que na referência mencionada não possui fissura.

O amido 16 do lítico $14353(17,65 \mu \mathrm{m})$ é pentagonal mas foi classificado nesta categoria de poligonais e irregulares. Possui comprimento menor que $18 \mu \mathrm{m}$, hilo cêntrico e aparentemente fissura em Y, o que não pode ser confirmado devido ao desfoque da imagem. Se assemelha a milho publicado em Pagán-Jimenez (2015:143). No mesmo lítico foi encontrado o amido do morfotipo $\mathrm{C}$ que provavelmente também é de milho (Cf. Pagán-Jimenez, 2015:143).

O amido 10 do lítico $14267(19,05 \mu \mathrm{m})$ possui fissura transversal característica de milho e não é gramínea selvagem, por ser maior que $18 \mu \mathrm{m}$ (ver Holst et al; 2007: 17610; Musaubach et al; 1191). É um amido de Poaceae semelhante a milho (Cf. Boyadjian et al; 2016: 141, letra d). 
O amido 2 do lítico $14292(19,23 \mu \mathrm{m})$ possui fissura linear que não chega a ser transversal e superfície áspera, por isso não é característico de batata-doce e nem de gramínea selvagem pelo tamanho.

O amido 20 do lítico $14353(20,34 \mu \mathrm{m})$ possui superfície áspera e fissura em Y e é maior que gramínea selvagem.

O grão 18 do lítico $14391(20,40 \mu \mathrm{m})$ é grande para ser gramínea selvagem e se assemelha a milho devido a fissura radial (ver Pagán-Jimenez, 2015: 103).

O amido 20 do lítico $13014(20,43 \mu \mathrm{m})$ possui fissura linear ou transversal, pelo tamanho pode ser relacionado a milho ou batata-doce.

O grão 9 do lítico $14017(21,20 \mu \mathrm{m})$ possui hilo cêntrico e fissura em Y. É grande para ser gramínea selvagem e se assemelha a milho publicado em PagánJimenez (2015: 143).

O amido 10 do lítico $14292(21,70 \mu \mathrm{m})$ possui fissura em Y e superfície áspera.

O grão $14(21,75 \mu \mathrm{m})$ do sedimento 14398 da quadra P11, possui fissura linear ou transversal e superfície lisa. Se assemelha a Araceae (taioba) de Torrence \& Barton (2006: Plate 16) que são menores que $20 \mu \mathrm{m}$, têm superfície lisa com fissuras e facetas de pressão.

O amido 2 do lítico $14192(21,84 \mu \mathrm{m})$ possui fissura transversal e um pouco radial.

Os grãos 18 do lítico $13014(22,45 \mu \mathrm{m})$ e 22 do lítico $13014(22,57 \mu \mathrm{m})$ possuem fissura transversal característica de milho mas também presente em batatadoce (ver Pagán-Jimenez, 2007: 134).

O grão 16 do lítico $14391(24,76 \mu \mathrm{m})$ é mais arredondado e possui fissura radial ou estrelada, que é característica de Manihot esculenta (mandioca), embora não possua superfície lisa característica de amido de mandioca (Cf. Piperno et al; 2000: 896; Cagnato \& Ponce, 2017: 281; Duncan et al; 2009: 13205; Boyadjian, 2012: 209; Cascon, 2017: 242). 
O amido 6 do lítico $14192(24,99 \mu \mathrm{m})$ possui a mesma fissura fissura transversal característica de milho mas também presente em batata-doce em Pagán-Jimenez (2007: 134), seu tamanho quase próximo a $25 \mu \mathrm{m}$ também poderia o aproximar a batata-doce.

O amido 22 do lítico $14391(25,70 \mu \mathrm{m})$ possui fissura transversal.

O amido 11 do lítico $14017(27,73 \mu \mathrm{m})$ é provavelmente de batata-doce devido ao seu maior tamanho e superfície lisa. Parece ter fissura em forma de "Y".

O amido 1 do lítico $14369(21,05 \mu \mathrm{m})$ possui forma bastante irregular e fissura radial.

\section{Morfotipo B (n=5)}

Os grãos deste morfotipo (Figura 43) são poligonais com hilo aberto. Não há padrão nas cruzes de interferência e as superfícies são lisas, com apenas uma exceção (24/25). O menor mede $15,26 \mu \mathrm{m}$ e o maior $19,30 \mu \mathrm{m}$ de comprimento.

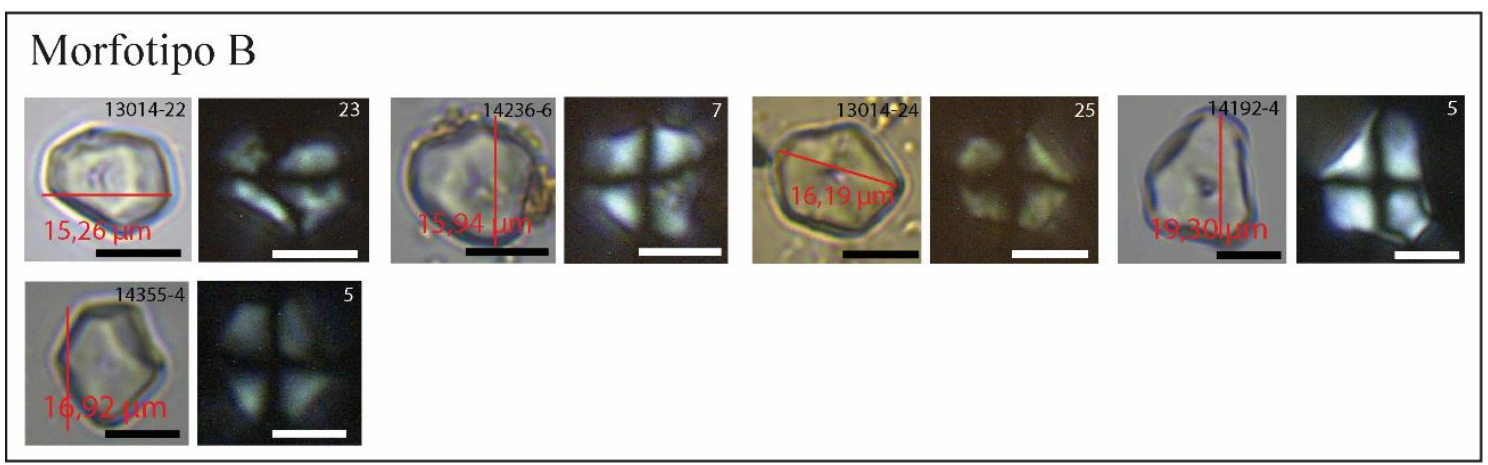

Figura 43. Grãos de amido classificados como Morfotipo B.

O amido 22 do lítico $13014(15,26 \mu \mathrm{m})$ possui fissura na região do hilo e superfície lisa com algumas partes ásperas. A cruz de interferência é distorcida com braços finos. Ele se assemelha a batata-doce (C.f Chinique de Armas, 2015: 7; Boyadjian et al; 2016: 141; Wesolowski et al; 2007: 202; Pagán-Jimenez, 2007: 134; Pagán-Jimenez, 2015: 54). Dependendo do tipo de batata-doce, o seu amido pode apresentar hilo aberto (ver Pagán-Jimenez, 2015: 54) ou fechado (Pagán-Jimenez, 2015: 56). O problema é que na coleção de referência o amido de batata-doce com hilo aberto não apresenta fissuras (ver Pagán-Jimenez, 2015: 54). Também há milho semelhante a 
este grão, com hilo aberto e fissuras pequenas, medianas ou grandes e em forma de "Y" (ver Pagán-Jimenez, 2015: 108, 110).

O amido 6 do lítico $14236(15,94 \mu \mathrm{m})$ possui bordas mais arredondadas e fissuras leves ao redor do hilo. Sua superfície é lisa com leve aspereza. Se assemelha a milho com hilo aberto e fissura em "Y" (Pagán-Jimenez, 2015: 110).

O amido 24 do lítico $13014(16,19 \mu \mathrm{m})$ é pentagonal, sem fissuras e apresenta superfície irregular. Se assemelha muito a batata-doce (ver Chinique de Armas, 2015: 7). Mas também há milho com hilo aberto (Pagán-Jimenez, 2015: 108, 110)

O amido 4 do lítico $14192(19,30 \mu \mathrm{m})$ possui superfície lisa e não possui fissuras. Os braços da cruz de interferência são simétricos de espessura regular. Se assemelha a batata-doce (Chinique de Armas, 2015: 7). Mas também há milho semelhante com hilo aberto (Pagán-Jimenez, 2015: 108, 110).

O amido 4 do lítico $12355(16,92 \mu \mathrm{m})$ possui hilo aberto, ainda que suave e difícil de visualizar. Não possui fissuras, a superfície é lisa e a cruz de interferência possui braços espessos.

\section{Morfotipo C (n=1)}

Esse morfotipo (Figura 44) é representado apenas por um grão esferoide, cuja superfície é lisa e o hilo cêntrico com fissura em " $X$ ". A cruz de interferência é de espessura regular e simétrica com um braço ondulado. Por medir 18,23 $\mu \mathrm{m}$ é possível que não seja gramínea selvagem. É muito semelhante a milho (Pagán-Jimenez, 2014: 543; 2015:129; Cascon, 2017:244).

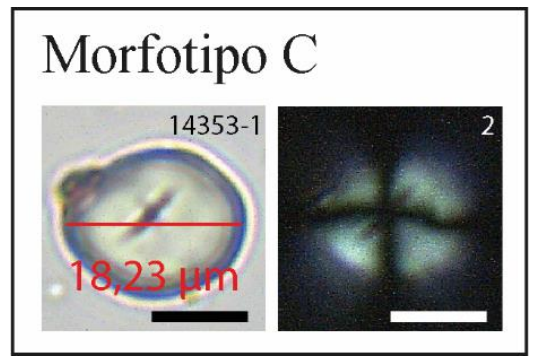

Figura 44. Grãos de amido classificados como Morfotipo C. 


\section{Morfotipo D (n=2)}

Os grãos de amido deste morfotipo (Figura 45) são eferoides, possuem hilo aberto e borda dupla. São bastante pequenos em relação aos demais morfotipos.

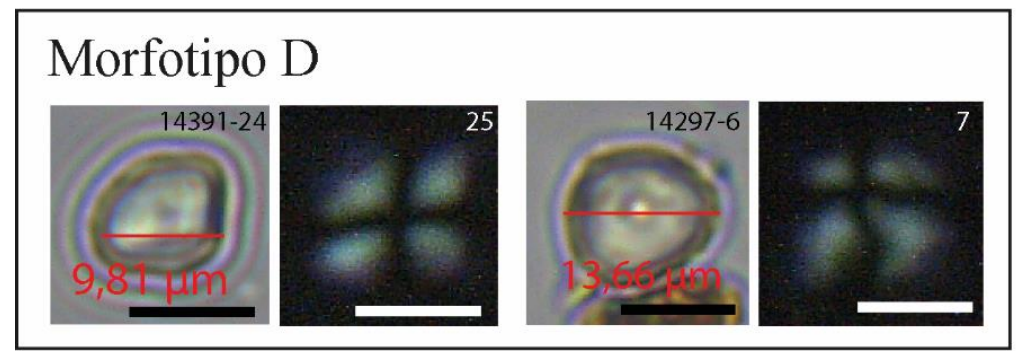

Figura 45. Grãos de amido classificados como Morfotipo D.

O amido 24 do lítico $14391(9,81 \mu \mathrm{m})$ possui facetas de pressão suaves e cruz de interferência de espessura regular, com simetria.

O grão 6 do lítico $14297(13,66 \mu \mathrm{m})$ possui cruz de interferência distorcida.

Grãos de amido de uma Arecaceae, Bactris gasipaes (palmito pupunha), também são esferoides e possuem hilo aberto, com cruzes de interferência assimétricas e são pequenos com até $10 \mu \mathrm{m}$ de diâmetro (Boyadjian, 2012:204, Pagán-Jimenez, 2015:28). Entretanto, tais características são muito gerais para uma associação diagnóstica com os grãos identificados.

\section{Morfotipo E (n=1)}

Este morfotipo (Figura 46) é representado pelo grão de amido 7 do lítico 14353 $(23,75 \mu \mathrm{m})$ com forma ovalada, superfície lisa, com borda dupla e uma fenda ou fissura longitudinal linear. A cruz de interferência é alongada, cêntrica com braços curvos (ver Pagán-Jimenez, 2015:14).

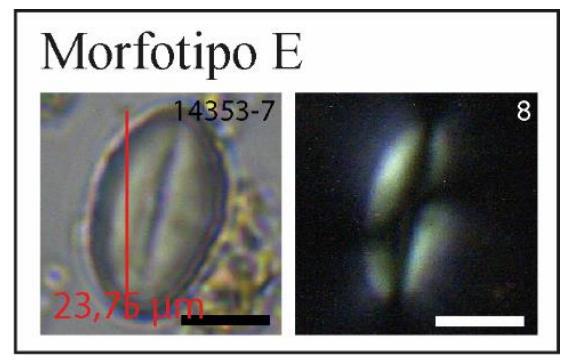

Figura 46. Grãos de amido classificados como Morfotipo E. 
O grão é muito semelhante à amido de Capsicum sp. (pimenta e pimentão), devido a linha central e linear do grão (Perry et al; 2007: 988; Duncan et al; 2009: 13205; Pagán-Jimenez, 2012: 88). Entretanto, o amido de Capsicum sp. é achatado com uma depressão central como uma hemoglobina, enquanto que o grão identificado não é achatado (mas ovalado) e não possui depressão quando rotado (ver Perry et al; 2007:986). As evidências mais antigas de Capsicum sp. foram encontradas nos Andes e no arquipélago de Bahamas há 6000 anos A.P. (Perry et al; 2007:986). Uma das espécies de pimenta, a Capsicum chinese (malaguetas), foi inicialmente domesticada na planície norte da Amazônia (Perry et al; 2007:986).

A "linha central" do grão poderia se tratar de uma fenda semelhante às existentes em amido de Fabaceae (leguminosas, vagens, ervilhas e feijões) (Pagán-Jimenez, 2015:70; Babot, 2003:71; Watling, 2018). Grãos de Phaseolus sp. (feijões) podem ser ovalados, esféricos ou reniformes; apresentam fissuras longitudinais lineares e regulares, cruz de interferência cêntrica ou excêntrica com braços curvos e a borda pode ser dupla (Pagán-Jimenez, 2015:70-75). Entretanto, esta cruz não é exatamente característica como as de Fabaceae (Ver, Babot, 2003:71; Watling, 2018). Um detalhe que Phaseolus sp. pode ter e que este grão não apresenta são pequenas fissuras paralelas à fissura principal (ver Pagán-Jimenez, 2015:70).

Grãos de amido de feijão (Phaseolus sp.) foram identificados em artefatos líticos do sítio Teotônio, na Amazônia, em fase arqueológica com ocupações que datam entre 8600 a 6400 anos A.P; período similar à identificação do feijão em contextos como a Mesoamérica e nos Andes (Watling et al; 2018).

\section{Morfotipo F (n=1)}

Este grão $8(31,29 \mu \mathrm{m})$ do lítico 14267 foi encontrado no mesmo lítico do morfotipo E e se assemelha a este por ser ovalado com cruz de interferência alongada e curva, semelhante àquela característica de Fabaceae (leguminosas), mas não é exatamente igual (Figura 47) (Pagán-Jimenez, 2015:70; 2015b:8; Babot, 2003:71; Watling, 2018; Chinique de Armas, 2015:7). Possui a superfície lisa com pequenas depressões e fenda quase pouco visível. 


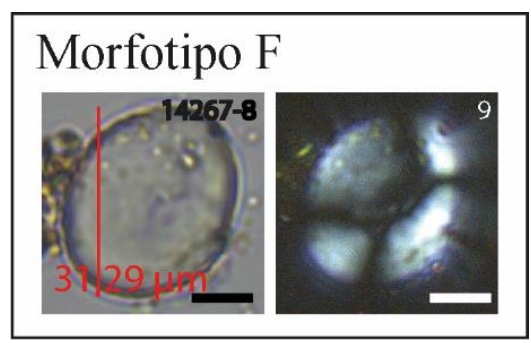

Figura 47. Grão de amido classificados como Morfotipo F.

\section{Morfotipo G (n=1)}

Este morfotipo consiste no grão $6(28,89 \mu \mathrm{m})$ do lítico 14391 (Figura 48). É ovalado com lamelas visíveis, hilo excêntrico e cruz de interferência excêntrica com braço curvo.

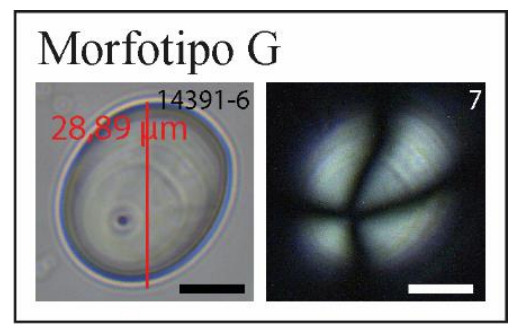

Figura 48. Grãos de amido classificados como Morfotipo G.

Poderia ser Dioscorea sp. (cará) devido a forma ovalada ou elíptica, hilo excêntrico, o conjunto de círculos concêntricos (lamelas) com a marcada projeção de uma das lamelas e cruz de interferência excêntrica (ver Pagán-Jimenez, 2015: 58). Entretanto, a cruz de Dioscorea sp. geralmente apresenta ondulação nos braços, o que não há no amido identificado (ver Pagán-Jimenez, 2015: 58).

A forma ovalada e lamelas visíveis deste grão se assemelhe a amido de Solanum tuberosum (batata-inglesa) (ver Torrence \& Barton, 2006: Plate 9; Babot, 2003: 71; Duke et al; 2018: 77). Como no contexto brasileiro não há registros précoloniais da batata-inglesa (andina), é possível que este grão se trate de uma contaminação laboratorial.

Assim como também se assemelha a Maranta arundinacea (araruta), exceto pelas fissuras ao redor do hilo que apresenta o amido dessa espécie e não há no grão 
identificado (ver Chandler-Ezell et al; 2006: 114; Pagán-Jimenez, 2014: 543; Perry, 2004: 1077; Pearsall, 2015: 610).

\section{Morfotipo H (n=3)}

Os grãos deste morfotipo são esferoides e achatados, com hilo invisível e possuem cruz de interferência simétrica com braços espessos (Figura 49). A superfície é lisa com pequenas depressões. Se assemelha a amido de Poaceae (ver Yang \& Perrry, 2013: 3173). O menor possui $18,60 \mu \mathrm{m}$ e o maior $36,71 \mu \mathrm{m}$.

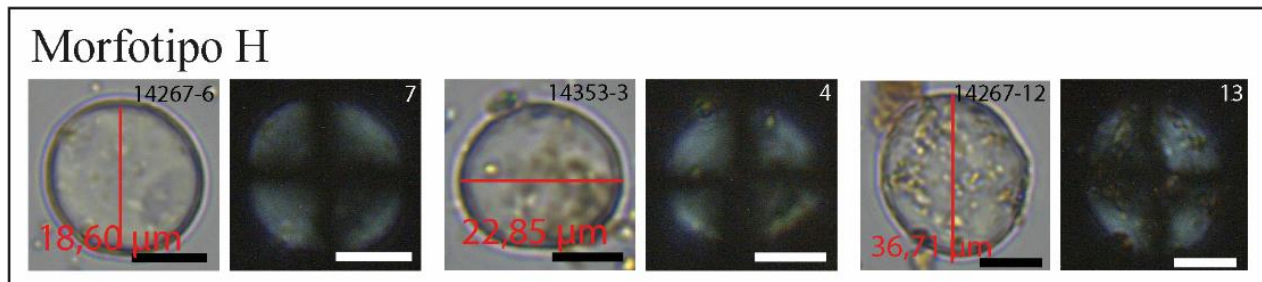

Figura 49. Grãos de amido classificados como Morfotipo H.

\section{Grãos de Amido Não Classificados (n=17)}

Esta categoria inclui amido com diferentes características não diagnósticas atribuíveis a possíveis táxons (Figura 50).

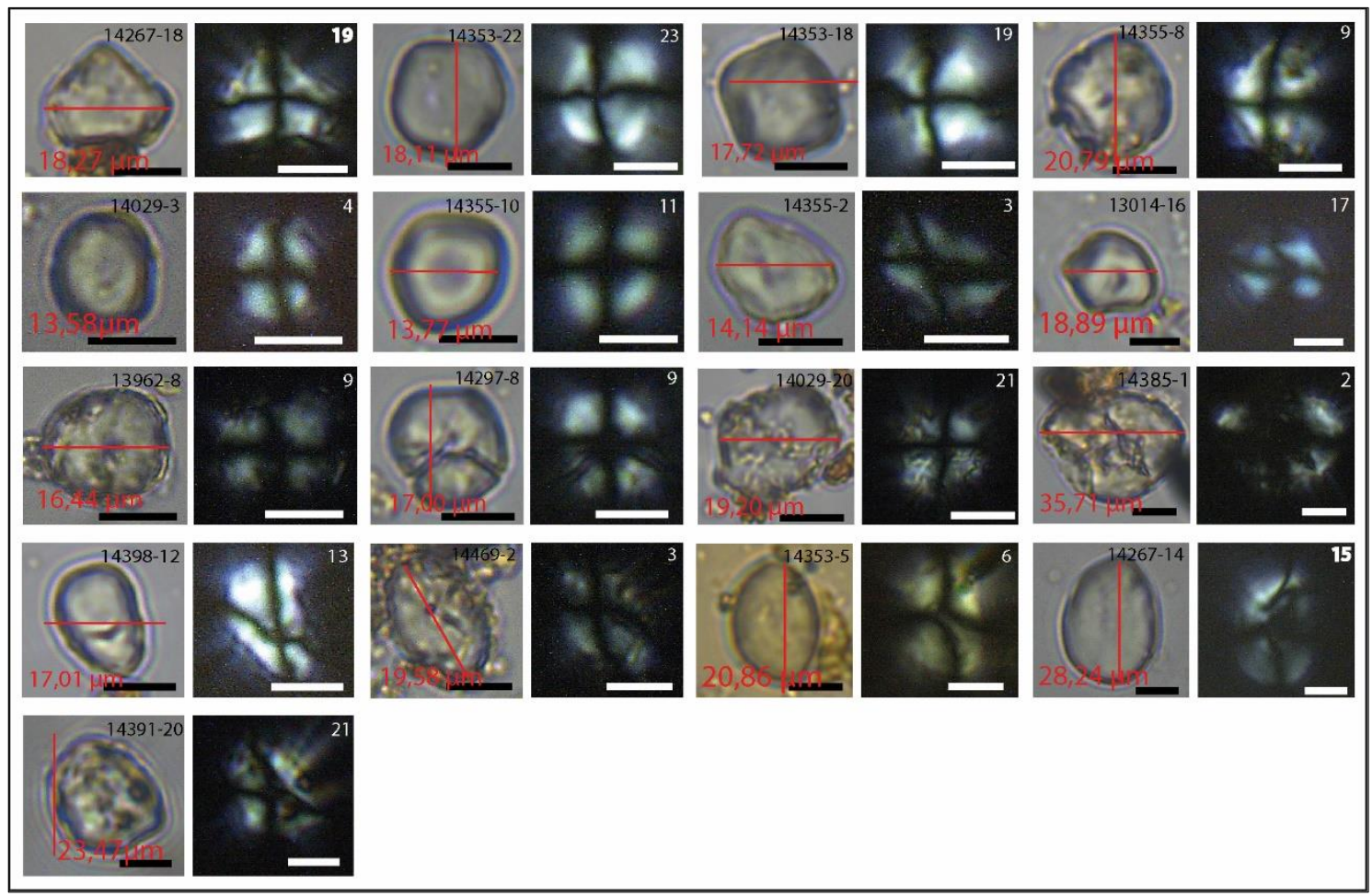

Figura 50. Grãos de amido não classificados. 
Os grãos 8 do lítico 14297 (17,00 $\mu$ m), 20 do lítico 14019 e 1 do lítico 14385 (35, $71 \mu$ ) estão danificados. O primeiro é esferoide, possui superfície lisa e cruz de interferência espessa. O segundo é esferoide e possui cruz de interferência com braços finos. O último apresenta fissuras e cruz de interferência com braços espessos em sentido ao hilo.

O amido 18 do lítico $14267(18,27 \mu \mathrm{m})$ é poligonal e possui hilo invisível. Sua cruz é simétrica com braços finos.

O amido 22 do lítico $14353(18,11 \mu \mathrm{m})$ é circular e achatado com facetas de pressão, superfície lisa e apresenta cruz de interferência distorcida.

O grão 18 do lítico 14353 é esférico mas apresenta facetas de pressão, superfície lisa e cruz de interferência distorcida.

O amido 8 do lítico $14355(20,70 \mu \mathrm{m})$ é esférico com facetas de pressão e apresenta cruz com braços finos.

O amido 3 do lítico $14029(13,58 \mu \mathrm{m})$ é esférico e achatado com depressão suave, superfície lisa, borda dupla e cruz de interferência com braços espessos.

O amido 10 do lítico $14355(13,77 \mu \mathrm{m})$ é esférico, com superfície lisa e possui depressão na área do hilo, o que é visível na cruz de interferência. No mesmo lítico e com comprimento semelhante, o grão 2 do lítico $14355(14,14 \mu \mathrm{m})$, parece também ter uma depressão, embora sua forma seja irregular e sua superfície rugosa.

O grão 16 do lítico $13014(18,89 \mu \mathrm{m})$ possui forma irregular e uma depressão ou cavidade como hilo. A cruz é distorcida e com espessura irregular.

O grão 8 do lítico 1967 (16,44 $\mu \mathrm{m})$ é esférico e possui superfície áspera, hilo aberto e cruz de interferência com braços espessos.

O amido $12(17,01 \mu \mathrm{m})$ do sedimento 14398 da quadra P11 é ovalado e afunila na região proxima onde está o hilo. Este é excêntrico e possui fissura. O grão possui borda dupla, superfície lisa e cruz de interferência é excêntrica com um braço ondulado e outro reto de espessuras finas. 
O amido 2 do lítico $14469(19,58 \mu \mathrm{m})$ é ovalado, possui fissura no sentido longitudinal e borda dupla. A cruz de interferência é excêntrica e curva com braços de espessura regular.

O amido 20 do lítico $14029(19,20 \mu \mathrm{m})$ possui forma arredondada, cruz de interferência com braços retos e finos. O hilo é cêntrico e apresenta rachadura que parece ser danificação.

O amido 5 do lítico $14353(20,86 \mu \mathrm{m})$ e o amido 14 do lítico $14267(28,24 \mu \mathrm{m})$ possuem forma ovalada, sem lamelas visíveis e hilo invisível e cêntrico. As cruzes de interferência são distorcidas.

\section{Síntese}

Uma síntese dos resultados deste tópico é apresentada na Tabela 12:

Tabela 12. Descrição dos morfotipos de grãos de amido encontrados nas amostras da Lapa do Santo

\begin{tabular}{|c|c|c|c|c|}
\hline & Descrição dos grãos & Qtd. & Táxons Possíveis & Foto \\
\hline $\mathrm{A}$ & $\begin{array}{l}\text { Irregulares, poligonais ou } \\
\text { poliédricos, com hilo cêntrico e } \\
\text { fissuras de várias formas: } \\
\text { ramificadas, em linha reta ou curvas } \\
\text { e em forma de X ou Y. A cruz é } \\
\text { distorcida ou simétrica, com braços } \\
\text { finos. A superfície pode ser lisa. O } \\
\text { menor possui } 16,39 \mu \mathrm{m} \text { e o maior } \\
27,73 \mu \mathrm{m} \text { de comprimento. }\end{array}$ & 18 & $\begin{array}{l}\text { Gramíneas selvagens } \\
\text { Zea mays (milho) } \\
\text { Ipomoea batatas } \\
\text { (batata-doce) } \\
\text { Araceae (taioba) }\end{array}$ & \\
\hline $\mathrm{B}$ & $\begin{array}{l}\text { Poligonais com hilo aberto. Não há } \\
\text { padrão nas cruzes de interferência e } \\
\text { as superfícies podem ser lisas ou } \\
\text { ásperas. O menor mede } 15,26 \mu \mathrm{m} \text { e o } \\
\text { maior } 19,30 \mu \mathrm{m} \text { de comprimento. }\end{array}$ & 5 & $\begin{array}{l}\text { Ipomoea batatas } \\
\text { (batata-doce) } \\
\text { Zea mays (milho) }\end{array}$ & \\
\hline
\end{tabular}




\begin{tabular}{|c|c|c|c|c|}
\hline & Descrição dos grãos & Qtd. & Táxons Possíveis & Foto \\
\hline $\mathrm{C}$ & $\begin{array}{l}\text { Esferoide, superfície lisa e hilo } \\
\text { cêntrico com fissura em "X". A cruz } \\
\text { de interferência é de espessura } \\
\text { regular e simétrica com um braço } \\
\text { ondulado. Mede } 18,23 \mu \mathrm{m} \text {. }\end{array}$ & 1 & Zea mays (milho) & \\
\hline $\mathrm{D}$ & $\begin{array}{l}\text { Eferoides, com hilo aberto e borda } \\
\text { dupla. Medem 19,81 } \mu \mathrm{m} \text { e } 13,66 \mu \mathrm{m} \text {. }\end{array}$ & 2 & $\begin{array}{l}\text { Arecaceae } \\
\text { (palmeiras) }\end{array}$ & \\
\hline $\mathrm{E}$ & $\begin{array}{l}\text { Ovalado, superfície lisa, com borda } \\
\text { dupla e uma fenda ou fissura } \\
\text { longitudinal linear a partir da } \\
\text { localização do hilo. A cruz de } \\
\text { interferência é alongada, cêntrica } \\
\text { com braços curvos. Mede } 23,75 \mu \mathrm{m} \text {. }\end{array}$ & 1 & $\begin{array}{l}\text { Capsicum sp. } \\
\text { (pimenta) }\end{array}$ & \\
\hline $\mathrm{F}$ & $\begin{array}{l}\text { Ovalado com cruz de interferência } \\
\text { alongada e curva, superfície lisa com } \\
\text { pequenas depressões. Mede } 31,29 \\
\mu \mathrm{m} \text {. }\end{array}$ & 1 & Não identificado & \\
\hline $\mathrm{G}$ & $\begin{array}{l}\text { Ovalado com lamelas visíveis, hilo e } \\
\text { cruz de interferência excêntricos, } \\
\text { esta com braço curvo. Mede } 28,89 \\
\mu \mathrm{m} \text {. }\end{array}$ & 1 & $\begin{array}{l}\text { Dioscoreae sp. } \\
\text { (cará) } \\
\text { Solanum tuberosum } \\
\text { (batata-inglesa) }\end{array}$ & \\
\hline $\mathrm{H}$ & $\begin{array}{l}\text { Esferoides e achatados, hilo invisível } \\
\text { e cruz de interferência simétrica com } \\
\text { braços espessos. Superfície lisa com } \\
\text { pequenas depressões. O menor } \\
\text { possui } 18,60 \mu \mathrm{m} \text { e o maior } 36,71 \mu \mathrm{m} \text {. }\end{array}$ & 3 & Poaceae (gramíneas) & \\
\hline
\end{tabular}




\subsubsection{Outros Microvestígios}

Espículas de esponjas e diatomáceas são outros microvestígios identificados junto às lâminas de fitólitos, por serem biomineralizações silicosas (Tabela 13) (Batista \& Volkmer-Ribeiro, 2002; Volkmer-Ribeiro \& Machado, 2007). A sua presença está indicada nas pranchas no tópico 4.2.6. Além disso, na amostra de fora do sítio (C2), também foi identificada uma base de pelo radicial de planta (Figura 75).

Tabela 13. Espículas e Diatomáceas

\begin{tabular}{|c|c|c|}
\hline & Espículas & Diatomáceas \\
\hline $\mathbf{N} 23$ & $\begin{array}{l}\text { Líticos sonicados: } 4 \\
\text { Líticos escovados: } 34 \\
\text { Sedimento: } 2\end{array}$ & $\begin{array}{l}\text { Líticos sonicados: } 1 \\
\text { Líticos escovados: } 1 \\
\text { Sedimento: } 0\end{array}$ \\
\hline P11 & $\begin{array}{l}\text { Líticos sonicados: } 0 \\
\text { Líticos escovados: } 6 \\
\text { Sedimento: } 2\end{array}$ & $\begin{array}{l}\text { Líticos sonicados: } 0 \\
\text { Líticos escovados: } 0 \\
\text { Sedimento: } 0\end{array}$ \\
\hline AE1 & $\begin{array}{l}\text { Líticos sonicados: } 2 \\
\text { Líticos escovados: } 47 \\
\text { Sedimento: } 66\end{array}$ & $\begin{array}{l}\text { Líticos sonicados: } \\
\text { Líticos escovados: } \\
\text { Sedimento: }\end{array}$ \\
\hline $\mathrm{C2}$ & 10 & 3 \\
\hline
\end{tabular}

\subsubsection{Síntese dos microvestígios identificados em de cada lítico analisado}

A seguir serão apresentadas pranchas com identificação e imagens da face superior e inferior (quando detectável) de cada lítico, junto com o que foi encontrado nas amostras sonicadas e escovadas dos mesmos. Há uma imagem de cada morfotipo de fitólito encontrado naquele lítico e imagem de todos os grãos de amido na íntegra, porque são poucos em relação à grande quantidade de fitólitos. Um exemplar de outros microvestígios como espículas de esponjas também constarão quando existentes nas amostras. 


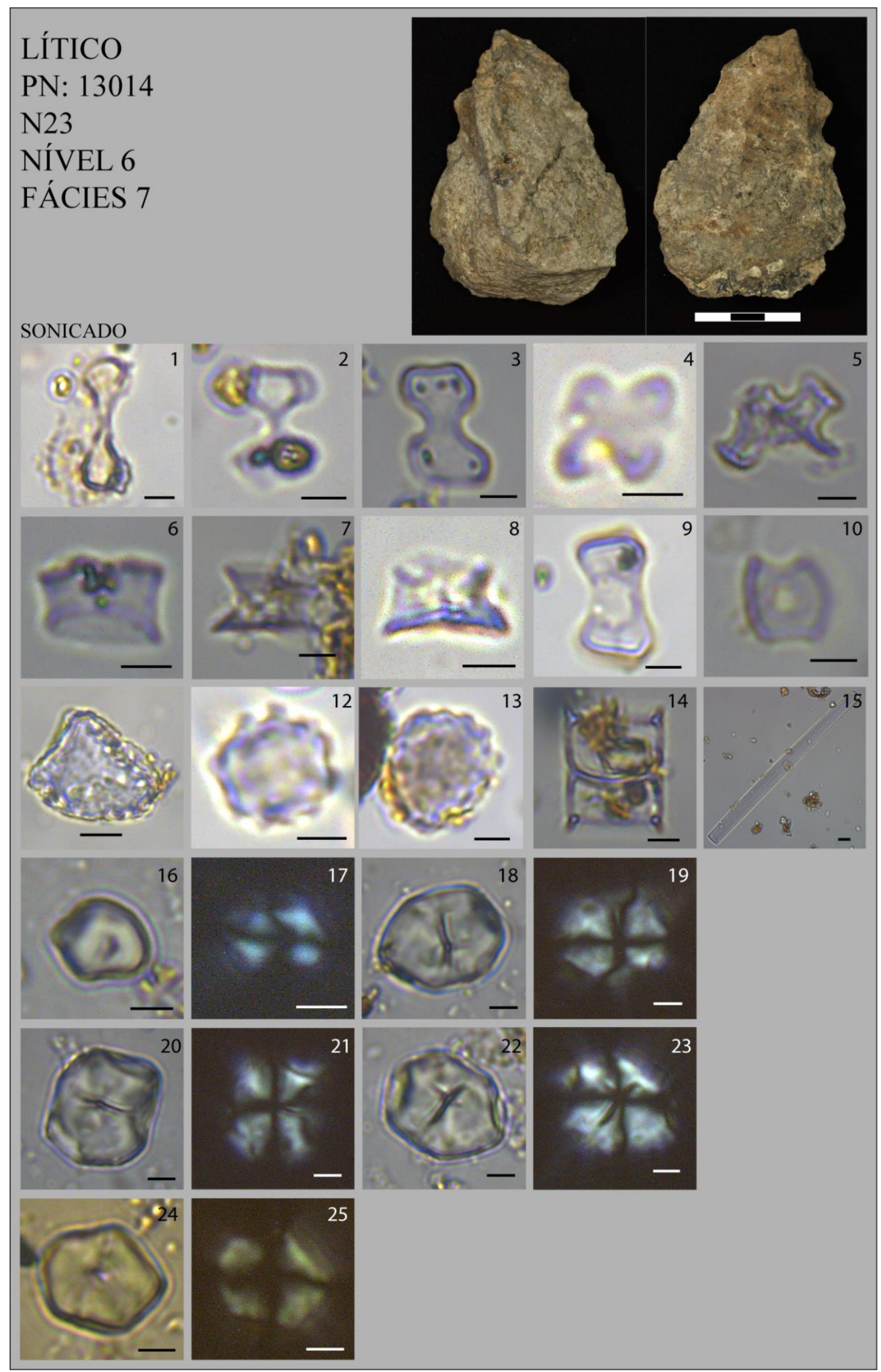

Figura 51. Microvestígios do Lítico 13014. Fitólitos: 1) bilobate de Aristidoideae, 2) bilobate de Bambusoideae, 3) bilobate de Panicoideae, 4) cross de Poaceae "variante 1", 5) cross de Poaceae "outras variantes", 6) rondel de Poaceae, 7) rondel de Poaceae, 8) 3-spiked rondel de 
Bambusoideae, 9) collapsed Saddle de Bambudoideae, 10) saddle de Chloridoideae, 11) bulliform de Poaceae, 12) globular echinate de Arecaceae (palmeira), 13) globular granulate de Eudicotiledônea (arbóreas), 14) diatomácea (organismo aquático), 15) espícula de esponja. Amido:16-17)Não identificado;18-19, 20-21, 22-23 e 24-25) Morfotipo A. Escala $10 \mu \mathrm{m}$. 


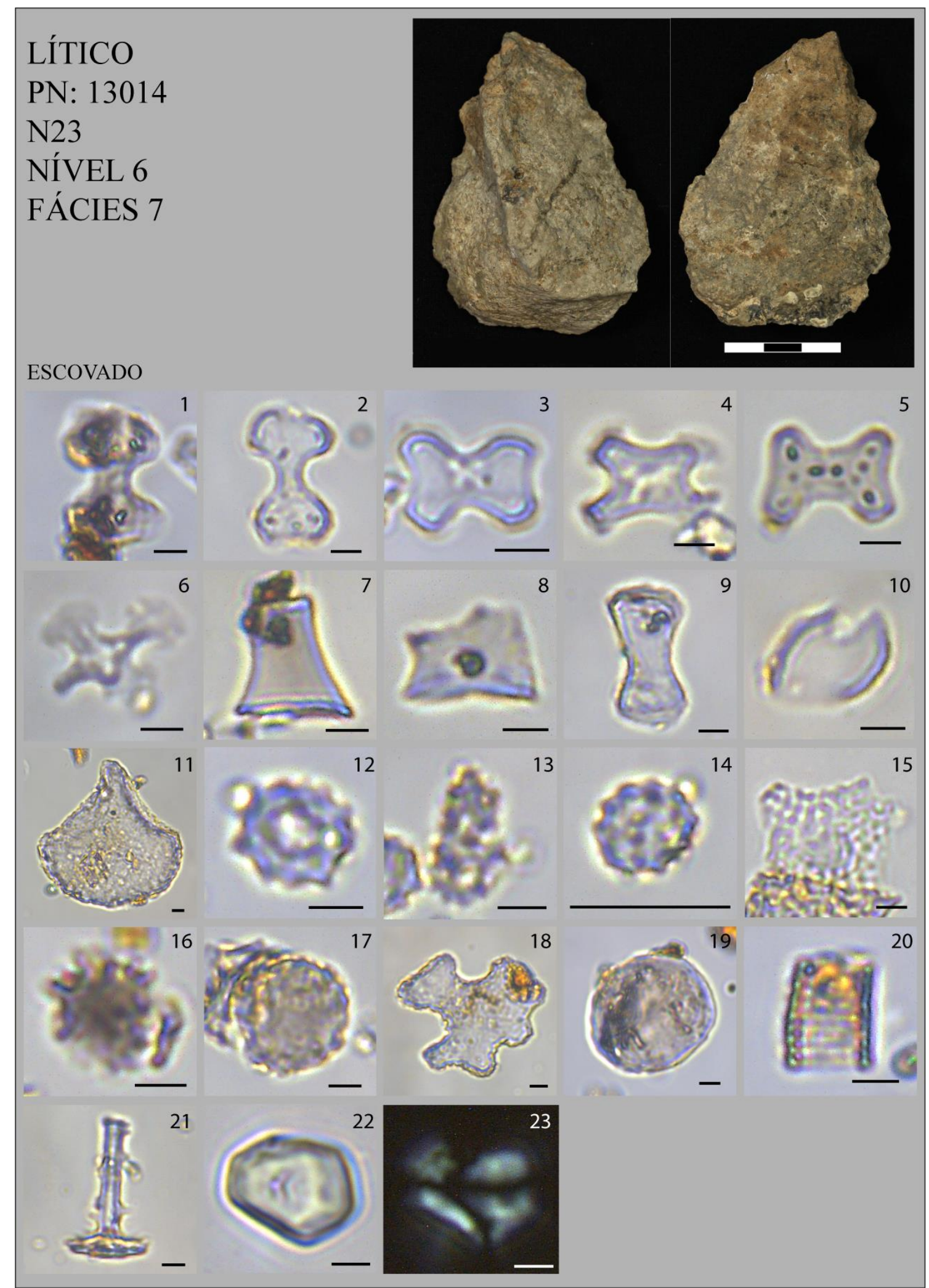

Figura 52. Microvestígios do Lítico 13014. Fitólitos e outros: 1) bilobate de Bambusoideae, 2) bilobate de Panicoideae; 3, 4 e 5) cross de Poaceae "variante 1"; 6) cross de Poaceae "outras variantes", 7) rondel de Poaceae, 8) 3-spiked rondel de Bambusoideae, 9) collapsed Saddle de Bambudoideae, 10) saddle de Chloridoideae, 11) bulliform de Poaceae, 12) globular echinate de Arecaceae (palmeira), 13) globular echinate elongate de Arecaceae, 14) globular echinate de Arecaceae with short acute projections, 15) stippled polygonal cone de Cyperus/Kyllinga sp; 16) globular nodular de Zingiberales, 17) globular granulate de Eudicotiledônea (arbóreas), 18) 
jigsaw de Eudicotiledônea, 19) globular psilate de Eudicotiledônea, 20) fragmento de diatomácea (organismo aquático), 21) espícula de esponja. Amido: 22-23) Morfotipo B. Escala $10 \mu \mathrm{m}$. 


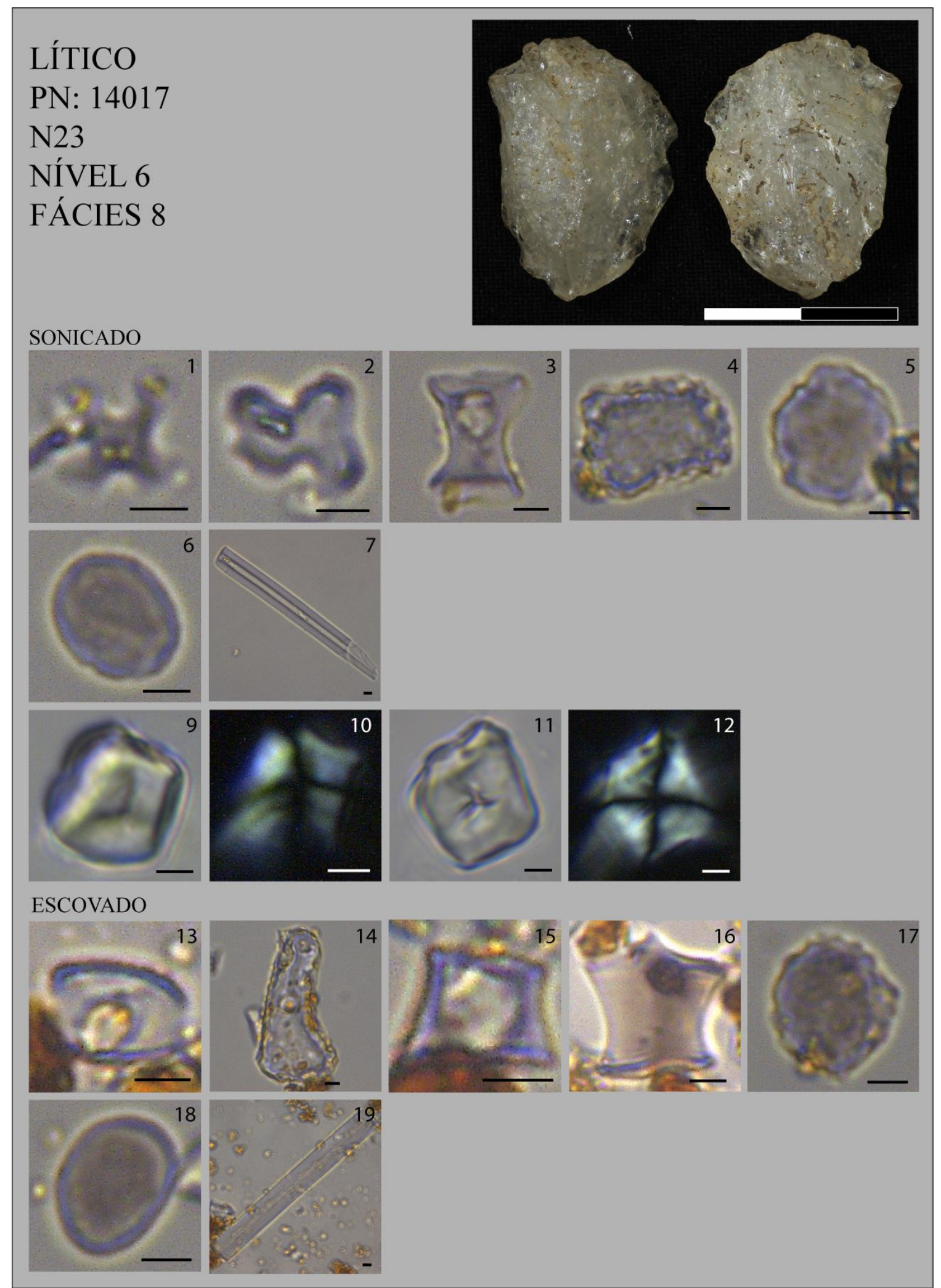

Figura 53. Microvestígios do Lítico 14017. Fitólitos e outros: 1) e 2) cross de Poaceae "outras variantes", 3) rondel de Poaceae, 4) bulliform de Poaceae, 5) globular granulate de Eudicotiledônea (arbóreas), 6) globular psilate de Eudicotiledônea, 7) espícula de esponja, 13) saddle de Chloridoideae, 14) bulliform de Poaceae, 15) rondel de Poaceae, 16) 3-spiked rondel de Bambusoideae, 17) globular granulate de Eudicotiledônea (arbóreas), 18) globular psilate de Eudicotiledônea, 19) espícula de esponja. Amido: 9-10 e 11-12 Morfotipo A. Escala $10 \mu \mathrm{m}$. 


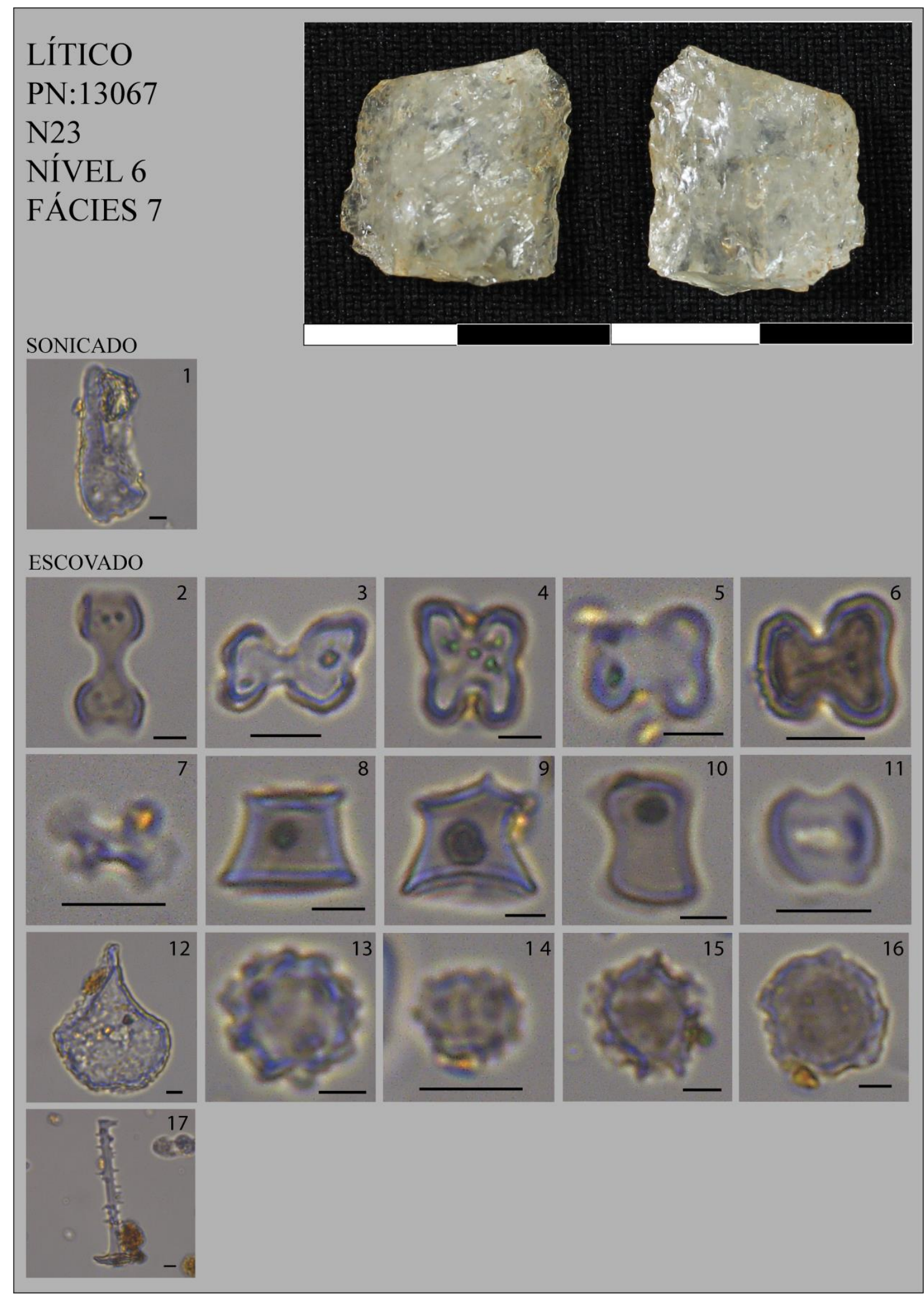

Figura 54. Microvestígios do Lítico 13067. Fitólitos e outros: 1) bulliform de Poaceae, 2) bilobate de Panicoideae; 3, 4, 5 e 6) cross de Poaceae "variante 1"; 7) cross de Poaceae "outras variantes", 8) rondel de Poaceae, 9) 3-spiked rondel de Bambusoideae, 10) collapsed Saddle de Bambusoideae, 11) saddle de Chloridoideae, 12) bulliform de Poaceae, 13) globular echinate de Arecaceae (palmeira), 14) globular echinate de Arecaceae with short acute projections, 15) globular nodular de Zingiberales, 16) globular granulate de Eudicotiledônea (arbóreas), 17) espícula de esponja. Escala $10 \mu \mathrm{m}$. 


\section{LÍTICO \\ PN: 13885 \\ N23 \\ NÍVEL 6 \\ FÁCIES 9}

SONICADO

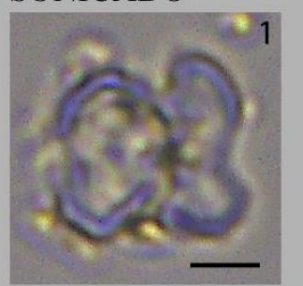

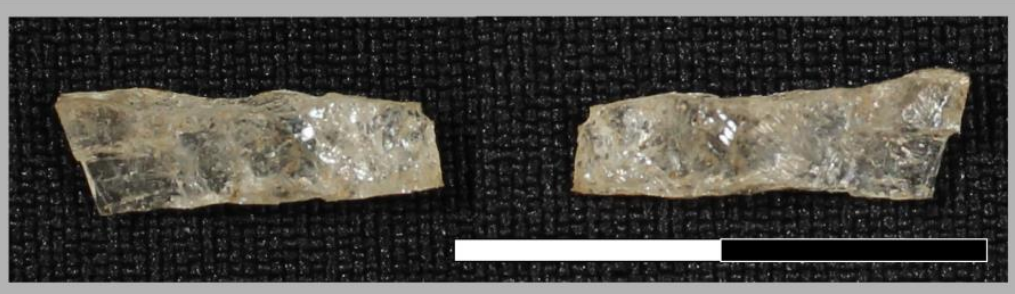

ESCOVADO

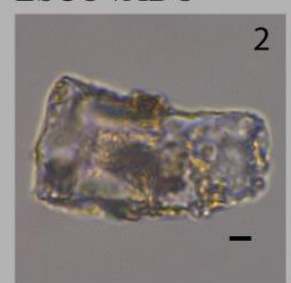

Figura 55. Microvestígios do Lítico 13885. Fitólitos: 1) cross de Poaceae "variante 1" e 2) bulliform de Poaceae. Escala $10 \mu \mathrm{m}$. 


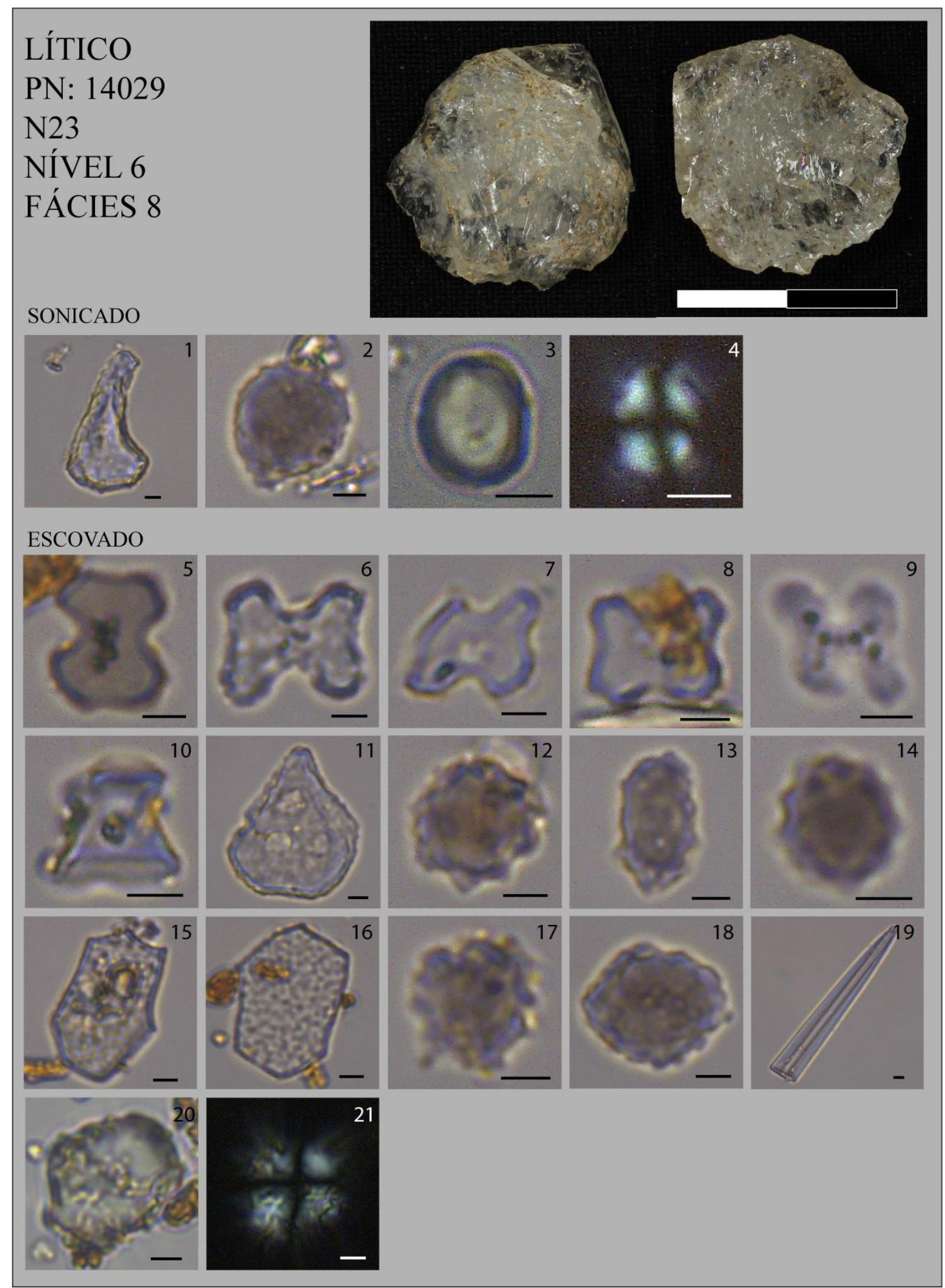

Figura 56. Microvestígios do Lítico 14029. Fitólitos: 1) bulliform de Poaceae, 2) globular granulate de Eudicotiledônea (arbóreas), 5) bilobate de Panicoideae; 6, 7 e 8) cross de Poaceae "variante 1"; 9) cross de Poaceae "outras variantes", 10) rondel de Poaceae, 11) bulliform de Poaceae, 12) globular echinate de Arecaceae (palmeira), 13) globular echinate elongate de Arecaceae, 14) globular echinate de Arecaceae with short acute projections, 15) stippled polygonal cone de Cyperus/Kyllinga sp; 16) polygonal stippled de Cyperaceae, 17) globular nodular de Zingiberales, 18) globular granulate de Eudicotiledônea (arbóreas), 19) espícula de esponja. Amido: 3-4 e 20-21) Não identificados. Escala $10 \mu \mathrm{m}$. 


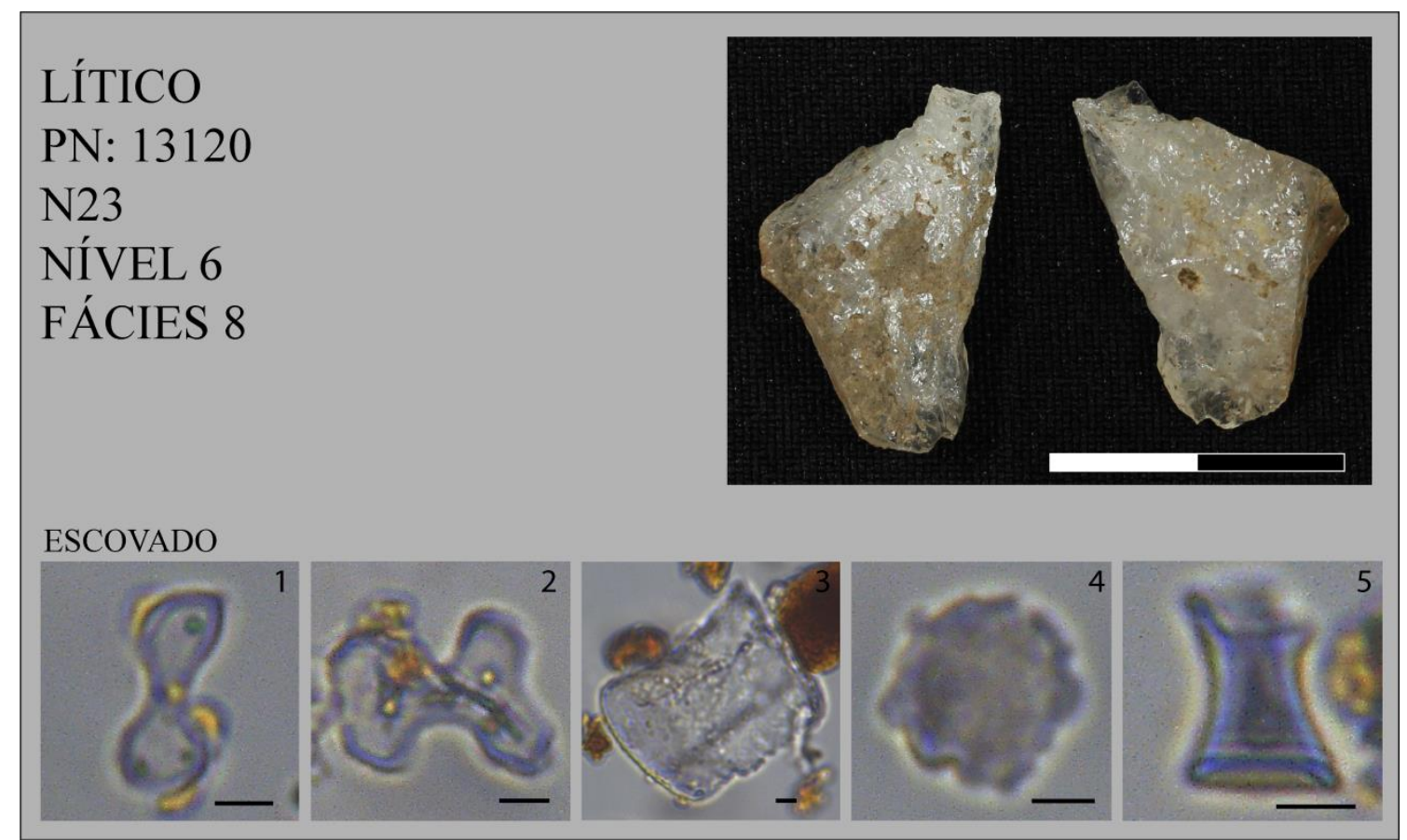

Figura 57. Microvestígios do Lítico 13120. Fitólitos: 1) bilobate de Panicoideae, 2) cross de Poaceae "variante 1", 3) bulliform de Poaceae, 4) globular granulate de Eudicotiledônea (arbóreas), 5) rondel de Poaceae. Escala $10 \mu \mathrm{m}$.

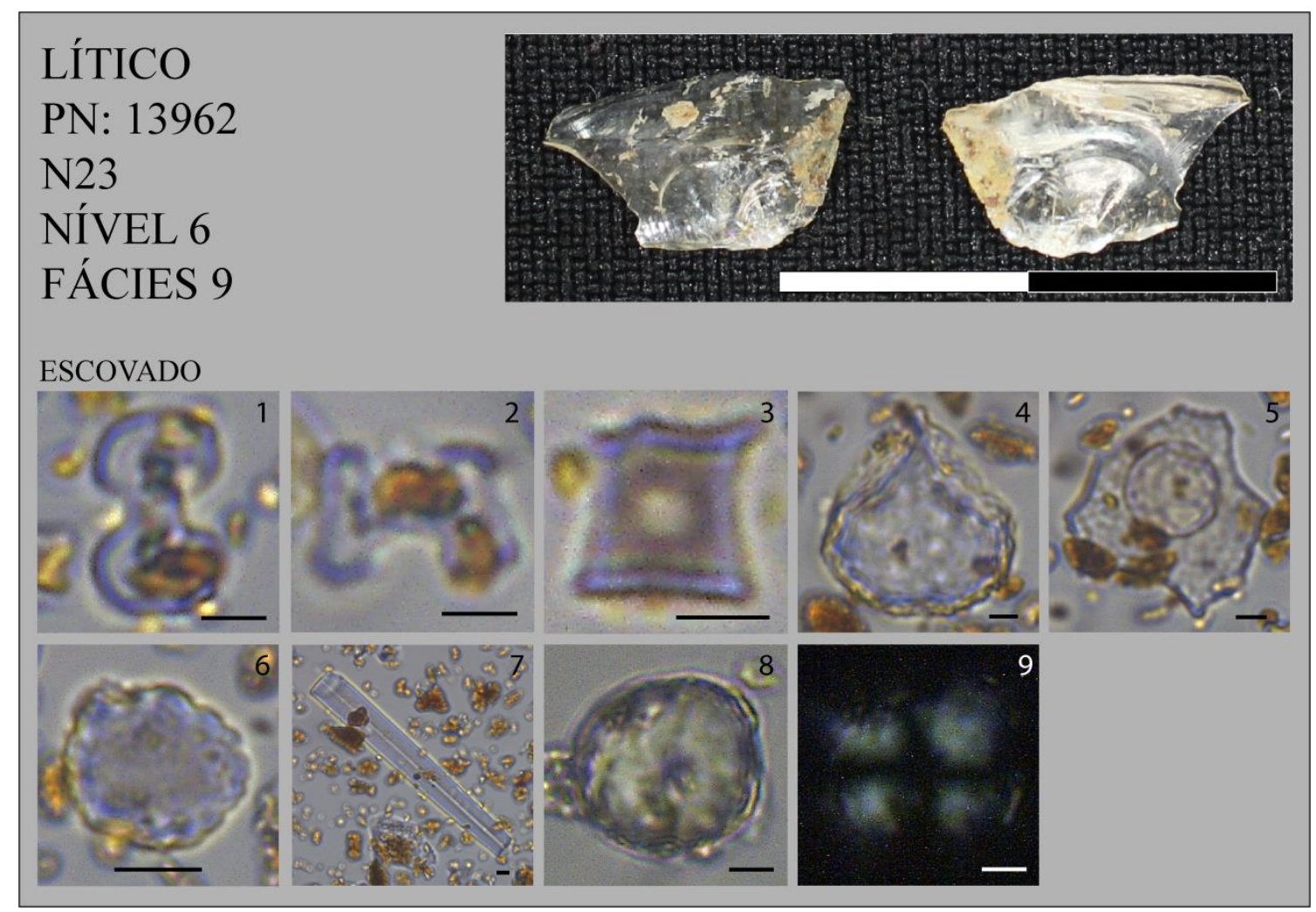

Figura 58. Microvestígios do Lítico 13962. Fitólitos: 1) bilobate de Panicoideae, 2) cross de Poaceae "outras variantes", 3) 3-spiked rondel de Bambusoideae, 4) bulliform de Poaceae, 5) stippled polygonal cone de Cyperus/Kyllinga sp; 6) globular granulate de Eudicotiledônea (arbóreas), 7) espícula de esponja. Amido: 8-9) Não identificado. Escala $10 \mu \mathrm{m}$. 


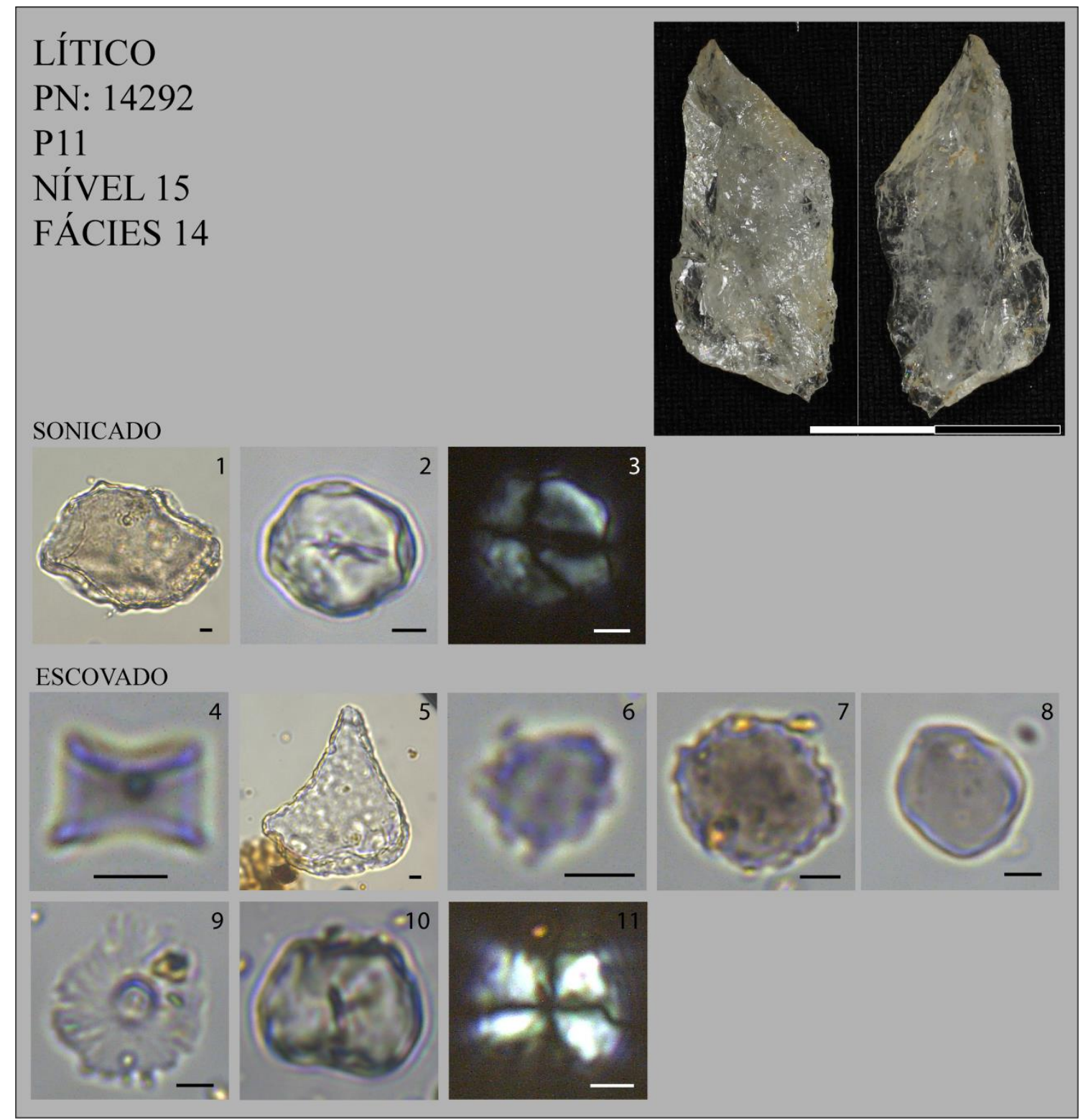

Figura 59. Microvestígios do Lítico 14292. Fitólitos: 1) bulliform de Poaceae, 4) rondel de Poaceae, 5) bulliform de Poaceae, 6) globular nodular de Zingiberales, 7) globular granulate de Eudicotiledônea (arbóreas), 8) globular psilate de Eudicotiledônea, 9) espícula de esponja. Amido: 2-3 e 10-11) Morfotipo A. Escala $10 \mu \mathrm{m}$. 


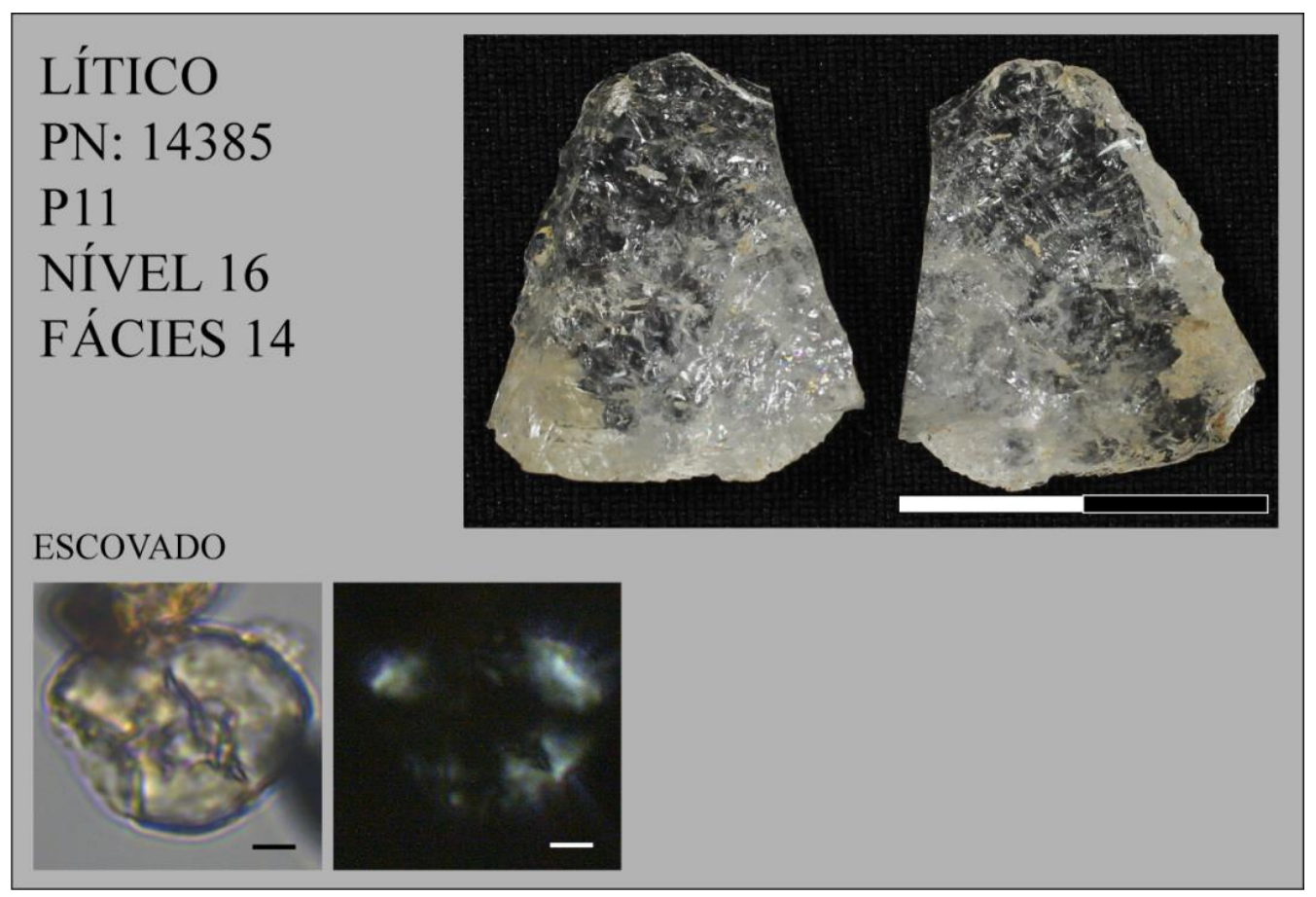

Figura 60. Microvestígio do Lítico 14385. Amido: Não identificado. Escala $10 \mu \mathrm{m}$. 


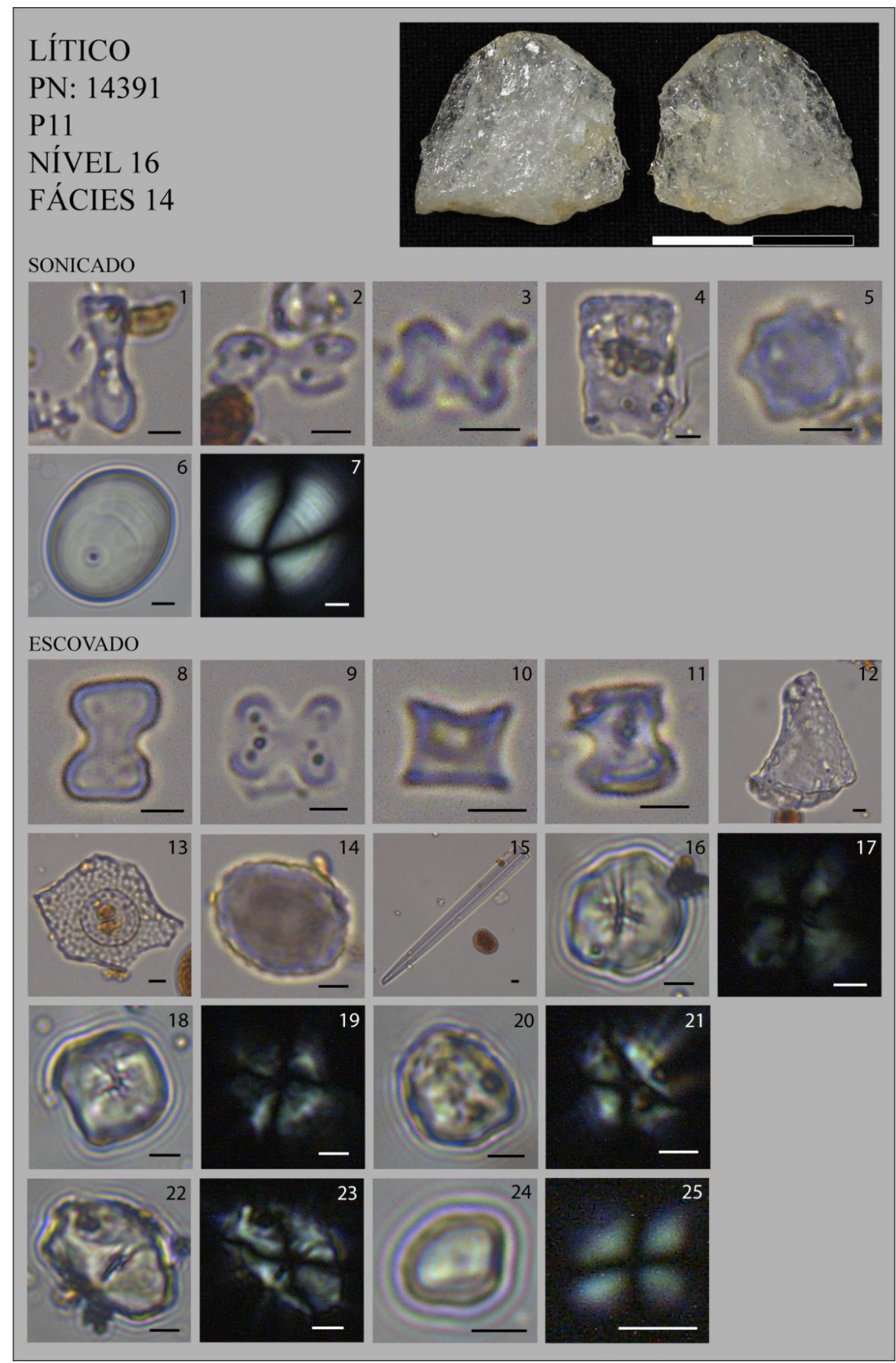

Figura 61. Microvestígio do Lítico 14391. Fitólitos e outros: 1) bilobate de Panicoideae, 2) cross de Poaceae "variante 1", 3) cross de Poaceae "outras variantes", 4) bulliform de Poaceae, 5) globular echinate de Arecaceae (palmeira), 8) bilobate de Panicoideae, 9) cross de Poaceae 
"variante 1", 10) rondel de Poaceae, 11) collapsed Saddle de Bambusoideae, 12) bulliform de Poaceae, 13) stippled polygonal cone de Cyperus/Kyllinga sp; 14) globular granulate de Eudicotiledônea (arbóreas), 15) espícula de esponja. Amido: 6-7) Morfotipo G; 16-17, 18-19 e 22-23 Morfotipo A; 20-21) Não identificado; 24-25) Morfotipo D. Escala $10 \mu \mathrm{m}$.

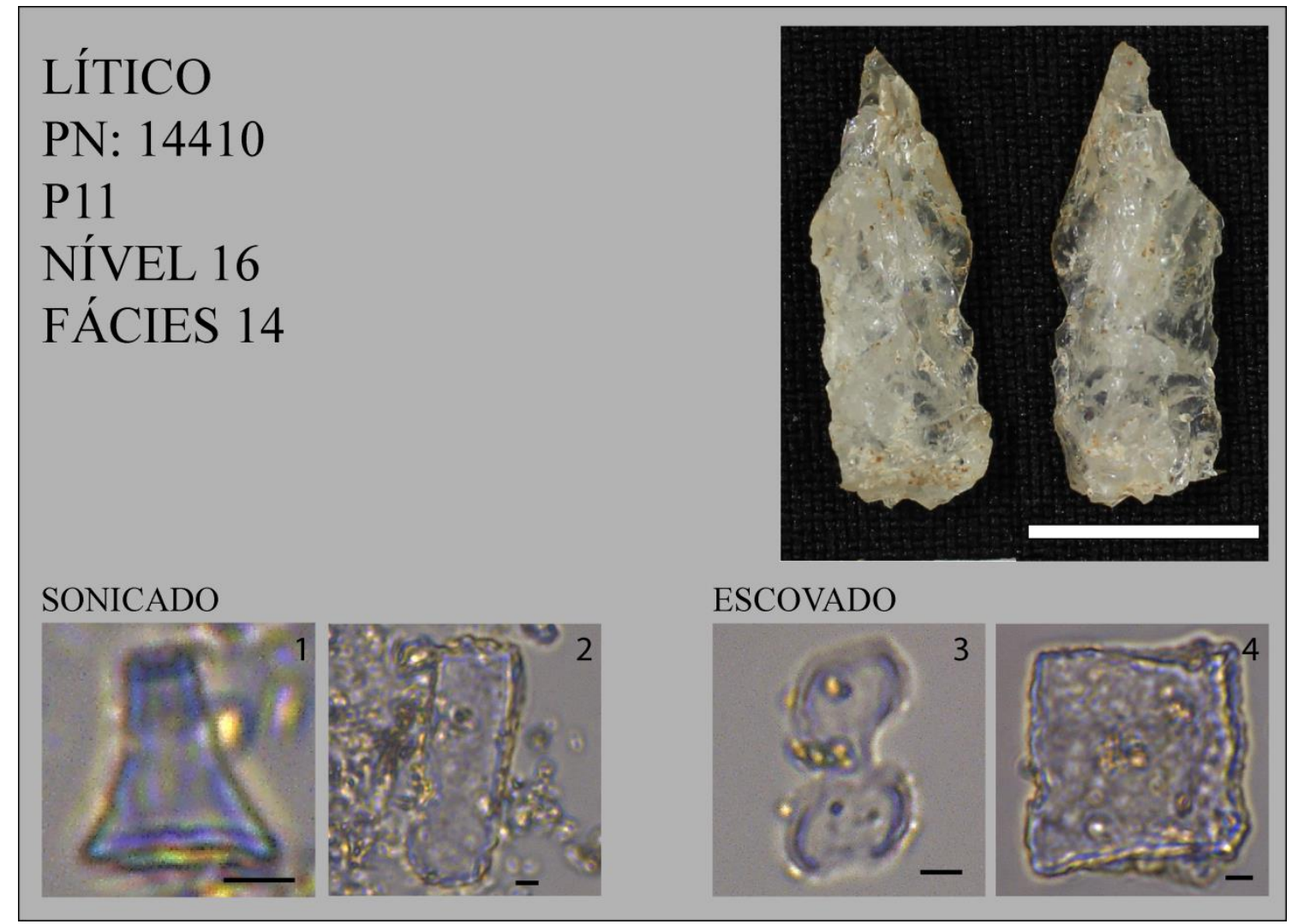

Figura 62. Microvestígio do Lítico 14410. Fitólitos: 1) rondel de Poaceae, 2) bulliform de Poaceae, 3) bilobate de Panicoideae, 4) bulliform de Poaceae. Escala $10 \mu \mathrm{m}$. 


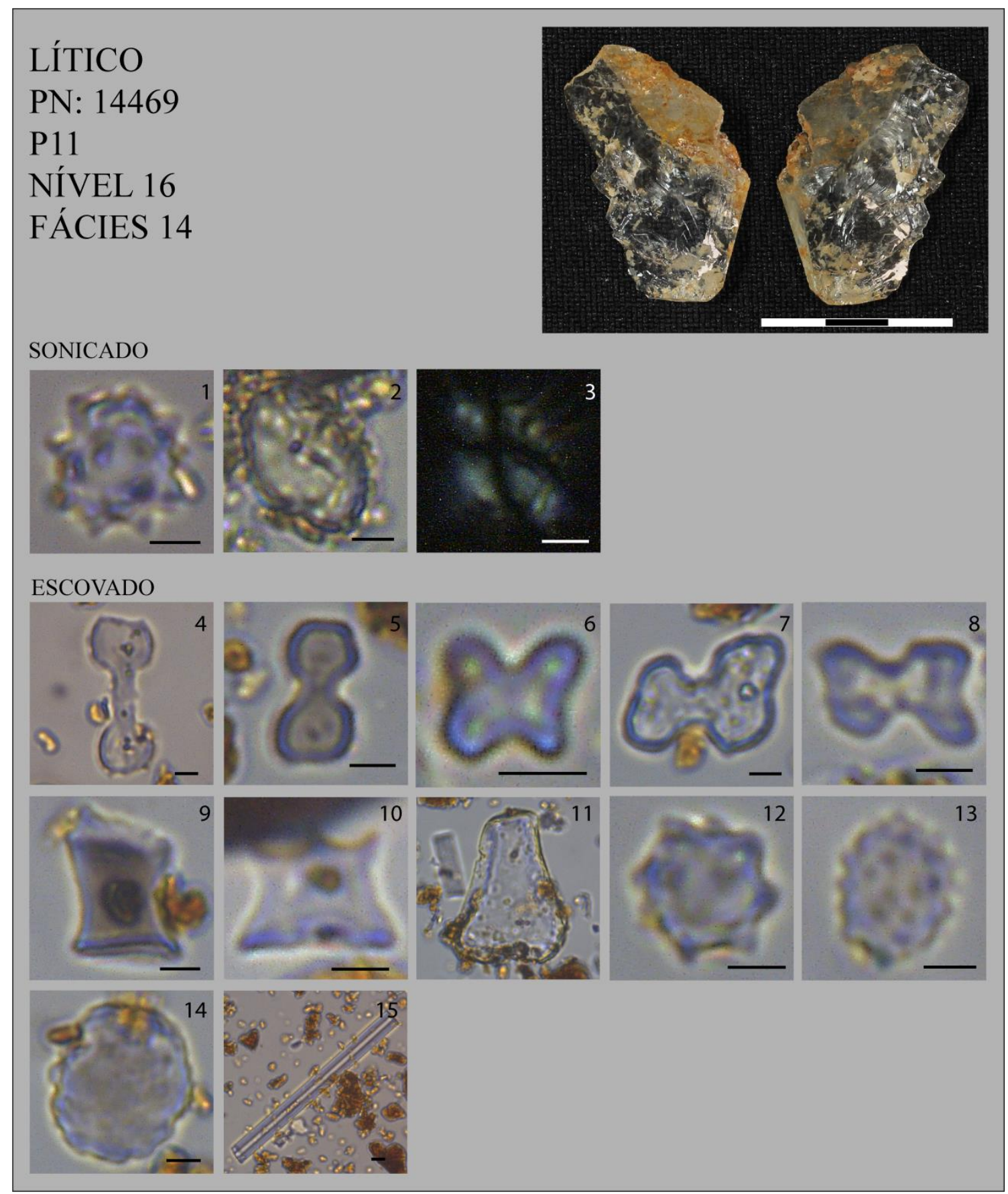

Figura 63. Microvestígio do Lítico 14469. Fitólitos: 1) globular echinate de Arecaceae (palmeira), 4) bilobate de Aristidoideae, 5) bilobate de Panicoideae; 6, 7 e 8) cross de Poaceae "variante 1"; 9) rondel de Poaceae, 10) 3-spiked rondel de Bambusoideae, 11) bulliform de Poaceae, 12) globular echinate de Arecaceae (palmeira), 13) globular echinate de Arecaceae with short acute projections, 14) globular granulate de Eudicotiledônea (arbóreas), 15) espícula de esponja. Amido: 2-3) Morfotipo I. Escala $10 \mu \mathrm{m}$. 


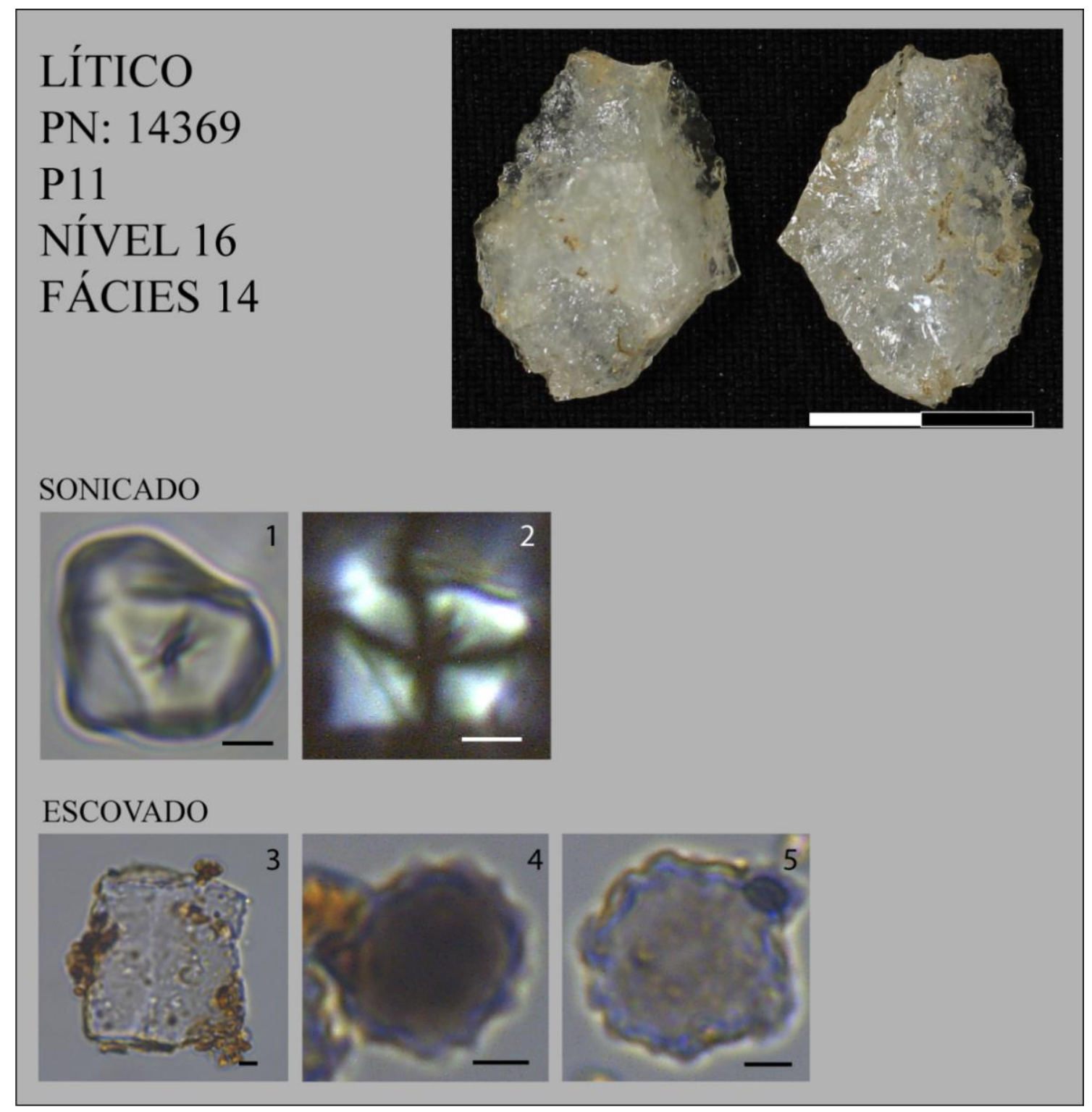

Figura 64. Microvestígio do Lítico 14369. Fitólitos: 3) bulliform de Poaceae, 4) globular echinate de Arecaceae with short acute projections, 5) globular granulate de Eudicotiledônea (arbóreas). Amido: 1-2) Morfotipo A. Escala $10 \mu \mathrm{m}$. 


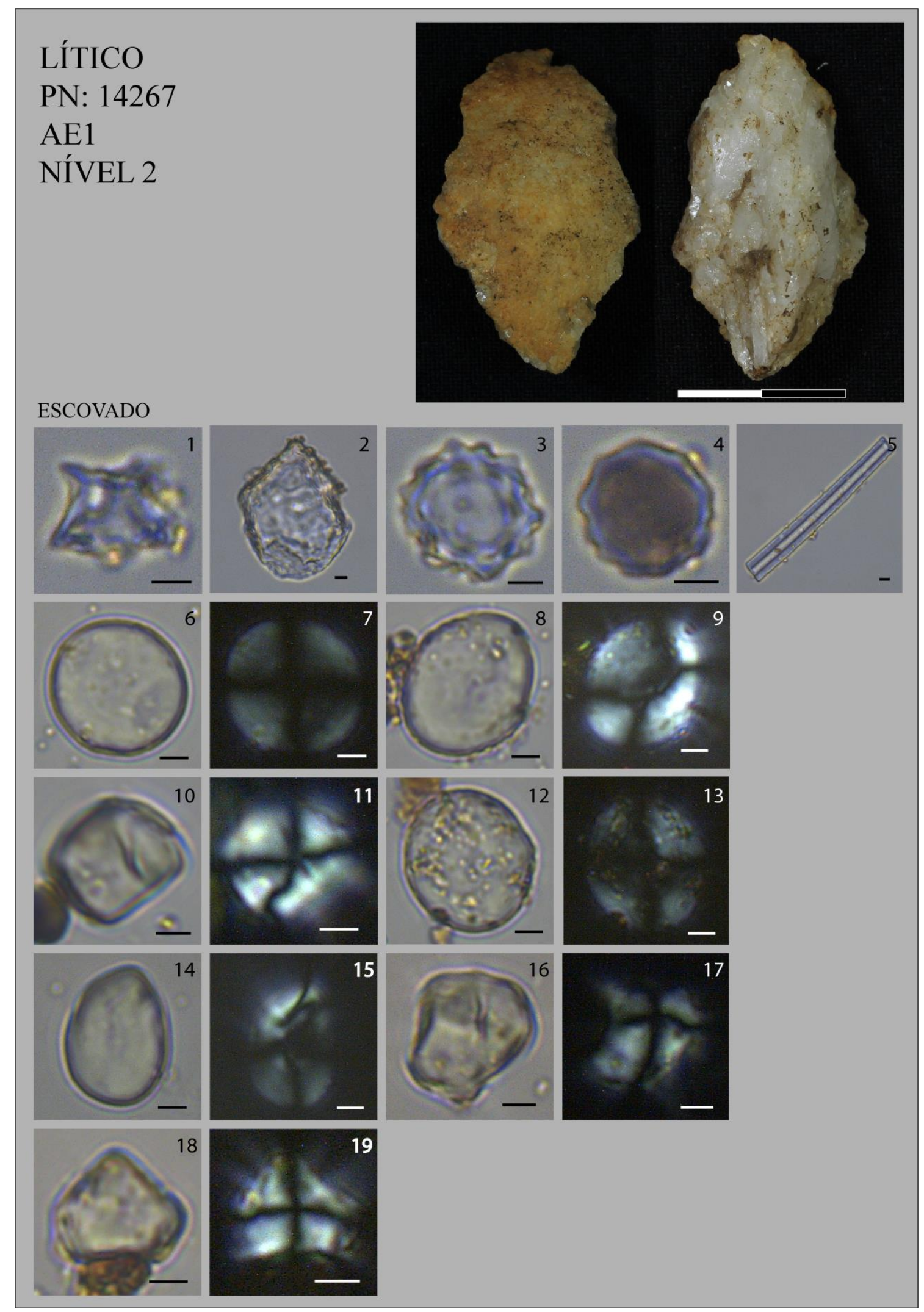

Figura 65. Microvestígio do Lítico 14267. Fitólitos: 1) rondel de Poaceae, 2) bulliform de Poaceae, 3) globular echinate de Arecaceae (palmeira), 4) globular granulate de Eudicotiledônea (arbóreas), 5) espícula de esponja. Amido: 6-7 e 12-13) Morfotipo H; 8-9) Morfotipo F; 10-11 e 16-17) Morfotipo A; 14-15) Morfotipo I; 18-19) Não identificado. Escala $10 \mu \mathrm{m}$. 


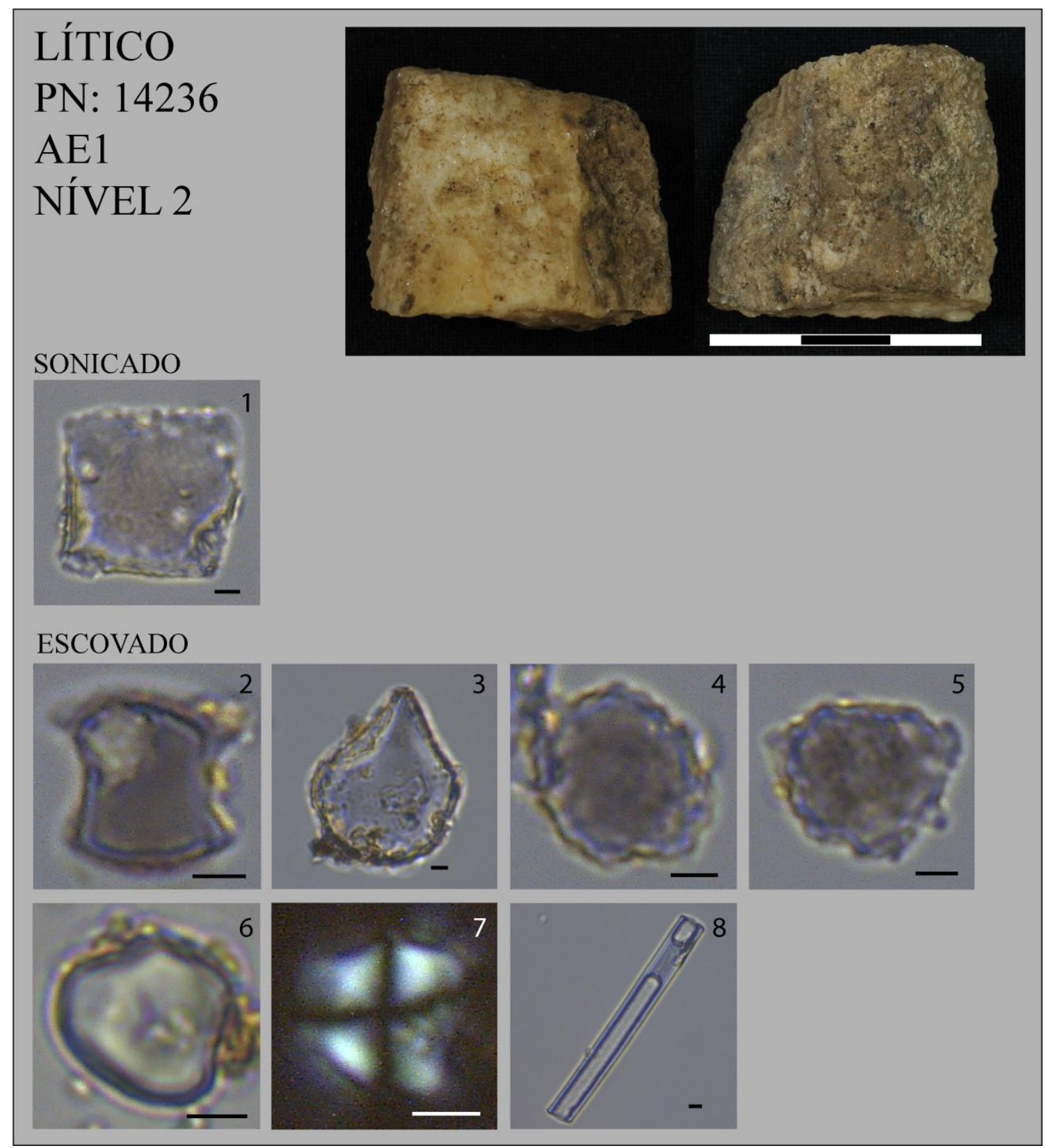

Figura 66. Microvestígio do Lítico 14236. Fitólitos: 1) bulliform de Poaceae, 2) collapsed Saddle de Bambudoideae, 3) bulliform de Poaceae, 4) globular granulate de Eudicotiledônea (arbóreas), 5) globular nodular de Zingiberales, 8) espícula de esponja. Amido: 6-7) Morfotipo B. Escala $10 \mu \mathrm{m}$. 


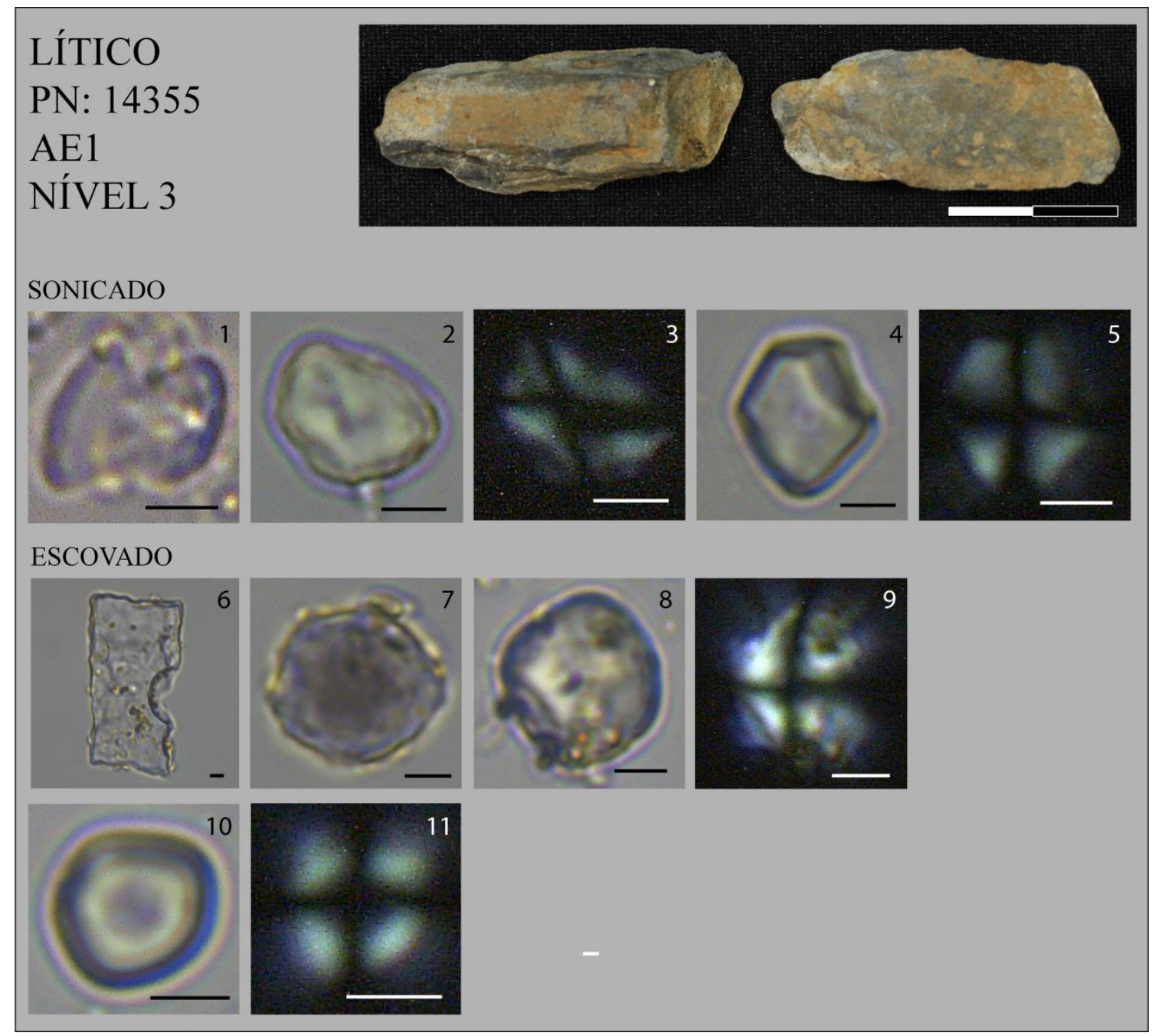

Figura 67. Microvestígios do Lítico 14355. 14355. Fitólitos: 1) saddle de Chloridoideae, 6) bulliform de Poaceae, 7) globular granulate de Eudicotiledônea (arbóreas). Amido:2-3) Não identificado; 4-5) Morfotipo B, 8-9 e 10-11) Não identificados. Escala $10 \mu \mathrm{m}$. 


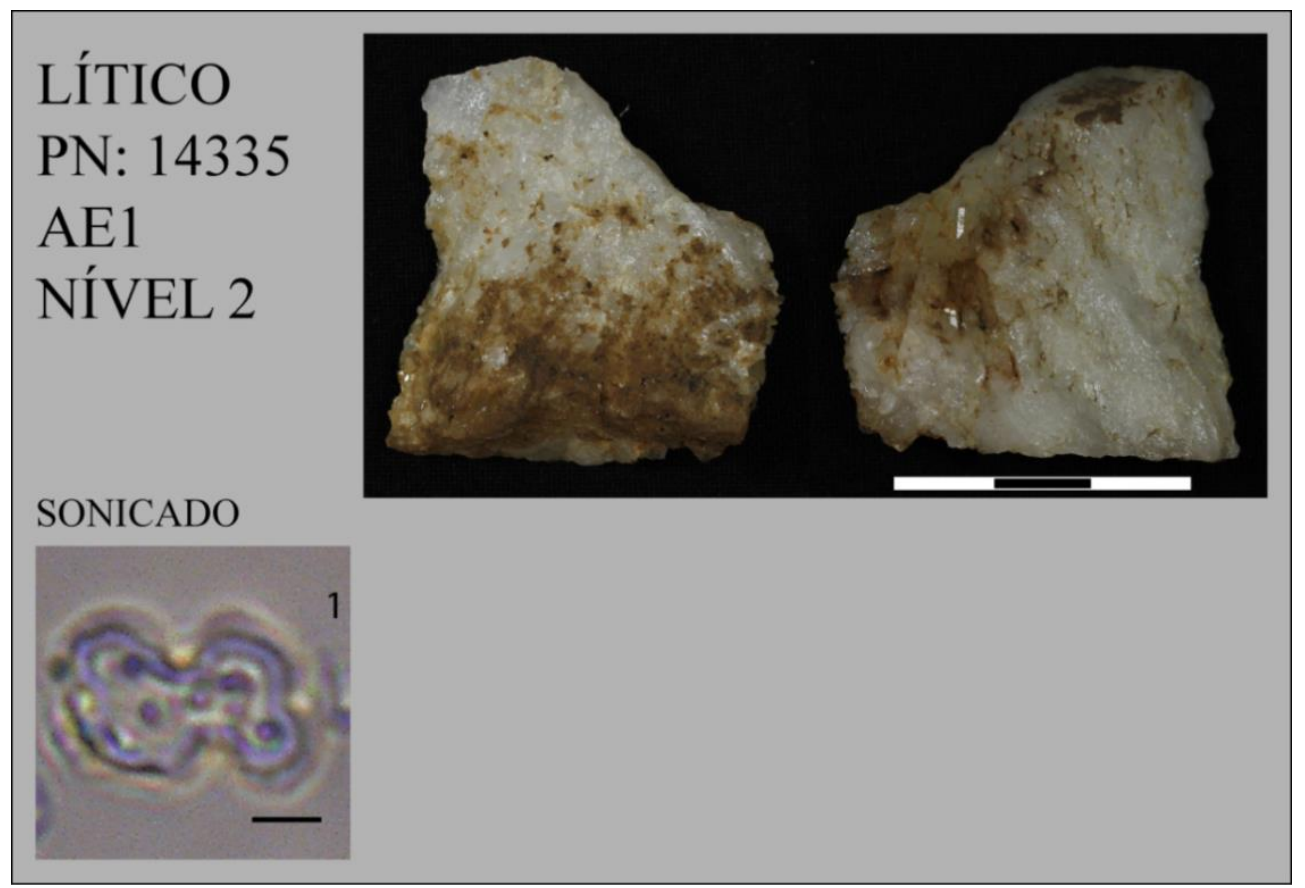

Figura 68. Microvestígio do Lítico 14335. Fitólito: 1) cross de Poaceae "variante 1". Escala $10 \mu \mathrm{m}$. 


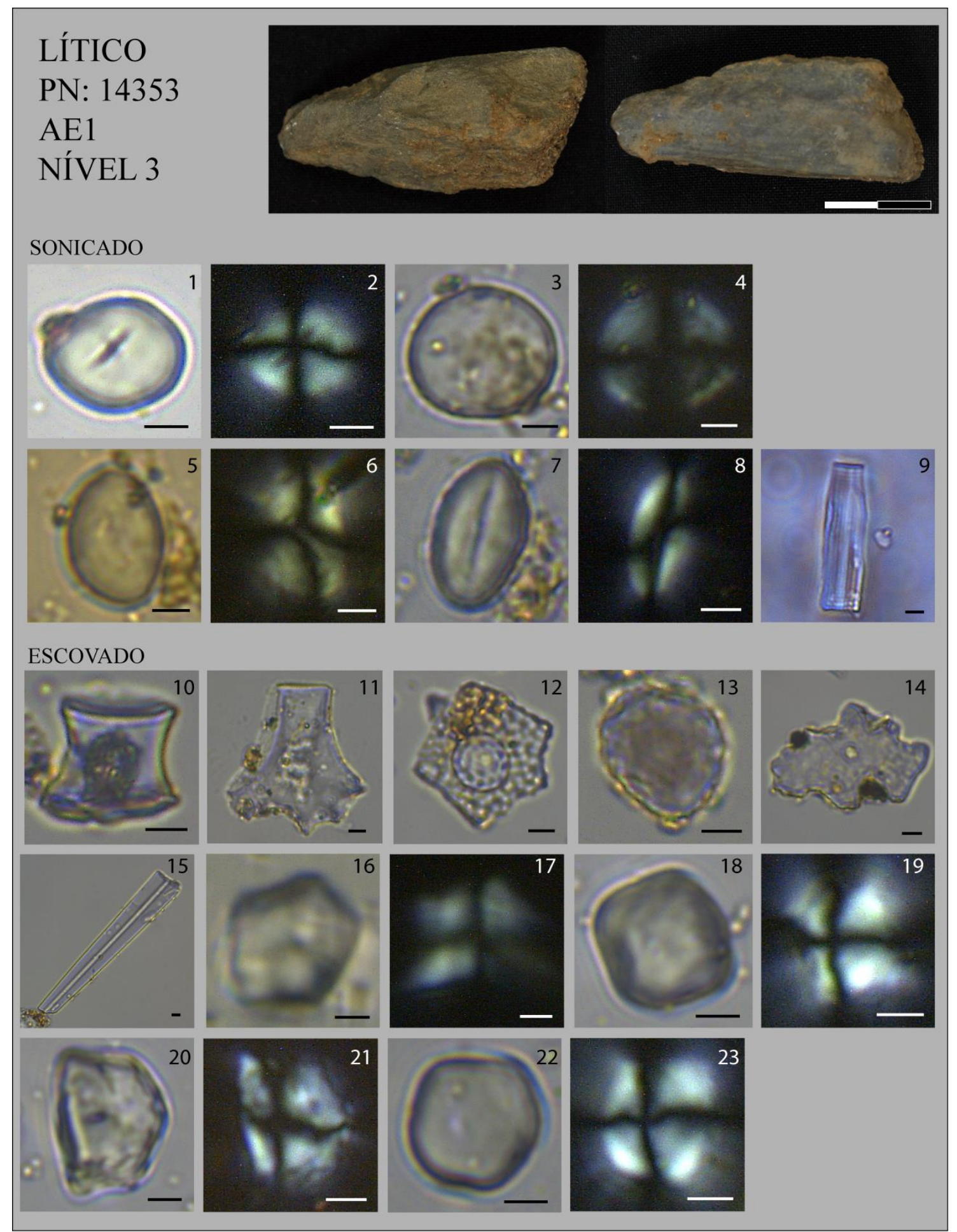

Figura 69. Microvestígio do Lítico 14353. Fitólitos e outros: 9) espícula de esponja, 10) rondel de Bambusoideae, 11) bulliform de Poaceae, 12) stippled polygonal cone de Cyperus/Kyllinga sp; 13) globular granulate de Eudicotiledônea (arbóreas), 14) jigsaw de Eudicotiledônea, 15) espícula de esponja. Amido:1-2) Morfotipo C; 3-4) Morfotipo H, 5-6) Morfotipo I; 7-8) Morfotipo E, 16-17) Morfotipo A; 18-19 e 22-23 Não identificados; 20-21) Morfotipo A. Escala $10 \mu \mathrm{m}$. 


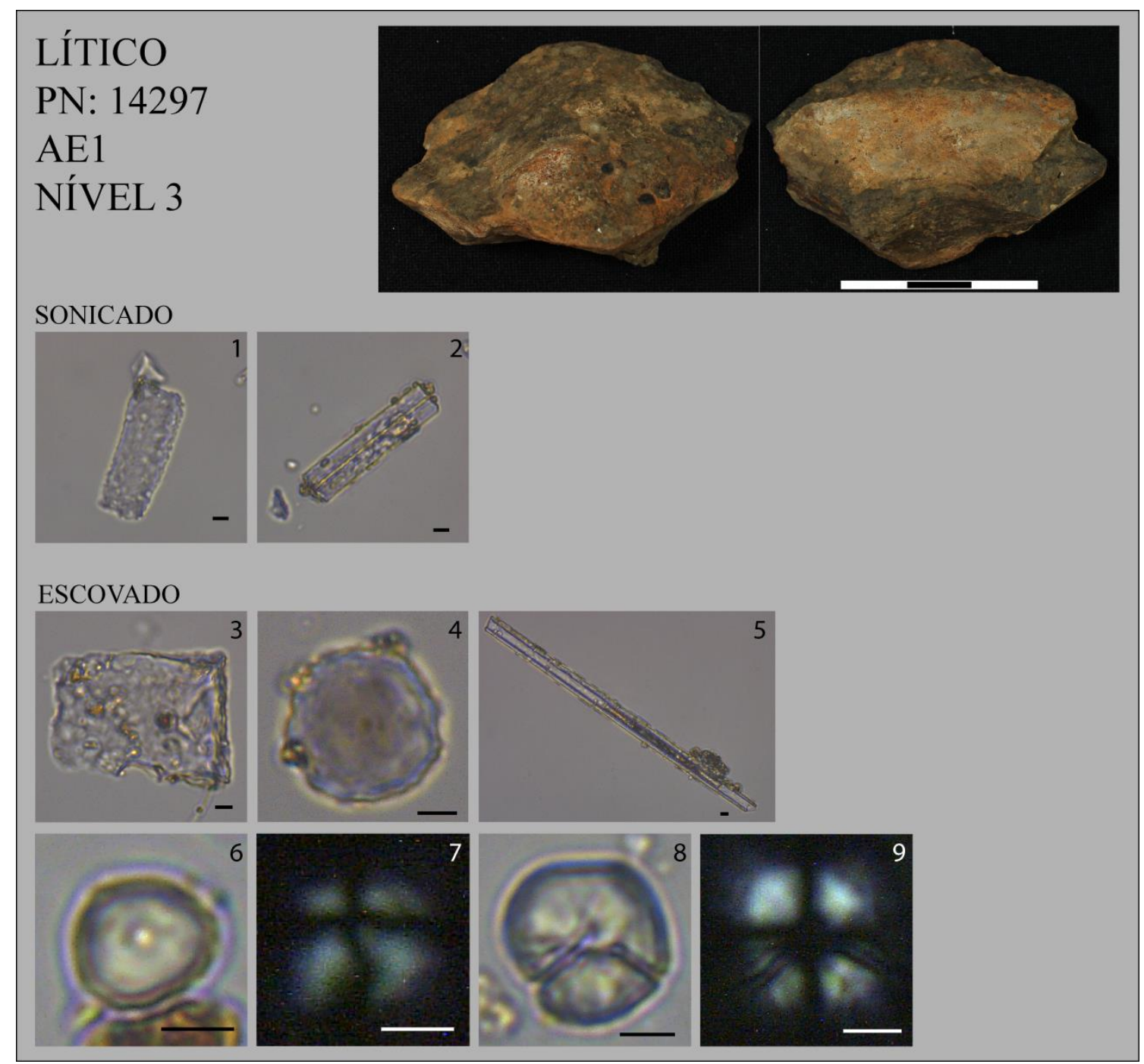

Figura 70.. Microvestígio do Lítico 14297. Fitólitos: 1) bulliform de Poaceae, 2) espícula de esponja, 3) bulliform de Poaceae, 4) globular granulate de Eudicotiledônea (arbóreas), 5) espícula de esponja. Amido:6-7) Morfotipo D; 8-9) Não identificado. Escala $10 \mu \mathrm{m}$ 


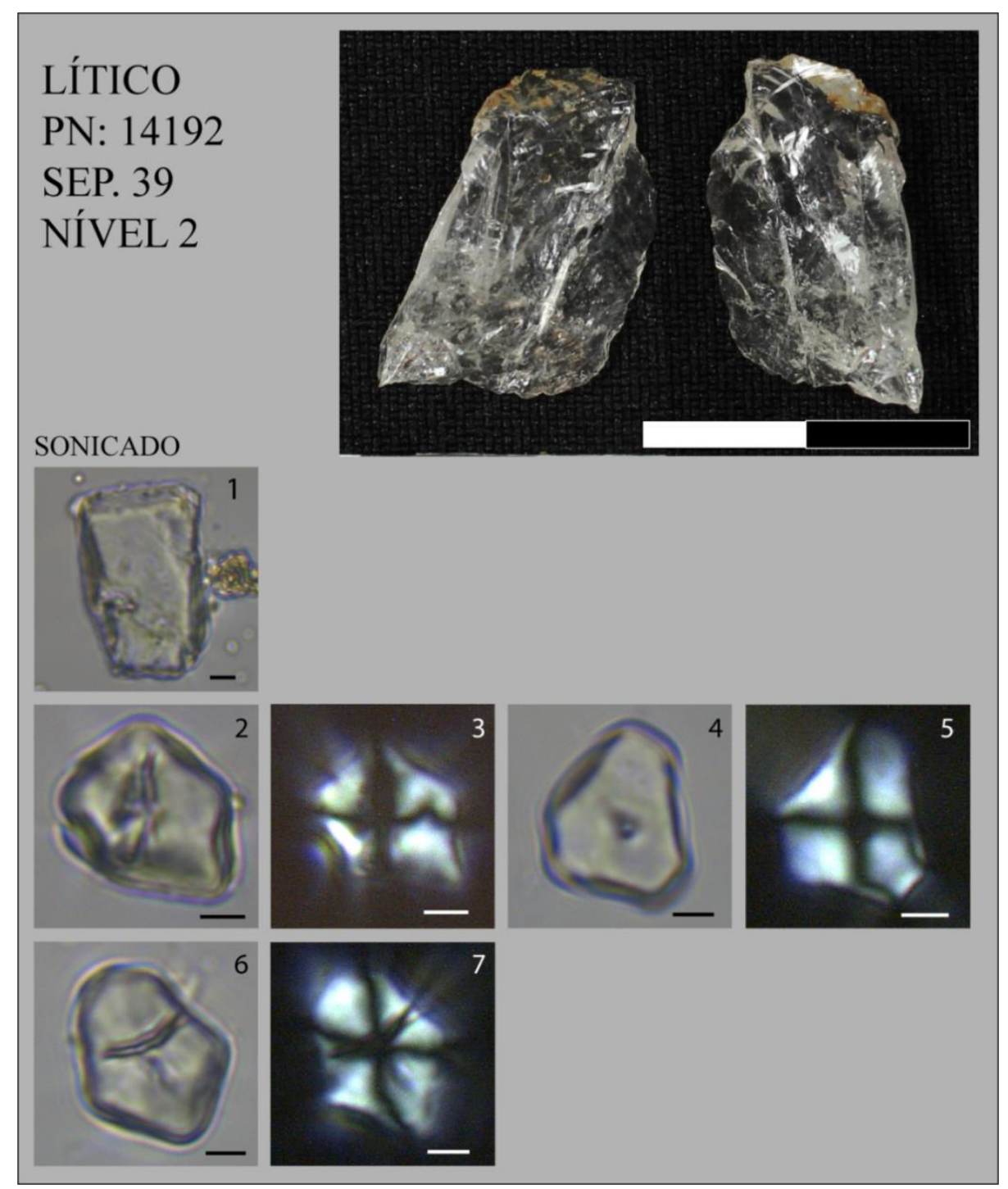

Figura 71. Microvestígios do Lítico 14192. Fitólitos:1) bulliform de Poaceae. Amido: 2-3 e 6-7) Morfotipo A; 4-5) Morfotipo B. Escala $10 \mu \mathrm{m}$. 


\subsubsection{Microvestígios identificados no sedimento arqueológico e natural}

A seguir serão apresentadas pranchas com identificação e imagens de microvestígios encontrados nas amostras de sedimento arqueológico associado aos líticos analisados e natural de referência.

Há uma imagem de cada morfotipo de fitólito encontrado naquela amostra e imagem de todos os grãos de amido (apenas encontrados na quadra P11). Um exemplar de outros microvestígios como espículas de esponjas também constarão quando existentes nas amostras. 


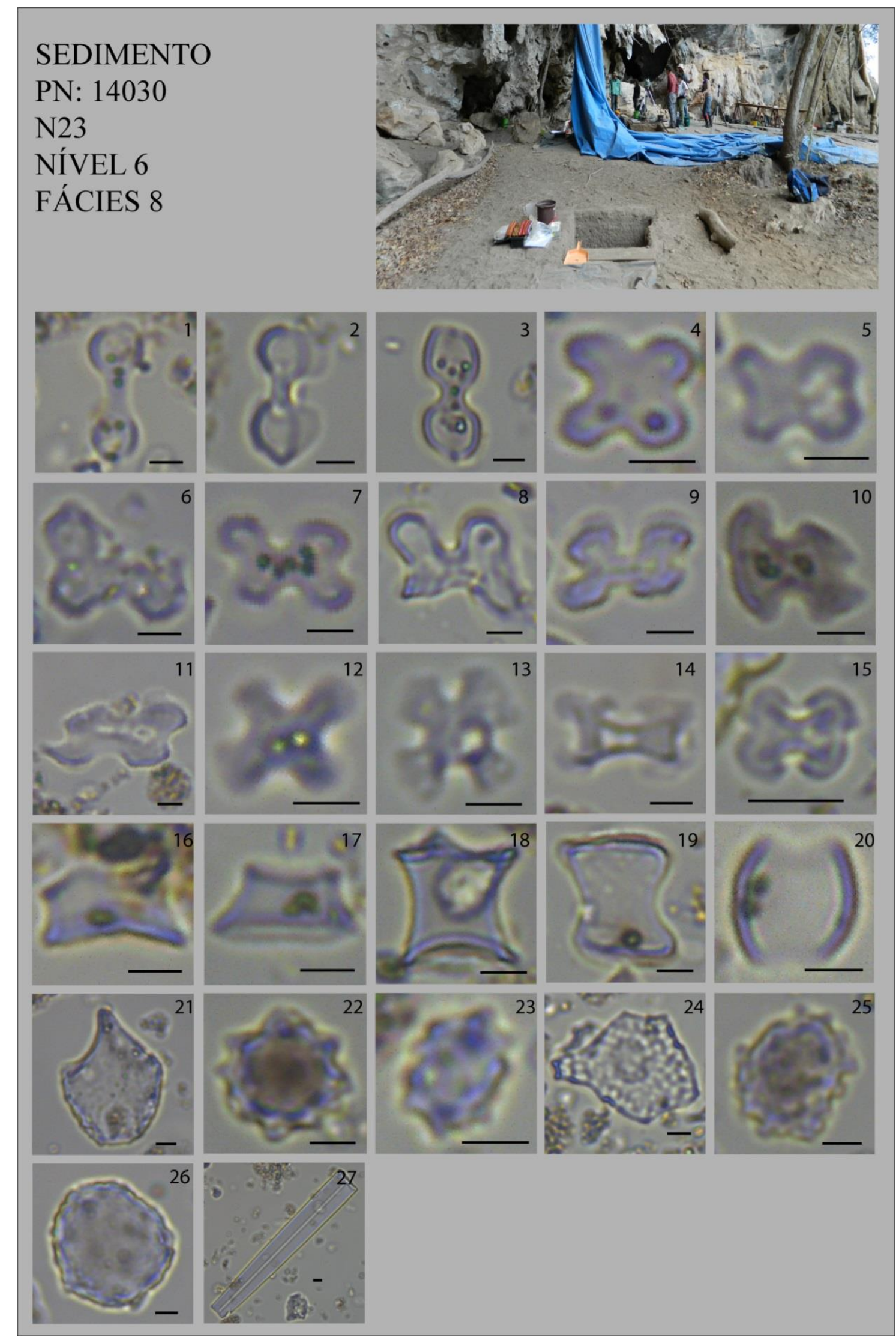

Figura 72. Microvestígios de sedimento da quadra N23. Fitólitos e outros: 1) bilobate de Aristidoideae, 2) bilobate de Bambusoideae, 3) bilobate de Panicoideae; 4, 5, 6, 7, 8, 9 e 10) cross de Poaceae "variante 1"; 11, 12, 13, 14 e 15) cross de Poaceae "outras variantes", 16 e 17) rondel de Poaceae, 18) 3-spiked rondel de Bambusoideae, 19) collapsed Saddle de 
Bambudoideae, 20) saddle de Chloridoideae, 21) bulliform de Poaceae, 22) globular echinate de Arecaceae (palmeira), 23) globular echinate elongate de Arecaceae, 24) stippled polygonal cone de Cyperus/Kyllinga sp; 25) globular nodular de Zingiberales, 26) globular granulate de Eudicotiledônea (arbóreas), 27) espícula de esponja. Escala $10 \mu \mathrm{m}$.

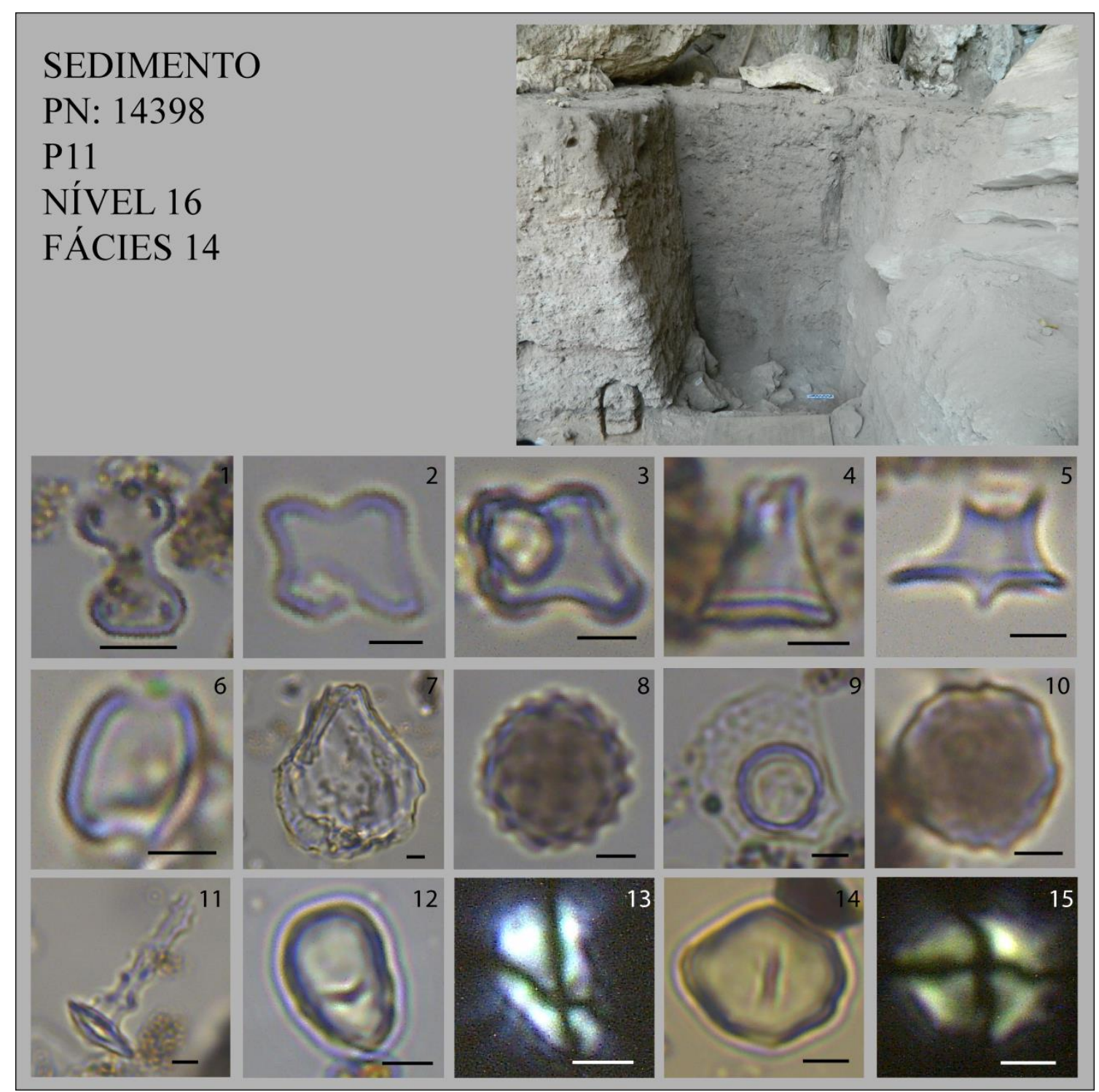

Figura 73. Microvestígios de sedimento da quadra P11. Fitólitos: 1) bilobate de Panicoideae; 2) cross de Poaceae "variante 1", 3) cross de Poaceae "outras variantes", 4) rondel de Poaceae, 5) 3-spiked rondel de Bambusoideae, 6) saddle de Chloridoideae, 7) bulliform de Poaceae, 8) globular echinate de Arecaceae with short acute projections, 9) stippled polygonal cone de Cyperus/Kyllinga sp; 10) globular granulate de Eudicotiledônea (arbóreas), 11) espícula de esponja. Amido: 12-13) Morfotipo I, 14-15) Morfotipo A. Escala $10 \mu \mathrm{m}$. 


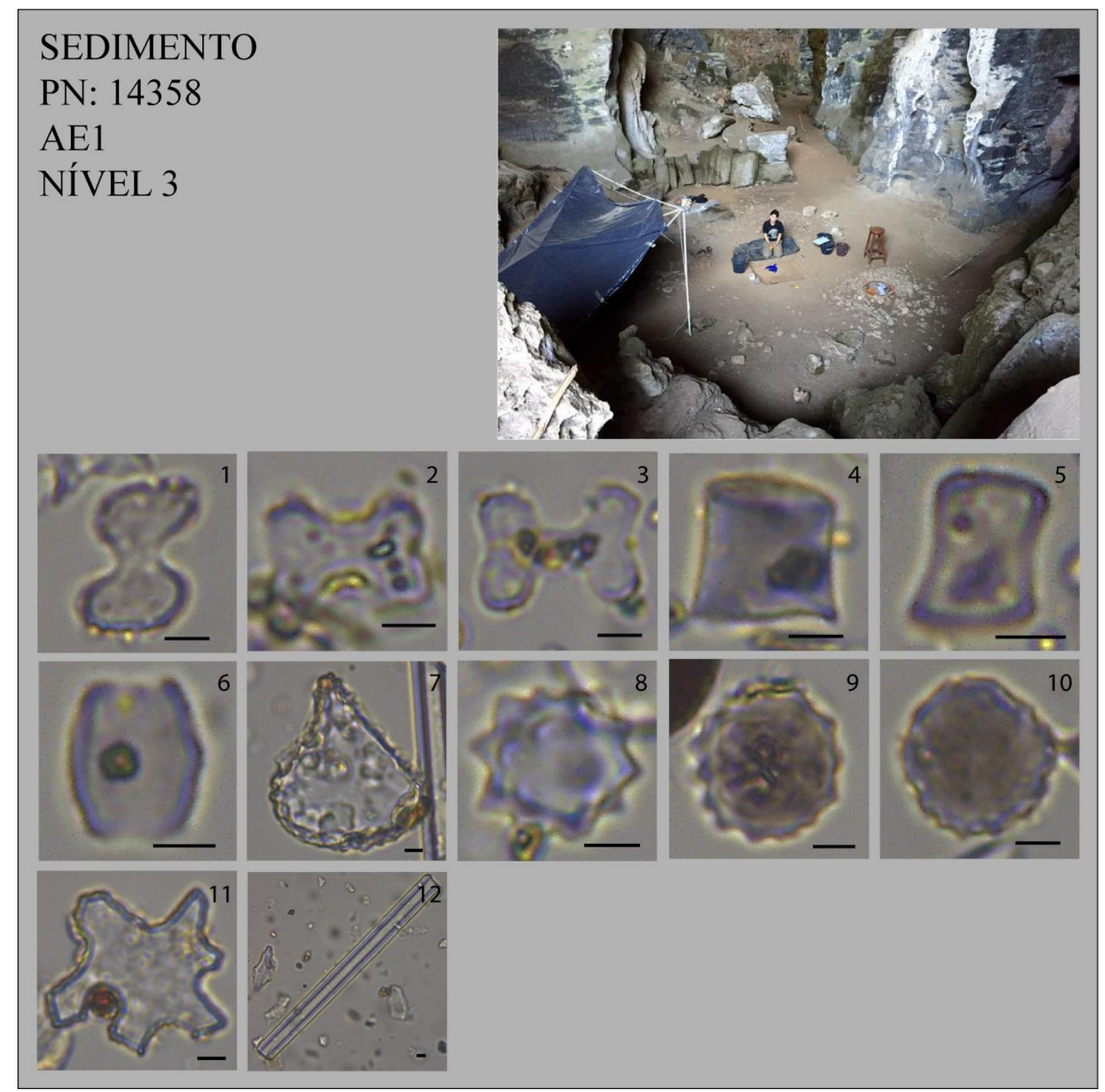

Figura 74. Microvestígios de sedimento da quadra AE1. Fitólitos: 1) bilobate de Panicoideae, 2 e 3) cross de Poaceae "variante 1", 4) rondel de Poaceae, 5) collapsed Saddle de Bambudoideae, 6) saddle de Chloridoideae, 7) bulliform de Poaceae, 8) globular echinate de Arecaceae (palmeira), 9) globular echinate de Arecaceae with short acute projections, 10) globular granulate de Eudicotiledônea (arbóreas), 11) jigsaw de Eudicotiledônea, 12) espícula de esponja. Escala $10 \mu \mathrm{m}$. 


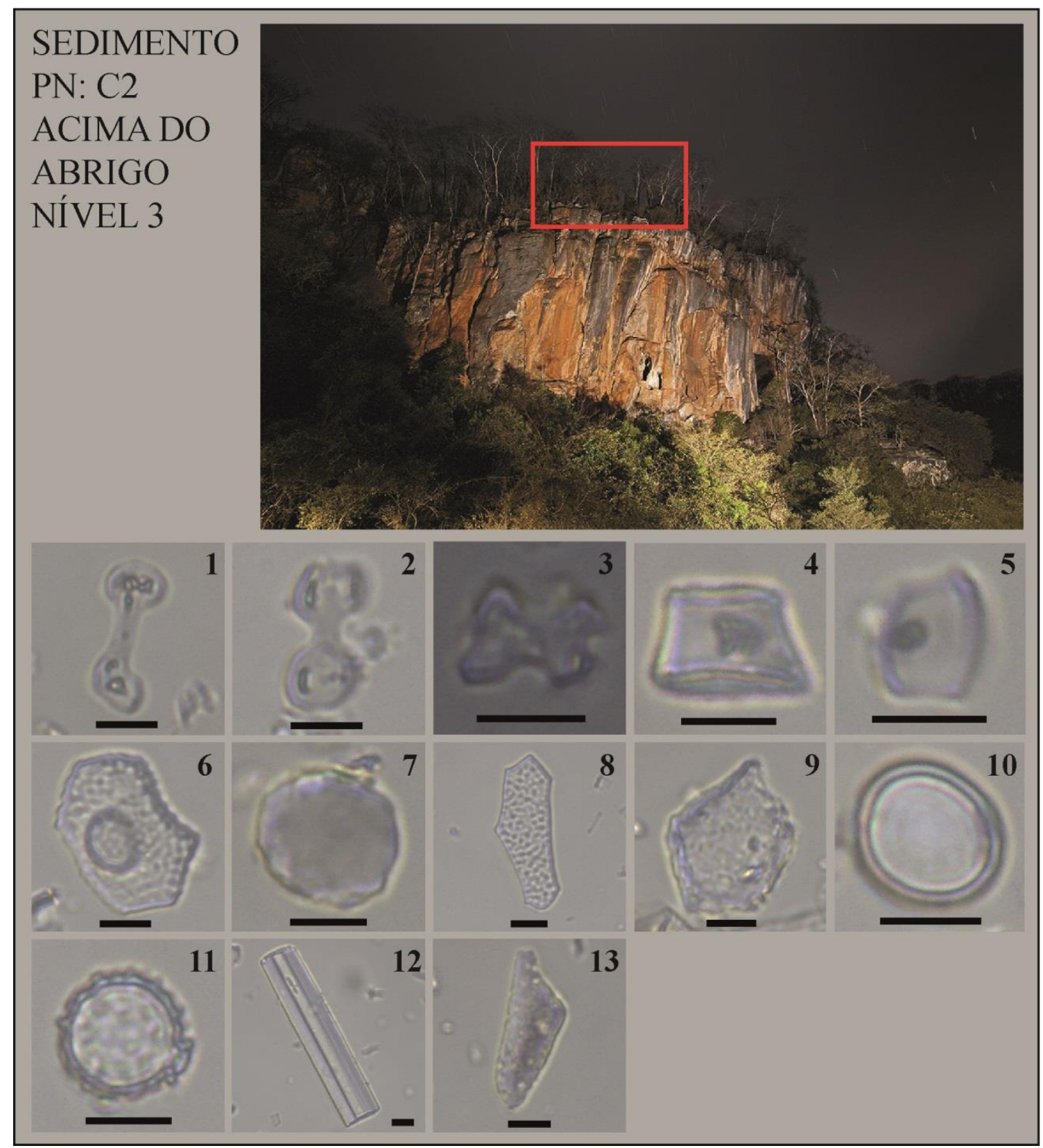

Figura 75. Microvestígios de sedimento da amostra C2. Fitólitos: 1) bilobate de Aristidoideae, 2) bilobate de Panicoideae, 3) cross de Poaceae "variante 1", 4) rondel de Poaceae, 5) saddle de Chloridoideae, 6) stippled polygonal cone de Cyperus/Kyllinga sp; 7) globular granulate de Eudicotiledônea (arbóreas), 8) polygonal stippled de Cyperaceae, 9) bulliform de Poaceae, 10) globular psilate de Eudicotiledônea, 11) diatomácea (organismo aquático), 12) espícula de esponja, 13) pelo radicial de planta. Autoria da foto do abrigo: Maurício de Paiva. Escala 10 $\mu \mathrm{m}$. 


\subsubsection{Amostras de materiais utilizados em laboratório para controle de contaminação}

Algumas amostras de materiais utilizados em labotarório foram verificadas para se controlar possíveis contaminações (Figura 76). Em água destilada foi identificado um grão de amido poligonal de superfície lisa e cruz de interferência com braços espessos, um reto e um curvo, além de ter sido identificado um tecido vegetal alongado. Nas lâminas de água destilada que ficaram ao ar livre foram identificados três itens globulares de superfícies irregulares (Figura 76). Nas amostras de papel toalha não foram identificadas grãos de amido, apenas fibras vegetais. Nas amostras de esmalte, foram identificados fragmentos vegetais (Figura 76).

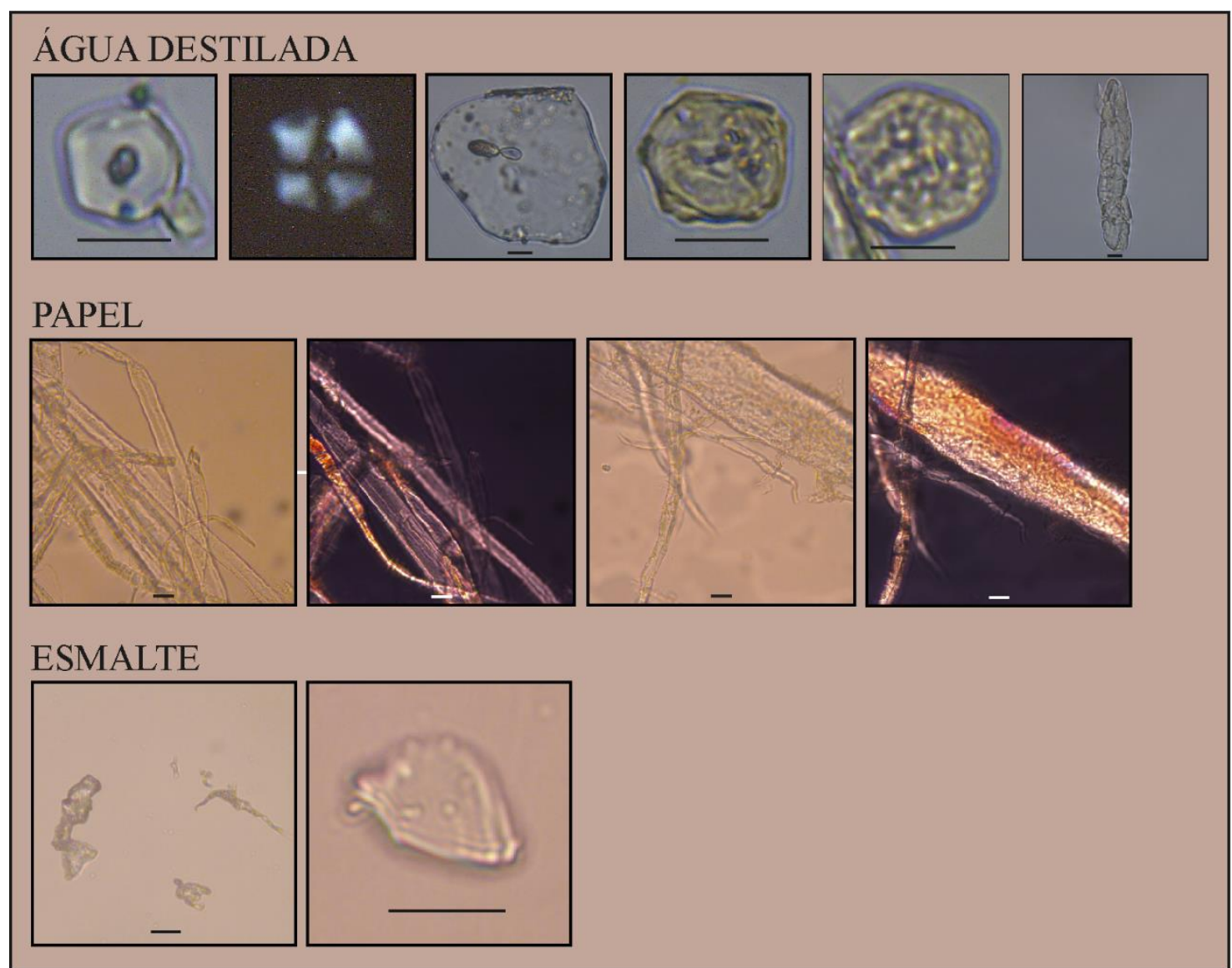

Figura 76. Itens identificados em amostra de água destilada: amido nas duas primeiras imagens e, itens de origem vegetal. Em papel toalha: fibras vegetais. Em esmalte: itens de origem vegetal. Escala $10 \mu \mathrm{m}$. 


\subsection{Descrição tecnológica preliminar dos artefatos líticos}

Os líticos foram preliminarmente descritos segundo critérios tecnológicos (Tópico 3.8 e Tabela 14). As matérias primas presentes são o quartzo hialino, o quartzo leitoso, o granito e o basalto. Com o córtex presente em alguns líticos foi possível identificar suporte como o cristal para quartzo hialino e leitoso, seixo para o quartzo leitoso e bloco para o basalto. Os líticos analisados das quadras N23 e P11 possuem como matéria prima predominantemente o quartzo hialino, com exceção de um lítico em basalto na quadra N23. Os líticos de dentro da caverna (quadra AE1) possuem uma variedade de matérias primas, também com a presença do quartzo hialino.

Tabela 14. Descrição tecnológica preliminar dos líticos

\begin{tabular}{|c|c|c|c|c|}
\hline $\begin{array}{l}\text { PN } \\
\text { QD }\end{array}$ & Classe & $\mathbf{M P}^{62}$ & Suporte & Descrição \\
\hline $\begin{array}{l}13067 \\
\mathrm{~N} 23\end{array}$ & lasca & $\begin{array}{l}\text { quartzo } \\
\text { hialino }\end{array}$ & desc. $^{63}$ & $\begin{array}{l}\text { possui bulbo, nervuras na face superior, } \\
\text { sem córtex }\end{array}$ \\
\hline $\begin{array}{l}13885 \\
\mathrm{~N} 23\end{array}$ & $\begin{array}{l}\text { fragmento } \\
\text { de lasca }\end{array}$ & $\begin{array}{l}\text { quartzo } \\
\text { hialino }\end{array}$ & desc. & possui negativos, sem córtex \\
\hline $\begin{array}{l}14029 \\
\mathrm{~N} 23\end{array}$ & $\begin{array}{l}\text { lasca } \\
\text { retocada }\end{array}$ & $\begin{array}{l}\text { quartzo } \\
\text { hialino }\end{array}$ & cristal & $\begin{array}{l}\text { possui bulbo, ondas de percussão, } \\
\text { negativos na face superior e retoque, e } \\
\text { córtex }\end{array}$ \\
\hline $\begin{array}{l}13120 \\
\mathrm{~N} 23\end{array}$ & lasca & $\begin{array}{l}\text { quartzo } \\
\text { hialino }\end{array}$ & cristal & córtex \\
\hline $\begin{array}{l}13962 \\
\mathrm{~N} 23\end{array}$ & lasca & $\begin{array}{l}\text { quartzo } \\
\text { hialino }\end{array}$ & desc. & $\begin{array}{l}\text { possui bulbo, e ondas de percussão, sem } \\
\text { córtex }\end{array}$ \\
\hline $\begin{array}{l}14292 \\
\text { P11 }\end{array}$ & lasca & $\begin{array}{l}\text { quartzo } \\
\text { hialino }\end{array}$ & desc. & $\begin{array}{l}\text { possui bulbo, ondas de percussão e } \\
\text { negativos na face superior, sem córtex }\end{array}$ \\
\hline $\begin{array}{l}14385 \\
\text { P11 }\end{array}$ & lasca & $\begin{array}{l}\text { quartzo } \\
\text { hialino }\end{array}$ & desc. & $\begin{array}{l}\text { possui bulbo, ondas de percussão, } \\
\text { negativo na face superior, sem córtex }\end{array}$ \\
\hline $\begin{array}{l}14391 \\
\text { P11 }\end{array}$ & lasca & $\begin{array}{l}\text { quartzo } \\
\text { hialino }\end{array}$ & desc. & possui negativos, sem córtex \\
\hline $\begin{array}{l}14410 \\
\text { P11 }\end{array}$ & lasca & $\begin{array}{l}\text { quartzo } \\
\text { hialino }\end{array}$ & desc. & $\begin{array}{l}\text { possui ondas de percussão, nervura na } \\
\text { face superior }\end{array}$ \\
\hline $\begin{array}{l}14369 \\
\text { P11 }\end{array}$ & lasca & $\begin{array}{l}\text { quartzo } \\
\text { hialino }\end{array}$ & cristal & possui córtex, bulbo e ondas de percussão \\
\hline $\begin{array}{l}14267 \\
\text { AE1 }\end{array}$ & $\begin{array}{l}\text { peça com } \\
\text { córtex }\end{array}$ & $\begin{array}{l}\text { quartzo } \\
\text { leitoso }\end{array}$ & seixo & córtex \\
\hline $\begin{array}{l}14236 \\
\text { AE1 }\end{array}$ & $\begin{array}{l}\text { peça com } \\
\text { negativos }\end{array}$ & $\begin{array}{l}\text { quartzo } \\
\text { leitoso }\end{array}$ & $\begin{array}{l}\text { estalactit } \\
\text { e }\end{array}$ & córtex e negativos \\
\hline $\begin{array}{l}14355 \\
\text { AE1 }\end{array}$ & fragmento & basalto & bloco & córtex \\
\hline $\begin{array}{l}14335 \\
\text { AE1 }\end{array}$ & $\begin{array}{l}\text { lasca } \\
\text { retocada }\end{array}$ & $\begin{array}{l}\text { quartzo } \\
\text { hialino }\end{array}$ & cristal & $\begin{array}{l}\text { possui retoque, córtex na face superior e } \\
\text { bulbo }\end{array}$ \\
\hline
\end{tabular}

\footnotetext{
${ }^{62}$ Matéria-prima.

${ }^{63}$ Desconhecido.
} 


\begin{tabular}{|c|c|c|c|c|}
\hline $\begin{array}{l}\text { PN } \\
\text { QD }\end{array}$ & Classe & $\mathrm{MP}^{62}$ & Suporte & Descrição \\
\hline $\begin{array}{l}14353 \\
\text { AE1 }\end{array}$ & fragmento & basalto & bloco & possui córtex e nervuras \\
\hline $\begin{array}{l}14297 \\
\text { AE1 }\end{array}$ & $\begin{array}{l}\text { lasca } \\
\text { retocada }\end{array}$ & basalto & desc. & possui retoques, bulbo, sem córtex \\
\hline $\begin{array}{l}14192 \\
\text { SEP. } \\
39\end{array}$ & lasca & $\begin{array}{l}\text { quartzo } \\
\text { hialino }\end{array}$ & $\begin{array}{l}\text { desconhe } \\
\text { cido }\end{array}$ & $\begin{array}{l}\text { possui ondas de percussão e nervuras, } \\
\text { sem córtex }\end{array}$ \\
\hline $\begin{array}{l}13014 \\
\mathrm{~N} 23\end{array}$ & lasca & granito & desc. & $\begin{array}{l}\text { Possui talão de forma circular, bulbo não } \\
\text { proeminente, uma única nervura vertical, } \\
\text { perfil côncavo. } \\
\text { É um possível resíduo de produção de } \\
\text { machado (Moreno de Sousa, } 2019 \text {, } \\
\text { comunicação pessoal). } \\
\text { Bordo esquerdo refletido } \\
\text { Extensão: } 43 \text { mm } \\
\text { Gume denticulado } \\
\text { Quatro negativos de retoque } \\
\text { Plano de corte: } 75^{\circ} \\
\text { Funcionalidade: cortar } \\
\text { Bordo direito } \\
\text { Extensão: } 30 \text { mm } \\
\text { Gume retilíneo } \\
\text { Um negativo de retoque e uma área } \\
\text { possivelmente retocada que apresenta } \\
\text { desgaste por uso } \\
\text { Plano de corte: } 60^{\circ} \\
\text { Funcionalidade: raspar e perfurar (com a } \\
\text { ponta) }\end{array}$ \\
\hline $\begin{array}{l}14017 \\
\mathrm{~N} 23\end{array}$ & $\begin{array}{l}\text { lasca } \\
\text { retocada }\end{array}$ & $\begin{array}{l}\text { quartzo } \\
\text { hialino }\end{array}$ & desc. & $\begin{array}{l}\text { Com perfil retilíneo, possui gume com } \\
\text { retoques no bordo direito, um negativo, } \\
\text { nervuras na face superior, sem córtex, } \\
\text { com talão circular, superfície irregular de } \\
90^{\circ} \text {, cornija sem lábio, com bulbo } \\
\text { parcialmente removido, houve } \\
\text { preparação do talão no bordo esquerdo } \\
\text { (Moreno de Sousa, 2019, comunicação } \\
\text { pessoal). }\end{array}$ \\
\hline $\begin{array}{l}14469 \\
\text { P11 }\end{array}$ & $\begin{array}{l}\text { lasca } \\
\text { retocada }\end{array}$ & $\begin{array}{l}\text { quartzo } \\
\text { hialino }\end{array}$ & Cristal & $\begin{array}{l}\text { Possui perfil côncavo, retoques no bordo } \\
\text { direito, negativos com nervuras em forma } \\
\text { de “y”, bulbo, ondas de percussão } \\
\text { Talão: com superfície lisa, comprimento: }\end{array}$ \\
\hline
\end{tabular}




\begin{tabular}{|c|c|c|c|c|}
\hline $\begin{array}{l}\text { PN } \\
\text { QD }\end{array}$ & Classe & $\mathrm{MP}^{62}$ & Suporte & Descrição \\
\hline & & & & $\begin{array}{l}6 \mathrm{~mm} \text {, espessura: } 3 \mathrm{~mm} ; 115^{\circ} \\
\text { (Moreno de Sousa, } 2019 \text {, comunicação } \\
\text { pessoal). }\end{array}$ \\
\hline
\end{tabular}

As dimensões de comprimento, largura e espessura dos líticos em mm são apresentadas no Gráfico 4. As dimensões em valores absolutos estão no Anexo I (

Tabela 16).

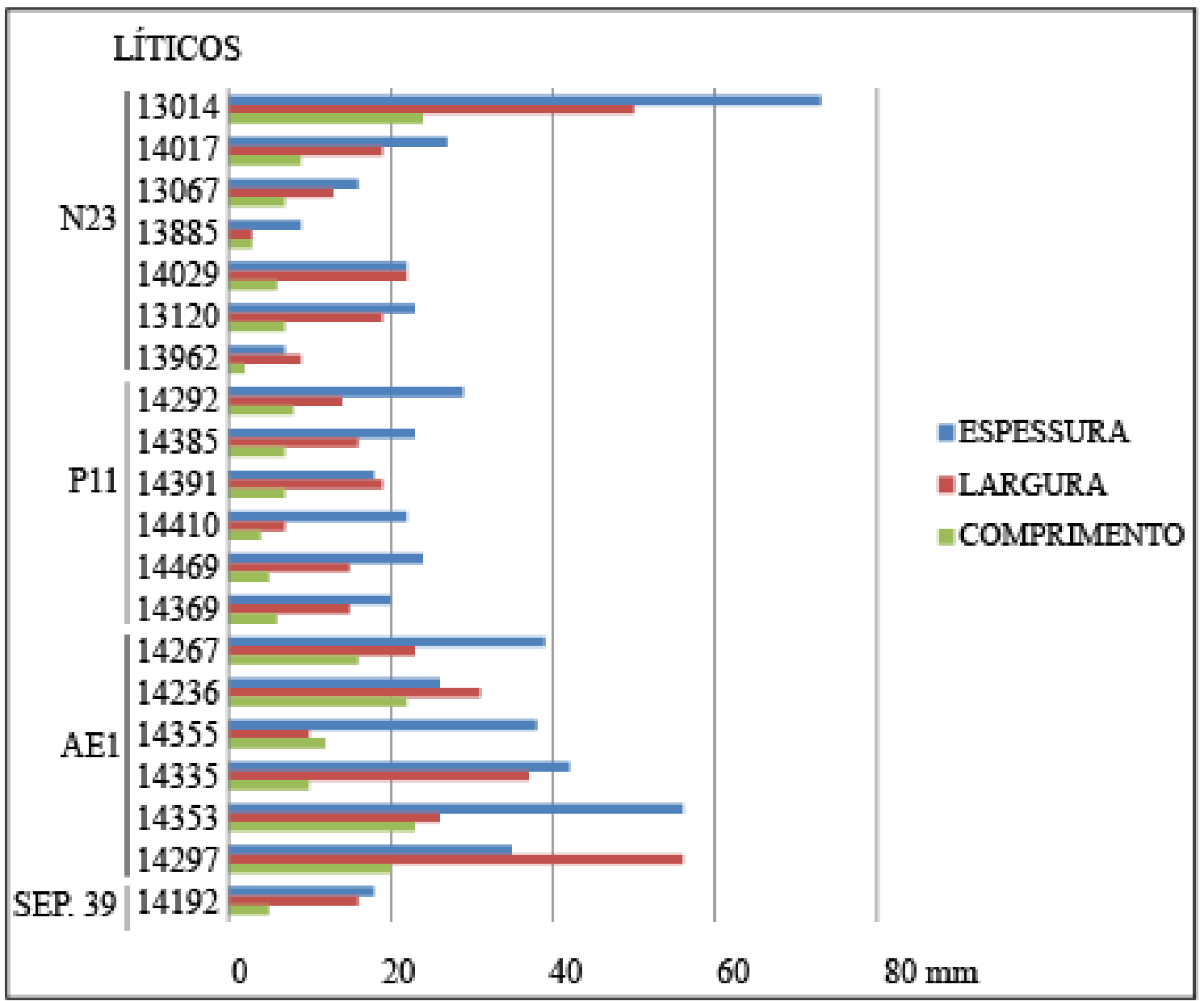

Gráfico 4. Dimensões dos líticos em espessura, largura e comprimento.

\subsubsection{Relação entre tamanho dos líticos e microvestígios identificados}


Para cada lítico se fez uma média das três medidas (comprimento, espessura e largura) considerada como o tamanho médio de cada lítico (Gráfico 5). Agrupando as dimensões médias de $10 \mathrm{em} \mathrm{10,} \mathrm{somente} \mathrm{um} \mathrm{ultrapassa} 40 \mathrm{~mm}$ (lítico 13014). Buscando uma classificação das dimensões em três categorias arbitrárias no conjunto analisado em pequeno, mediano e grande, se dividiu $40 \mathrm{~mm}$ por três. Dessa forma, foram considerados como pequenos aqueles com dimensão média entre 0 e 13,33; medianos aqueles com dimensão média entre 13,33 e 26,66; e grandes aqueles com dimensões médias entre 26, 66 a 39,99 e a exceção que é o maior lítico também considerado na categoria grande com média entre 39,99 e 53,32.

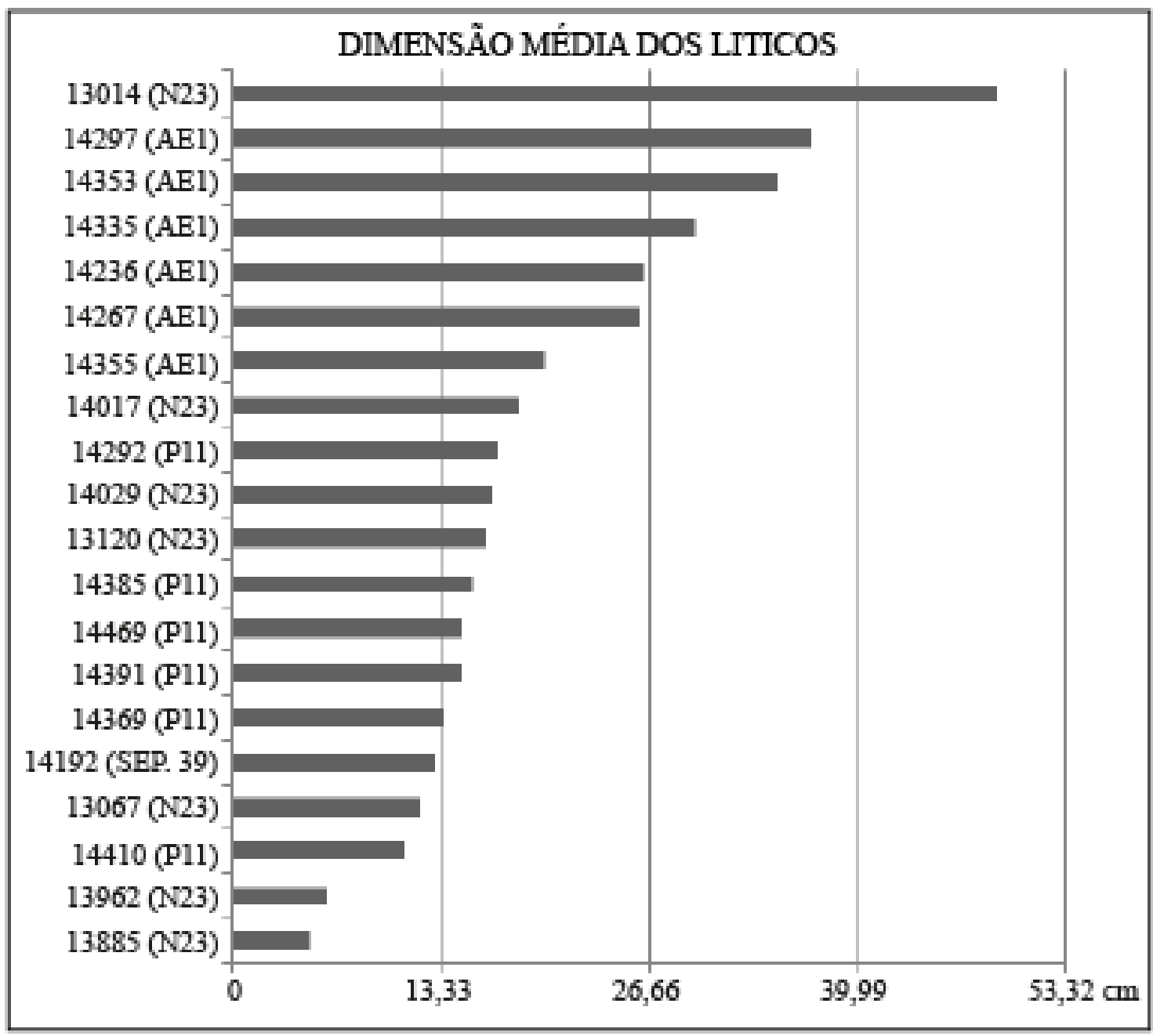

Gráfico 5. Dimensão média (comprimento, espessura e largura) dos líticos

Comparando as dimensões médias dos líticos (Gráfico 5) com as tabelas de presença e ausência de microvestígios (Tabela 8 e Tabela 9), é possível observar que: 
1. Os dois menores líticos do conjunto (13067 e 13885), não têm amido mas têm fitólitos em suas amostras sonicadas e escovadas. Ambos são da quadra N23.

2. Os dois maiores líticos do conjunto (13014-N23 e 14353-AE1) possuem amido nas amostras sonicadas e escovadas, mais fitólitos.

3. O terceiro maior lítico do conjunto (14297) apresenta amido, mas só no sedimento escovado.

4. O lítico do sepultamento 39 é pequeno e apresenta amido e fitólitos. 


\section{DISCUSSÃO}

\subsection{Comparação dos métodos aplicados para recuperação de microvestígios botânicos (Etapa 1 vs. Etapa 2)}

Dois métodos foram utilizados para a recuperação dos microvestígios botânicos e a montagem de lâminas. O primeiro foi a Etapa $1^{64}$ (Tópico 3.6.1) e aplicado a oito líticos da quadra N23, com amostras extraídas com pipeta (método step-wise)e posteriormente por meio da sonicação do lítico, sem aplicação de reagentes.

O segundo método foi a Etapa ${ }^{65}$ (Tópico 3.7) aplicado a 20 líticos pertencentes às quadras N23, P11 e AE1 e um deles do contexto do sepultamento 39, assim como às amostras de sedimento arqueológico das três quadras e da coletada acima do abrigo.

\subsubsection{Recuperação de Microvestígios em Quantidade}

A quantidade de microvestígios recuperados com a Etapa 1 foi muito inferior, apesar de ter sido realizada em apenas oito líticos (Tabela 7). Das amostras extraídas com pipeta, apenas quatro fitólitos foram identificados; das amostras extraídas através de sonicação, 12 fitólitos e quatro grãos de amido foram recuperados. As extrações com a pipeta foram pontuais nos artefatos, portanto, quando a Etapa 2 foi aplicada aos mesmos, eles ainda continham microvestígios, exceto pelo lítico 13431. Este lítico não foi analisado na Etapa 2 porque sua dimensão é muito pequena, menor que $2 \mathrm{~cm}$, e por isso por mais que a coleta tenha sido pontual, quase toda a área do lítico foi amostrada, por isso seria possível que ele não conteria mais microvestígios após essa primeira extração (Figura 33).

Na Etapa 1, se encontraram fitólitos em cinco líticos e amido em dois líticos (Tabela 7).

Com a Etapa 2 se recuperaram fitólitos de 19 líticos (Tabela 8). Só não se encontraram fitólitos no lítico 14385 (P11), mas nele foi encontrado um amido (Tabela 8). Na Etapa 2 foram encontrados grãos de amido em 15 líticos (Tabela 8). Em um lítico, o 13885, não foi encontrado amido, mas na Etapa 1 tinha se encontrado um grão de amido neste lítico (Tabela 7 e Tabela 8).

\footnotetext{
${ }^{64}$ Microvestígios Extraídos de Líticos com Pipeta ou Método Step-Wise e Sonicação.

${ }^{65}$ Fitólitos e Amido Extraídos de Líticos e Sedimento: Método com Sonicação e Aplicação de Reagentes".
} 
Assim, a quantidade de microvestígios recuperados dos líticos na Etapa 2 foi muito maior à Etapa 1 (Tabela 7 e Tabela 8). As amostras sonicadas da Etapa 2 apresentaram 101 fitólitos e 20 grãos de amido (Tabela 8). As amostras escovadas da Etapa 2 apresentaram 849 fitólitos e 27 grãos de amido (Tabela 8).

\subsubsection{Visualização dos Microvestígios}

Com a Etapa 1 os microvestígios apresentaram uma visibilidade um pouco comprometida, com a presença de minerais e partículas botânicas aderidas a eles. Além disso, o glicerol foi usado como meio de montagem para amido e fitólito em uma mesma lâmina. O glicerol pode ser adequado como meio de montagem para o amido mas não tanto para a visualização de fitólitos (ver Boyadjian, 2012: 59; Lombardo et al; 2016).

\section{Com a Etapa 2 a visualização dos microvestígios foi satisfatória e melhor. $O$} processo de limpeza das amostras com a desagregação de partículas e eliminação de matéria orgânica e minerais com reagentes e flotação com líquido pesado foi essencial para uma concentração maior dos microvestígios de interesse e separação dos mesmos. Além de que se usaram os meios de montagem adequados e em lâminas separadas para cada tipo de microvestígio: o Entellan ${ }^{\circledR}$ para a visualização de fitólitos (ver Lombardo et al; 2016); e o glicerol para a visualização de amido (ver Boyadjian, 2012:59).

\subsubsection{Considerações finais}

O método da Etapa 1 é mais rápido e financeiramente menos caro em comparação à Etapa 2, que demanda uma maior quantidade de tempo para realização das etapas de extração e um laboratório devidamente equipado. Entretanto, é com a Etapa 2 que se atingiu uma recuperação de fitólitos e amido imensamente mais eficiente no tocante à quantidade e qualidade de visualização dos mesmos. Por isso, as discussões abaixo se referem aos microvestígios recuperados unicamente na Etapa 2.

\subsection{Resultados da Etapa 2}

É preciso deixar claro que a massa das amostras de sedimento das quadras N23, P11, AE1 e amostra C2 é comparável em quantidade, porque a mesma quantidade de sedimento foi utilizada nas extrações (Tabela 9 e Gráfico 3). Dessa maneira, as quadras 
N23 e AE1 apresentaram quantidades de fitólitos em certa medida equivalentes à amostra C2 (acima do abrigo) e somente a quadra P11 apresentou menor quantidade de fitólitos (Tabela 9 e Gráfico 3).

No entanto, a massa das amostras de fitólitos nos líticos escovados não são comparáveis entre si, porque cada lítico tinha uma quantidade diferente de sedimento aderido e utilizado na análise (Tabela 8 e Gráfico 2). Da mesma forma, a massa de fitólitos nos líticos sonicados não é comparável entre si, uma vez que cada lítico possui dimensões diferentes (Tabela 8, Tabela 14, Gráfico 1 e Gráfico 5). Ao mesmo tempo, não é comparável a quantidade de fitólitos entre as amostras sonicadas (menor quantidade) e escovadas (maior quantidade), tendo sido recuperados 101 fitólitos no total das amostras sonicadas, e 849 fitólitos das amostras escovadas.

É curioso notar que a regra que supõe que uma maior massa de sedimento equivale a maior quantidade de fitólitos recuperados não se sustenta para o amido. Vale lembrar que os fitólitos e grãos de amido são provenientes da mesma amostra e separados somente após o processamento dela, por exemplo: a amostra escovada de um lítico é uma só, e dela serão recuperados fitólitos e amido. Portanto, se as amostras escovadas possuem maior quantidade de fitólitos que as amostras sonicadas, por terem um volume maior de sedimento, também deveria haver maior quantidade de amido nas amostras escovadas. Segundo a Tabela 8, as amostras sonicadas possuem 20 grãos de amido $^{66}$ no total e as amostras escovadas possuem 27 grãos de amido no total. Em comparação com a discrepância da quantidade de fitóltios (101 sonicados e 849 escovados), essa diferença para o amido não parece refletir a quantidade de amostra, mas sim o fato da presença do amido nos artefatos.

Isso parece se confirmar com a análise dos sedimentos, uma vez que só na quadra P11 foi identificado amido (2 grãos) em sedimento. Ou seja, o amido está presente nos artefatos, mas não no sedimento do sítio (com exceção de dois grãos na quadra P11).

\footnotetext{
${ }^{66} 8$ grãos de amido da N23, 3 da P11, 6 da AE1 e 3 do Sep. 39 (Tabela 8).
} 


\subsubsection{Comparação dos microvestígios nos líticos com o sedimento de cada quadra}

\subsubsection{Quadra N23}

No sedimento da quadra N23 há Aristidoideae, Bambusoideae, Chloridoideae, Panicoideae, Zea mays, Poaceae em geral, Arecaceae, Cyperus/Kyllinga sp; Zingiberales, Eudicotiledôneas e espículas (Gráfico 3). Não há Cyperaceae em geral nem diatomácea (Gráfico 3).

Nas amostras sonicadas da quadra N23 há em alguns líticos: Zea mays, Poaceae em geral, Eudicotiledôneas e espículas (Gráfico 1). Os táxons Aristidoideae, Bambusoideae, Chloridoideae, Panicoideae, Arecaceae e diatomácea só estão presentes no lítico 13014. Em nenhum há Zingiberale, Cyperus/Kyllinga sp. nem Cyperaceae em geral (Gráfico 1).

Nas amostras escovadas dos líticos da quadra N23 há todos os táxons identificados (Bambusoideae, Chloridoideae, Panicoideae, Zea mays, Poaceae em geral, Arecaceae, Cyperus/Kyllinga sp; Cyperaceae em geral, Zingiberales, Eudicotiledôneas), menos Aristidoideae, também há diatomácea e espículas (Gráfico 2). As amostras escovadas apresentam maior aproximação com o que há no sedimento (Gráfico 2).

É possível perceber uma maior quantidade de fitólitos recuperados do lítico 13014 (Gráfico 1 e Gráfico 2). Isso se deve à maior dimensão desse lítico (Gráfico 4 e Gráfico 5), com mais superfície de contato e retenção de microvestígios e sedimento.

Cyperaceae em geral, presente em amostra sonicada, não foi encontrada no sedimento, o que pode indicar que ela tenha outra origem que não seja o contato como o mesmo. Essa é a única exceção, uma vez que o sedimento contempla todos os fitólitos presentes nos líticos, abrindo e reforçando a possibilidade de contaminação com o sedimento. 


\subsubsection{Quadra P11}

No sedimento da quadra P11 há Bambusoideae, Chloridoideae, Panicoideae, Zea mays, Poaceae em geral, Arecaceae, Cyperus/Kyllinga sp; Eudicotiledôneas e espículas. Não há Aristidoideae, Cyperaceae em geral, Zingiberales nem diatomácea (Gráfico 3).

Nas amostras sonicadas da quadra P11 há em alguns líticos Poaceae em geral e Arecaceae. Panicoideae e Zea mays só são presentes no lítico 14391 e só há Zingiberales no lítico 14410 (Gráfico 1). Não há, nas amostras sonicadas, Aristidoideae, Bambusoideae, Chloridoideae, Eudicotiledôneas, Cyperus/Kyllinga sp; Cyperaceae em geral, diatomácea nem espículas (Gráfico 1).

Nas amostras escovadas dos líticos da quadra P11 há Aristidoideae, Bambusoideae, Panicoideae, Zea mays, Arecaceae e Cyperus/Kyllinga sp; Zingiberales, Eudicotiledôneas e espículas (Gráfico 2). Não há Chloridoideae, Cyperaceae em geral nem diatomácea. Pode haver contaminação com o sedimento principalmente nas amostras escovadas, porque o que foi encontrado nos líticos também está presente no sedimento (Gráfico 2 e Gráfico 3 ).

\subsubsection{Quadra AE1}

O sedimento da quadra AE1 apresenta Panicoideae, Zea mays, Poaceae em geral, Arecaceae, Eudicotiledôneas e espículas (Gráfico 3). Não há Aristidoideae, Bambusoideae, Chloridoideae, Cyperus/Kyllinga sp; Cyperaceae em geral, Zingiberales nem diatomácea (Gráfico 3).

As amostras sonicadas dos líticos da quadra AE1 apresentam Chloridoideae, Zea mays, Poaceae em geral e espículas (Gráfico 1). Não há Aristidoideae, Bambusoideae, Panicoideae, Arecaceae, Zingiberales, Eudicotiledôneas nem diatomácea (Gráfico 1).

As amostras escovadas dos líticos apresentam Bambusoideae, Poaceae, Arecaceae, Cyperus/Kyllinga sp; Zingiberales, Eudicotiledôneas e espículas. Não há Chloridoideae, Panicoideae, Zea mays, Cyperaceae em geral nem diatomácea.

Os resultados das amostras tanto sonicadas quanto escovadas dos líticos destoam um pouco do que há no sedimento, uma vez que há táxons encontrados nos líticos que 
não foram encontrados no sedimento: Bambusoideae, Chloridoideae, Cyperus/Kyllinga sp. e Zingiberales (Gráfico 1, Gráfico 2e Gráfico 3). Isso pode indicar que a presença desses táxons nos líticos não seja de origem do sedimento mas possivelmente do uso do artefato.

\subsubsection{Comparação do sedimento arqueológico (quadras N23, P11 e} AE1) com o sedimento de fora do sítio (C2)

Uma vez que estudos indicam que a vegetação da região de Lagoa Santa não teria se alterado muito durante o Holoceno, apesar do desmatamento (ver Freire, 2011; Nakamura, 2011; Raczka, 2009) é possível que a mata de fora do sítio (acima do abrigo) seja semelhante à vegetação do passado. Nesse caso, a amostra C2 de fora do sítio (acima do abrigo) pode representar, até certa medida, quais plantas estariam localmente presentes no passado.

Os resultados indicam que Panicoideae, Poaceae em geral, Arecaceae e Eudicots estão tanto no sedimento do sítio quanto fora do abrigo (C2) (Gráfico 3).

Os táxons identificados somente no sítio e que não estão presentes fora do abrigo (C2) são: Bambusoideae, Zea mays e Zingiberales (Gráfico 3). Isso pode estar relacionado às escolhas técnicas e culturais humanas das plantas que entrariam no contexto da área de ocupação da Lapa do Santo (Tópico 5.2.7) (ver Lemonnier, 1993: 2).

$\mathrm{Na}$ amostra de fora do sítio (C2) não foi identificado amido, nem nas quadras AE1 e N23 no sítio (somente dois grãos na quadra P11), o que pode sugerir que: o amido não preserva no solo natural e no sedimento arqueológico; ou que o amido do ambiente não é tão facilmente detectável (Tabela 9).

Outra observação é que há muitos fitólitos de Eudicotiledôneas no sedimento da quadra AE1, quase equivalente à quantidade de Eudicotiledôneas no sedimento de fora do sítio (C2) (Gráfico 3). A existência de mata com vegetaçao arbórea dentro da caverna não é viável, porque não há luz, solo ou água suficiente para o desenvolvimento dessa vegetação (ver Poulson \& White, 1969; Marimon Junior \& Haridasan, 2005). 
No sedimento do sítio há carvões e microcarvões que resistiram à queima completa e não se tornaram cinzas. A identificação de Eudicotiledôneas na caverna pode derivar do seu uso como combustível para as fogueiras acesas no sítio (ver Villagran et al. 2017). Outra hipótese, é de que as madeiras fossem empilhadas ou estocadas no abrigo, se decompondo no local e depositando os fitólitos (ver Madella \& Lancelotti, 2012). De fato, Villagran et al. (2017) identificaram o uso de madeiras em decomposição para acessar as fogueiras na Lapa do Santo, que os autores inferiram como provenientes da serapilheira. Uma alternativa é que estas madeiras tenham sido guardadas na parte mais abrigada do sítio para depois ter sido utilizadas nas fogueiras.

Na quadra AE1 há uma grande quantidade de espículas de esponja $(\mathrm{n}=66)$ em comparação com a amostra C2 $(\mathrm{n}=10)$ (Tópico 0 e Tabela 13), o que poderia indicar acúmulo de água no local (ver Batista \& Volkmer-Ribeiro, 2002; Volkmer-Ribeiro, 2007). Isso poderia ter ocorrido através dos condutos intra-carsticos que trazem água de fora para dentro da caverna.

\subsubsection{Táxons Botânicos Identificados}

As plantas identificadas com base nos morfotipos de fitólitos são aquelas pertencentes aos seguintes táxons: Arecaceae (palmeiras); Poaceae (gramíneas), incluindo, Aristidoideae, Bambusoideae, Chloridoideae, Panicoideae e, dentre essas, Zea mays (milho); Cyperaceae, inclusive Cyperus/Kyllinga sp; Zingiberales e Eudicotiledôneas (Gráfico 1, Gráfico 2 e Gráfico 3).

Os grãos de amido identificados apresentam semelhanças com aqueles pertencentes aos táxons: Araceae (taioba), Arecaceae; Poaceae, incluindo gramíneas selvagens e Zea mays; Ipomoea batatas (batata-doce), Capsicum sp. (pimenta e pimentão), Dioscorea sp. (cará) e Solanum tuberosum (batata-inglesa) (Tópico 4.2.4).

\subsubsection{Dificuldade de associar táxons ao amido}

A identificação para os grãos de amido realizada neste trabalho é uma tentativa. Como foi mencionado, não há certeza absoluta sobre as associações realizadas, apenas 
grandes semelhanças e a possibilidade de que sejam os táxons indicados ou próximo a eles (ver Boyadjian, 2012: 121; Copeland \& Hardy, 2018).

Isso se deve ao fato de que plantas de grupos taxonômicos diferentes podem produzir grãos com as mesmas características morfológicas e por isso diferentes morfotipos podem se referir a um mesmo táxon botânico (Boyadjian, 2012: 120; Copeland \& Hardy, 2018: 4). Além disso, determinadas plantas podem produzir conjuntos de grãos heteromórficos ${ }^{67}$ e/ou de diferentes tamanhos (Boyadjian, 2012:120 apud Reichert, 1913; Copeland \& Hardy, 2018:4). Ainda há o problema de o amido moderno e de plantas muitas vezes domesticadas, de coleções de referência, não serem excelentes bases para comparação com plantas selvagens do passado (Copeland \& Hardy, 2018:4).

\section{Arecaceae (Palmeiras)}

Algumas espécies de Arecaceae (palmeiras) são diagnósticas pelo tipo de fitólito que produzem (Marcote-Ríos et al; 2016). Neste estudo, como diagnóstico de Arecaceae foram identificados os morfotipos globular echinate, globular echinate elongate e globular echinate with short acute projections. Conforme estudo de fitóltios em 92 espécies de palmeiras da Amazônia, podemos saber quais espécies produzem ou não produzem determinados fitólitos (Marcote-Ríos et al; 2016). Com base no estudo mencionado, ainda que não seja em contexto de cerrado, podemos fazer uma relação de quais palmeiras amazônicas produzem os fitólitos encontrados nesta pesquisa e ao mesmo tempo não produzem fitólitos que não foram detectados (Tabela 15):

Tabela 15.Espécies de Arecaceae e os fitólitos que produzem. Estas não produzem fitólitos que não foram identificados neste estudo.

\begin{tabular}{|l|l|}
\hline Espécie & Fitólitos \\
\hline Mauritiella aculeata & Globular echinate \\
Phytelephas macrocarpa & \\
\hline Itaya amicorum & Globular echinate \\
Attalea butyracea & Globular echinate elongate \\
Attalea luetzelburgii & \\
Attalea maripa & \\
Attalea microcarpa & \\
Attalea phalerata & \\
Attalea septuagenata & \\
\hline
\end{tabular}

\footnotetext{
${ }^{67}$ Quando a mesma planta produz diferentes tipos de grãos de amido (Boyadjian, 2012:120-121).
} 


\begin{tabular}{|l|l|}
\hline $\begin{array}{l}\text { Attalea plowmanii } \\
\text { Attalea racemosa } \\
\text { Elaeis oleifera }\end{array}$ & Globular echinate elongate \\
\hline $\begin{array}{l}\text { Syagrus orinocensis } \\
\text { Oenocarpus bacaba } \\
\text { Oenocarpus balickii }\end{array}$ & $\begin{array}{l}\text { Globular echinate } \\
\text { Globular echinate with short acute } \\
\text { projections }\end{array}$ \\
\hline Syagrus smithii & $\begin{array}{l}\text { Globular echinate } \\
\text { Globular echinate elongate } \\
\text { Globular echinate with short acute } \\
\text { projections }\end{array}$ \\
\hline
\end{tabular}

Bactris gasipaes (palmito pupunha) só foi registrada produzindo fitólito cônico, o que não foi identificado neste estudo (Marcote-Ríos, 2016). Portanto, é pouco provável que esta planta esteja no sítio, por isso, o amido do morfotipo F não deve estar relacionado a esta espécie.

\section{Zea mays (milho)}

Há possibilidade de que grãos de amidos dos morfotipos A (recuperados nas quadras N23, P11, AE1 e Sep. 39), B (recuperados nas quadras N23, AE1 e Sep. 39) e C (recuperado na quadra AE1) (Erro! Fonte de referência não encontrada.) pertençam a Zea mays (milho) (Tópico 4.2.4). Com relação aos fitólitos, também foram encontrados morfotipos que podem ser produzidos no milho (Tópico 4.2.3).

Os fitólitos rondel wavy-top, ruffle-top e metade-decorados são produzidos pelo sabugo do milho e as cruzes variante 1 são produzidas pelas folhas do milho (Pearsall e Piperno, 1990; Pearsall et al; 2003). Nesta pesquisa, não se pode afirmar que haja rondel wavy-top nem ruffle-top, uma vez que não foi possível rotar dois fitólitos que poderiam ser desses tipos, impedindo a confirmação da identificação (Figura 40).

Foram detectadas 21 fitólitos em cruzes associadas a variante 1 (diagnósticas de Zea mays), 12 extra grandes (entre $20.70 \mu \mathrm{m}$ e $37,55 \mu \mathrm{m}$ de largura), seis grandes (entre $16,33 \mu \mathrm{m}$ e $20,59 \mu \mathrm{m})$ e três medianas (entre $13,20 \mu \mathrm{m}$ e $14,28 \mu \mathrm{m})($

Tabela 11 e Figura 41). Se considera que as cruzes variante 1 grandes e, mais seguramente, as extra grandes, sejam produzidas exclusivamente por milho (Pearsall, 1978; Piperno 1984; Pearsall \& Piperno, 1990; Iriarte, 2003). 
Os fitólitos em cruz variante 1 (Zea mays) foram encontrados na quadra N23 em lítico sonicado e escovado, na quadra P11 em lítico escovado e no sedimento das três quadras: N23, P11 e AE1 (Gráfico 1, Gráfico 2 e Gráfico 3). Não há variante 1 nas amostras sonicadas e escovadas dos líticos da AE1, no lítico do Sepultamento 39, nem no sedimento atual acima do sítio (C2) (Gráfico 1, Gráfico 2 e Gráfico 3). Assim, a presença de possíveis fitólitos de milho nos artefatos sugerem contaminação com o sedimento arqueológico, onde estão presentes esses fitólitos.

O amido que se assemelha a Zea mays (milho) foi identificado na quadra N23 em amostras sonicadas e escovadas dos líticos (Tópico 4.2.4). Na quadra P11 é possível que alguns grãos de amido sejam de Zea mays em amostras sonicadas e escovadas dos líticos (Tópico 4.2.4). Na quadra AE1 há amido semelhante a Zea mays também em amostras sonicadas e escovadas dos líticos (Tópico 4.2.4). No lítico do Sepultamento 39 há três grãos de amido, sendo que todos podem ser de Zea mays, ainda que também se assemelhem a Ipomoea batatas (batata-doce) (Tópico 4.2.4).

Em suma, há fitólitos de Zea mays (milho) nas três quadras (N23, P11 e AE1) tanto no sedimento quanto aderido aos líticos (

Tabela 11, Figura 41, Gráfico 1, Gráfico 2 e Gráfico 3). Na amostra de sedimento de fora do sítio (C2), há uma cruz que se parece muito a variante 1 , mas é mais espessa contendo bastante sílica e por isso não foi classificada como tal (Figura 72).

Grãos de amido que possivelmente são de Zea mays estão nos líticos das três quadras e também do Sepultamento 39, mas não foram encontrados em nenhuma amostra sedimento (Tópico 4.2.4). Na única amostra de sedimento em que foi encontrada amido - dois grãos na quadra P11 -, nenhum foi atribuído a Zea mays: um do morfotipo A mas associado a Araceae (taioba) (Figura 42) e o outro não foi identificado (Figura 50).

Em vista das evidências de fitólitos e amido, que indicam a presença do milho na Lapa do Santo, se pode considerar a possibilidade de que não se trate de contaminação, mas sim do uso dessa planta pelas populações pré-coloniais no sítio (

Tabela 11, Figura 41, Gráfico 1, Gráfico 2 e Gráfico 3). Porém, antes de avançar nesta interpretação, dois elementos devem ser considerados: a possível má preservação dos amidos nos sedimentos e sua melhor preservação no material aderido aos líticos 
onde, de fato, se recuperaram todos os amidos (com exceção dos dois amidos no sedimento da quadra P11); o fato de que outras espécies de Poaceae podem produzir cruzes variante 1 como as observadas nos fitólitos da Lapa do Santo.

Conforme Piperno \& Pearsall (1990), ainda com a evidência diagnóstica do milho, outras espécies de Poaceae (gramíneas) hoje desconhecidas poderiam produzir cruzes variante 1 de grande tamanho por exemplo. Da mesma maneira, existe e existiria no passado, na América Central e do Sul, uma variedade de milhos - selvagens e domesticados - que não seriam necessariamente os que se conhece hoje; mas é importante destacar que não há registros de teosinto na América do Sul (Pearsall, Piperno, 1990).

O que devemos ponderar é a falta de fitólitos do sabugo do milho (rondel wavytop) e a exclusiva presença de fitólitos da folha da planta (cruzes variante 1) (Figura 41). É possível que rondel wavy-top estejam presentes no sítio e não tenham sido contemplados nesta amostragem, e/ou até mesmo poderiam ter um local de descarte específico no sítio, no caso, os sabugos, que são a parte do milho que contém os rondel wavy top (ver Piperno, 2009). A presença de fitólitos das folhas também poderiam sugerir uma atividade de plantio muito próxima ao sítio ou descascamento do milho próximo ou no local (ver Iriarte et al; 2004).

O estudo de Hermenegildo (2009) (apresentado no tópico 1.5) constatou a presença do milho na região de Santana do Riacho com a antiguidade de 2800 anos A.P; na dieta de Cavia aperea (preá). Entretanto, a análise não foi aplicada em períodos mais antigos, portanto, o autor deixou em aberto a possibilidade de que novos estudos indiquem uma maior antiguidade do milho no Brasil Central (Hermenegildo, 2009). Além disso, esse estudo identificou que indivíduos humanos da Lapa do Santo apresentaram uma porcentagem de 19,6 $\pm 1,6 \%$ de consumo de plantas de origem $\mathrm{C}_{4}$ (que poderia ser milho) na dieta (Hermenegildo, 2009). Como não havia possíveis evidências de milho em Lagoa Santa no Holoceno Inicial, o autor considerou que pudesse se tratar de uma contaminação durante as análises (Hermenegildo, 2009) (Tópico 1.5). Posteriormente, Angeles Flores (2015) identificou grãos de amido que poderiam ser de milho em Lapa Grande de Taquaraçu (Tópico 1.3).

Em períodos mais recentes, em Lagoa Santa, o milho é presente (Gardiman, 2014). No sítio Vereda III, Gardiman (2014) identificou amido de Zea mays (milho) em 
cerâmica e evidências de fermentação do mesmo. O sítio é associado a grupos indígenas falantes de tronco linguístico Macro-Jê e a cerâmica à Tradição Aratu-Sapucaí, que abrange o período de 300 a 1800 AD. (Rodrigues \& Gardiman, 2016).

Alguns estudos sugerem uma maior antiguidade para a domesticação de plantas, inclusive, o milho, na Mesoamérica e América do Sul (Pearsall \& Piperno, 1990; Zizumbo et al; 2010; Kaplan \& Lynch, 1999). Na parte oeste da Mesoamérica e no Peru, há 10.000 anos A.P. grupos humanos praticavam a coleta e caça de pequenos animais iniciaram o processo de domesticação de plantas (Zizumbo et al; 2010). Uma agricultura baseada em milho (Zea mays), feijão (Phaseolus vulgaris) e abóbora (Curcubita spp.) teria se estabelecido e se difundido na região há 7000 anos A.P. (Zizumbo et al; 2010; Kaplan \& Lynch, 1999). Nesse mesmo período de 7000 anos A.P; em Tehuacan, no México foram identificados sabugos de domesticações primitivas de teosinto (Manglesdorf et al; 1967 apud Pearsall \& Piperno, 1990).

Em sítios pré-cerâmicos, no Equador, foram identificados fitólitos de Zea mays (milho) e material carbonizado, que indicou haver duas raças de milho diferentes, atestando que o milho já estava presente há pelo menos 7000 anos A.P; dentre as evidências mais antigas para a planta na América do Sul (Tópico 3.8) (Pearsall \& Piperno, 1990).

Para a América do Sul se propunha que a introdução do milho teria ocorrido há 5000 anos A.P; mas segundo Pearsall \& Piperno (1990) haveria pouco tempo para a cultura Valdívia desenvolver no Equador as diferentes variedades de milho que se sabe que desenvolveram e outros cultivos.

Um estudo identificou fitólitos e amido de milho (Zea mays L.) e de abóbora (Curcubita spp.) em cerâmica e sedimento do complexo arqueológico Los Ajos, no Uruguai, com ocupações que teriam iniciado entre 4840 e 4100 anos cal. A.P e perdurado até 500 anos A.P. (Iriarte et al; 2004). Conjuntos de fitólitos de milho com a morfologia de cross (cruz) demonstraram uma dispersão no sítio que indica que eles eram plantados ou descascados no local (Iriarte et al; 2004).

Na Colômbia foi identificado pólen de milho há 7000 anos A.P. (Bray et al; 1985; Monsalve, 1985 apud Pearsall \& Piperno, 1990) assim como no Panamá (Piperno 
et al; 1985). Pearsall \& Piperno (1990) defendem que a antiguidade do pólen de milho e a identificação de fitólitos da planta em contextos pré-cerâmicos e iniciais da cultura Valdivia são suficientes para propor uma data mais antiga para a introdução do milho na América do Sul, há pelo menos 7000 anos A.P.

Piperno et al; (2009) identificaram amido e fitólitos de milho e espécies domesticadas de abóbora, em sítio no vale do rio Balsas, no México há 8700 anos cal. A.P; em contexto pré-cerâmico. As evidências foram encontradas em líticos polidos associados a moagem (Piperno et al; 2009).

Piperno (2011) e Lima et al; (2018) revisam diversos estudos que apontam para essa antiguidade não somente da domesticação de plantas na América do Sul, mas do cultivo de plantas, do Holoceno Inicial entre 11.000 anos A.P. e 7000 anos A.P. Os autores sugerem que esses grupos não devam ser considerados apenas como forrageiros, uma vez que há fortes evidências de que também eram agricultores (Piperno, 2011; Lima et al; 2018).

\subsubsection{Tafonomia dos Microvestígios}

Atividades humanas e processos naturais determinam como os microvestígios de plantas chegam ao contexto cultural e arqueológico (Madella \& Lancelotti, 2012). As plantas são selecionadas e trazidas para o contexto cultural visando usos como na dieta, produção de utensílios, material construtivo e ornamentos, dentre diversas outras possibilidades (Madella \& Lancelotti, 2012).

A preservação dos microvestígios botânicos depende bastante do que ocorre nos estágios iniciais da deposição dos mesmos no ambiente, pois é nesse período que há o maior potencial para a degradação (Mercader et al; 2018: 779). No contexto cultural do passado ocorre a necrólise na planta e bioestratinomia dos fitólitos, bem como inicia-se a diagênese fóssil que ocorre até o momento da escavação dos vestígios (Madella \& Lancelotti, 2012). Além disso, antes, depois ou durante todos esses processos tafonômicos, as pessoas também interferem deslocando os microvestígios para outros contextos com a movimentação de sedimento, a limpeza e até mesmo a convexão de ar provocada pelo fogo, como de fogueiras (Madella \& Lancelotti, 2012). 
Autores denfendem haver boa preservação de amido na superfície e em fendas de líticos e demais artefatos (ver Piperno et al; 2000; Pearsall, 2015, Torrence \& Barton, 2006).

Microambientes com pouca umidade, PH próximo ao neutro e temperatura baixa favorecem a preservação do amido (Copeland \& Hardy, 2018: 4). O grão de amido, quando absorve muita água do ambiente, pode perder sua cristalinidade e birrefringência (Copeland \& Hardy, 2018: 5). Além disso, em ambiente com pouca água os microorganismos reduzem a mobilidade e atividade enzimática o que limitaria os ataques ao amido (Copeland \& Hardy, 2018: 5).

Na Lapa do Santo, o amido encontrado no sedimento é mínimo (somente 2 grãos na quadra P11) em relação ao amido encontrado em líticos, tanto no seu sedimento escovado quanto sonicado. O fato é que o amido está mais presente nos artefatos. Isso pode ser dever a tais razões: 1) $\mathrm{O}$ amido foi melhor preservado aderido aos artefatos que no sedimento; 2) $\mathrm{O}$ amido está mais presente nos artefatos devido ao uso dos mesmos para processar plantas amiláceas; 3) $\mathrm{O}$ amido presente nos artefatos seria oriundo de contaminação com o ambiente, mas no sedimento eles não teriam se preservado, somente nos artefatos.

Na Lapa do Santo, é provável que a movimentação de fitólitos com o sedimento tenha sido pouco expressiva, uma vez que não é detectada na estratigrafia grandes movimentações de sedimento pela ação humana - exceto no caso da construção de covas e do retrabalhamento local de algumas fogueiras (ver Villagran et al; 2017; Strauss, 2010; Strauss et al; 2016). Uma circulação de água de baixa energia existente no sítio e pouca bioturbação detectada, poderiam causar uma movimentação pouco expressiva de fitólitos (ver Villagran et al; 2017). As fogueiras (ver Villagran et al; 2017) podem ter causado convexões de ar que agiriam na movimentação de fitólitos (ver Madella \& Lancelotti, 2012).

\subsubsection{Contaminação}

Em relação a identificação de plantas que poderiam não "encaixar" no contexto de antiguidade das camadas analisados da Lapa do Santo, aquelas provenientes de domesticação são problemáticas. Os resultados indicam a presença de cruzes variante 1 grandes e extra grandes que seriam características de milho (Zea mays) ( 
Tabela 11, Figura 41) (ver Pearsall, 1978; Piperno, 1984; Piperno, 1988; Pearsall \& Piperno, 1990; Iriarte, 2003; Dickau et al; 2016). Alguns grãos de amido também apresentam semelhanças a amido de milho e de batata-doce, plantas provenientes de cultivo (Tópico 4.2.4). A antiguidade para a introdução do milho na porção norte da América do Sul é proposta por Pearsall \& Piperno (1990) há cerca de 7000 anos A.P.

$\mathrm{Na}$ Lapa do Santo, devido à antiguidade dos contextos em que foram encontradas essas plantas cultivadas (Tópico 3.5.1), se poderia considerar que a presença do milho no sítio se trate de contaminação. Nos arredores do sítio há lavouras e seria possível que contaminassem as camadas superiores de sedimento do sítio. Entretanto, as cruzes variante 1 foram encontradas em grande profundidade na quadra P11 (em nível entre $150 \mathrm{~cm}$ a $160 \mathrm{~cm}$ ) e no Sepultamento 39 (em nível entre $120 \mathrm{~cm}$ e $130 \mathrm{~cm})$.

De acordo com a observação macroscópica preliminar em campo, da textura e coloração do sedimento, os contextos analisados não estariam perturbados a ponto de ter havido grandes movimentações verticais de material arqueológico. Uma exceção é a quadra N23 que está localizada em declive de $10^{\circ}$, o que fez com que material da parte sul do abrigo caísse por gravidade na região norte da quadra N23 (ver Bissaro, 2008; Perez, 2009; Araujo et al; 2018). Além disso, Bissaro (2008) e Perez (2009) consideram a área de escavação norte, da quadra N23, como uma área de descarte de restos alimentares e líticos (Tópico 1.5).

Em laboratório, uma mínima contaminação de amido por água destilada é possível de ter ocorrido, como apresentado no tópico 4.2.8 (Figura 76). Ainda assim, de seis lâminas de água destilada, apenas uma apresentou um grão de amido, o que torna inviável pensar que os 49 grãos de amido identificados nesta pesquisa se tratem de contaminação no laboratório (Tópico 4.2.8 e Figura 76). As amostras de papel toalha e de esmalte de unhas não apresentaram nenhum grão de amido, apenas fibras ou tecidos vegetais (Tópico 4.2.8 e Figura 76). A clara exceção é o amido de batata-inglesa identificado, porque no contexto brasileiro não há registros pré-coloniais da batatainglesa (andina), portanto é evidente que este se trata de uma contaminação laboratorial. Fitólitos não foram identificados em nenhuma amostra de controle de contaminação em laboratório, o que demonstra que há uma confiabilidade no caráter arqueológico dos microvestígios identificados (Tópico 4.2.8 e Figura 76). 


\subsubsection{Paleoambiente}

Em estudos paleoambientais com fitólitos, a identificação de Poaceae, Arecaceae e Zingiberales pode sugerir uma vegetação mais aberta como a de cerrado, por exemplo, enquanto que as Eudicotiledôneas são representativas de mata mais fechada de árbóreas-arbustivas (Cf. Monteiro, 2015; Macedo et al; 2015; Watling et al; 2016).

Este estudo não é paleoambiental, porque foi realizado em artefatos e sedimento de sítio arqueológico. Portanto, os resultados aqui apresentados são representativos principalmente das escolhas culturais que selecionaram quais plantas entrariam no contexto em que hoje é o sítio (ver Lemonnier, 1993; Madella \& Lancelotti, 2012).

Ainda assim, no sítio há ambas as vegetações, aberta e arbórea-arbustiva. Em termos de quantidade de fitólitos, há uma quantidade um pouco mais representativa de vegetação aberta do que Eudicotiledônea (arbóreas) (Gráfico 1, Gráfico 2 e Gráfico 3). Entretanto, é preciso ter em conta que as Eudicotiledôneas produzem menos fitólitos (Piperno, 2006) o que leva a crer que no sítio haveria enorme quantidade de madeira para que todos esses fitólitos de Eudicotiledôneas se depositassem no sedimento. A presença da madeira no sítio já foi comprovado com o estudo de Villagran et al. (2017), uma vez que as constantes e abundantes fogueiras realizadas no sítio - e que acumularam até $5 \mathrm{~m}$ de sedimento - consumiam bastante madeira para a combustão.

Alguns pesquisadores (ver Ledru et al; 1998; Raczka, 2009; Freire, 2011), através de análises palinológicas, dentre outras, realizaram levantamentos da vegetação existente durante o Holoceno em Lagoa Santa. A revisão desses trabalhos e listagem de espécies e táxons está no Tópico 1.6 deste trabalho.

Por exemplo, entre 12.000 e 5500 anos A.P; em Lagoa Santa, a partir do início da intensificação das ocupações humanas, foi constatado que havia as plantas dos gêneros: Mauritia (palmeira, família Arecaceae), Myrsine (arbóreas-arbustivas, família Myrsinaceae), Araucaria (pinheiro, família Araucariaceae), Cyathea (samambaia arbórea, família Cyatheaceae) e Lycopodium (herbácea medicinal, família Lycopodiaceae), Caryocar (pequi, família Caryocaraceae), Bombax (arbórea, família Bombacaceae), Pseudobombax (arbórea, família Bombacaceae), Qualea (arbóreaarbustiva, familia Vochysiaceae), Vochysia (arbórea, família Vochysiaceae) e 
Stryphnodendron (barbatimão, medicinal, família Fabaceae) que são de cerrado; Daphnopsis (arbórea, família Thymelaeaceae), Protium (arbórea, família Burseraceae), Rubiaceae (arbustivas florais) e Roupala (arbóreas, família Proteaceae) que são de florestas tropicais; e Asteraceae (girassóis, artemísia, alface, arnica), Cyathea, Lycopodium e Zygnema (alga) que são de brejo (Ledru et al; 1998; Raczka, 2009; Freire, 2011). E para uma listagem completa ver Tabela 1.

Dentre essas plantas identificadas com palinologia em Lagoa Santa, na Lapa do Santo o estudo palinológico de Morrow (2014) também identificou Arecaceae e Asteraceae, dentre outras que esses estudos não identificaram, como Chenopodiaceae (que não produz fitólitos) (ver tópico 1.5 e Tabela 1). Nesta pesquisa, muitas desses táxons não foram identificados, porque ainda não há estudos que demonstrem a presença de fitólitos ou amido diagnósticos e existe uma gama de plantas cuja análise de fitólitos e amido ainda não consegue abarcar.

\subsubsection{Atividades Relacionadas às Plantas}

As plantas identificadas na Lapa do Santo neste estudo poderiam estar relacionadas a diversas atividades humanas. As Bambusoideae (bambu) são utilizadas na dieta com o cozimento do broto, como material construtivo de habitações e objetos móveis e sua fibra pode ser usada para confecção de cestarias. Dentre as Cyperaceae, uma espécie - Cyperus rotundus (barba-de-bode) - pode ser indicativa de solos menos férteis: ácidos, expostos, compactados e deficientes em magnésio ( $\mathrm{Mg}$ ) (Meira et al; 2018). As Zingiberales possuem usos na dieta como por exemplo as bananeiras (Musaceae) e usos farmacêuticos com o gengibre (Zingiber officinale) (Rufino, 2007; Oliveira et al; 2018). As Panicoideae também podem possuir uso na dieta (Rufino, 2007). As Arecaceae (palmeiras) podem ter seus coquinhos utilizados na dieta, na combustão de fogueiras, são ricas em óleo (por ex: babaçu - Orbignya phalerata), suas folhas podem ser raspadas para produzir cera e as fibras são usadas na cestaria (Rufino, 2007). O buriti (Mauritia) é um indicador de recursos hídricos na paisagem porque estão presentes à margem de rios e lagos, suas folhas são utilizadas como material construtivo para habitações (Rufino, 2007). As Eudicotiledôneas (arbóreas-arbustivas) fornecem madeira para combustão e material construtivo de habitações e objetos, seus cipós podem ser usados para confecção de cestarias (Rufino, 2007; Oliveira et al; 2018). 
Um importante trabalho sobre o conhecimento tradicional da população atual de Lagoa Santa, realizado por Oliveira, Da-Glória e Neves (2018), traz as percepções do ambiente no tocante aos recursos de fauna e vegetais, relfetindo sobre a disponibilidade dos mesmos naquele ambiente e sua presença ou não nos registros arqueológicos da região. Segundo os moradores, os meses de dezembro a março, época chuvosa, seriam o que mais teriam disponibilidade de frutas comestíveis na região, sendo as mais citadas o araticum, o pequi, o caju e a cagaita (Oliveira et al., 2018). A sazonalidade dos frutos também indica que nos meses de maio e junho os carboidratos são escassos (Oliveira et al., 2018). Restos de pequi foram identificados na Lapa do Santo, carbonizados, não se sabe se antes ou depois do consumo (Silva, 2006; Oliveira et al., 2018). Uma maior quantidade de macrovestígios de araticum na Lapa do Santo, sugere que havia um maior consumo desse fruto (Silva, 2006; Oliveira et al., 2018). No sítio também foram encontrados macrovestígios de 228 espécimes de jatobá (Nakamura et al., 2010; Oliveira et al., 2018). Oliveira et al. (2018) aletra para a não preservação de macrovestígios de demais frutos, e neste trabalho podemos pensar que evidências de amido desses frutos não tenham sido preservadas, ainda mais se não foram processadas com os líticos, ou mesmo identificadas.

\subsection{Função dos líticos}

\subsubsection{Amido Danificado}

No conjunto identificado, há três grãos de amido com danificação: amido 8 do lítico 14297, o amido 1 do lítico 14385 e o amido 20 do lítico 14029 (Figura 50). Os danos em dois grãos (8 do lítico 14297 e 20 do lítico 14029) são fraturas e podem ter sido causadas por ações mecânicas (Figura 50) (Babot, 2003:76; Cascon, 2017:237; ICSN, 2011). E um grão (1 do lítico 14385) (Figura 50) apresenta fissuras grandes e braços espessos da cruz de interferência, o que pode ter sido uma expansão causada pelo calor (Figura 50) (ver Babot, 2003: 73; Cascon, 2017: 244).

Ainda assim, o conjunto em geral não apresenta danificações. Isso pode indicar que os líticos estariam processando plantas em estado cru, que não haviam sido cozinhados ou processados em fogo. 


\subsubsection{Função dos líticos}

Os resultados sugerem que os líticos analisados da Lapa do Santo se tratam de instrumentos que processaram (cortaram e rasparam) plantas cruas, dentre elas as plantas amiláceas (Tabela 8, Tabela 9, Gráfico 1, Gráfico 2, Gráfico 3, Tópico 4.3, Tópico 5.2.3, Tópico 4.2.4, Tópico 5.3.1.). Se observa uma especialização de uso em alguns líticos, na qual há líticos que só apresentam evidências de terem processado plantas macias (estes são de todas as dimensões do conjunto) e outros só plantas rígidas (estes são os de dimensão mediana a grande para os padrões do conjunto) (Erro! Fonte de referência não encontrada.).

Contudo, os microvestígios encontrados não necessariamente podem ter sido aderidos aos líticos devido ao uso dos mesmos para processar plantas, uma vez que demais processos como a produção, retoque, manipulação e preensão podem deixar resíduos (ver Rots et al; 2016; Xhauflair et al; 2016). Portanto, pode ser que uma porção do amido e dos fitólitos reflitam o uso e outra porção reflita outros tipos de manipulação do artefato. Mesmo assim, eles são indícios (diretos ou indiretos) da presença das plantas no contexto.

A função dos líticos poderia ser mais ampla, uma vez que este estudo só buscou identificar microvestígios botânicos, em detrimento de outros resíduos como lipídios (gordura) e sangue. Esses resíduos não foram detectados a olho nu e seu estudo requer outros métodos que seriam necessários em estudos futuros para averiguar se há a preservação de outros microvestígios nos líticos, que possam indicar mais funções.

\subsection{Contexto regional: função dos líticos da Lapa do Santo e de Lapa Grande de Taquaraçu}

Os líticos lagoassantenses do sítio Lapa Grande de Taquaraçu (tanto lascas quanto resíduos de lascamento) teriam sido utilizados para processar plantas amiláceas e lenhosas, alguns processariam fauna devido a detecção de resíduo de sangue e os artefatos teriam usos generalizados sem especialização (Angeles Flores, 2015).

O estudo de microvestígios no plano-convexo (lesma ou limace) encontrado na Lapa Grande de Taquaraçu é a evidência mais antiga de processamento de plantas 
amiláceas na América (Angeles Flores et al; 2016). O plano-convexo, ou lesma, está associado à Tradição Itaparica, em contexto que data cerca de 11.500 anos A.P; mais antigo que a indústria lítica Lagoassantense (Angeles Flores et al; 2016). Neste artefato foram detectados grãos de amido, alguns com gelatinização, que indica processos de cozimento de plantas amiláceas (Angeles Flores et al; 2016). O autor aponta como possibilidade que os grãos sejam de Arecaceae e Dioscorea e observa que isso é uma diferença com os líticos da indústria Lagoassantense, que não teriam amido semelhante a essas plantas (Angeles Flores et al; 2016).

Esta pesquisa corrobora a identificação do processamento de plantas em líticos de Lagoa Santa. O que temos de diferente nos resultados é que, na Lapa do Santo foi encontrado Arecaceae e possivelmente Dioscorea nos líticos, enquanto que em Lapa Grande de Taquaraçu essas plantas só apareceram na lesma da Tradição Iataparica (ver Angeles Flores, 2015; Angeles Flores et al; 2016). Além disso, na Lapa do Santo se identificou uma certa especialização entre artefatos para uso exclusivo em plantas macias, outros em plantas rígidas e outros em ambas as plantas (Tópico 2035.3 e Erro!

\section{Fonte de referência não encontrada.).}

\section{CONSIDERAÇÕES FINAIS}

Este trabalho detectou a presença de plantas no sítio Lapa do Santo e identificou parte delas, presentes em líticos e no sedimento. 
As plantas identificadas com base nos morfotipos de fitólitos pertencem aos sguintes táxons: Aristidoideae, Bambusoideae, Chloridoideae, Arecaceae (palmeiras); Poaceae (gramíneas), incluindo Panicoideae e, dentre essas, Zea mays (milho); Cyperaceae, inclusive Cyperus/Kyllinga sp; Zingiberales e Eudicotiledôneas.

Os grãos de amido identificados apresentam semelhanças, embora nem sempre completas, com aqueles pertencentes aos táxons: Araceae (taioba), Arecaceae; Poaceae (gramíneas), incluindo gramíneas selvagens e Zea mays; Ipomoea batatas (batata-doce), Capsicum sp. (pimenta e pimentão) e Dioscorea sp. (cará).

É importante ressaltar que essas plantas foram levadas para o sítio intencionalmente. Algumas delas são fontes de alimento e poderiam ser consumidas na dieta. A presença de milho no sítio é sugerida segundo os fitólitos das folhas da planta e o amido semelhante a milho identificados, entretanto, não foram identificados fitólitos produzidos pelo sabugo. Não estamos aqui discutindo a domesticação do milho e um amplo uso dessa planta, pelo contrário, apenas há evidências de que a planta estivesse presente, mas de forma inexpressiva em comparação à variedade de outras plantas identificadas.

As análises realizadas confirmam a hipótese de que os líticos da Lapa do Santo seriam utilizados para processar plantas amiláceas, dentre outras funções possíveis que os métodos deste trabalho não abarcou. Essas plantas foram processadas em estado cru. Os líticos poderiam ter raspado cascas, cortado partes de tubérculos e frutos, e também sido manipulados por mãos e um ambiente que continha essas plantas, que de alguma forma deixaram seus resíduos nos líticos e no sedimento do sítio.

Se levarmos em conta: 1) A enorme quantidade de plantas que eram levadas e queimadas no sítio e deixaram suas cinzas e carvão 2) Os indícios de que a dieta das populações de Lagoa Santa seria fortemente baseada no consumo de vegetais 3) As lâminas de machados polidas presentes na Lapa do Santo, artefatos que estão relacionados à atividades como corte de plantas e árvores, 4) A adequação da indústria lítica em cortar e raspar materiais macios como vegetais, mais 4) Os resultados deste trabalho, podemos levantar a hipótese de que poderia haver algum cultivo de plantas pelas populações que habitaram a Lapa do Santo.

Estudados futuros podem auxiliar na investigação desta hipótese, com mais subsídios sobre as plantas da região e aprofundamento na aplicação destes e outros 
métodos da microarqueobotânica, a ser aplicada como por exemplo nos machados polidos da Lapa do Santo.

Este estudo demonstra a escolha cultural de plantas (de alguma forma, com a coleta ou o cultivo) e o ato de levar para o sítio e utilizar essas plantas, pelos grupos humanos do Holoceno Inicial na Lapa do Santo. A sua relevância se dá por ser inédito no sítio, fortalecer outros estudos de microarqueobotânica no sítio e da região de Lagoa Santa e trazer evidências antigas de atividades de uso de plantas por populações indígenas do passado.

Ainda que a população pré-colonial de Lagoa Santa do Holoceno Inicial estudada aqui possua características de morfologia craniana diferentes de grande parte dos povos indígenas atuais, buscamos valorizar e esperamos que de alguma forma este trabalho honre as culturas indígenas brasileiras do passado e do presente.

\section{REFERÊNCIAS BIBLIOGRÁFICAS}

ACEITUNO, F. J.; LOAIZA, N. Domesticación del Bosque en el Cauca Medio Colombiano entre el Pleistoceno Final y el Holoceno Medio. BAR International Series 1654. Oxford: Archaeopress, 2007. 
AFONSO, Marisa Coutinho. Um painel da arqueologia pré-histórica no Estado de São Paulo: os sítios cerâmicos. Especiaria - Cadernos de Ciências Humanas. vs. 11 e 12, ns. 20, p. 127-155, 2009.

ANDERSON, A. B; POSEY, D. A. Manejo de cerrado pelos índios Kayapó. Boletim do Museu Paraense Emílio Goeldi, Série Botânica, 2(1), 77-98, 1985.

ANGELES FLORES, R. Uso de Recursos Vegetais em Lapa Grande de Taquaraçu: Evidencias Macro e Microscópicas. 2015. 308 f. Dissertação de Mestrado - Museu de Arqueologia e Etnologia, Universidade de São Paulo, São Paulo, 2015.

ANGELES FLORES, R; MORENO DE SOUSA, J. C; ARAUJO, A. G. M; CECCANTINI, G. Before Lagoa Santa: Micro-remain and technological analysis in a lithic artifact from the Itaparica industry. Journal of Lithic Studies, vol. 3, nr. 1, p. 124, 2016.

ARAUJO, A. G. M.; STRAUSS, A. M; FEATHERS, J. K; PAISANI, J. C; SCHRAGE, T. J. Paleoindian Open-Air Sites in Tropical Settings: A Case Study in Formation Processes, Dating Methods, and Paleoenvironmental Models in Central Brazil. Geoarchaeology - An International Journal, v. 28, n. 3, SI, p. 195-220, MAY-JUN. 2013.

ARAUJO, A. G. M; FEATHERS, J; ARROYO-KALIN, M; TIZUKA; M. M. "Lapa das Boleiras Rockshelter: Stratigraphy and Formation Processes at a Paleoamerican Site in Central Brazil." Journal of Archaeological Science, 35: 3186-3202. doi:10.1016/j.jas. 2008.07.007. 2008.

ARAUJO, A. G. M; NEVES, W. A. Lapa das Boleiras: um sítio paleoíndio do Carste de Lagoa Santa, MG, Brasil. São Paulo: Annablume Editora, 2010.

ARAUJO, A. G. M; NEVES, W. A; KIPNIS, R. Lagoa Santa revisited: an overview of the chronology, subsistence, and material culture of paleoindian sites in eastern central Brazil. Latin American Antiquity, vol.24, p. 533-550, 2012.

ARAUJO, A. G. M; NEVES, W. A; PILÓ, L. B. Eventos de seca no holoceno e suas implicações no povoamento pré-histórico do Brasil Central. II Congresso sobre Planejamento e Gestão das Zonas Costeiras dos Países de Expressão Portuguesa; IX Congresso da Associação Brasileira de Estudos do Quaternário; II Congresso do Quaternário dos Países de Língua Ibéricas. 2003.

ARAUJO, A. G. M; NEVES, W. A; PILÓ, L. B; ATUI, J. P. V. Holocene dryness and human occupation in Brazil during the "Archaic Gap". Quaternary Research, 64, 298$307,2005$.

ARAUJO, A. G. M; PUGLIESE JR, F. A; SANTOS, R. O; OKUMURA, M. Extreme cultural persistence in eastern-central Brazil: the case of Lagoa Santa Paleaeoindians. Anais da Academia Brasileira de Ciências, 2018.

AULER, A. Hydrogeological and Hydrochemical Characterization of the Matozinhos-Pedro Leopoldo Karst, Brazil. Master Thesis. Western Kentucky University. 1994. 
AULER, A. S; PILÓ, L. B. As Descobertas de Lund. IN: DA-GLORIA, P; NEVES, W. A; HUBBE, M (Orgs). Cap 3. Lagoa Santa: História das Pesquisas Arqueológicas e Paleontológicas. São Paulo: Annablume Arqueológica, p. 37-52, 2016.

AULER, A. S; SMART, P. L; WANG, X; PILÓ, L. B; EDWARDS, R. L; CHENG, H. Cyclic sedimentation in Brazilian caves: Mechanisms and palaeoenvironmental significance. Geomorphology, 106, 142-153. 2009.

BABOT, M. D. P. Damage on Starch from Processing Andean Food Plants. In: TORRENCE, R; BARTON, H. (Ed.). Ancient Starch Research. California: Leaf Coast Press, p. 66-67, 2006.

BABOT, M. D. P. Granos de Almidón en Contextos Arqueológicos: Posibilidades y Perspectivas a Partir de Casos del Noroeste Argentino. In: MARCONETTO, B; BABOT, P; OLISZEWSKI, N (Eds.). Paleoetnobotánica Del Cono Sur: Estudios de caso ypropuestas metodológicas.- Comp. CAP. 5, p. 95-126, 2007.

BABOT, M. P. Starch Grain Damage as an Indicator of Food Processing. In: D. HART, D; WALliS, L. (Eds.). Phytolith and Starch Grain Research in Australia-PacificAsian Regions: The State of Art,69-81. Canberra: Pandanus Books, vol. 19, p. 69-81, 2003.

BAETA, A. Os Grafismos Rupestres e suas Unidades Estilísticas no Carste de Lagoa Santa e Serra do Cipó, MG. Tese de Doutorado, Universidade de São Paulo. 2011.

BALFET, H. Des chaînes opératoires, pour quoi faire. In: In: BALFET, H. (Ed). Observerl'action technique. Des chaînes opératoires, pour quoi faire? Paris: Centre National de la Recherche Scientifique, p.11-20, 1991.

BANKS, W; GREENWOOD, C. T. Starch and its Components. Edinburgh University Press, 342 p; 1975.

BARBERI, M. Mudanças paleoambientais na região dos cerrados do Planalto Central durante o Quaternário Tardio: o estudo da Lagoa Bonita, DF. Tese de doutorado. Universidade de São Paulo. 227 pp. 2001.

BARTON, H. Clues to Stone Tool Function Re-examined: Comparing Starch Grain Frequencies on Used and Unused Obsidian Artefacts. Journal of Archaeological Science, 25, 1231-1238, Article No. as980300, 1998.

BARTON, H; MATHEWS, P. J. Taphonomy. In: TORRENCE, R; BARTON, H. (Ed.). Ancient Starch Research. California: Leaf Coast Press, p. 75-94, 2006.

BATISTA, T. C. A; VOLKMER-RIBEIRO, C. Comunidades de esponjas do curso superior dos rios Paraná (Goiás) e Paraguai (Mato Grosso), Brasil, com redescrição de Oncosclera schubarti (Bonetto \& Ezcurra de Drago). Revta bras. Zool. 19 \{1\}: 123 136, 2002.

BEHLING, H. Late glacial and Holocene végétation, climate and fire histoiy inferred from Lagoa Nova in the southeastern. Veget Hist Archaeobot 12:263-270, 2003. 
BELTRÃO, M. C. Industries Lithiques trouvées au cours de la prospection 1971. In: A. Laming-Emperaire, A; Prous, A; Vilhena de Moraes, A; Beltrão, M. C. (Orgs.) Grottes et abris de la region de Lagoa Santa, Minas Gerais, Brésil. Cahiers D'Archaeologie D’Amerique du Sud, pp. 123-133; 1974.

BELTRÃO, M.C.M.C. Industrie litiques trouvées au de la prospection 1971. In: Grottes et Abris de la Région de Lagoa Santa - Minas Gerais, Brésil - Cahiers d'Archéologie d'Amérique du Sud 1 (pp. 123-133). Paris: Imprimerie Nationale. 1974.

BERNARDO, A. V; NEVES, W. A; KIPNIS, R. O projeto "Origens" e a questão dos primeiros americanos. Cap 9. IN: DA-GLORIA, P; NEVES, W. A; HUBBE, M (Orgs). Lagoa Santa: História das Pesquisas Arqueológicas e Paleontológicas. São Paulo: Annablume Arqueológica, p. 151-225, 2016.

BICHO, N. F. Manual de Arqueologia Pré-Histórica. Lisboa: Edições 70, 2006.

BISSARO JR. M. C. Tafonomia como ferramenta zooarqueológica de interpretação: viés de representatividade óssea em sítios arqueológicos, paleontológico e etnográfico. Dissertação de Mestrado. Universidade de São Paulo. 2008.

BOËDA, E. Technogénèse des systèmes de production lithique au Paléolithique moyen inférieur et moyen en Europe occidentale et au Proche-Orient. Habilitation à diriger des recherches. 179 f. 2 vol. Tese de Doutorado - Université de Paris X, Nanterre, 1997.

BOËDA, E. Techno-logique \& Technologie: Une Paléo-histoire des objets lithiques tranchants. S/l:@rchéo-éditions, 2013.

BOWEN, W. H; LAWRENCE, R. A. Comparison of the cariogenicity of cola, honey, cow milk, human milk, and sucrose. Pediatrics, vol. 116, p. 921-926, 2005.

BOYADJIAN, C. H. C. Análise e identificação de microvestígios vegetais de cálculo dentário para a reconstrução de dieta sambaquieira: estudo de caso de Jabuticabeira II, SC. 226 f. Tese de doutorado - Instituto de Biociências, Universidade de São Paulo, São Paulo, 2012.

BOYADJIAN, C. H. C; EGGERS, S; REINHARD, K; SCHEEL-YBERT, R. Dieta no sambaqui Jabuticabeira-II (SC): Consumo de plantas revelado por microvestígios provenientes de cálculo dentário. Cadernos do LEPAARQ, vol. XIII, n² 25, p.132-161, 2016.

BOYADJIAN, C. H.C. Microfósseis contidos no cálculo dentário como evidência do uso de recursos vegetais dos sambaquis de Jabuticabeira II (SC) e Moraes (SP). 147 f. Dissertação de Mestrado - Departamento de Genética e Biologia Evolutiva, Universidade de São Paulo, São Paulo, 2007.

BRADBURY, S. The Evolution of the Microscope. New York: Pergamon Press. pp. 375 p; 1967.

BRIUER, F. L. New Clues to Stone Tool Function: Plant and Animal Residues. American Antiquity, vol. 41, No. 4 (Oct.), p. 478-484, 1976. 
BRYANT, V. M. Jr; HALL, S. A. Archaeological Palynology in the United States: A Critique. American Antiquity, vol. 58, nº 2, p. 277-286. 1993.

BUENO, L. Entre Abrigos e Lagoas: Tecnologia Lítica e Territorialidade em Lagoa Santa (Minas Gerais, Brasil). Revista de Arqueologia, vol. 25, n. 2, p. 62-83, 2012.

BUENO, L. M. R; ISNARDIS. A. Lithic Technology in Lagoa Santa in the Early Holocene. In: DA-GLORIA, P; NEVES, W. A; HUBBE, M. Archaeological and Paleontological Research in Lagoa Santa The Quest for the First Americans. Springer, 404 pp; 2017.

BUENO, L; DIAS, A. S; STEELE, J. The Late Pleistocene/Early Holocene archaeological record in Brazil: A geo-referenced database. Quat. Int. 301, 74-93. 2013.

CAROMANO, C. F; CASCON, L. M; NEVES, E. G; SCHEEL-YBERT, R. Revealing Fires and Rich Diets: Macro- and Micro-archaeobotanical Analysis at the Hatahara Site, Central Amazonia. Tipití: Journal of the Society for the Anthropology of Lowland South America, Vol. 11, Iss. 2, Art. 5, 2013.

CARRAPIÇO, F. Glossário científico de termos botânicos usados na disciplina de Biologia (Botânica), v. 1.0.1@, 2012.

CASCON, L. M. Alimentação na Floresta Tropical: um estudo de caso no sítio Hatahara, Amazônia Central, com base em MicrovestígiosBotânicos. 195 f. Dissertação de Mestrado - Museu Nacional, Universidade Federal do Rio de Janeiro, Rio de Janeiro, 2010.

CASCON, L. M. Indo à Raíz da Questão: Repensando o papel de plantas cultivadas no passado Amazônico através da Etnoarqueologia entre os Asurini do Rio Xingu. 411 pp. Tese de Doutorado - Museu de Arqueologia e Etnologia da Universidade de São Paulo. São Paulo, 2017.

CHANDLER-EZELL, K; PEARSALL, D. M; ZEIDLER, A. J. Root and tuber phytoliths and starch grains document manioc (Manihot esculenta), arrowroot (Maranta arundinacea) and Llerén (Calathea sp.) at the Real Alto site, Ecuador. Economic Botany, 60(2), pp. 103-120, 2006.

CHARLES, M; CROWTHER, A; ERTUG, F; HERBIG, C; JONES, G; KUTTERER, J; LONGFORD, C; MADELLA, M; MAIER, U. Phytoliths and Starch - Sampling. Archaeobotanical Online

Tutorial: <http://archaeobotany.dept.shef.ac.uk/wiki/index.php/Phytoliths_and_Starch__Sampling> Acesso em julho de 2016, publicado em 2009.

CHIM, E. N. Zooarqueologia da Lapa Grande de Taquaraçu. 265 f. Dissertação de Mestrado - Museu de Arqueologia e Etnologia da Universidade de São Paulo, São Paulo, 2018.

CHINIQUE DE ARMAS, Y; BUHAY, W. M; RODRÍGUEZ-SUAREZ, R; BESTEL, S; SMITH, D; MOWAT, S. D; ROCKSANDIC, M. Starch analysis and isotopic evidence of consumption of cultigens among fisheregatherers in Cuba: the 
archaeological site of Canímar Abajo, Matanzas. Journal of Archaeological Science, 1e12, 2015.

CORADIN, T.; LOPEZ, P.J.; GAUTIER, C. \& LIVAGE, J. From biogenic to biomimetic silica. Comptes Rendus Palevol; 3:443-452, 2004.

COSTA, F. W. S. The Minas Gerais Academy of Sciences: Lund's Inheritors. In: DAGLORIA, P; NEVES, W. A; HUBBE, M. Archaeological and Paleontological Research in Lagoa Santa The Quest for the First Americans. Springer, 404 pp; 2017.

COSTA, L. M; SANTOS, R. F; SCHAEFER, C. E. G. R; MOREAU, A. M. S. S; MOREAU, M. A. OCORRÊNCIA DE CORPOS SILICOSOS EM HORIZONTES SUPERFICIAIS DE SOLOS DE DIFERENTES ECOSSISTEMAS. R. Bras. Ci. Solo, 34:871-879p; 2010.

COUTO, C. P. Memórias sobre a paleontologia brasileira. Instituto Nacional do Livro, Rio de Janeiro. 1950.

CRESSWELL, R. Técnica. In: Enciclopédia Eianudi, Lisboa, IN-CM, vol. 16 - Homo - Domesticação - Cultura Material, 1989, p. 329-352.

CROWTHER, A. The differential survival of native starch during cooking and implications for archaeological analyses: a review. Anthropological and Archaeological Sciences, vol. 4 (3), p. 221-235, 2012.

CROWTHER, A; HASLAM, M; OAKDEN, N; WALDE, D; MERCADER, J. Documenting Contamination in Ancient Starch Laboratories. Journal of Archaeological Science, vol. 49, 90-104, 2014.

CZAJA, A. Structure of starch grains and the classification of vascular plant families. Taxon: Journal of the International Association for Plant Taxonomy, vol. 27(5/6), p. 463-470, 1978.

DA-GLORIA, P. J. T. Health and lifestyle in the Paleoamericans: Early Holocene Biocultural Adaptation at Lagoa Santa, Central Brazil. 780 f. Tese de Doutorado, The Ohio State University, 2012.

DA-GLORIA, P. J. T; LARSEN, C. Oral health of the Paleoamericans of Lagoa Santa, Central Brazil. American Journal of Physical Anthropology, vol. 154, p. 11-26, 2014.

DA-GLORIA, P; OLIVEIRA, R. E. History of the Research into Health and Lifestyle in Lagoa Santa. In: DA-GLORIA, P; NEVES, W. A; HUBBE, M. Archaeological and Paleontological Research in Lagoa Santa The Quest for the First Americans. Springer, 404 pp; 2017.

DA-GLORIA, P; OLIVEIRA, R. E; NEVES, W. A. Dental caries at Lapa do Santo, central-eastern Brazil: An Early Holocene archaeological site. Anais da Academia Brasileira de Ciências, vol. 89, n.1, p. 307-316, 2017.

DARDENNE, M. A. Síntese sobre a estratigrafia do Grupo Bambuí no Brasil Central, SBG, Congresso Brasileiro de Geologia 30, Recife, Anais 2, p. 597-610, 1978. 
DAUVOIS, M. Precis de Dessin Dynamique et Structural des Industries LithiquesPréhistoriques. Fanlac: Périgueux, 262 p; 1976.

DAYTON, W. A. Glossary of botanical terms commonly used in range research. 40 pp; 1931.

DE OLIVEIRA, P. E. A palynological record of late Quaternary vegetation and climatic change in Southeastern Brazil. Doctoral Thesis. The Ohio State University, Columbus, Ohio. 1992.

DE OLIVEIRA, P. E; BARRETO, A. M. F; SUGUIO, K. Late Pleistocene/Holocene climatic and vegetational history of the Brazilian caatinga: The fóssil dunes of the middle São Francisco River. Palaeogeography, Palaeoclimatology, Palaeoecology, 152, 319-337. 1999.

DIAS, A. S. Diversificar para poblar: el contexto arqueológico braliseño en la transición PleistocenoeHoloceno. Complutum 15, 249e263. 2004.

DICKAU, R; RANERE, A. J; COOKE, R. G. Starch grain evidence for the preceramic dispersals of maize and root crops into tropical dry and humid forests of Panama. Proceedings of the National Academy of Sciences of the United States of America (PNAS),vol. 104(9), p. 3651-3656, 2007.

DIMBLEBY, G. W. Plants and Archaeology. London: John Baker, 187 p; 1967.

DOMINGO, I.; BURKE, H.; SMITH, C. Manual de campo del arqueólogo. Barcelona: Ariel, 2007.

DUKE, G. S; VÁSQUEZ-SANCHEZ, V. F; ROSALES-THAM, T. E. Starch grain evidence of potato consumption at the Late Moche (AD 600-850) site of Wasi Huachuma, Peru. Journal of Archaeological Science, 100, 74-79, 2018.

DUNCAN, N. A; PEARSALL, D. M. BENFER JR; R. A. Gourd and squash artifacts yield starch grains of feasting foods from preceramic Peru. PNAS, vol. 106, n. 32, 2009.

ENGLISH, H. K; PACK, A. R; MOLAN, P. C. The effects of manuka honey on plaque and gingivitis: A pilot study. Journal of the International Academy of Periodontology, vol. 6, p. 63- 67, 2004.

FAEGRI, K. "In memoriam O. Gunnar E. Erdtman". Pollen et Spores, 15: 5-12, 1973.

FÆGRI, K; IVERSEN, J. Textbook of Pollen Analysis. Oxford: Blackwell Scientific Publications, 1964.

FEATHERS, J; KIPNIS, R; PILÓ, L. B; ARROYO-KALIN, M; COBLENTZ, D. How old is Luzia? Luminescence dating and stratigraphic integrity at Lapa Vermelha, Lagoa Santa, Brazil. Geoarchaeology, 25(4), 395-436. 2010.

FERNÁNDEZ, R. R. Arqueología: métodos y técnicas. 3. ed. Barcelona: Bellaterra, 1980. 
FERRAZ-VICENTINI, K. R; SALGADO-LABOURIAU, M. L. Palynological Analysis of a Palm Swamp in Central Brazil. Journal of South American Earth Sciences, Vol. 9, Nos 3 e 4, 207-219,1996.

FIELD, J. Reference Collections. In: BARTON, H; TORRENCE, R (Eds.). Ancient Starch Research. California: Left Coast Press, p. 95-113, 2006.

FOGAÇA, E. Mãos para o pensamento. A variabilidade tecnológica de indústriaslíticas de caçadores-coletores holocênicos a partir de um estudo de caso:ascamadasVIII e VII da Lapa do Boquete (Minas Gerais, Brasil - 12.000/10.500 B.P.). 452 f. Tese de Doutorado - Faculdade de Filosofia e Ciências Humanas, Pontifícia Universidade Católica do Rio Grande do Sul, Porto Alegre, 2001.

FREIRE, G. Q. Madeiras fósseis holocênicas de Ribeirão da Mata: anatomia ecológica, relações florísticas e interpretação paleoambiental da região arqueológica de Lagoa Santa, MG. Tese (Doutorado em Botânica) - Instituto de Biociências, Universidade de São Paulo, São Paulo, 2011.

FREITAS, F. O. Uso de material arqueológico no estudo de evolução de plantas estudo de caso: milho - Zea mays L. e mandioca - Manihot esculenta CRANTZ. Revista de Arqueologia, vol. 17, p. 33-40, 2004.

FULLAGAR, R. Starch on Artifacts. In: BARTON, H; TORRENCE, R (Eds.). Ancient Starch Research. California: Left Coast Press, p. 177-204, 2006.

FULLAGAR, R. Stones, Stories and Science. In: HASLAM, M; ROBERTSON, G; CROWTHER, A; NUGENT, S; KIRKWOOD, L. (Eds.). Archaeological Science Under a Microscope: Studies in residue and ancient DNA analysis in honour to Thomas H. Loy. Canberra: ANU E Press, vol. 30, p. 4-7, 2009.

GALLAY, A. L'Archéologie demain. Paris: Belfond, 319 p; 1998.

GARDIMAN, G. G. VEREDA III: Uma análise paleoetnobotânica. 142 f. Monografia de conclusão de curso - Departamento de Sociologia e Antropologia da Faculdade de Filosofia e Ciências Humanas da Universidade Federal de Minas Gerais, Belo Horizonte, 2014.

GARDIMAN, G. G; RODRIGUES, I.M. M.; CASCON, L. M; ISNARDIS, A. A morfologia dos vasos Jê na produção de cauim de milho em Vereda III: uma proposição. R. Museu Arq. Etn; 27: 111-120, 2016.

GARDIMAN. Fora das grandes aldeias: o sítio Vereda III e suas informações complementares sobre sistemas de ocupação de grupos portadores de cerâmica associada à tradição Aratu-Sapucaí. R. Museu Arq. Etn; 27:103-110, 2016.

GÉMINARD, L. Avant-Propos. In: DEFORGE, Y. Technologie et génétique de l'objet industriel. Paris: Ed. Maloine (Collection Université de Compiègne), 196p; 1985.

GOTT, B; BARTON, H; SAMUEL, D; TORRENCE, R. Biology of Starch. In: BARTON, H; TORRENCE, R. Ancient Starch Research. Left Coast Press, p.35-47, 2006. 
GREEN, W; TOLMIE, C. Analysis of Plant Remains from Blood Run. Plains Anthropologist, vol. 49, No. 192: 525-542. 2004.

GREGORY, W. On the presence of Diatomaceae, Phytolitharia, and sponge spicules in soils which support vegetation. Proceedings of the Botanical Society, Edinburgh: 6972,1855 .

HARDY, B. L; KAY, M; MARKS, A. E; MONIGAL, K. Stone tool function at the paleolithic sites of Starosele and Buran Kaya III, Crimea: behavioral implications. Proceedings of the National Academy of Sciences, vol. 98(19), p. 10972-10977, 2001.

HASLAM, M; ROBERTSON, G; CROWTHER, A; NUGENT, S; KIRKWOOD, L. Archaeological Science Under a Microscope: Studies in residue and ancient DNA analysis in honour to Thomas H. Loy. Canberra: ANU E Press, vol. 30, 271 p; 2009.

HAYDEN, B; KAMMINGA, J. An Introduction to Use-Wear. In: HYDEN, B. Lithic Use-Wear Analysis. Burnaby: Simon Fraser University, p. 1-13, 1977.

HENRY, A. G; BROOKS, A. S; PIPERNO, D. R. Microfossils in calculus demonstrate consumption of plants and cooked foods in Neanderthal diets (Shanidar III, Iraq; Spy I and II, Belgium). Proceedings of the National Academy of Sciences of the United States od America (PNAS), vol. 108, n. 2, p. 486-491, 2010.

HENRY, A. G; BROOKS, A. S; PIPERNO, D. R. Plant foods and the dietary ecology of Neanderthals and early modern humans. Journal of Human Evolution, vol. 69, p. 44-54, 2014.

HERMANN, G; KOHLER, H. C; DUARTE, J. C; CARVAlHO, P. G. S (Orgs.). Estudo do meio biótico. Belo Horizonte: IBAMA/CPRM, 1998.

HERMENEGILDO, T. Reconstituição da dieta e dos padrões de subsistência das populações pré-históricas de caçadores-coletores do Brasil Central através da ecologia isotópica. $126 \mathrm{f}$. Dissertação de Mestrado - Escola Superior de Agricultura "Luiz de Queiroz", Universidade de São Paulo, Piracicaba, 2009.

HOLST, I; MORENO, E; PIPERNO, D. R. Identification of teosinte, maize, and Tripsacum in Mesoamerica by using pollen, starch grains, and phytoliths. PNAS, vol. 104, n. 45, 2007.

HOLTEN, B; STERLL, M. Peter Wilhelm Lund - Vida e Objetivos. IN: DA-GLORIA, P; NEVES, W. A; HUBBE, M (Orgs). Cap 2. Lagoa Santa: História das Pesquisas Arqueológicas e Paleontológicas. São Paulo: Annablume Arqueológica, p. 11-36, 2016.

HUBBE, A; HUBBE, M; NEVES, W. A. The Brazilian megamastofauna of the Pleistocene/Holocene transition and its relationship with the early human settlement of the continente. Earth-Science Reviews, 118, 1-10, 2013.

HUBBE, M; HANIHARA, T; NEVES, W. A. Paleoamerican morphology in the context of European and East Asian Late Pleistocene Variation: Implications for Human Dispersion into the New World. Am J Physical Anthropology 144:442-453. 2011. 
HUBBE, M; OKUMURA, M; BERNARDO, D. V; NEVES, W. A. Cranial morphological diversity of early, middle and late Holocene Brazilian groups: implications for human dispersion in Brazil. Am J Phys Anthropol 155:546-558. 2014.

HUBBE, M; STRAUSS, A; HUBBE, A; NEVES, W. A. Early South Americans cranial morphological variation and the origin of American biological diversity. Plos One 10:e0138090. 17pp; 2015.

HURT, W; BLASI, O. O projeto arqueológico "Lagoa Santa", Minas Gerais, Brasil. Arquivos do Museu Paranaense, Arqueologia, 4, 1-60. 1969.

ICSN. The International Code for Starch Nomenclature. 2011. Disponível em:<http://fossilfarm.org/ICSN/Code.html>, Accessado: 12/08/2016.

INIZAN, M. L; REDURON, M; ROCHE, H; TIXIER, J. Technologie de la pierre tailée. Meudon: Centre National de la Recherche Scientifique, Cercle de recherches et d’etudes préhistoriques, 195 p; 1995.

IRIARTE, J. Assessing the feasibility of identifying maize through the analysis of cross-shaped size and three-dimensional morphology of phytoliths in the grasslands of southeastern South America. Journal of Archaeological Science, 30, 1085-1094, 2003.

IRIARTE, J; GLASER, B; WATLING, J; WAINWRIGHT, A; BIRK, J. J; RENARD, D; ROSTAIN, S; MCKEY, D. Late Holocene Neotropical agricultural landscapes: phytolith and stable carbon isotope analysis of raised fields from French Guianan coastal savannahs. Journal of Archaeological Science, 37, p. 2984-2994, 2010.

IRIARTE, J; HOLST, I; MAROZZI, O; LISTOPAD, C; ALONSO, E; RINDERKNECHT, A; MONTANA, J. Evidence for cultivar adoption and emerging complexity during the mid-Holocene in the La Plata basin. Nature, vol. 432, n. 2, 614617 pp; 2004.

KEALHOFER, L; TORRENCE, R; FULLAGAR, R. Integrating phytoliths within usewear/residue studies of stone tools. Journal of Archaeological Science, 26:527-546. 1999.

KIPNIS, R. Foraging Societies of Eastern Central Brazil: An Evolutinary Ecological Study of Subsistence Strategy. $523 \mathrm{f}$. Tese de Doutorado - The University of Michigan, Ann Arbor, 2002.

KOBUSKI, C. E. A Revised Glossary of the More Common Botanical and Horticultural Terms. Harvard University, Arnoldia, Vol. 15, Issue: 5-7, 1955, 25-44 pp.

LAMING EMPERAIRE, A; PROUS, A; MORAES, A. V; BELTRÃO, M. C. Grottes et abris de la Région de Lagoa Santa, Minas Gerais, Brésil, Cahiers d' Archéologie d' Amérique du Sud (1), Paris, 1975.

LAMING-EMPERAIRE, A. La arqueología Pré-Histórica. Barcelona: Martínez Roca, 1984. 
LAMING-EMPERAIRE, A. Missions archéologiques franco-brésiliennes de Lagoa Santa, Minas Gerais, Brésil - Le Grand abri de Lapa Vermelha. Revista de PréHistória, 1:53-89, 1979.

LANARI, C. U. Ossadas humanas fósseis encontradas numa caverna calcárea das vizinhanças do Mocambo. Annaes da Escola de Minas de Ouro Preto, v. 11, p. 15-35, 1909.

LARSEN, C. S. Bioarchaeology: interpreting behavior from the human skeleton. Cambridge: Cambridge University Press, 240 p; 1997.

LEDRU, M. P; BRAGA, P. I. S; SOUBIÈS, F; FOURNIER, M; MARTIN, L; SUGUIO, K; TURCQ, B. The last 50,000 years in the Neotropics (Southern Brazil): Evolution of vegetation and climate. Palaeogeography, Palaeoclimatology, Palaeoecology, v. 123, p. 239-257, 1996.

LEISTNER, O. A. Seed plants of southern tropical Africa: families and genera. Southern African Botanical Diversity Network. Report No. 26. SABONET, 2005.

LEMONNIER, P. Introduction. In: LEMONNIER, P. (Org.) Technological choices transformation in material culture since the Neolitic. London: Routledge. 2002. p. 135 .

LENTFER, C; THERIN, M. Collecting Starch in Papua New Guinea. In: In: BARTON, HUW; TORRENCE, ROBIN. Ancient Starch Research. California: Left Coast Press, p. 35-45, 2006.

LEROI-GOURHAN, A. Le Geste et la parole. Paris: Ed. Albin Michel, 421 p; 1964.

LIMA, P. G. C; SANTOS, R. S; MAGALHÃES, M. P; SCHEEL-YBERT, R; COELHO-FERREIRA, M; FELICIANO, A. L. P; ALBERNAZ, A. L. K. M. Plantas úteis na flora contemporânea e pretéria de Carajás. In: MAGALHÃES M. P. (Org.). A Humanidade e a Amazônia. Belém: Museu Paraense Emílio Goeldi, 183-209 pp; 2018.

LINGSTROM, P; VAN HOUTE, J; KASUYA, T. Food starches and dental caries. Critical Reviews in Oral Biology and Medicine, vol. 11, p. 336-380, 2000.

LOMBARD, M; WADLEY, L. The Impact Of Micro-Residue Studies On South African Middle Stone Age Research. In: HASLAM, M; ROBERTSON, G; CROWTHER, A; NUGENT, S; KIRKWOOD, L. Archaeological Science Under a Microscope: Studies in residue and ancient DNA analysis in honour to Thomas H. Loy. Canberra: ANU E Press, vol. 30, p. 11-28, 2009.

LOMBARDO, U; RUIZ-PÉREZ, J; MADELLA, M. Sonication improves the efficiency, efficacy and safety of phytolith extraction. Review of Palaeobotany and Palynology, vol. 235, p. 1-5, 2016.

LOURDEAU, A. Le technocomplexe Itaparica: Définition techno-fonctionnelle des industries à pièces façonnées unifacialement à une face plane dans le centre et le nordest du Brésil pendant la transition Pléistocène-Holocène et l'Holocène ancien. $477 \mathrm{f}$. Tese de Doutorado - Université Paris Ouest Nanterre La Défense, Paris, 2010. 
LOY, T. H. Methods in the analysis of starch residues on prehistoric stone tools. In: HATHER, J. G. (Ed.). Tropical Archaeobotany: Applications and new developments, London: Routledge, pp. 86-114, 1994.

LOY, T. H; FULLAGAR, R. Residue Extraction. In: BARTON, H.; TORRENCE, R (Eds.). Ancient Starch Research. Left Coast Press, p. 197-198, 2006.

LOY, T. Optical Properties Of Potential Look-Alikes. In: BARTON, H; TORRENCE, R. Ancient Starch Research. Left Coast Press, p.123-124, 2006.

LUNA FILHO, P. E. Peter Wilhelm Lund: o auge das suas investigações científicas e a razão para o término das suas pesquisas. Tese. (doutor em História). São Paulo, Universidade de São Paulo, FFLCH, 2007.

LUND, P. W. Notice sur des ossements humains fossiles, trouvés dans une caverne du Brésil. Mémoires de la Societé Royale des Antiquaires du Nord, pp. 49-77. 1845.

MACEDO, R. A; MADELLA, M; CALEGARI, M. R; TEIXEIRA, W. G; MARTINS, G. C; VIDAL-TORRADO, P. Fitólitos como subsídio para estudos de reconstrução da vegetação e indicador de mudanças hidrológicas em solos tropicais. XXXV Congresso Brasileiro de Ciência do Solo, Natal (RN), 2015.

MADELLA, M; LANCELOTTI, C. Taphonomy and phytoliths: A user manual. Quaternary International, 275, 76e83, 2012.

MAESTRO, C; COLLINA, C. The Quest fo a Common Semantics: Observations on Definitional Criteria of Cognitive Process in Prehistory. In: BEAUNE, S; COOLIDGE, F; WYNN, T (Eds.). Cognitive Archaeology and Human Evolution. Cambridge: Cambridge University Press, p. 85-94, 2009.

MARCHAND, G; BARROS, A. F. (trad.) La neolithisation de l'ouest de la France: caracterisation des industries lithiques. British. Archaeological Reports. International Series, 1999.

MARIMON JUNIOR, B. H; HARIDASAN, M. Comparação da vegetação arbórea e características edáficas de um cerradão e um cerrado sensu stricto em áreas adjacentes sobre solo distrófico no leste de Mato Grosso, Brasil. Acta bot. bras. 19(4): 913-926. 2005.

MARINHO, L. C; SETÚVAL, F. A. R; AZEVEDO, C. O. Botânica Geral de Angiospermas no ensino médio uma análise comparativa entre livros didáticos. Investigações em Ensino de Ciências - V20(3), pp. 237-258, 2015

MARLOWE, F. W. Hunting and gathering: the human sexualdivision of foraging labor. Cross Cultural Research,vol. 41, p. 170-195, 2007.

MARREIROS, J. M; GIBAJA, J. F. G; BICHO, N. F. Use-wear and residue analysis in archaeology. Springer. 231pp, 2015.

MATTOS, A. Pré-História Brasileira. São Paulo: Companhia Editora Nacional.1938. 
MEIRA, A. L; LEITE, C. D; MOREIRA, V. R. R. Fichas Agroecológicas. Ministério da Argicultura, Pecuária e Abastecimento. Acesso em 2018. Acesso em: http://www.agricultura.gov.br/assuntos/sustentabilidade/organicos/fichasagroecologicas/arquivos-fertilidade-do-solo/35-plantas-indicadoras-parte-2.pdf

MERCADER, J; AKEJU, T; BROWN, M; BUNDALA, M; COLLINS, M. J; COPELAND, L; CROWTHER, A; DUNFIELD, P; HENRY, A; INWOOD, J; ITAMBU, M; KIM, J-J; LARTER, S; LONGO, L; OLDENBURG, T; PATALANO, R; SAMMYNAIKEN, R; SOTO, M; TYLER, R; XHAUFLAIR, H. Exaggerated expectations in ancient starch research and the need for new taphonomic and authenticity criteria. FACETS 3: 777-798. doi:10.1139/facets-2017-0126, 2018.

MEYER, K. E. B; CASSINO, R. F; LORENTE, F; RACZKA, M; PARIZZI, M G. Paleoclima e paleoambiente do cerrado durante o Quaternário com base em análises palinológicas. Paleontologia: Cenários de Vida - Paleoclimas. 19 pp; 2014.

MINGATOS, G. S. Caça ou Deixa Passar? A Dieta dos Grupos Humanos do Sítio Lapa do Santo, Lagoa Santa, Minas Gerais. Dissertação (Mestrado EM Arqueologia) Museu de Arqueologia e Etnologia da Universidade de São Paulo, 2017. 89 p.

MINGATOS, G. S; OKUMURA, M. Modelo de Amplitude de Dieta aplicada a restos faunísticos do sítio Lapa do Santo (MG) e suas implicações para o entendimento da dieta em grupos Paleoíndios do Brasil central. Palaeoindian Archaeology, vol. 1, n. 1, 13 pp. 2016.

MOLAN, P. C. The potential of honey to promote oral wellness. General Dentistry, vol. 49, p. 584-589, 2001.

MORENO DE SOUSA, J. C. Cognição e Cultura no Mundo Material: Os Itaparicas, os Umbus e os "Lagoassantenses". Volume 1. MAE-USP. Dissertação de Mestrado. pp 200; 2014.

MORENO DE SOUSA, J. C. Cognição e Cultura no Mundo Material: Os Itaparicas, os Umbus e os "Lagoassantenses". Volume 2. MAE-USP. Dissertação de Mestrado, 2014.

MORENO DE SOUSA, J. C. Tecnologia de Ponta a Ponta: Em busca de mudanças culturais durante o Holoceno em indústrias líticas do Sudeste e Sul do Brasil. Tese de Doutorado. Museu Nacional, Universidade Federal do Rio de Janeiro: 445 p. 2018.

MORENO DE SOUSA, J. C; ARAUJO, A. G. M. Microliths and Polished Stone Tools during the Pleistocene-Holocene Transition and Early Holocene in South America: The Lagoa Santa Lithic Industry, PaleoAmerica, 20 pp, 2018.

MORROW, J. A Palynological Analysis of Sediments from a Pollen Column Collected During the 2014 Excavations of Lapa do Santo, Minas Gerais, Brazil. Relatório apresentado ao LAAAE-USP, não publicado.Pathoecology and Palynology Laboratory, School of Natural Resources, University of Nebraska-Lincoln, 3310 Holdrege Street, Lincoln, Nebraska, 68583-0962, United States. 2014.

MUSAUBACH, M. G; PLOS, A; BABOT, M. P. Differentiation of archaeological maize (Zea mays L.) from native wild grasses based on starch grain morphology. Cases 
from the Central Pampas of Argentina. Journal of Archaeological Science, 40, 1186e1193, 2013.

NAKAMURA, C. Folhas fósseis do Ribeirão da Mata: uma abordagem florística e anatômica para caracterização do paleoambiente do Holoceno Médio de Lagoa Santa, MG. Dissertação de Mestrado. Universidade de São Paulo, 120 pp; 2011.

NETO, V. V. G; RODRIGUES-CARVALHO, C. O Arquivo de Antropologia Física do Museu Nacional: Lagoa Santa na Primeira Metade do Século XX. IN: DA-GLORIA, P; NEVES, W. A; HUBBE, M (Orgs). Cap 5. Lagoa Santa: História das Pesquisas Arqueológicas e Paleontológicas. São Paulo: Annablume Arqueológica, p. 77-96, 2016

NEVES W. A; PILÓ L. B. O povo de Luzia: em busca dos primeirosamericanos. São Paulo: Editora Globo, 334p. 2008.

NEVES, W. A; ARAUJO, A. G. M; BERNARDO, D. V; KIPNIS, R.; FEATHERS, J. K. Rock Art at the Pleistocene/Holocene Boundary in Eastern South America. PLOS ONE, vol. 7(2), p. 1-5, 2012.

NEVES, W. A; GONZALEZ JOSE, R; HUBBE, M; KIPNIS, R; ARAUJO, A; BLASI, O. Early Holocene human skeletal remains from Cerca Grande, Lagoa Santa, Central Brazil, and the origins of the first Americans. World Archaeol. 36, 479-501, 2004.

NEVES, W. A; HUBBE, M. Cranial morphology of early Americans from Lagoa Santa, Brazil - Implications for the settlement of the New World. Proceedings of the National Academy os Science, 102:18309-18314, 2005.

NEVES, W. A; HUBBE, M; BERNARDO, D; STRAUSS, A; ARAUJO, A; KIPNIS, R. Early human occupation of Lagoa Santa, Eastern Central Brazil: Craniometric variation of the initial settlers of South America. In: Graf E, Ketron CV, Waters MR. (Eds.). Paleoamerican Odyssey. Center for the Study of First Americans. English, 2013.

NEVES, W. A; HUBBE, M; PILÓ, L. B. Early Holocene human skeletal remains from Sumidouro Cave, Lagoa Santa, Brazil: history of discoveries, geological and chronological context, and comparative cranial morphology. Journal of Human Evolution, 52(1), 16-30, 2007.

NEVES, W. A; HUBBE, M; STRAUSS, A. M; BERNARDO, D. V. Morfologia craniana dos remanescentes ósseos humanos da Lapa do Santo, Lagoa Santa, Minas Gerais, Brasil: implicações para o povoamento das Américas. Boletim do Museu Paraense Emílio Goeldi. Ciências Humanas, Belém, vol. 9, n. 3, p. 715-740, 2014.

NEVES, W. A; KIPNIS, R. Further evidence of a highly cariogenic diet among late Paleoindians of Central Brazil. Current Research on Pleistocene, (21), 81-83. 2004.

NEVES, W. A; MUNFORD, D; ZANINI, M. C. Cranial Morphological Variation and the Colonisation of the New World: Towards a Four Migration Model. American Journal of Physical Anthropology, vol. 22, 176p; 1996. 
NEVES, W. A; PILÓ, L. B. Solving Lund's dilemma: new AMS dates confirm that humans and megafauna coexisted at Lagoa Santa. Current Research in the Pleistocene, Orono, v. 20, p. 57-60, 2003.

NEVES, W. A; POWELL, J. F; OZOLINS, E. G. Extra-Continental Morphological Affinities of Lapa Vermelha IV, Hominid 1:A MultivariateAnalysis with Progressive Numbers of Variables. HOMO 50:262-282. 1999.

NEVES, W. A; PROUS, A; GONZÁLEZ-JOSÉ, R; KIPNIS, R; POWELL, J. Early Holocene human skeletal remains from Santana do Riacho, Brazil: implications for the settlement of the New World. J Hum Evol 45:19-42. 2003.

NEVES, W. A; PUCCIARELLI, H. M. Extra continental biological relationships of early South American human remains: a multivariate analysis. Ciência e Cultura 41: 566-575. 1989.

NEVES, W. A; PUCCIARELLI, H. M. Morphological affinities of the first Americans: an exploratory analysis based on early South American human remains. J Hum Evol 21: 261-273. 1991.

NEVES, W. A; PUCCIARELLI, H. M. The Origins of the First Americans: an Analysis Based on the Cranial Morphology of Early South American Human Remains. American Joumal of Physical Anthropology, vol. 81, p. 141-321; 1990.

OGILVIE, M. B; HARVEY, J. D. The Biographical Dictionary of Women in Science: Pioneering Lives From Ancient Times to the Mid-20th Century. New York: Routledge, 1499pp, 2000.

OKUMURA, M.; ARAUJO, A. Pontas bifaciais no Brasil Meridional: Caracterização estatística das formas e suas implicações culturais. R. Museu Arq. Etn; São Paulo, n. 23, p. 111-127, 2013.

OLIVEIRA, E. V. S; PRATA, A P. N; PINTO, A. S. Caracterização e atributos da vegetação herbácea em um fragmento de Caatinga no Estado de Sergipe, Brasil. Hoehnea 45(2): 159-172, 3 tab; 3 fi g; 2018.

PAGÁN JIMENEZ, J. R. De antiguos pueblos y culturas botánicas en el Puerto Rico indígena. Paris: Monographs in American Archaeology, 18, BAR International Series 1687, 297pp; 2007.

PAGÁN-JIMÉNEZ, J. Early use of maize and other food crops among early ceramic and later neoindian traditions of northeastern amazonia revealed by ancient starch grains from ceramic and lithic artifacts of the chemin saint-louis archaeological site, french guiana. Archaeology and Anthropology, 17.2, 2012.

PAGÁN-JIMÉNEZ, J. R; OLIVER, J. R. Starch residues on lithic artifacts from two contrasting contexts in northwestern Puerto Rico: Los Muertos Cave and Vega de Nelo Vargas farmstead. In: HOFMAN, C. L.; HOOGLAND, M. L. P.; VAN GIN, A. L. (Eds.). Crossing the Borders: New methods and techniques in the study of archaeological materials from the Caribbean. Tuscaloosa: The University of Alabama Press, p. 137-158, 2008. 
PAGÁN-JIMENEZ, J; GUACHAMÍN-TELLO, A. M; ROMERO-BASTIDAS, M; CONSTANTINE-CASTRO, A. R. Late ninth millennium B.P. use of Zea mays L. at Cubilan area, highland Ecuador, revealed by ancient starches. Quaternary International, 1e19, 2015b.

PAGÁN-JIMÉNEZ, J; RODRÍGUEZ-RAMOS, R; REID, B. A; VAN DEN BEL, M; HOFMAN, C. L. Early dispersals of maize and other food plants into the Southern Caribbean and Northeastern South America. Quaternary Science Reviews, vol. 123, p. 231-246, 2015.

PARIZZI, G. M; SALGADO-LABOURIAU, M. L; KOHLER, H. C. Genesis and environmental history of Lagoa Santa, southeastern Brazil. The Holocene, 8,3 (1998) pp. 311-321. 1998.

PARRY, W; KELLY, R. Expedient core technology and sedentism. The Organization of Core Technology. Westview Press, Boulder, Colorado, 285p; 1987.

PATRUS, M. L. R. A. Estudos hidrológicos e qualidade das águas de superfície - Belo Horizonte: IBAMA/CPRM, 1998.

PEARSALL, D. M. Paleoethnobotany: a Handbook of Procedures. Third Edition. New York: Academic Press, 513 p; 2015.

PEARSALL, D. M. Phytolith analysis of archaeological soils: evidence for maize cultivation in formative Ecuador, Science, 199, 177-178, 1978.

PEARSALL, D. M; PIPERNO, D. R Antiquity of maize cultivation in Ecuador: summary and reevaluation of the evidence, American Antiquity, 55, 324-337, 1990.

PELEGRIN, J. Taille. In: LEROI-GOURHAN, A. [Ed.] Dictionnaire de la Préhistoire. Paris, Press Universitaires de France: 1019-1020, 1988.

PELEGRIN, J. Technologie lithique: le Châtelperronien de Roc de Combe (Lot) et de la Côte (Dordogne). Cahiers du Quaternaire,Paris: Centre National de la Recherche Scientifique, vol. 20, p.19-39, 1995.

PELLI, A; BARBOSA, F. A. R. Herbivoria Em Salvinia Molesta Mitchel em um Lago do Planalto Kárstico de Lagoa Santa, Minas Gerais, Brasil. SaBios: Rev. Saúde e Biol; v.6, n.1, p.60-66, jan./abr; 2011.

PEREIRA, B. A. D. S; VENTUROLI, F; CARVALHO, F. A. Florestas estacionais no cerrado: uma visão geral. Pesq. Agropec. Trop. 41: 446-455. 2011.

PEREZ, C. P. Paleoecologia de mamíferos viventes como ferramenta na caracterização do ambiente holocênico de Lagoa Santa, MG. Dissertação de Mestrado. Universidade de São Paulo. 2009;

PERLES, C. Economie de la matiere première et economie de debitage. In: Prehistoire et Technologie lithique. Org. Tixeir. CNRS. Paris. 1979. 
PERRY, L. Prehispanic Subsistence in the Middle Orinoco Basin: Starch Analyses Yield New Evidence. PhD diss; Department of Anthropology, Southern Illinois university at Carbondale, Cardondale, 2001.

PERRY, L. Starch analyses reveal the relationship between tool type and function: an example from the Orinoco valley of Venezuela. Journal of Archaeological Science, vol. 31, p. 1069-1081, 2004.

PERRY, L. Starch Extraction Protocol. Disponível em: <http://fossilfarm.org/Methods/Methods/Protocol.html> Acesso em julho de 2016, publicado em 2010.

PERRY, L; SANDWEISS, D. H; PIPERNO, D. R; RADEMAKER, K; MALPASS, M. A; UMIRE, A; DE LA VERA, P. Early maize agriculture and interzonal interaction in southern Peru. Nature, vol. 440, p. 76-79, 2006.

PILÓ L. B. Morfologia cárstica e materiais constituintes: dinâmica e evolução da depressão poligonal Macacos-Baú - Carste de Lagoa Santa, MG. 1998.

PILÓ, L. B. Geomorfologia Cárstica. Revista Brasileira de Geomorfologia, v ol.1, n. 1, 88-102, 2000.

PILÓ, L. B. Morfologia cárstica e materiais constituintes: dinâmica e evolução da Depressão Poligonal Macacos-Baú - Carste de Lagoa Santa, Minas Gerais. Tese de Doutorado, Universidade de São Paulo, 1998.

PILÓ, L. B; AULER, A. S; NEVES, W. A; WANG, X; CHENG, H; EDWARDS, R. L. Geochronology, sediment provenance, and fossil emplacement at Sumidouro Cave, a classic late Pleistocene/early Holocene Paleoanthropological site in eastern Brazil. Geoarchaeology, 20, 751-764. 2005.

PIPERNO D. R. Phytoliths: A comprehensive guide for archaeologists and paleoecologists. Oxford: Altimira Press; 2006.

PIPERNO, D. R. A comparison and differentiation of phytoliths from maize and wild grasses: use of morphological criteria, American Antiquity, 49, 361-383, 1984.

PIPERNO, D. R. Paleoethnobotany in the Neotropics from Microfossils: New Insights into Ancient Plant Use and Agricultural Origins in the Tropical Forest. Journal of World Prehistory, Vol. 12, No. 4, 1998.

PIPERNO, D. R. Phytolith Analysis: an archaeological and geological perspective. Academic Press, 284 pp, 1988.

PIPERNO, D. R. The Origins of Plant Cultivation and Domestication in the New World Tropics: Patterns, Process, and New Developments. Current Anthropology , Vol. 52, No. S4, pp. S453-S470, 2011.

PIPERNO, D. R; HOLST, I. The presence of starch grains on prehistoric stone tools from the humid neotropics: indications of early tuber use and agriculture in Panama. Journal of Archaeological Science, 25:765-776. 1998. 
PIPERNO, D. R; PEARSALL, D. M. The Origins o f Agriculture in the Lowland Neotropics. Academic Press, vol. 14, 400 p; 1998.

PIPERNO, D. R; RANERE, A. J; HOLST, I; HANSELL, P. Starch grains reveal early root crop horticulture in the Panamanian tropical forest. Nature, vol. 407, p. 894-897, 2000.

PORSANI, J. L; JANGELME, G. M; KIPNIS, R. GPR survey at Lapa do Santo archaeological site, Lagoa Santa Karstic region, Minas Gerais State, Brazil. Journal of Archaeological Science, 37, 1141-1148, 2010.

POSEY, D. A. Indigenous management of tropical forest ecosystems: the case of the Kayapó Indians of the Brazilian Amazon. Agroforestry Systems 3(2):139-158; 1985.

POSEY, D. A. Interpreting and Applying the "Reality" of Indigenous Concepts: what is necessary to learn from the natives?. In: Redford, K.H. \& Padoch, C. (eds.). Conservation of Neotropical Forests: working from traditional resource use. New York: Columbia University Press, 1992, pp. 21-34.

POSTH, C; NAKATSUKA, N; LAZARIDIS, I; SKOGLUND,, P; MALLICK, S; LAMNIDIS, T; ROHLAND, N; NAGELE, K; ADAMSKI, N; BERTOLINI, E; BROOMANDKHOSHBACHT, N; COOPER, A; CULLETON, B; FERRAZ, T; FERRY, M; FURTWANGLER, A; HAAK, W; HARKINS, K; HARPER, T; HUNEMEIER, T; LAWSON, A. M; LLAMAS, B; MICHEL, M; NELSON, E; OPPENHEIMER, J; PATTERSON, N; SCHIFFELS, S; SEDIG, J; STEWARDSON, K; TALAMO, S; WANG, C; HUBLIN,J; HUBBE, M; HARVATI, K; DELAUNAY, A. $\mathrm{N}$; BEIER, J; FRANCKEN, $\mathrm{M}$; KAULICKE, P; REYES-CENTENO, $\mathrm{H}$; RADEMAKER, K; TRASK, W; ROBINSON, M; GUTIERREZ, S; PRUFER, K. M; SALAZAR-GARCIA, D. C; CHIM, E. N; GOMES, L. M. P; ALVES, M. L; LIRYO, A; INGLEZ, M; OLIVEIRA, R. E; BERNARDO, D. V; BARIONI, A; WESOLOWSKI, V; SCHEIFLER, N. A; RIVERA, M. A; PLENS, C. R; MESSINEO, P. G; FIGUTI, L; CORACH, D; SCABUZZO, C; EGGERS, S; DEBLASIS, P; REINDEL, M; MENDEZ, C; POLITIS, G; TOMASTO-CAGIGAO, E; KENNETT, D. J; STRAUSS, A; FEHREN-SCHMITZ, L; KRAUSE, J; REICH, D. Reconstructing the Deep Population History of Central and South America. CELL, vol. 175, issue 5, p1185-1197.e22, november 15, 2018.

POULSON, T. L; WHITE, W. B. The Cave Environment. Science, 165(3897), 971981, 1969.

POWELL, J. F; NEVES, W. A. Craniofacial morphology of the First Americans: pattern and process in the peopling of the New World. Yearbook of Physical Anthropology, 42, 153-188. 1999.

PROUS, A. As Missões arqueológicas desenvolvidas na região de Lagoa Santa na segunda metade do século XX. Cap 7. IN: DA-GLORIA, P; NEVES, W. A; HUBBE, M (Orgs). Lagoa Santa: História das Pesquisas Arqueológicas e Paleontológicas. São Paulo: Annablume Arqueológica, p. 111-130, 2016.

PROUS, A. Santana do Riacho - Tomo I. Arquivos do Museu de História Natural 12, 1991. 
PROUS, A; LIMA, M. A. A tecnologia de debitagem do quartzo no centro de Minas Gerais: lascamento bipolar. Arquivos do Museu de História Natural da UFMG 11:91-111, 1986.

PUGLIESE, Jr. F. Os Líticos de Lagoa Santa: um estudo sobre organização tecnológica de caçadores-coletores do Brasil Central. $154 \mathrm{f}$. Dissertação de Mestrado Museu de Arqueologia e Etnologia, Universidade de São Paulo, São Paulo, 2007.

RABARDEL, P. Les Hommes et les technologies: Approche cognitive des instruments contemporains. Paris: Armand Colin, 193 p; 1995.

RACZKA, M. F. Mudanças Paleoambientais Quaternárias na Região de Lagoa Santa, MG, Brasil: A Palinologia como Subsídio para o Entendimento do Padrão de Ocupação Humana. Dissertação de Mestrado. Universidade Guarulhos. 2009.

RACZKA, M. F; OLIVEIRA, P. E; BUSH, M; MCMICKAEL, C. H. Two paleoecological histories sapnning the period of human settlement in southeastern Brazil. Journal of Quaternary Science, 28 (2), 144-151, 2013.

RAMOS, M. P. M. AS INDÚSTRIAS LÍTICAS DO HOLOCENO MÉDIO NO SÍTIO GO JA-01: UMA REAVALIAÇÃO A PARTIR DA ABORDAGEM TECNOFUNCIONAL. 308 f., 2016.

RAVEN, P. H; EVERT, R. F; EICCHORN, S. E. Biologia Vegetal. 6.ed. Rio de Janeiro: Guanabara Koogan, 928p; 2001.

RAVEN. Biologia Vegetal. Ray F. Evert e Susan E. Eichhorn; revisão técnica Jane Elizabeth Kraus; tradução Ana Claudia M. Vieira... [et.al.]. - 8. ed. - Rio de Janeiro: Guanabara Koogan, 2014.

READ, D. Intuitive typology and automatic classification: Divergence or full circle? Journal of Anthropological Archaeology, 8(2):158-188, 1989.

REICHERT, E. T. The differentiation and specificity of starches in relation to genera, species, Etc: Stereochemistry Applied to Protoplasmic Processes and Products, and as a Strictly Scientific Basis for the Classification of Plants and Animals. Washington: Carnegie institution, 1913.

REIS, S. P. W; BARBOSA, F. A. R. Estudo da composição de macrófitas aquáticas da Lagoa dos Mares, município de Lagoa Santa, com ênfase em aspectos ecológicos de Salvinia herzogii (Aubl). Acta Limnol. Brasil. VI:196-208. 1993.

RENFREW, C; BAHN, P. Arqueología: teorías, métodos y práctica. Madrid: Ediciones Akal, 640p; 1998.

ROBERTSON, G. Aboriginal craft and subsistence activities at Native Well I and Native Well II, Central Western Highlands, Queensland: results of a residue and usewear analysis of backed artefacts. In: HASLAM, M; ROBERTSON, G; CROWTHER, A; NUGENT, S; KIRKWOOD, L. (Eds.). Archaeological Science Under a Microscope: Studies in residue and ancient DNA analysis in honour to Thomas H. Loy. Canberra: ANU E Press, vol. 30, p. 259-257, 2009. 
ROBYT, J. F. Polysaccharides: Energy Storage. ENCYCLOPEDIA OF LIFE SCIENCES, John Wiley \& Sons, Ltd. 2001.

RODET, M. J; DUARTE-TALIM, D; BARRI, L. F. Reflexões sobre as primeiras populações do Brasil Central: "Tradição Itaparica". Habitus, Goiânia: v. 9, n.1, p. 81100, jan./jun. 2011.

RODRIGUES, I. M. M; GARDIMAN, G. G DIAS JUNIOR; CHEUICHE, L; CARVALHO, E. "Fase Belvedere: Uma Fase Tupiguarani do Estado de Minas Gerais". Boletim do Instituto de Arqueologia Brasileira, N.7, pp.5-17, Rio de Janeiro, 1975.

ROTS, V; HAYES, E; CNUTS, D; LEPERS, C; FULLAGAR, R. Making Sense of Residues on Flaked Stone Artefacts: Learning from Blind Tests. PLOS ONE, 38 pp; 2016.

RUFINO, M. U. L. Fitólitos como subsídio para estudos de reconstrução da vegetação e indicador de mudanças hidrológicas em solos tropicais. Dissertação de Mestrado, Universidade Federal de Pernambuco, Recife, 55 pp; 2007.

RUPRECHT, F. J. Geobotanical investigations on chernozem. USSR, Academy of Science, 1866.

SAMUEL, D. Modified Starch. In: BARTON, H; TORRENCE, R. Ancient Starch Research. California: Left Coast Press, p. 205-216, 2006.

SANDWEISS, D. H. Small is big: The Microfossil Perspective on Human-Plant Interaction. Proceedings of the National Academy of Sciences of the United States of America (PNAS), vol. 104, n. 9, p. 3021-3022, 2007.

SCHEEL-YBERT, R. Editorial: Arqueobotânica na América do Sul: Paisagem, subsistência e uso de plantas no passado. In: SCHEEL-YBERT, R. (Org). DOSSIE ARQUEOBOTÂNICA NA AMÉRICA DO SUL. Cadernos do LEPAARQ, Vol. XIII, $\mathrm{n}^{\circ} 25, \mathrm{p} .118-130,2016$.

SCHEEL-YBERT, R. Man and Vegetation in Southeastern Brazil during the Late Holocene. Journal of Archaeological Science 28, 471-480, 2001.

SCHIFFER, M. B. Behavioral archaeology: origins and the four strategies. In: M.B. Schiffer. Behavioral Archaeology. Principles and Practice. London/Oakville, EQUINOX Publ.Ltda. pp.3-8, 2010.

SCHMITZ, P. I. Prehistoric Hunters and Gatherers of Brazil. Journal of World Prehistory, vol. 1(I), p. 53-125, 1987.

SCHMITZ, P.I.; ROGGE, J.H. Um sítio da tradição cerâmica Aratu em Apucarana, PR. Revista do Museu de Arqueologia e Etnologia, São Paulo, 18: 47-68, 2008.

SHANNON, I. L; EDMONDS E. J; MADSEN K. O. Honey: sugar content and cariogenicity. Journal of Dentistry for Children, vol. 33, p. 46:29, 1979.

SHINZATO, E. S; LUMBRERAS, J. F (Orgs.). Caracterização pedológica. - Belo Horizonte: IBAMA/CPRM, 1998. 
SIGAUT, F. Technology. In: INGOLD, T. (Ed.) Companion Encyclopedia of Anthropology, London, Routledge, p. 420-459, 2002.

SIMONDON, Gilbert. El modo de existencia de los objetos técnicos. Paris: AubierMontaigne, (Unidade I). p. 31-70, 1969.

SOUZA, S. M; LIRYO, A. The National Museum's Contributions to Lagoa Santa Research in the Second Half of the Twentieth Century. In: DA-GLORIA, P; NEVES, W. A; HUBBE, M. Archaeological and Paleontological Research in Lagoa Santa The Quest for the First Americans. Springer, 404 pp; 2017.

Strauss A, Hubbe M, Bernardo DV, Neves WA, Atui JPV. The cranial morphology of the Botocudo Indian. Brazil. American Journal of Physical Anthropology: 157:202-216. USA. English. 2015b.

STRAUSS, A. M. As práticas mortuárias dos caçadores-coletores pré-históricos da região de Lagoa Santa (MG): um estudo de caso do sítio arqueológico "Lapa do Santo". 742 f. Dissertação de Mestrado - Instituto de Biociências, Universidade de São Paulo, 2010.

STRAUSS, A. M. Os padrões de sepultamento do sítio arqueológico Lapa do Santo (Holoceno Inicial, Brasil). Bol. Mus. Para. Emílio Goeldi. Cienc. Hum; Belém, v. 11, n. 1, p. 243-276, 2016c.

STRAUSS, A. M. Paleoamerican origins and behavior: a multidisciplinary study of the archaeological record from Lagoa Santa region (east-central Brazil). 399 f. Tese de Doutorado - Mathematisch-Naturwissenschaftlichen Fakultät der Eberhard Karls Universität Tübingen, Tübingen, $2016 b$.

STRAUSS, A.; OLIVEIRA, R.E. A prática de individualização e de decapitação na região de Lagoa Santa durante o Holoceno Inicial (Brasil). R. Museu Arq. Etn; 28: 86108, 2017.

STRAUSS, A; OLIVEIRA, R. E; BERNARDO, D. V; SALAZAR-GARCÍA, D. C; TALAMO, S; JAOUEN, K; HUBBE, M; BLACK, S; WILKINSON, C; RICHARDS, M. P; ARAUJO, A. G. M; KIPNIS, R; NEVES, W. A. The Oldest Case of Decapitation in the New World (Lapa do Santo, East-Central Brazil). PLOS ONE, vol. 10,e0137456, p. 1-31, 2015.

STRAUSS, A; OLIVEIRA, R. E; VILLAGRAN, X. S; BERNARDO, D. V; SALAZAR-GARCÍA D. C; BISSARO, M. C/ PUGLIESE, F; HERMENEGILDO, T; SANTOS, R; BARIONI; OLIVEIRA, E. C; MORENO DE SOUSA, J. C; JAOUEN, K; ERNANI, M; HUBBE, M; INGLEZ, M; GRATÃO, M.; ROCKWELL, H; MACHADO, M; SOUZA, G; CHEMALE, FARID; KAWASHITA, K; O'CONNELL, T. C; ISRADE, I; FEATHERS, J; CAMPI, C; RICHARDS, M; WAHL, J; KIPNIS, R; ARAUJO, A; NEVES, W. Early Holocene ritual complexity inSouth America: the archaeologicalrecord of Lapa do Santo (east-centralBrazil). Antiquity, vol. 90, n 354 (Dec), p. 1454-1473, 2016.

TANNÚS, M. B (Org). Uso da terra e caracterização da cobertura vegetacional: Município de Sete Lagoas. Informações Básicas para Gestão Territorial. GATE. Projeto 
VIDA - Viabilidade Industrial e Defesa Ambiental. Belo Horizonte: CPRM/CETEC, 1996.

TIXIER, J. A Method for the Study of Stone Tools: Méthode pour L'Étude desOutillages Lithiques. Luxemburgo: Centre National de Recherche Archéologique du Louxembourg, vol. 1, 195 p; 2012.

TORRENCE, R. Description, Classification, and Identification. In: BARTON, H; TORRENCE, R. Ancient Starch Research. Left Coast Press, p.115-143, 2006a.

TORRENCE, R. Starch and Archaeology. In: BARTON, H; TORRENCE, R. Ancient Starch Research. Left Coast Press, p.17-33, $2006 b$.

TRIGGER, Bruce G. História do Pensamento Arqueológico. São Paulo. Odysseus Editora. 2004.

VIALOU, D; BENABDELHADI, M; FEATHERS, J; FONTUGNE, M; VIALOU, A. V. Peopling South America's centre: the late Pleistocene site of Santa Elina. Antiquity 91358 (2017): 865-884, 2017.

VIANA, H. A; KOHLER, H. C; TAVARES, V. P (Orgs.). Síntese da geologia, recursos minerais e geomorfologia; Belo Horizonte: IBAMA/CPRM, 1998.

VIANA, S. A. Variabilidade tecnológica do sistema de debitagem e de confecção dos instrumentos líticos lascados de sítios lito-cerâmicos da região do Rio Manso/MT. 2005. 340 f. Tese de Doutorado - Programa de Pós-Graduação em história, Pontifícia Universidade Católica do Rio Grande do Sul, Porto Alegre, 2005.

VIEIRA, L. C. A Formação Sete Lagoas (Grupo Bambuí) e as variações paleoambientais no final do Proterozóico. Tese de doutorado. Universidade de São Paulo. 198 pp. 2007.

VILLAGRAN, X. S; STRAUSS, A; MILLER, C; LIGOUIS, B; OLIVEIRA, R. Buried in ashes: formation processes at Lapa do Santo rockshelter, east-central Brazil. Journal of Archaeological Science, vol. 30, p. 1-25, 2017.

VOLKMER-RIBEIRO, C; MACHADO, V. S. Freshwater sponges (Porifera, Demospongiae) indicators of some coastal habitats in South America: redescriptions and key to identification. Iheringia, Sér. Zool; Porto Alegre, 97(2):157-167, 2007.

WALTER, H. V. Arqueologia da região de Lagoa Santa. SEDEGRA, Rio de Janeiro, 1958.

WALTER, H. V. Arqueologia da região de Lagoa Santa, Minas Gerais. Rio de Janeiro: Sociedade Editora e Gráfica Ltda. 1958.

WARMING, E. Lagoa Santa: Contribuição para a geographia phytobiologica. Belo Horizonte: Imprensa Oficial do Estado de Minas Gerais. 282 pp. 1908.

WARMING, E. Lagoa Santa: Et Bidrag til den biologiske Plantegeografi. Copenhague: B. Luno. 1892. 
WATLING, J. G. Environmental Impact of the Pre-Columbian Geoglyph Builders of Western Amazonia. $367 \mathrm{f}$. Tese de Doutorado. College of Humanities, University of Exeter, 2014.

WATLING, J. G; IRIARTE, J; MAYLEC, F. E; SCHAAND, D; PESSENDA, L. C. R; LOADER, N. J; STREET-PERROTT, F. A; DICKAU, R. E; DAMASCENO, A; RANZO, A. Impact of pre-Columbian "geoglyph" builders on Amazonian forests. Proceedings of the National Academy of Sciences of the United States of America (PNAS), vol. 114(8), p. 1-6, 2016.

WATLING, J. G; IRIARTE, J; WHITNEY, B. S; MAYLE, F; CASTRO, W; SCHAAN, D; FELDPAUSH, T. R. Differentiation of neotropical ecosystems by modern soil phytolith assemblages and its implications for palaeoenvironmental and archaeological reconstructions II: Southwestern Amazonian forests. Review of Palaeobotany and Palynology 226, 30-43, 2016 b.

WATLING, J; SAUNALUOMA, S; PARSSINEN, M; SCHAAN, D. Subsistence practices among earthwork builders: phytolith evidence from archaeological sites in the southwest Amazonian interfluves. J Archaeol Sci Reports, 4:541-51, 2015.

WATLING, J; SHOCK M, P; MONGELO G. Z; ALMEIDA F, O; KATER T, OLIVEIRA, P. E; NEVES, E. G. Direct archaeological evidence for Southwestern Amazonia as an early plant domestication and food production centre. PLoS ONE 13(7): e0199868, 2018.

WESOLOWSKI, V. Cáries, desgaste, cálculos dentários e micro-resíduos da dieta entre grupos pré-históricos do litoral norte de Santa Catarina: É possível comer amido e não ter cárie? 2007. 192 f. Tese de Doutorado. Fundação Oswaldo Cruz. Escola Nacional de Saúde Pública Sérgio Arouca, 2007.

WESOLOWSKI, V. Micro-vestígios vegetais: o que os olhos não vêem. In: GASPAR, M; SOUZA S. M. Abordagens Estratégicas em Sambaquis, FAPERJ, Habilis Editora, Erechim, RS, 219-235, 2013.

WESOLOWSKI, V; MENDONÇA DE SOUZA, S. M. F; KARL REINHARD, K; CECCANTINI, G. Grânulos de amido e fitólitos em cálculos dentários humanos: contribuição ao estudo do modo de vida e subsistência de grupos sambaquianos do litoral sul do Brasil. Revista do Museu de Arqueologia e Etnologia, São Paulo, 17: 191-210, 2007.

WESOLOWSKI, V; MENDONÇA DE SOUZA, S. M. F; KARL REINHARD, K; CECCANTINI, G. Evaluating microfossil content of dental calculus from Brazilian sambaquis. Journal of Archaeological Science, p. 1-13, 2010.

WILLIAMSON, B. Investigation of potencial contamination on stone tools. In: BARTON, H; TORRENCE, R. Ancient Starch Research. California: Left Coast Press, p. 89-90, 2006.

WINTON, A, L; WINTON, K. G. B. The Structure and Composition of Foods. Universidade de Michigan, Editora Wiley, 1932. 
WINTON, A. L; WINTON, K. G. B. Norwalk Potteries. Friends of Lockwood House, 40p, 1981.

WINTON, A. L; WINTON, K. G. B. The Analysis of Food. Universidade de Michigan, Editora Wiley, 999p, 1945.

XHAUFLAIR, H; PAWLIK, A; FORESTIER, H; SAOS, T; DIZON, E; GAILLARD, C. Use related or contamination? Residue and use-wear mapping on stone tools used for experimental processing of plants from Southeast Asia. Quaternary International, 1e14, 2016.

YANG, X; PERRY, L. Identification of ancient starch grains from the tribe Triticeae in the North China Plain. Journal of Archaeological Science, 40, 3170e3177, 2013. 
ANEXOS 


\begin{tabular}{|c|c|}
\hline Local & Táxons botânicos identificados \\
\hline $\begin{array}{l}\text { Lagoa Santa } \\
\text { (Warming, 1892; 1908) }\end{array}$ & $\begin{array}{l}\text { Floresta: } \\
\text { Mimosaceae: Acacia polyphylla (monjoleiro) } \\
\text { Anacardiaceae: Astronium fraxinifolium (gonçalo } \\
\text { alves) Tapirira guianensis (pau pombo) } \\
\text { Caesalpiniaceae: Cassia ferruginea (chuva de ouro), } \\
\text { Hymenea stilbocarpa (jatobá), } \\
\text { Meliaceae: Cedrella fissilis (cedro) } \\
\text { Bombacaceae: Chorisia speciosa (barriguda) } \\
\text { Burseraceae: Protium heptaphyllum (breu branco) } \\
\text { Vochysiaceae: Vochysia tucanorum (pau de tucano) } \\
\text { Cerrado: } \\
\text { Caryocaraceae: Caryocar brasiliensis (pequi) } \\
\text { Vochysiaceae: Qualea grandiflora (pau terra grande) } \\
\text { Clusiaceae: Kielmeyera coriacea (pau santo) }\end{array}$ \\
\hline $\begin{array}{l}\text { Lagoa da Cauaia } \\
\text { Lapinha } \\
\text { Castelo da Jaguara } \\
\text { Vargem Comprida } \\
\text { (Hermann et al; 1998). }\end{array}$ & $\begin{array}{l}\text { Floresta: } \\
\text { Acacia sp. (unha de gato) } \\
\text { Acosmium cardenasii (alecrim) } \\
\text { Acrocomia aculeata (macaúba) } \\
\text { Anadenanthera peregrina (angico) } \\
\text { Callisthene dryadum } \\
\text { Casearia sylvestris (guaçatonga) } \\
\text { Copaifera langsdorffii (copaíba) }\end{array}$ \\
\hline & \\
\hline
\end{tabular}




\begin{tabular}{|c|c|}
\hline Local & Táxons botânicos identificados \\
\hline & $\begin{array}{l}\text { Cupania vernalis (camboatá) } \\
\text { Dalbergia nigra (jacarandá) } \\
\text { Deguelia costata (pau carrapato) } \\
\text { Eugenia brasiliensis (jaboticabinha) } \\
\text { Galipea jasminiflora (Grumixara) } \\
\text { Ilicura militaris (tangarazinho) } \\
\text { Mabea fistulifera (canudo de pito) } \\
\text { Machaerium cf. lanceolatum (jacarandá) } \\
\text { Myracrodruon urundeuva (aroeira) } \\
\text { Myrcia rostrata (guamirim) } \\
\text { Myrcia sp. (guamirim) } \\
\text { Myrciaria floribunda (cambuíva) } \\
\text { Nectandra sp. (canela) } \\
\text { Psychotria florestana } \\
\text { Priper amalago (pimenta-demorcego) } \\
\text { Platymiscium pubescens (roxinho) }\end{array}$ \\
\hline $\begin{array}{l}\text { Mata Poções } \\
\text { Mata da Horta } \\
\text { (Hermann et al; 1998) }\end{array}$ & $\begin{array}{l}\text { Floresta: } \\
\text { Acosmium cardenasii (alecrim) } \\
\text { Allophylus sericea (baga de morcego) }\end{array}$ \\
\hline
\end{tabular}




\begin{tabular}{|c|c|}
\hline Local & Táxons botânicos identificados \\
\hline & 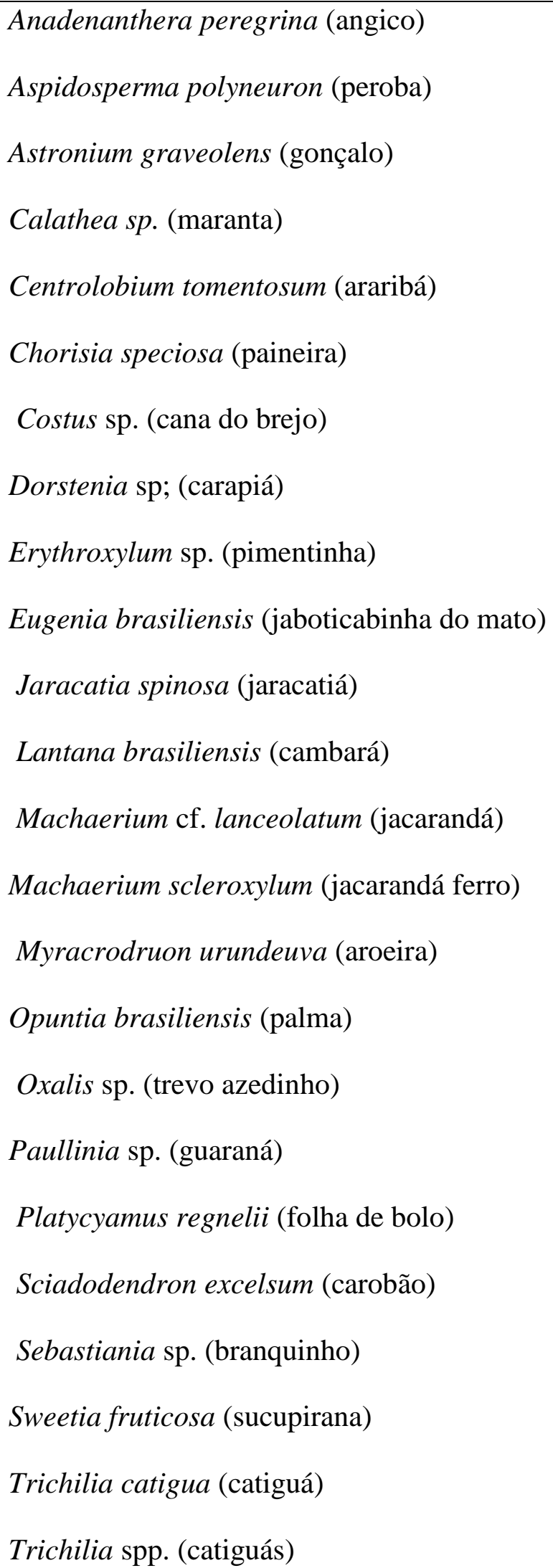 \\
\hline
\end{tabular}




\begin{tabular}{|c|c|}
\hline Local & Táxons botânicos identificados \\
\hline $\begin{array}{l}\text { Mata Infraero } \\
\text { (Hermann et al; 1998) }\end{array}$ & $\begin{array}{l}\text { Copaifera langsdorffii (copaíba) } \\
\text { Dalbergia miscolobium (caviúna) } \\
\text { Mabea fistulifera (canudo de pito) } \\
\text { Machaerium opacum (jacarandá) } \\
\text { Myrsine ferruginea (capororoca) } \\
\text { Ocotea acutifolia (canela) }\end{array}$ \\
\hline $\begin{array}{l}\text { Sumidouro } \\
\text { Império, } \\
\text { Infraero } \\
\text { Promissão } \\
\text { (Hermann et al; 1998) }\end{array}$ & $\begin{array}{l}\text { Aspidosperma tomentosum (peroba do campo) } \\
\text { Banisteriopsis malifolia (cipó prata) } \\
\text { Brosimum gaudichaudi (marmelada de cachorro) } \\
\text { Siparuna guianensis (folha santa) } \\
\text { Byrsonima coccolobifolia (murici) } \\
\text { Pouteria ramiflora (curriola) } \\
\text { Cabralea cangerana (cangerana) } \\
\text { Caryocar brasiliense (pequizeiro), } \\
\text { Copaifera langsdorffii (copaíba) } \\
\text { Dalbergia miscolobium (jacarandá) } \\
\text { Didymopanax macrocarpum (mandiocão), } \\
\text { Xylopia aromatica (pimenta de macaco) } \\
\text { Erythroxylum campestre (mercúrio do campo) } \\
\text { Piptocarpha rotundifolia (candeião) } \\
\text { Myracrodruon urundeuva (aroeira) } \\
\text { Miconia albicans (canela de velho) } \\
\text { Lucoriacea (pau santo) }\end{array}$ \\
\hline
\end{tabular}




\begin{tabular}{|c|c|}
\hline Local & Táxons botânicos identificados \\
\hline & $\begin{array}{l}\text { Miconia spp. (pixirica) } \\
\text { Myrcia variabilis, } \\
\text { Myrsine venosa (capororoca) } \\
\text { Plathymenia reticulata (vinhático) } \\
\text { Sclerolobium paniculatum (angá branco do cerrado) } \\
\text { Platypodium elegans (jacarandá canzil) } \\
\text { Qualea grandiflora (pau terra grande) } \\
\text { Qualea parviflora (pau terra pequeno) } \\
\text { Qualea spp. (pau terra) } \\
\text { Rudgea viburnoides (congonha-debugre) } \\
\text { Serjania sp. (cipó-timbó) } \\
\text { Siparuna guianensis (folha santa) } \\
\text { Sthryphnodendron adstringens (barbatimão) } \\
\text { Tapirira guianensis (pau pombo) } \\
\text { Terminalia argentea (capitão do campo), } \\
\text { Tocoyena formosa (jenipapo de cavalo) } \\
\text { Xylopia aromatica (pimenta de macaco) } \\
\text { (maria pobre) }\end{array}$ \\
\hline $\begin{array}{l}\text { Lagoa dos Mares (município } \\
\text { de Lagoa Santa) } \\
\text { (Reis \& Barbosa, 1993) }\end{array}$ & $\begin{array}{l}\text { Macrófitas aquáticas: } \\
\text { Eicchornia azurea } \\
\text { Hydrocleis nymphoides } \\
\text { Nymphaea ampla } \\
\text { Salvinia herzogii }\end{array}$ \\
\hline
\end{tabular}




\begin{tabular}{|c|c|}
\hline Local & Táxons botânicos identificados \\
\hline & Cyperus sp. \\
\hline $\begin{array}{l}\text { Lagoa Olhos D’água } \\
\text { (município de Lagoa Santa) } \\
\text { (Pelli \& Barbosa, 2011) }\end{array}$ & $\begin{array}{l}\text { Myzus persicae } \\
\text { Samea multiplicalis } \\
\text { Salvinia molesta }\end{array}$ \\
\hline $\begin{array}{l}\text { Sete Lagoas } \\
\text { (Tannús, 1996) }\end{array}$ & 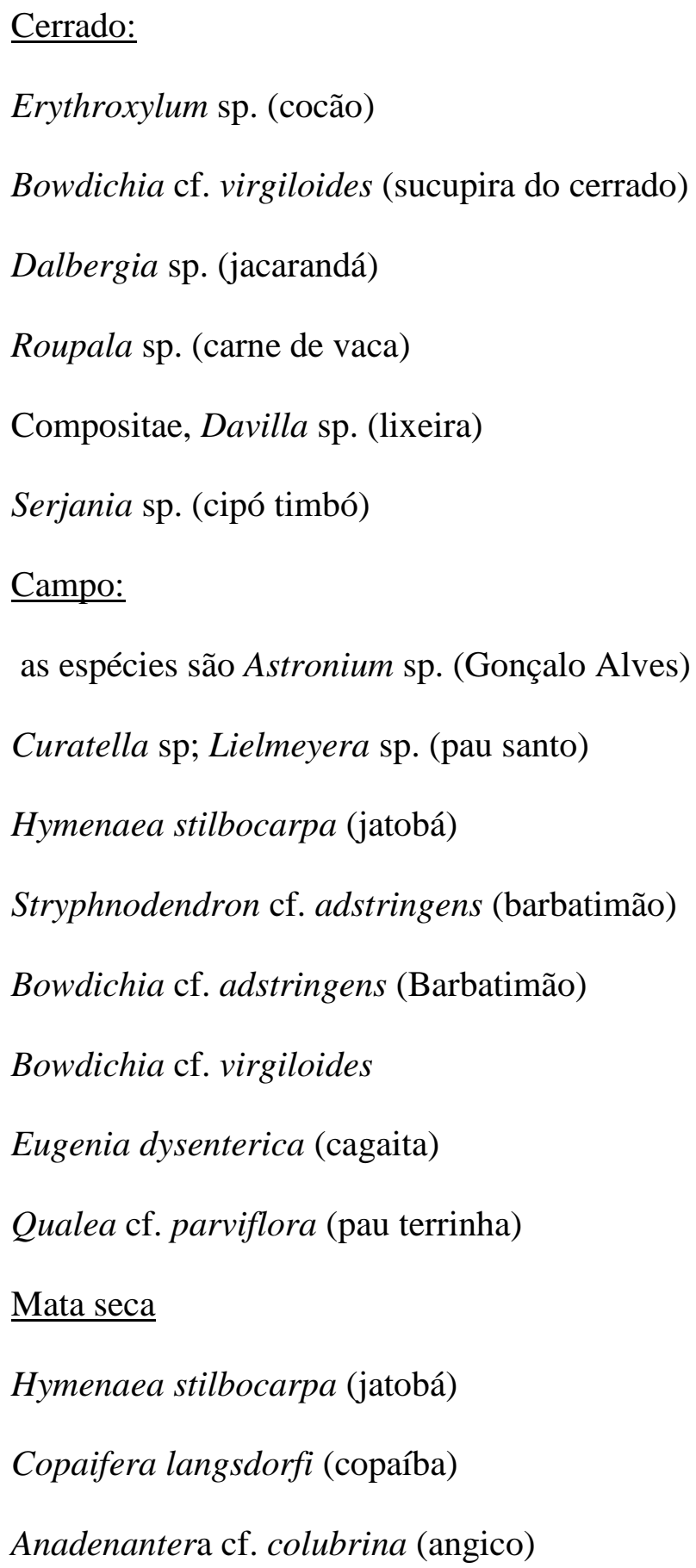 \\
\hline
\end{tabular}




\begin{tabular}{|l|l|}
\hline Local & $\begin{array}{l}\text { Táxons botânicos identificados } \\
\text { Sobre rochas calcárias: } \\
\text { Anacadiaceae Astronium sp. } \\
\text { Leguminosae Bauhinia sp. (unha de vaca) } \\
\text { Orchidiaceae } \\
\text { Bromeliaceae } \\
\text { Cactaceae } \\
\text { Mata pluvial: } \\
\text { Copaifera langsdorfi } \\
\text { Tabebuia sp. (ipê amarelo) } \\
\text { Ocotea sp. (canela) } \\
\text { Vitex sp. (tarumã) } \\
\text { Cupania sp. (camboatá) } \\
\text { Sclenia sp. (campim navalha) } \\
\text { Pasto: } \\
\text { Bacchiaria spp. (gramínea braquiária) } \\
\text { Melinis minutiflora (capim gordura) } \\
\text { Hyparrheni rufa (jaraguá) }\end{array}$ \\
\hline
\end{tabular}




\section{ANEXO II}

Tabela 16. Medições dos líticos em valores absolutos.

\begin{tabular}{|c|c|c|c|c|c|}
\hline QD. & $\mathrm{PN}$ & NÍV. (CM) & $\begin{array}{c}\text { COMPRIMENTO } \\
(\mathrm{mm})\end{array}$ & $\begin{array}{l}\text { LARGURA } \\
(\mathrm{mm})\end{array}$ & $\begin{array}{c}\text { ESPESSUR } \\
\text { A }(\mathrm{mm})\end{array}$ \\
\hline $\mathrm{N} 23$ & 13014 & $6(50-60)$ & 73 & 50 & 24 \\
\hline $\mathrm{N} 23$ & 14017 & $6(50-60)$ & 27 & 19 & 9 \\
\hline $\mathrm{N} 23$ & 13067 & $6(50-60)$ & 16 & 13 & 7 \\
\hline $\mathrm{N} 23$ & 13885 & $6(50-60)$ & 9 & 3 & 3 \\
\hline $\mathrm{N} 23$ & 14029 & $6(50-60)$ & 22 & 22 & 6 \\
\hline $\mathrm{N} 23$ & 13120 & $6(50-60)$ & 23 & 19 & 7 \\
\hline $\mathrm{N} 23$ & 13962 & $6(50-60)$ & 7 & 9 & 2 \\
\hline $\mathrm{P} 11$ & 14292 & $15(140-150)$ & 29 & 14 & 8 \\
\hline P11 & 14385 & $16(150-160)$ & 23 & 16 & 7 \\
\hline $\mathrm{P} 11$ & 14391 & $16(150-160)$ & 18 & 19 & 7 \\
\hline $\mathrm{P} 11$ & 14410 & $16(150-160)$ & 22 & 7 & 4 \\
\hline P11 & 14469 & $16(150-160)$ & 24 & 15 & 5 \\
\hline P11 & 14369 & $16(150-160)$ & 20 & 15 & 6 \\
\hline A1 & 14267 & $2(10-20)$ & 39 & 23 & 16 \\
\hline $\mathrm{A} 1$ & 14236 & $2(10-20)$ & 26 & 31 & 22 \\
\hline A1 & 14355 & $3(20-30)$ & 38 & 10 & 12 \\
\hline A1 & 14335 & $3(20-30)$ & 42 & 37 & 10 \\
\hline $\mathrm{A} 1$ & 14353 & $3(20-30)$ & 56 & 26 & 23 \\
\hline A1 & 14297 & $3(20-30)$ & 35 & 56 & 20 \\
\hline SEP.39 & 14192 & 13(120-130) & 18 & 16 & 5 \\
\hline
\end{tabular}




\section{ANEXO 3}

Ficha de Análise de Fitólitos de Líticos Sonicados

\begin{tabular}{|c|c|c|c|c|c|c|c|c|c|c|c|c|c|c|}
\hline \multirow[b]{3}{*}{ QD. } & \multirow[b]{3}{*}{ PN } & \multirow[b]{3}{*}{ CODE } & \multirow[b]{3}{*}{ NíV. (CM) } & \multicolumn{4}{|c|}{ Poaceae } & \multirow{3}{*}{$\begin{array}{c}\text { Chloridoideae } \\
\text { Saddle } \\
\end{array}$} & \multirow{3}{*}{$\begin{array}{c}\text { Panicoideae } \\
\text { Bilobate } \\
\end{array}$} & \multirow{2}{*}{\multicolumn{2}{|c|}{ Zea mays }} & \multirow{2}{*}{\multicolumn{3}{|c|}{ Non-diagnostic Poaceae }} \\
\hline & & & & \multirow{2}{*}{$\begin{array}{c}\text { Aristidoideae } \\
\text { Bilobate }\end{array}$} & \multicolumn{3}{|c|}{ Bambusoideae } & & & & & & & \\
\hline & & & & & Bilobate & Collapsed saddle & 3-spiked rondel & & & Cross v1 & Wavy-top rondel & Bulliform & Cross Other Variants & Rondel \\
\hline $\mathrm{N} 23$ & 13014 & $\underline{\mathrm{D} 27-\mathrm{S}}$ & $6(50-60)$ & 2 & 1 & 5 & 1 & 5 & 32 & 1 & 0 & 8 & 1 & 1 \\
\hline $\mathrm{N} 23$ & 14017 & $\underline{\mathrm{D} 45-\mathrm{S}}$ & $6(50-60)$ & 0 & 0 & 0 & 0 & 0 & 0 & 0 & 0 & 1 & 2 & 1 \\
\hline $\mathrm{N} 23$ & 13067 & D43-S & $6(50-60)$ & 0 & 0 & 0 & 0 & 0 & 0 & 0 & 0 & 1 & 0 & 0 \\
\hline $\mathrm{N} 23$ & 13885 & D40-S & $6(50-60)$ & 0 & 0 & 0 & 0 & 0 & 0 & 1 & 0 & 0 & 0 & 0 \\
\hline $\mathrm{N} 23$ & 14029 & $\underline{\mathrm{D} 42-\mathrm{S}}$ & $6(50-60)$ & 0 & & 0 & 0 & 0 & 0 & 0 & 0 & 2 & 0 & 0 \\
\hline $\mathrm{N} 23$ & 13120 & D44-S & $6(50-60)$ & 0 & 0 & 0 & 0 & 0 & 0 & 0 & 0 & 0 & 0 & 0 \\
\hline $\mathrm{N} 23$ & 13962 & D41-S & $6(50-60)$ & 0 & 0 & 0 & 0 & 0 & 0 & 0 & 0 & 0 & 0 & 0 \\
\hline P11 & 14292 & D38-S & $15(140-150)$ & 0 & 0 & 0 & 0 & 0 & 0 & 0 & 0 & 3 & 0 & 0 \\
\hline P11 & 14385 & D34-S & $16(150-160)$ & 0 & 0 & 0 & 0 & 0 & 0 & 0 & 0 & 0 & 0 & 0 \\
\hline P11 & 14391 & D36-S & $16(150-160)$ & 0 & 0 & 0 & 0 & 0 & 2 & 1 & 0 & 1 & 1 & 0 \\
\hline P11 & 14410 & D35-S & $16(150-160)$ & 0 & 0 & 0 & 0 & 0 & 0 & 0 & 0 & 1 & 0 & 1 \\
\hline P11 & 14469 & D37-S & $16(150-160)$ & 0 & 0 & 0 & 0 & 0 & 0 & 0 & 0 & 0 & 0 & 0 \\
\hline P11 & 14369 & $\underline{\mathrm{D} 33-\mathrm{S}}$ & $16(150-160)$ & 0 & 0 & 0 & 0 & 0 & 0 & 0 & 0 & 0 & 0 & 0 \\
\hline A1 & 14267 & D29-S & $2(10-20)$ & 0 & 0 & 0 & 0 & 0 & 0 & 0 & 0 & 0 & 0 & 0 \\
\hline A1 & 14236 & D31-S & $2(10-20)$ & 0 & 0 & 0 & 0 & 0 & 0 & 0 & 0 & 1 & 0 & 0 \\
\hline A1 & 14355 & $\underline{\mathrm{D} 32-\mathrm{S}}$ & $3(20-30)$ & 0 & 0 & 0 & 0 & 1 & 0 & 0 & 0 & 0 & 0 & 0 \\
\hline A1 & 14335 & D30-S & $3(20-30)$ & 0 & 0 & 0 & 0 & 0 & 0 & 1 & 0 & 0 & 0 & 0 \\
\hline A1 & 14353 & $\underline{\mathrm{D} 46-\mathrm{S}}$ & $3(20-30)$ & 0 & 0 & 0 & 0 & 0 & 0 & 0 & 0 & 0 & 0 & 0 \\
\hline $\mathrm{A} 1$ & 14297 & D28-S & $3(20-30)$ & 0 & 0 & 0 & 0 & 0 & 0 & 0 & 0 & 1 & 0 & 0 \\
\hline SEP. 3 & 14192 & D47-S & $13(120-130)$ & 0 & 0 & 0 & 0 & 0 & 0 & 0 & 0 & 1 & 0 & 0 \\
\hline
\end{tabular}




\section{ANEXO 3}

Ficha de Análise de Fitólitos de Líticos Sonicados

\begin{tabular}{|c|c|c|c|c|c|c|c|c|c|c|c|c|c|}
\hline \multirow[b]{3}{*}{ CODE } & \multirow[b]{3}{*}{ NÍV. (CM) } & \multirow{2}{*}{\multicolumn{3}{|c|}{$\begin{array}{l}\text { Arecaceae } \\
\text { Arecaceae }\end{array}$}} & \multicolumn{2}{|c|}{ Cyperaceae } & \multirow{2}{*}{$\begin{array}{l}\text { Zingiberales } \\
\text { Zingiberales }\end{array}$} & \multirow{2}{*}{\multicolumn{3}{|c|}{$\begin{array}{l}\text { Eudicots } \\
\text { Eudicots }\end{array}$}} & \multicolumn{2}{|c|}{ Aquatic organisms } & \multirow{3}{*}{$\begin{array}{l}\text { Total de } \\
\text { fitólitos } \\
\text { contados }\end{array}$} \\
\hline & & & & & \multirow{2}{*}{$\begin{array}{l}\text { Cyperus/Kyllinga sp. } \\
\text { Stippled polygonal } \\
\text { cone }\end{array}$} & \multirow{2}{*}{\begin{tabular}{|l|} 
Non-diagnostic \\
polygonal stippled
\end{tabular}} & & & & & Algae & Porifera & \\
\hline & & $\begin{array}{l}\text { Globular } \\
\text { echinate }\end{array}$ & $\begin{array}{c}\text { Globular echinate } \\
\text { elongate }\end{array}$ & $\begin{array}{l}\text { Globular echinate with } \\
\text { short acute projections }\end{array}$ & & & $\begin{array}{c}\text { Globular } \\
\text { nodular }\end{array}$ & $\begin{array}{l}\text { Globular } \\
\text { granulate }\end{array}$ & Jigsaw & $\begin{array}{l}\text { Globular } \\
\text { psilate }\end{array}$ & Diatom & $\begin{array}{l}\text { Sponge } \\
\text { Spicule }\end{array}$ & \\
\hline D27-S & $6(50-60)$ & 0 & 0 & 1 & 0 & 0 & 0 & 8 & 0 & 0 & 1 & 3 & 66 \\
\hline$\underline{\mathrm{D} 45-\mathrm{S}}$ & $6(50-60)$ & 0 & 0 & 0 & 0 & 0 & 0 & 4 & 0 & 1 & 0 & 1 & 9 \\
\hline D43-S & $6(50-60)$ & 0 & 0 & 0 & 0 & 0 & 0 & 0 & 0 & 0 & 0 & 0 & 1 \\
\hline D40-S & $6(50-60)$ & 0 & 0 & 0 & 0 & 0 & 0 & 0 & 0 & 0 & 0 & 0 & 1 \\
\hline D42-S & $6(50-60)$ & 0 & 0 & 0 & 0 & 0 & 0 & 3 & 0 & 0 & 0 & 0 & 5 \\
\hline D44-S & $6(50-60)$ & 0 & 0 & 0 & 0 & 0 & 0 & 0 & 0 & 0 & 0 & 0 & 0 \\
\hline D41-S & $6(50-60)$ & 0 & 0 & 0 & 0 & 0 & 0 & 0 & 0 & 0 & 0 & 0 & 0 \\
\hline D38-S & $15(140-150)$ & 0 & 0 & 0 & 0 & 0 & 0 & 0 & 0 & 0 & 0 & 0 & 3 \\
\hline D34-S & $16(150-160)$ & 0 & 0 & 0 & 0 & 0 & 0 & 0 & 0 & 0 & 0 & 0 & 0 \\
\hline D36-S & $16(150-160)$ & 1 & 0 & 0 & 0 & 0 & 0 & 0 & 0 & 0 & 0 & 0 & 6 \\
\hline D35-S & $16(150-160)$ & 0 & 0 & 0 & 0 & 0 & 1 & 0 & 0 & 0 & 0 & 0 & 3 \\
\hline D37-S & $16(150-160)$ & 1 & 0 & 0 & 0 & 0 & 0 & 0 & 0 & 0 & 0 & 0 & 1 \\
\hline D33-S & $16(150-160)$ & 0 & 0 & 0 & 0 & 0 & 0 & 0 & 0 & 0 & 0 & 0 & 0 \\
\hline D29-S & $2(10-20)$ & 0 & 0 & 0 & 0 & 0 & 0 & 0 & 0 & 0 & 0 & 0 & 0 \\
\hline D31-S & $2(10-20)$ & 0 & 0 & 0 & 0 & 0 & 0 & 0 & 0 & 0 & 0 & 0 & 1 \\
\hline D32-S & $3(20-30)$ & 0 & 0 & 0 & 0 & 0 & 0 & 0 & 0 & 0 & 0 & 0 & 1 \\
\hline D30-S & $3(20-30)$ & 0 & 0 & 0 & 0 & 0 & 0 & 0 & 0 & 0 & 0 & 0 & 1 \\
\hline D46-S & $3(20-30)$ & 0 & 0 & 0 & 0 & 0 & 0 & 0 & 0 & 0 & 0 & 1 & 1 \\
\hline D28-S & $3(20-30)$ & 0 & 0 & 0 & 0 & 0 & 0 & 0 & 0 & 0 & 0 & 1 & 1 \\
\hline D47-S & 13(120-130) & 0 & 0 & 0 & 0 & 0 & 0 & 0 & 0 & 0 & 0 & 0 & 1 \\
\hline
\end{tabular}




\section{ANEXO 4}

Ficha de Análise de Fitólitos em Líticos Escovados

\begin{tabular}{|c|c|c|c|c|c|c|c|c|c|c|c|c|c|c|}
\hline \multirow[b]{3}{*}{ QD. } & \multirow[b]{3}{*}{$\mathrm{PN}$} & \multirow[b]{3}{*}{ CODE } & \multirow[b]{3}{*}{ NÍV. (CM) } & \multicolumn{4}{|c|}{ Poaceae } & \multirow{3}{*}{$\begin{array}{c}\text { Chloridoideae } \\
\text { Saddle }\end{array}$} & \multirow{3}{*}{$\begin{array}{c}\text { Panicoideae } \\
\text { Bilobate }\end{array}$} & \multirow{2}{*}{\multicolumn{2}{|c|}{ Zea mays }} & \multirow{2}{*}{\multicolumn{3}{|c|}{ Non-diagnostic Poaceae }} \\
\hline & & & & Aristidoideae & & Bambusoide & & & & & & & & \\
\hline & & & & Bilobate & Bilobate & $\begin{array}{l}\text { Collapsed } \\
\text { saddle }\end{array}$ & $\begin{array}{c}\text { 3-spiked } \\
\text { rondel }\end{array}$ & & & Cross v1 & $\begin{array}{c}\text { Wavy-top } \\
\text { rondel }\end{array}$ & Bulliform & $\begin{array}{l}\text { Cross } \\
\text { Other }\end{array}$ & Rondel \\
\hline $\mathrm{N} 23$ & 13014 & $\underline{\mathrm{D} 13-\mathrm{C}}$ & $6(50-60)$ & 0 & 1 & 11 & 2 & 5 & 25 & 3 & 0 & 27 & 1 & 13 \\
\hline $\mathrm{N} 23$ & 14017 & D18-C & $6(50-60)$ & 0 & 0 & 0 & 1 & 1 & 0 & 0 & 0 & 10 & 0 & 1 \\
\hline $\mathrm{N} 23$ & 13067 & D17-C & $6(50-60)$ & 0 & 0 & 4 & 4 & 1 & 55 & 4 & 0 & 77 & 1 & 44 \\
\hline $\mathrm{N} 23$ & 13885 & D20-C & $6(50-60)$ & 0 & 0 & 0 & 0 & 0 & 0 & 0 & 0 & 4 & 0 & 0 \\
\hline $\mathrm{N} 23$ & 14029 & D16-C & $6(50-60)$ & 0 & 0 & 0 & 0 & 0 & 15 & 3 & 0 & 42 & 1 & 10 \\
\hline $\mathrm{N} 23$ & 13120 & D15-C & $6(50-60)$ & 0 & 0 & 0 & 0 & 0 & 2 & 1 & 0 & 3 & 0 & 3 \\
\hline $\mathrm{N} 23$ & 13962 & $\underline{\mathrm{D} 14-\mathrm{C}}$ & $6(50-60)$ & 0 & 0 & 0 & 1 & 0 & 4 & 0 & 0 & 14 & 1 & 0 \\
\hline P11 & 14292 & $\underline{\text { D9-C }}$ & $15(140-15($ & & 0 & 0 & 0 & 0 & 0 & 0 & 0 & 20 & 0 & 4 \\
\hline P11 & 14385 & $\underline{\mathrm{D} 7-\mathrm{C}}$ & $16(150-16($ & & 0 & 0 & 0 & 0 & 0 & 0 & 0 & 0 & 0 & 0 \\
\hline P11 & 14391 & D8-C & $16(150-160$ & & 0 & 1 & 0 & 0 & 7 & 1 & 0 & 36 & 0 & 2 \\
\hline P11 & 14410 & D10-C & $16(150-16 c$ & & 0 & 0 & 0 & 0 & 1 & 0 & 0 & 2 & 0 & 0 \\
\hline P11 & 14469 & $\underline{\mathrm{D} 11-\mathrm{C}}$ & $16(150-16 c$ & & 0 & 0 & 3 & 0 & 26 & 3 & 0 & 24 & 0 & 6 \\
\hline P11 & 14369 & D12-C & $16(150-16 c$ & & 0 & 0 & 0 & 0 & 0 & 0 & 0 & 1 & 0 & 0 \\
\hline A1 & 14267 & $\underline{\text { D6-C }}$ & $2(10-20)$ & 0 & 0 & 0 & 0 & 0 & 0 & 0 & 0 & 9 & 0 & 1 \\
\hline $\mathrm{A} 1$ & 14236 & $\overline{\mathrm{D} 4-\mathrm{C}}$ & $2(10-20)$ & 0 & 0 & 1 & 0 & 0 & 0 & 0 & 0 & 16 & 0 & 0 \\
\hline $\mathrm{A} 1$ & 14355 & D5-C & $3(20-30)$ & 0 & 0 & 0 & 0 & 0 & 0 & 0 & 0 & 2 & 0 & 0 \\
\hline A1 & 14335 & D3-C & $3(20-30)$ & 0 & 0 & 0 & 0 & 0 & 0 & 0 & 0 & 0 & 0 & 0 \\
\hline $\mathrm{A} 1$ & 14353 & $\underline{\text { D1-C }}$ & $3(20-30)$ & 0 & 0 & 0 & 0 & 0 & 0 & 0 & 0 & 31 & 0 & 1 \\
\hline $\mathrm{A} 1$ & 14297 & $\overline{\mathrm{D} 2-\mathrm{C}}$ & $3(20-30)$ & 0 & 0 & 0 & 0 & 0 & 0 & 0 & 0 & 7 & 0 & 0 \\
\hline
\end{tabular}




\section{ANEXO 4}

Ficha de Análise de Fitólitos em Líticos Escovados

\begin{tabular}{|c|c|c|c|c|c|c|c|c|c|c|c|c|c|c|c|c|}
\hline \multirow[b]{3}{*}{ QD. } & \multirow[b]{3}{*}{ PN } & \multirow[b]{3}{*}{ CODE } & \multirow[b]{3}{*}{ NÍV. (CM) } & \multirow{2}{*}{\multicolumn{3}{|c|}{$\begin{array}{l}\text { Arecaceae } \\
\text { Arecaceae }\end{array}$}} & \multirow[b]{3}{*}{$\begin{array}{l}\text { Globular } \\
\text { echinate with } \\
\text { short acute } \\
\text { projections }\end{array}$} & \multicolumn{2}{|c|}{ Cyperaceae } & \multirow{2}{*}{$\begin{array}{l}\text { Zingiberales } \\
\text { Zingiberales }\end{array}$} & \multirow{2}{*}{\multicolumn{3}{|c|}{$\begin{array}{l}\text { Eudicots } \\
\text { Eudicots }\end{array}$}} & \multirow{2}{*}{\multicolumn{2}{|c|}{$\begin{array}{l}\text { Aquatic organisms } \\
\text { Algae } \quad \text { Porifera }\end{array}$}} & \multirow[b]{3}{*}{$\begin{array}{c}\text { Total de } \\
\text { fitólitos } \\
\text { contados na } \\
\text { lâmina }\end{array}$} \\
\hline & & & & & & & & \multirow{2}{*}{$\begin{array}{l}\text { Cyperus/Ky } \\
\text { llinga sp. } \\
\text { Stippled } \\
\text { polygonal } \\
\text { cone }\end{array}$} & \multirow{2}{*}{$\begin{array}{l}\text { Non-diagnostic } \\
\text { Cyperaceae }\end{array}$} & & & & & & & \\
\hline & & & & $\begin{array}{l}\text { Globular } \\
\text { echinate }\end{array}$ & $\begin{array}{l}\text { Globular } \\
\text { echinate } \\
\text { elongate }\end{array}$ & $\begin{array}{c}\text { Globular echinate } \\
\text { with short acute } \\
\text { projections }\end{array}$ & & & & $\begin{array}{c}\text { Globular } \\
\text { nodular }\end{array}$ & $\begin{array}{l}\text { Globular } \\
\text { granulate }\end{array}$ & Jigsaw & $\begin{array}{l}\text { Globular } \\
\text { psilate }\end{array}$ & Diatom & $\begin{array}{l}\text { Sponge } \\
\text { Spicule }\end{array}$ & \\
\hline $\mathrm{N} 23$ & 13014 & D13-C & $6(50-60)$ & 4 & 1 & 5 & 1 & 1 & 0 & 2 & 6 & 1 & 1 & 1 & 8 & 110 \\
\hline $\mathrm{N} 23$ & 14017 & $\overline{\mathrm{D} 18-\mathrm{C}}$ & $6(50-60)$ & 0 & 0 & 0 & & 0 & 0 & 0 & 9 & 0 & 1 & 0 & 2 & 23 \\
\hline $\mathrm{N} 23$ & 13067 & D17-C & $6(50-60)$ & 3 & 0 & 5 & 4 & 0 & 0 & 9 & 37 & 0 & 0 & 0 & 15 & 263 \\
\hline $\mathrm{N} 23$ & 13885 & D20-C & $6(50-60)$ & 0 & 0 & 0 & & 0 & 0 & 0 & 0 & 0 & 0 & 0 & 0 & 4 \\
\hline $\mathrm{N} 23$ & 14029 & D16-C & $6(50-60)$ & 2 & 1 & 1 & 1 & 1 & 1 & 1 & 21 & 0 & 0 & 0 & 6 & 100 \\
\hline $\mathrm{N} 23$ & 13120 & $\overline{D 15-C}$ & $6(50-60)$ & 0 & 0 & 0 & & 0 & 0 & 0 & 2 & 0 & 0 & 0 & 0 & 11 \\
\hline $\mathrm{N} 23$ & 13962 & D14-C & $6(50-60)$ & 0 & 0 & 0 & & 1 & 0 & 0 & 5 & 0 & 0 & 0 & 3 & 26 \\
\hline P11 & 14292 & D9-C & $15(140-15$ & & 0 & 0 & & 0 & 0 & 2 & 9 & 0 & 1 & 0 & 2 & 36 \\
\hline P11 & 14385 & D7-C & $16(150-16$ & & 0 & 0 & & 0 & 0 & 0 & 0 & 0 & 0 & 0 & 0 & 0 \\
\hline P11 & 14391 & $\underline{\mathrm{D} 8-\mathrm{C}}$ & $16(150-16$ & & 0 & 0 & & 1 & 0 & 0 & 15 & 0 & 0 & 0 & 2 & 63 \\
\hline P11 & 14410 & $\overline{\mathrm{D} 10-\mathrm{C}}$ & $16(150-16$ & & 0 & 0 & & 0 & 0 & 0 & 0 & 0 & 0 & 0 & 0 & 3 \\
\hline P11 & 14469 & $\underline{\mathrm{D} 11-\mathrm{C}}$ & $16(150-16$ & & 1 & 0 & & 0 & 0 & 0 & 18 & 0 & 0 & 0 & 2 & 85 \\
\hline P11 & 14369 & D12-C & $16(150-16$ & & 0 & 1 & 1 & 0 & 0 & 0 & 9 & 0 & 0 & 0 & 0 & 12 \\
\hline $\mathrm{A} 1$ & 14267 & $\underline{\text { D6-C }}$ & $2(10-20)$ & 1 & 0 & 0 & & 0 & 0 & 0 & 8 & 0 & 0 & 0 & 8 & 19 \\
\hline A1 & 14236 & $\underline{\mathrm{D} 4-\mathrm{C}}$ & $2(10-20)$ & 0 & 0 & 0 & & 0 & 0 & 1 & 9 & 0 & 0 & 0 & 14 & 27 \\
\hline Al & 14355 & D5-C & $3(20-30)$ & 0 & 0 & 0 & & 0 & 0 & 0 & 1 & 0 & 0 & 0 & 0 & 3 \\
\hline A1 & 14335 & $\overline{\mathrm{D} 3-\mathrm{C}}$ & $3(20-30)$ & 0 & 0 & 0 & & 0 & 0 & 0 & 0 & 0 & 0 & 0 & 0 & 0 \\
\hline A1 & 14353 & $\underline{\mathrm{D} 1-\mathrm{C}}$ & $3(20-30)$ & 0 & 0 & 0 & & 1 & 0 & 0 & 20 & 1 & 0 & 0 & 24 & 54 \\
\hline $\mathrm{A} 1$ & 14297 & D2-C & $3(20-30)$ & 0 & 0 & 0 & & 0 & 0 & 0 & 3 & 0 & 0 & 0 & 1 & 10 \\
\hline
\end{tabular}




\section{ANEXO 5}

Ficha de Análise de Fitólitos em Sedimento

\begin{tabular}{|c|c|c|c|c|c|c|c|c|c|c|c|c|c|c|}
\hline \multirow[b]{3}{*}{ QD. } & \multirow[b]{3}{*}{ PN } & \multirow[b]{3}{*}{ CODE } & \multirow[b]{3}{*}{ NÍV. (CM) } & & \multicolumn{10}{|l|}{ Poaceae } \\
\hline & & & & \multirow{2}{*}{$\begin{array}{l}\text { Aristidoideae } \\
\text { Bilobate }\end{array}$} & \multicolumn{3}{|c|}{ Bambusoideae } & \multirow{2}{*}{$\begin{array}{l}\text { Chloridoideae } \\
\text { Saddle }\end{array}$} & \multirow{2}{*}{$\begin{array}{c}\text { Panicoideae } \\
\text { Bilobate }\end{array}$} & \multicolumn{2}{|c|}{ Zea mays } & \multicolumn{3}{|c|}{ Non-diagnostic Poaceae } \\
\hline & & & & & Bilobate & Collapsed saddle & 3-spiked rondel & & & Cross v1 & Wavy-top rondel & Bulliform & Cross Other Variants & Rondel \\
\hline $\mathrm{N} 23$ & 14030 & D21-E & $6(50-60)$ & 3 & 1 & 5 & 2 & 6 & 70 & 7 & 1 & 48 & 5 & 26 \\
\hline P11 & 14398 & D24-E & $16(150-160)$ & 0 & 0 & 0 & 1 & 1 & 13 & 1 & 0 & 24 & 1 & 4 \\
\hline A1 & 14358 & D23-E & $3(20-30)$ & 0 & 0 & 1 & 0 & 2 & 16 & 2 & 0 & 69 & 0 & 16 \\
\hline $\mathrm{C} 2$ & C2 & $\mathrm{C} 2$ & $3(20-30)$ & 6 & 0 & 0 & 0 & 14 & 27 & 1 & 0 & 76 & 0 & 17 \\
\hline
\end{tabular}

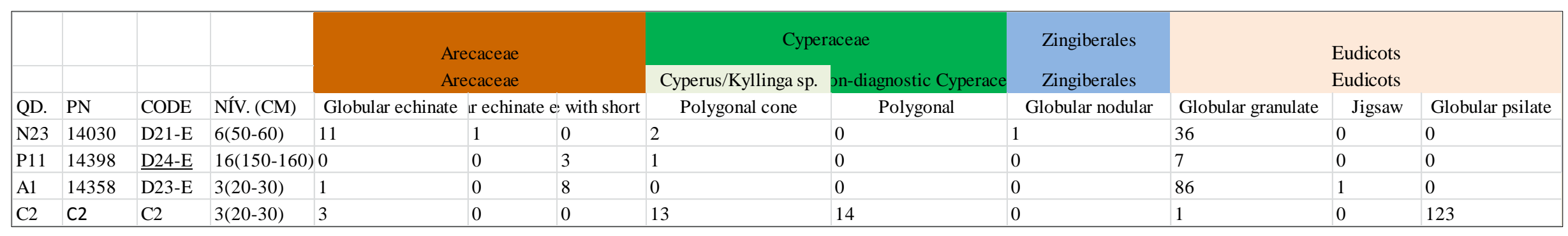

\begin{tabular}{|c|c|c|c|c|c|c|c|}
\hline QD. & PN & CODE & NÍV. (CM) & \multirow{2}{*}{$\begin{array}{c}\text { Aquatic organisms } \\
\text { Algae }\end{array}$} & \multirow[b]{2}{*}{ Porifera } & & $\begin{array}{l}\text { Total contados na } \\
\text { lâmina }\end{array}$ \\
\hline $\mathrm{N} 23$ & 14030 & D21-E & $6(50-60)$ & & & & \\
\hline P11 & 14398 & D24-E & $16(150-160)$ & Diatom & Sponge Spi & hair cell & \\
\hline A1 & 14358 & D23-E & $3(20-30)$ & 0 & 2 & 0 & 225 \\
\hline \multirow[t]{3}{*}{$\mathrm{C} 2$} & $\mathrm{C} 2$ & $\mathrm{C} 2$ & $3(20-30)$ & 0 & 2 & 0 & 56 \\
\hline & & & & 0 & 66 & 0 & 202 \\
\hline & & & & 3 & 10 & 1 & 295 \\
\hline
\end{tabular}

